Illinois State University

ISU ReD: Research and eData

Theses and Dissertations

$10-5-2016$

\title{
Synthesis And Characterization Of Polycyclic Aromatic Hydrocarbon (pah) - Porphyrin Hybrids
}

Ruixiao Gao

Illinois State University, snowwind23@hotmail.com

Follow this and additional works at: https://ir.library.illinoisstate.edu/etd

Part of the Organic Chemistry Commons

\section{Recommended Citation}

Gao, Ruixiao, "Synthesis And Characterization Of Polycyclic Aromatic Hydrocarbon (pah) - Porphyrin Hybrids" (2016). Theses and Dissertations. 614.

https://ir.library.illinoisstate.edu/etd/614

This Thesis is brought to you for free and open access by ISU ReD: Research and eData. It has been accepted for inclusion in Theses and Dissertations by an authorized administrator of ISU ReD: Research and eData. For more information, please contact ISUReD@ilstu.edu. 


\title{
SYNTHESIS AND CHARACTERIZATION OF POLYCYCLIC AROMATIC HYDROCARBON (PAH) - PORPHYRIN HYBRIDS
}

\begin{abstract}
Ruixiao Gao
130 Pages

Carbaporphyrins are porphyrin analogs where one or more pyrrole units are replaced with a carbocyclic ring. Benziporphyrins are porphyrin analogues with a 1,3-phenylene unit replacing one of the pyrrole subunits. Because of cross-conjugation, benziporphyrins are not aromatic species. However, protonation of benziporphyrins can afford some aromatic characteristics. Although the synthesis of many examples of monocarbaporphyrins have been successfully executed, no examples of porphyrinoids with pyrene subunits have been prepared. Pyrenecontaining porphyrinoids, which have been named as pyreniporphyrins, are theoretically significant molecules that provide insights into the aromaticity and reactivity of porphyrinoid systems.
\end{abstract}

In this thesis, two projects were conducted to explore the synthesis, reactivity, aromaticity, and coordination chemistry of pyreniporphyrins. The first project involved the development of a synthetic route to a pyreniporphyrin. A pyrene dialdehyde was prepared and reacted with a tripyrrane using an acid-catalyzed MacDonald " $3+1$ " condensation. The proton NMR spectrum of the pyreniporphyrin in $\mathrm{CDCl}_{3}$ demonstrated the absence of global aromatic character. 
However, in the presence of acid, the corresponding dication exhibited significant diatropic properties. Pyreniporphyrin reacted with palladium(II) acetate to give an organometallic derivative. In the second project, a thiapyreniporphyrin was prepared from a pyrenitripyrrane.

This intermediate condensed with a thiophene dicarbinol to afford, following an oxidation step, a tetraphenyl thiaporphyrinoid in modest yield.

KEYWORDS: Carbaporphyrins, Aromaticity, Porphyrin Science, Polycyclic Aromatic Hydrocarbons 
SYNTHESIS AND CHARACTERIZATION OF POLYCYCLIC AROMATIC HYDROCARBON (PAH) - PORPHYRIN HYBRIDS

RUIXIAO GAO

\author{
A Thesis Submitted in Partial \\ Fulfillment of the Requirements \\ for the Degree of \\ MASTER OF SCIENCE \\ Department of Chemistry \\ ILLINOIS STATE UNIVERSITY
}


Copyright 2016 Ruixiao Gao 
SYNTHESIS AND CHARACTERIZATION OF POLYCYCLIC AROMATIC HYDROCARBON (PAH) - PORPHYRIN HYBRIDS

RUIXIAO GAO

COMMITTEE MEMBERS:

Timothy D. Lash, Chair

Shawn R. Hitchcock

Christopher G. Hamaker 


\section{ACKNOWLEDGMENTS}

I would like to acknowledge all members of my research group for their continued support and friendship throughout my graduate school at Illinois State University. I would like to thank the faculty, staff, and fellow students in the Department of Chemistry at Illinois State University, and my family for support, as well. I also acknowledge financial support from the National Science Foundation under grants No. CHE-1465049.

I would especially like to appreciate my research advisor Dr. Timothy D. Lash for his encouragement, endless support, enthusiasm, understanding, and patience. I feel very privileged to have such an excellent mentor in the past two years.

R. G. 


\section{CONTENTS}

Page

ACKNOWLEDGMENTS

CONTENTS

FIGURES

SCHEMES Ni vi v v v v

CHAPTER

I. PORPHYRINS AND RELATED SYSTEMS 1

Structure of Porphyrins 1

Aromatic Properties 5

Biosynthesis of Heme $\quad 12$

$\begin{array}{ll}\text { Synthesis of Porphyrins } & 14\end{array}$

Reactivity of Porphyrins and Related Systems $\quad 24$

$\begin{array}{ll}\text { Applications } & 25\end{array}$

$\begin{array}{ll}\text { Carbaporphyrins } & 27\end{array}$

II. PAH-PORPHYRIN HYBRIDS 31

Introduction to Benziporphyrins $\quad 31$

Introduction of Polycyclic Aromatic Compounds 36

Results and Discussion $\quad 39$

tert-Butylpyrene Dialdehyde $\quad 42$

$\begin{array}{ll}\text { tert-Butylpyreniporphyrin } & 43\end{array}$

$\begin{array}{lr}\text { Thiapyreniporphyrin } & 50\end{array}$

$\begin{array}{ll}\text { Tetraphenylpyreniporphyrin } & 58\end{array}$

Conclusion $\quad 59$ 
$\begin{array}{ll}\text { III. EXPERIMENTAL } & 60\end{array}$

$\begin{array}{lc}\text { REFERENCES } & 81\end{array}$ APPENDIX A: SELECTED NMR SPECTRA AND CHEMICAL SHIFT ASSIGNMENTS 85 APPENDIX B: SELECTED UV-VIS SPECTRA 122 


\section{FIGURES}

Figure

Page

1. Resonance Forms of Pyrrole $\quad 1$

2. Structure of Porphin $\quad 4$

3. Tautomers of Porphin $\quad 4$

4. Examples of Aromatic, Antiaromatic, and Nonaromatic Structures 6

$\begin{array}{ll}\text { 5. Structures of [18]Annulene and Porphyrin } & 7\end{array}$

6. Reduced Forms of Porphyrins $\quad 8$

7. Induced Ring Current Effects for Porphyrin 9

8. UV-vis Spectrum of Tetraphenylporphyrin 10

9. Naturally Occurring Porphyrin Structures 11

10. Structures of Dipyrrolic Intermediates 17

11. Structures of Tripyrrane Analogs with Different Central Rings 22

12. Metal-Stabilized Carbaporphyrins with Rare Oxidation States on Metals 24

13. Oxygen-Confused and Sulfur-Confused Porphyrins 29

14. Tautomers of Benziporphyrin 32

15. Early Examples of PHAs 37

16. $500 \mathrm{MHz}$ Proton NMR Spectrum of 68 in $\mathrm{CDCl}_{3}$ 
17. UV-vis Spectra of $\mathbf{6 8}$ in $1 \% \mathrm{Et}_{3} \mathrm{~N}-\mathrm{CH}_{2} \mathrm{Cl}_{2}, 1$ equivalent TFA-CH $\mathrm{Cl}_{2}$, and $1 \%$ TFA$\mathrm{CH}_{2} \mathrm{Cl}_{2}$

18. $500 \mathrm{MHz}$ Proton NMR Spectrum of $68 \mathrm{H}_{2}{ }^{+}$in $\mathrm{CDCl}_{3}$

19. UV-Vis Spectrum of $\mathbf{8 5}$ in Dichloromethane

20. Internal Proton Chemical Shifts for Pyreniporphyrin Systems

21. Proton NMR of Tetraphenyl Thiapyreniporphyrin

22. Proton NMR for Protonated Thiapyreniporphyrin

23. UV-vis Spectra of $\mathbf{8 8}$ in $1 \% \mathrm{Et}_{3} \mathrm{~N}-\mathrm{CH}_{2} \mathrm{Cl}_{2}$ (red), 1 equivalent TFA- $\mathrm{CH}_{2} \mathrm{Cl}_{2}$ (blue), and $5 \%$ TFA- $\mathrm{CH}_{2} \mathrm{Cl}_{2}$ (grey) 


\section{SCHEMES}

Scheme

Page

1. Mechanism of Knorr Pyrrole Synthesis

2. Mechanism of Hantzsch Pyrrole Synthesis

3. Synthesis of Uroporphyrinogen III

4. Biosynthesis of Heme

5. Synthesis of meso-Substituted Porphyrins

6. Fischer Synthesis of Porphyrin

7. MacDonald '2+2' Porphyrin Condensation

8. Synthesis of Porphyrins from Oxophlorins

9. Synthesis of Thiaporphyrins and Oxaporphyrins

10. Synthesis of Kenner's Tripyrrane

11. Optimized Synthesis of Sessler's Tripyrrane

12. Synthesis of Porphyrin through a Tetrapyrrolic Intermediate

13. Bromination of Porphyrins in Different Positions

14. Metalloporphyrin Catalyzed Cyclopropanation

15. Synthesis of N-Confused Porphyrin

16. Synthesis of Neo-Confused Porphyrins

17. Synthesis of Benziporphyrin 
18. Synthesis of Methoxybenziporphyrins and Oxybenziporphyrins

19. Synthesis and Protonation of Dimethoxy Benziporphyrins

20. Synthesis of Oxybenziporphyrin through Methoxy Cleavage

21. Cleavage of the Methoxy Units in Dimethoxybenziporphyrins with $\mathrm{HBr}$ in Refluxing Acetic Acid

22. Example of the Metalation of a Porphyrin with a Fused PAH Unit

23. Naphthiporphyrin 67 and Retrosynthetic Analysis of Pyreniporphyrin 68

24. Preparation of Pyrrole Ester 73 using a Knorr-Type Pyrrole Synthesis

25. Preparation of 3,4-Diethylpyrrole via a Barton-Zard Synthesis

26. Preparation of a Tripyrrane

27. Preparation of tert-Butylpyrene Dialdehyde

28. Synthesis of Pyreniporphyrin

29. Protonation of Pyreniporphyrin

30. Synthesis of a Pyreniporphyrin Metal Complex

31. Preparation of a Pyrene Dicarbinol

32. Preparation of Diphenyl Pyrenitripyrrane

33. Synthesis of a Thiapyreniporphyrin 


\section{CHAPTER I}

\section{PORPHYRINS AND RELATED SYSTEMS}

\section{Structure of Porphyrins}

Porphyrins, which have four pyrrole units linked by methine bridges, are aromatic macrocyclic pigments. ${ }^{1,2}$ The pyrrole building blocks are five membered aromatic rings possessing a nitrogen atom. Pyrrole's conjugated six $\pi$-electron system is created by the delocalization of a pair of electrons on the nitrogen atom with a diene component. ${ }^{3}$ Pyrrole is a $\pi$ excessive system and can be represented by the five resonance contributions shown in Figure 1 . Since the lone pair of electrons in pyrrole are delocalized, the heterocycle is nonbasic.

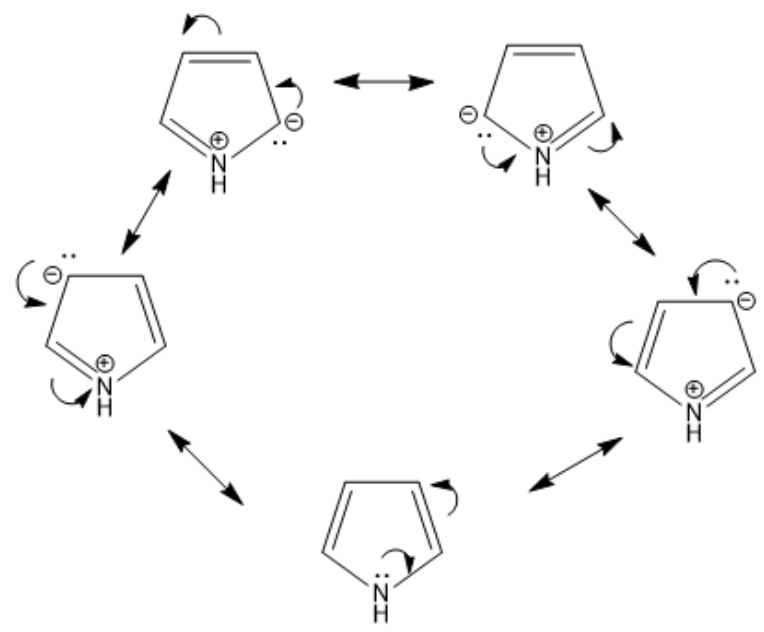

Figure 1: Resonance Forms of Pyrrole 
The dipolar contributors indicate that pyrrole is likely to readily undergo electrophilic aromatic substitution. ${ }^{3}$

There are various methods for synthesizing pyrroles. Two of the most common reactions for pyrrole synthesis are the Knorr pyrrole synthesis and the Hantzsch synthesis. ${ }^{2}$ Scheme 1 shows the Knorr pyrrole synthesis, where amino ketone $\mathbf{1}$ is reacted with a dicarbonyl compound $\mathbf{2}$ to provide the substituted pyrrole $\mathbf{3}$. The highly reactive intermediate $\mathbf{1}$ is generated by reducing an oxime 4 with zinc in presence of acetic acid.

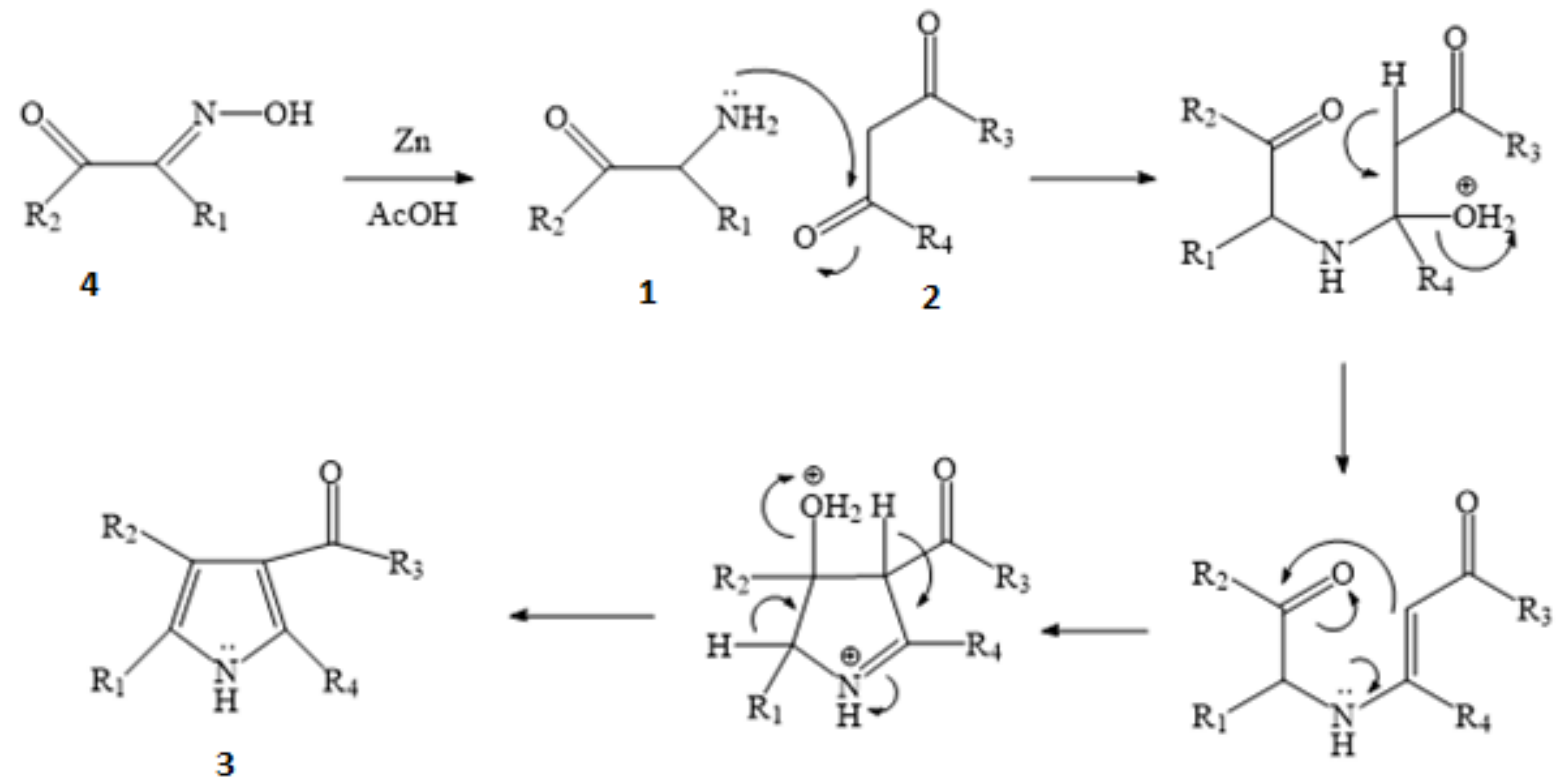

Scheme 1: Mechanism of Knorr Pyrrole Synthesis

An alternative method to prepare pyrroles is the Hantzch Synthesis (Scheme 2), where a haloketone $\mathbf{7}$ is reacted with a primary amine/ammonia and a ketoester $\mathbf{5}$. $^{2}$ When using ammonia, initial nucleophilic substitution occurs at the keto group of $\mathbf{5}$ giving an enamine intermediate following elimination of water. The enamine attacks the primary alkyl halide to generate a 
carbon-carbon bond, and following ring closure onto the keto-group and elimination of water, pyrrole $\mathbf{8}$ is formed.
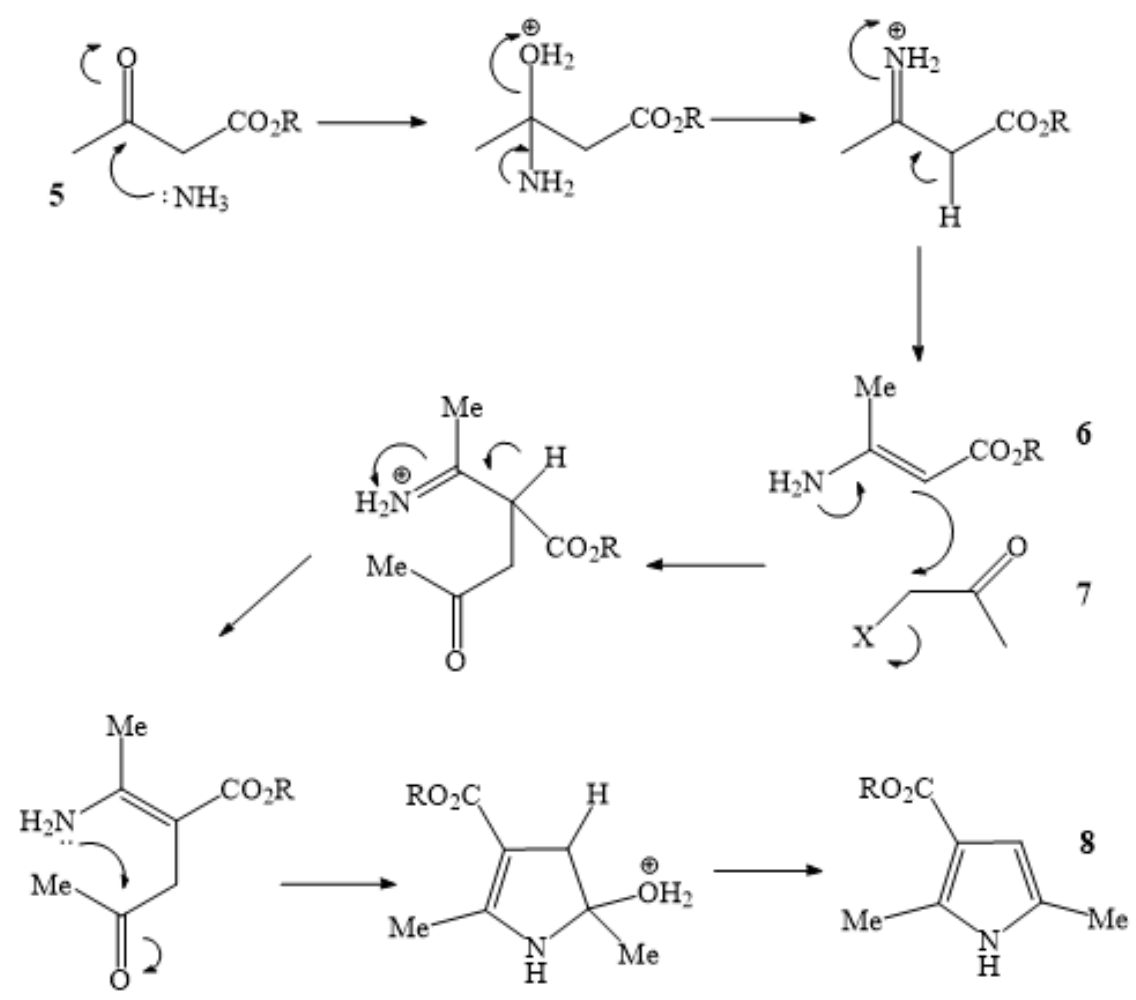

Scheme 2: Mechanism of Hantzsch Pyrrole Synthesis

The unique reactivity of pyrroles provides multiple possibilities for use as building blocks to form more complicated compounds, such as tetrapyrrolic porphyrins and related macrocycles. The simplest porphyrin is porphin (Figure 2), which has no substituents on the ring. ${ }^{1}$ 


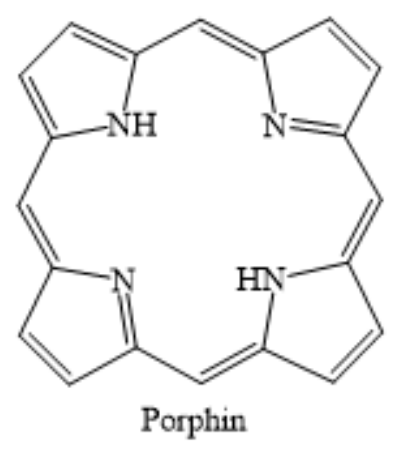

Figure 2: Structure of Porphin

Porphyrins can exist as several tautomeric forms which are determined by substitution patterns. However, there are two major tautomers for the general porphyrin structure 9 (Figure 3 ). ${ }^{1}$
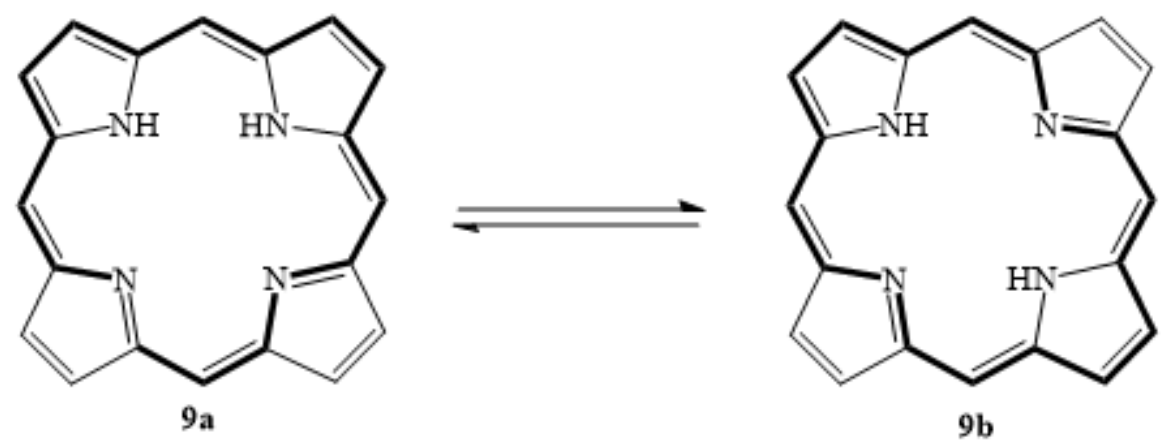

Figure 3: Tautomers of Porphin

Tautomer $\mathbf{9 b}$ is the preferred form for porphyrin and $9 \mathbf{a}$ is less favorable because the two adjacent hydrogens in the cavity of macrocycle lead to steric crowding. ${ }^{1}$ 


\section{Aromatic Properties}

Porphyrins are generally isolated as deep purple colored crystals and in fact the name porphyrin is derived from the Greek word porphura meaning purple. ${ }^{2}$ The color of these substances is due to their highly conjugated structures. The feature is also responsible for the aromatic characteristics. ${ }^{1,2}$ In 1865 , Kekule first introduced the concept of aromaticity in an effort to interpret the stability of benzene. ${ }^{4}$ The term "aromatic" was originally proposed by Hofmann, who found that many benzene derivatives had a sweet odor. ${ }^{5}$ Examples of these sweet smelling benzene derivatives include methyl salicylate, vanillin, and $p$-cymene. Vanillin, as the name suggests, is responsible for the odor associated with vanilla. Methyl salicylate smells like wintergreen, while $p$-cymene has an odor like cumin. ${ }^{3}$

As the study of aromatic benzene derivatives and other aromatic-like compounds progressed, it was gradually realized that the greatest denominator of these sorts of compounds was higher stability, instead of aroma. Hückel could mathematically predict the aromaticity of unsaturated cyclic systems. This is usually summarized as Hückel's rule, which states that the molecule has to have $[4 n+2] \pi$ electrons to satisfy the criteria for aromaticity, where $n$ is an integer. In addition, the system must be sufficiently planar and possess continuous conjugation in order to be aromatic. The more planar the molecule, the easier it is for the $\pi$ electrons to interact with each other to allow delocalization. ${ }^{2}$

Benzene has a traditional type of aromaticity with $6 \pi$ electrons $(n=1)$, and follows Hückel's rule for aromaticity. Porphyrins are more complicated due to the presence of multiple rings but can also be considered to follow Hückel's rule for aromaticity. Porphyrins have $22 \pi$ electrons ( $26 \pi$ electrons if the lone pair of electrons on the nitrogen atoms are included), but they 
have $18 \pi$ electrons in a continuous delocalization pathway and therefore follow Hückel's rule where $n=4 .{ }^{2}$ Unsaturated systems can also be categorized as anti-aromatic or non-aromatic (Figure 4).

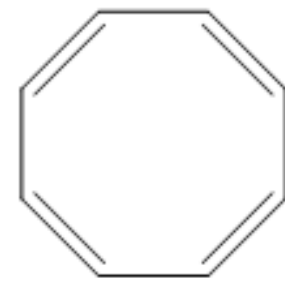

cyclooctatetraene non-aromatic

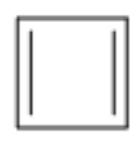

cyclobutadiene anti-aromatic

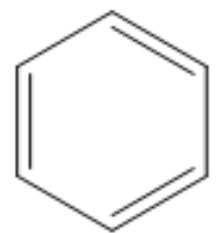

Benzene aromatic

Figure 4: Examples of Aromatic, Antiaromatic, and Nonaromatic Structures

Anti-aromatic species are also fully conjugated and planar but have $4 n \pi$-electrons. Non-aromatic compounds are unsaturated systems that are either not fully conjugated or not sufficiently planar. For example, cyclooctatetraene is non-aromatic due to its non-planar conformation. This leads cyclooctatetraene to be very reactive and relatively unstable. ${ }^{3}$

Due to the $18 \pi$ electron delocalization pathways, porphyrins are considered to be diaza[18]annulene systems. Annulenes are conjugated hydrocarbon macrocycles. [18]Annulene (10) is an aromatic structure that was first synthesized by Sondheimer et al. in 1962 (Figure 5). ${ }^{5}$ These authors noted the similarity between the structures of [18]annulene and porphyrins. Indeed, the porphyrins can be considered to be nature's [18]annulene. The concept of [18]annulene substructures explain the characteristics of aromaticity in porphyrins and provides 
insights into reduced porphyrin derivatives, such as isobacteriochlorin (11), chlorin (12), and bacteriochlorin (13) (Figure 6).

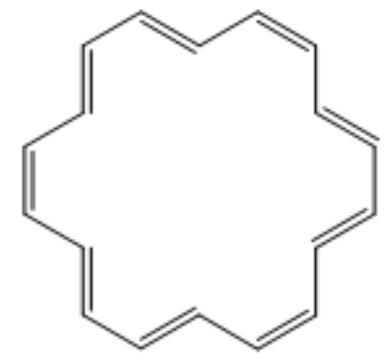

10

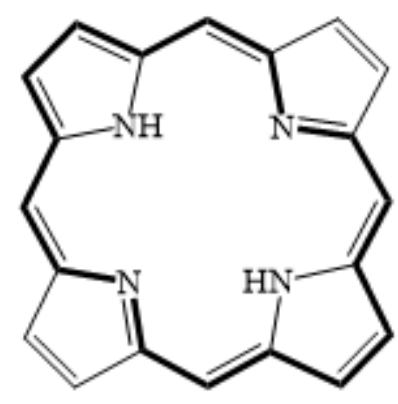

9

Figure 5: Structures of [18]Annulene and Porphyrin

The hydroporphyrins in this category are reduced on the pyrrole rings. For instance, chlorin $\mathbf{1 2}$ has one reduced pyrrole ring, while $\mathbf{1 1}$ and $\mathbf{1 3}$ have two reduced rings either opposite or adjacent to one another. In all three cases, the macrocycles retain the $18 \pi$ electron conjugation pathways, and as a result these are aromatic systems. Moreover, other examples of hydroporphyrins, such as phlorins (14), are not aromatic due to interruption of the $\pi$-conjugation pathway. ${ }^{2}$ The presence of a methylene bridge prevents continuous conjugation and the aromaticity of the macrocycle is lost. 


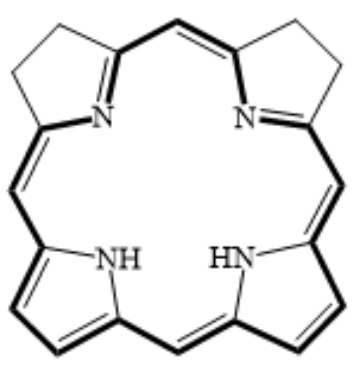

11

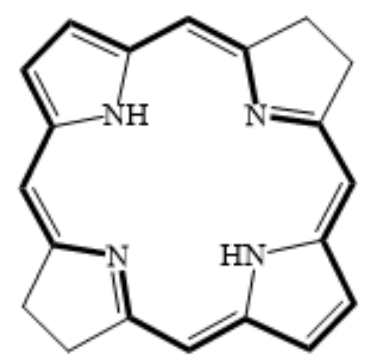

13

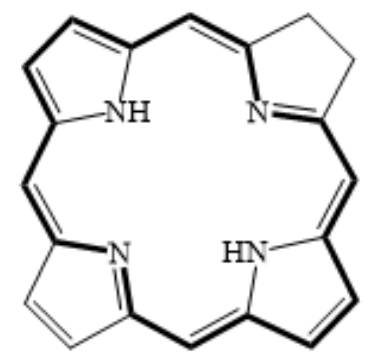

12

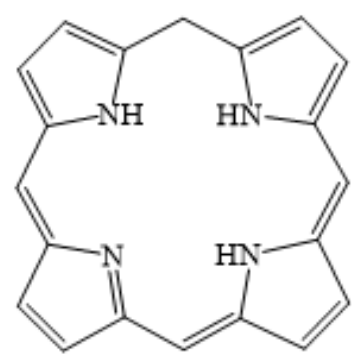

14

Figure 6: Reduced Forms of Porphyrins

The stabilization of aromatic compounds is due to $\pi$ electron delocalization. However, when the molecule is not sufficiently planar, the aromatic characteristics will be reduced. Bulky substituents on the macrocycle can inhibit the planarity. In addition, distortion can result from metal binding in the cavity of the macrocycle. When the metal cation is a good fit for the porphyrin cavity, the metalated derivative will be planar. However, when the metal cation is of an inappropriate size for the cavity of the porphyrin, the macrocycle will distort itself for binding with the metal. For instance, octaethylporphyrin is quite planar. However, when it binds with the relatively small nickel(II) cation, the macrocycle twists the conformation to bind to the metal. ${ }^{2}$ 
The degree of aromatic character can be assessed by proton nuclear magnetic resonance (NMR) spectroscopy and to a lesser extent by UV-vis spectroscopy. When the macrocycle is introduced to a strong magnetic field, the $\pi$ electrons create a ring current that affords a secondary induced magnetic field (Figure 7). This secondary induced magnetic field creates deshielding and shielding effects to the outer and inner protons of the porphyrin, respectively. ${ }^{2}$ Normally, the internal protons have a chemical shift of $-4 \mathrm{ppm}$, while the outer proton chemical shift is around $+10 \mathrm{ppm}$. Addition of acid leads to diprotonation, and the resulting dications show strong diamagnetic ring currents. In the proton NMR spectra, the external hydrogens are slightly deshielded and the internal protons are further shielded. ${ }^{6}$

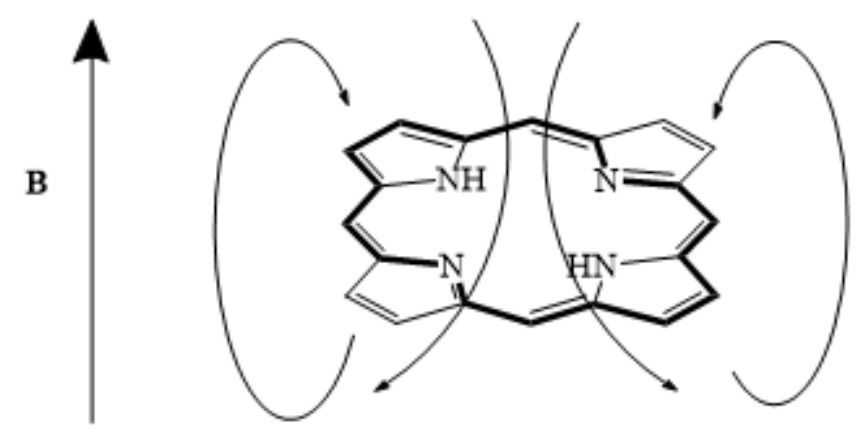

Figure 7: Induced Ring Current Effects for Porphyrin ${ }^{2}$

Highly conjugated systems also absorb light in the UV-visible region. The $\pi$ bonds are able to absorb light at comparatively larger wavelengths compared to sigma bonds, and with increasing $\pi$ bond conjugation the absorptions intensify and shift to higher values. The strong absorptions exhibited by porphyrins in the visible region lead to their deep colors. Porphyrins have a strong absorptive peak between $390-425 \mathrm{~nm}$ in the near ultraviolet region. ${ }^{2}$ In 1883 , 
Soret first noticed the distinct peaks while investigating hemoglobin, and these were subsequently named "Soret Bands" or B bands. A series of smaller peaks are observed in the visible region and these are known as $\mathrm{Q}$ bands. ${ }^{7}$ The intensity of $\mathrm{B}$ bands has been correlated to the aromaticity of system. In other words, the larger the molar absorptivity of the Soret band, the more aromatic the system. ${ }^{2}$ In the case of tetraphenylporphyrin, the B band shows up at $417 \mathrm{~nm}$, while the Q bands are present at $514 \mathrm{~nm}, 549 \mathrm{~nm}, 589 \mathrm{~nm}$, and $646 \mathrm{~nm}$ (Figure 8). ${ }^{6}$

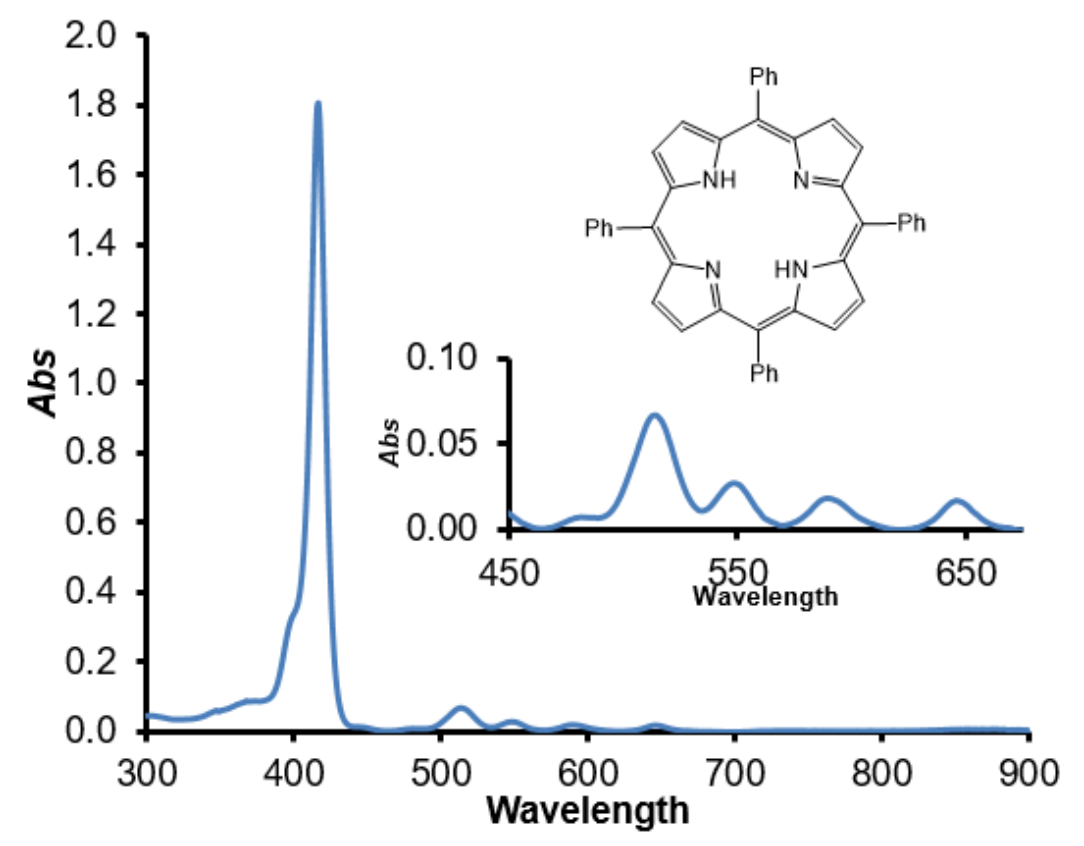

Figure 8: UV-vis Spectrum of Tetraphenylporphyrin ${ }^{6}$

The differences in the colors of porphyrinoid systems are due to different absorptions in their spectra that are related to distinct chromophores and conjugations. Most metalloporphyrins are red, while chlorophylls are green. Chlorins have strong absorption peak around $650 \mathrm{~nm}$. This explains why chlorophylls, which are magnesium chlorins, have an excellent ability absorb red light. $^{2}$ 
The different substituents on the macrocyclic rings can be manipulated for different applications based on their physical properties. These substituent effects are readily observed in nature. Common examples of porphyrin related structures found naturally are chlorophyl1 a (15), vitamin $\mathrm{B}_{12}$, and heme (16). The iron(II) found in $\mathbf{1 6}$ is used to transport oxygen, and $\mathbf{1 5}$ is essential for photosynthesis (Figure 9). ${ }^{2}$ Vitamin B12 has a corrin (17) core and is a cobalt complex. This macrocycle is known to prevent pernicious anemia. ${ }^{2}$
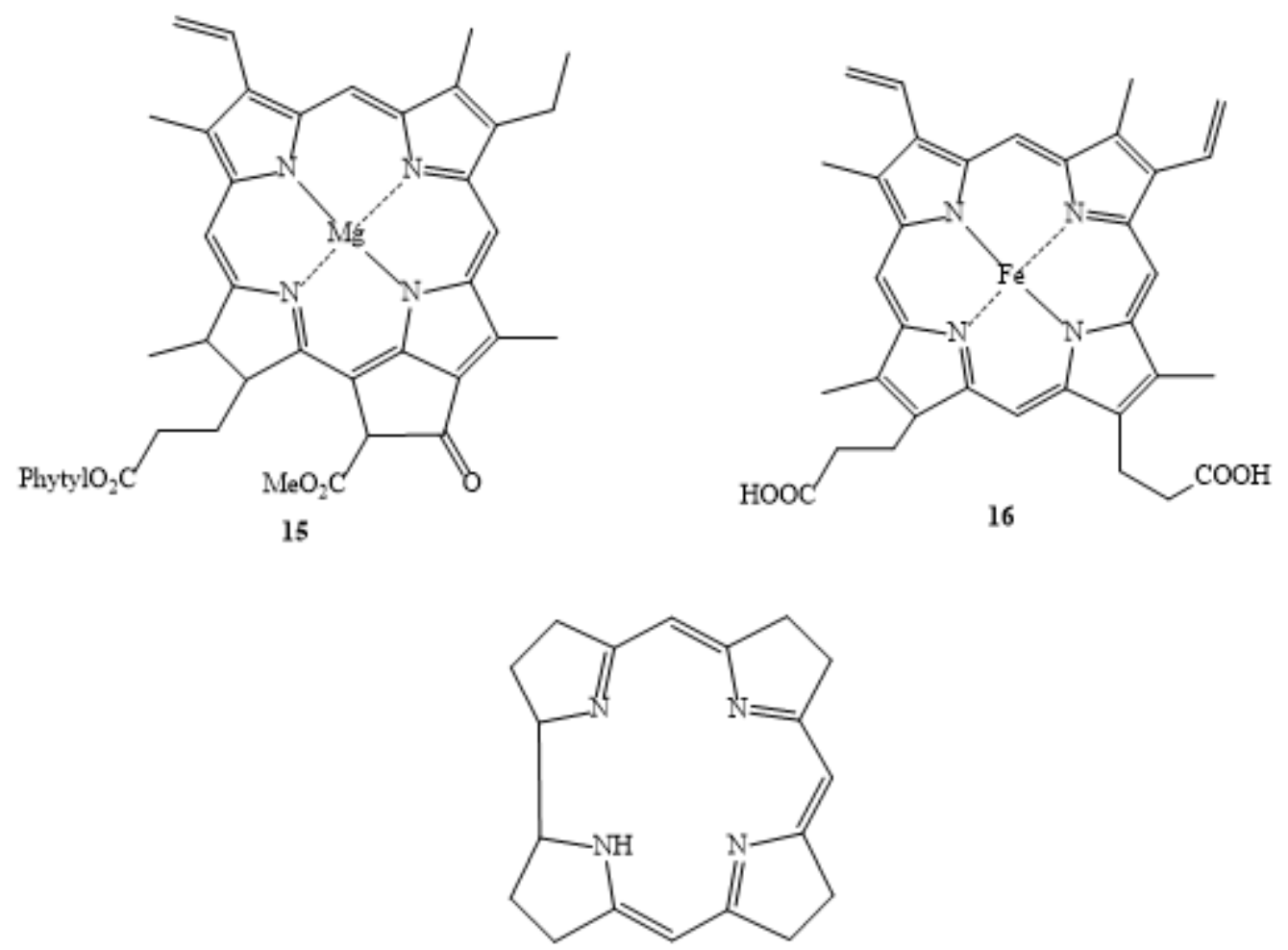

17

Figure 9: Naturally Occurring Porphyrin Structures 


\section{Biosynthesis of Heme}

In 1912, the structure of porphyrin was proposed by Kuster. ${ }^{9}$ However, it was not until 1929 when protoheme was synthesized by Fischer, that the previous proposal was fully accepted. ${ }^{10}$ The biosynthesis of porphyrins involves a series of enzyme-catalyzed steps, starting with 5aminolevulinic acid (ALA). Hence, ALA is the precursor to the chlorophylls, vitamin $\mathrm{B}_{12}$, and heme. The precursors to ALA are the amino acid glycine and succinyl coenzyme A (CoA), which is produced during the citric acid cycle (Krebs cycle). ALA is self-condensed to give the pyrrolic intermediate porphobilinogen (PBG). Four pyrrole units then condense together in the presence of PBG deaminase to give a tetrapyrrolic hydroxymethylbiliane. Cyclization, facilitated by uroporphyrinogen III cosynthetase, then generates uroporphyrinogen III (Scheme 3 ). ${ }^{2}$ This process involves inversion of ring D to give the arrangement of substituents found in nearly all naturally occurring porphyrin derivatives. Vitamin $\mathrm{B}_{12}$, a naturally occurring organometallic compound, is generated from uroporphyrinogen $\mathrm{III} .^{2}$ Uroporphyrinogen III is also the precursor to heme and the chlorophylls. 


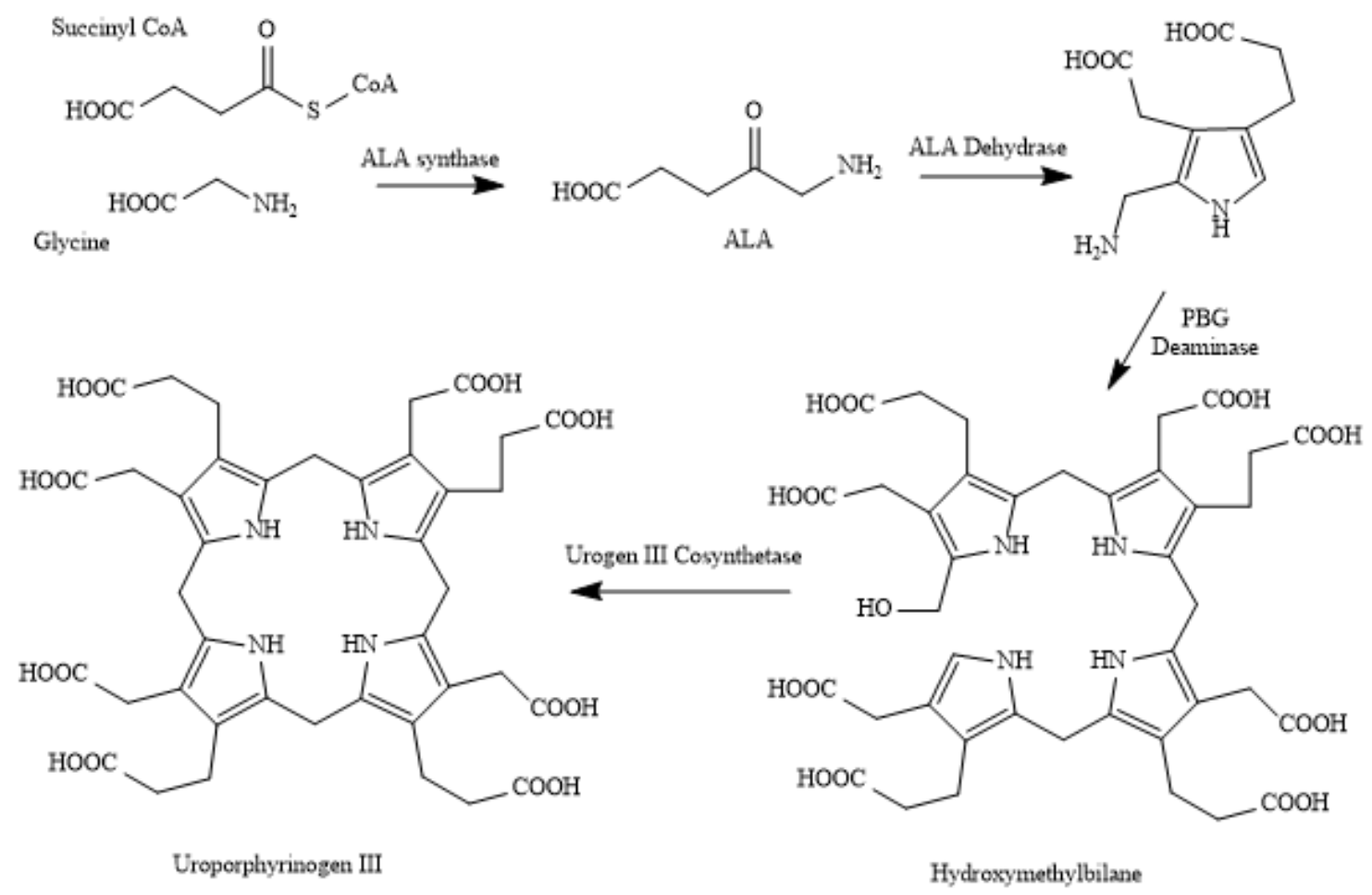

Scheme 3: Synthesis of Uroporphyrinogen $\mathrm{III}^{2}$

Decarboxylation of the acetic acid side chains is mediated by the enzyme uroporphyrinogen decarboxylase, while two of the propionic acid side chains are oxidatively decarboxylated by coproporphyrinogen oxidase. Enzymatic oxidation of the resulting tetrapyrrole protoporphyrinogen IX then gives protoporphyrin IX, and metalation with iron(II) affords the metalloporphyrin heme (Scheme 4). Heme is then inserted into the proper position in a globular protein to generate myoglobin or hemoglobin. Hemoglobin is used for the transportation of oxygen in the blood stream, while myoglobin stores oxygen in the muscles. Protoporphyrin IX is also a precursor in the biosynthesis of chlorophylls. ${ }^{2}$ 

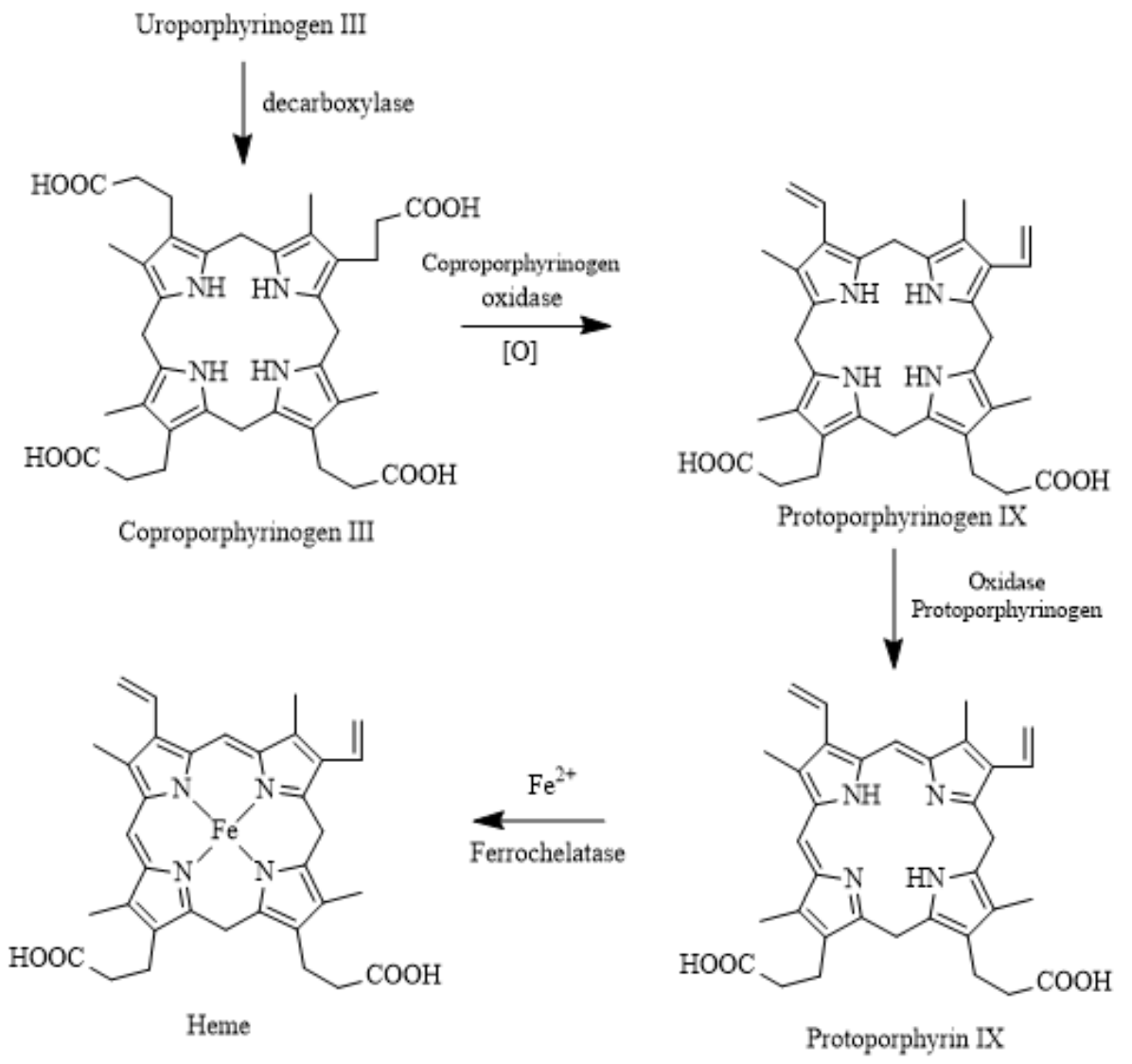

Scheme 4: Biosynthesis of $\mathrm{Heme}^{2}$

\section{Synthesis of Porphyrins}

As porphyrins are found widely in nature, they can be isolated from plants, blood and algae. ${ }^{2}$ These materials can be modified to give synthetically useful porphyrins. Although this can be applied to the preparation of numerous porphyrin-type products, this approach is limited due to structural limitations associated with the natural products. In order to overcome these issues, multistep synthetic routes have been developed. These synthetic routes may involve the intermediacy of monopyrrolic, dipyrrolic, tripyrrolic, or tetrapyrrolic intermediates. ${ }^{11}$ 
The simplest porphyrins are formed by the tetramerization of monopyrroles and this has been a successful technique for the synthesis of highly symmetrical porphyrins, including tetraphenylporphyrin or octaethylporphyrin. ${ }^{11}$ Tetraphenylporphyrin was first synthesized in low yield by Rothemund. ${ }^{12}$ In this chemistry, pyrrole undergoes electrophilic substitution at the $\alpha$ positions with benzaldehyde and subsequent cyclization leads to the formation of the porphyrin macrocycle. Reactions of pyrrole with formaldehyde, acetaldehyde and propionaldehyde were also investigated, but these all gave low yields of porphyrin products.

In 1967, Alder and Longo ${ }^{13}$ developed a better method to synthesize meso-substituted porphyrins by refluxing benzaldehyde and pyrrole in propionic acid in the presence of air. This synthetic method required much shorter reaction times and generated superior yields of tetraarylporphyrins compared to Rothemund's method. Even though Alder and Longo's method was a great improvement, it still had some drawbacks. The yields still remained moderate and the acidic conditions, together with the high temperatures required, placed limitations on what aldehydes that could be used. Moreover, difficulties in the purification of porphyrin products was also a drawback due to side reactions. ${ }^{2}$

In 1987, a further synthetic improvement for making meso-substituted porphyrins was reported by Lindsey using a two-step approach. The first step involved condensation of pyrrole with an aldehyde in the presence of an acid catalyst such as trifluoroacetic acid (TFA) or boron trifluoride etherate to generate a porphyrinogen $\mathbf{1 8}$. In the second step, $\mathbf{1 8}$ is oxidized with an electron-poor quinone such as p-chloranil or 2,3-dichloro-5,6-dicyano-1,4-benzoquinone (DDQ) to generate the meso-substituted porphyrins 19 (Scheme 5). ${ }^{14}$ Yields are typically close to $40 \%$. 
Compared to previous synthetic methods, the greatest benefits of Lindsey's methodology were the comparatively high yields and compatability with aldehydes bearing sensitive functionality.

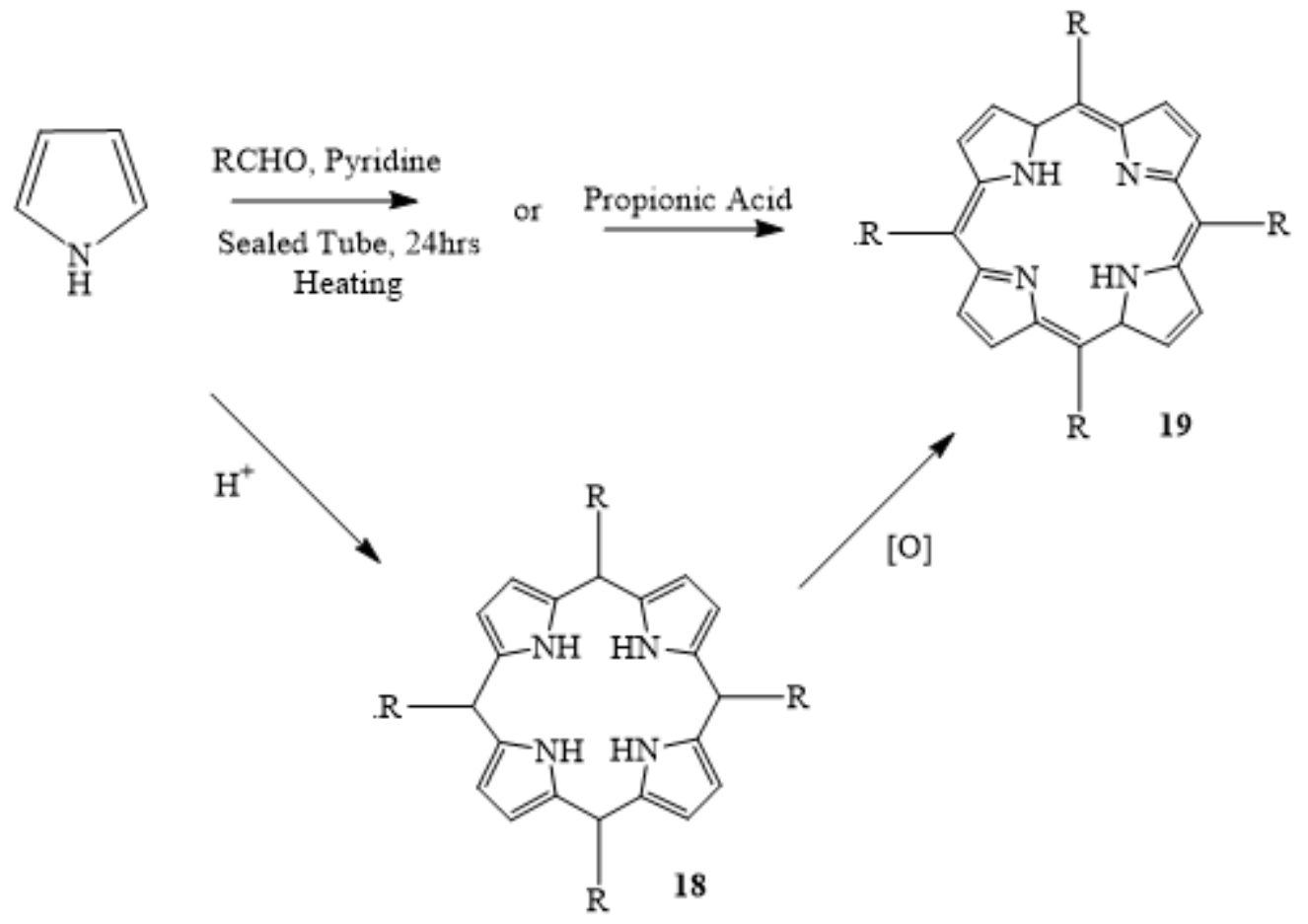

Scheme 5: Synthesis of meso-Substituted Porphyrins

However, these methods are not viable choices for the synthesis of asymmetrical porphyrins. To overcome this problem, a number of stepwise routes have been developed, such as ' $2+2$ ' condensations, ' $3+1$ ' condensations and cyclizations of open-chain tetrapyrroles. ${ }^{11}$

Syntheses using ' $2+2$ ' condensations start with precursors such as dipyrromethane $\mathbf{2 0}$ and dipyrromethene $\mathbf{2 1}$ that have two pyrroles linked together by a carbon bridge (Figure 10). 

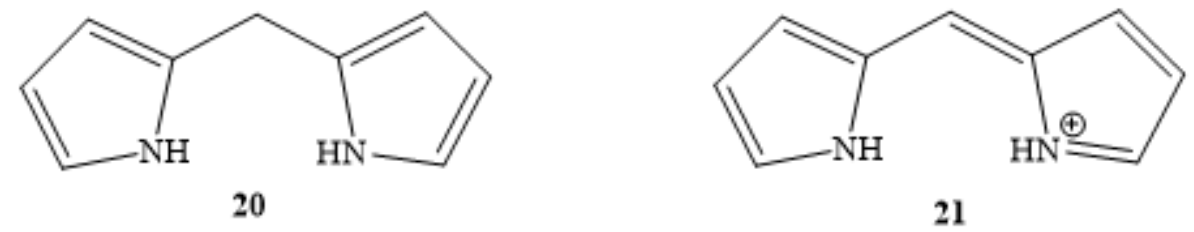

Figure 10: Structures of Dipyrrolic Intermediates

Dipyrromethane $\mathbf{2 0}$ has a saturated bridge, while $\mathbf{2 1}$ has a methine linkage and is generally isolated as a halide salt. Fischer reported many syntheses of porphyrins using ' $2+2$ ' condensations of dipyrromethenes (Scheme 6). For instance, dipyrromethenes $\mathbf{2 2}$ and $\mathbf{2 3}$ were reacted in molten succinic acid to generate deuteroporphyrin IX (24), which was a key intermediate in the total synthesis of heme. ${ }^{11}$

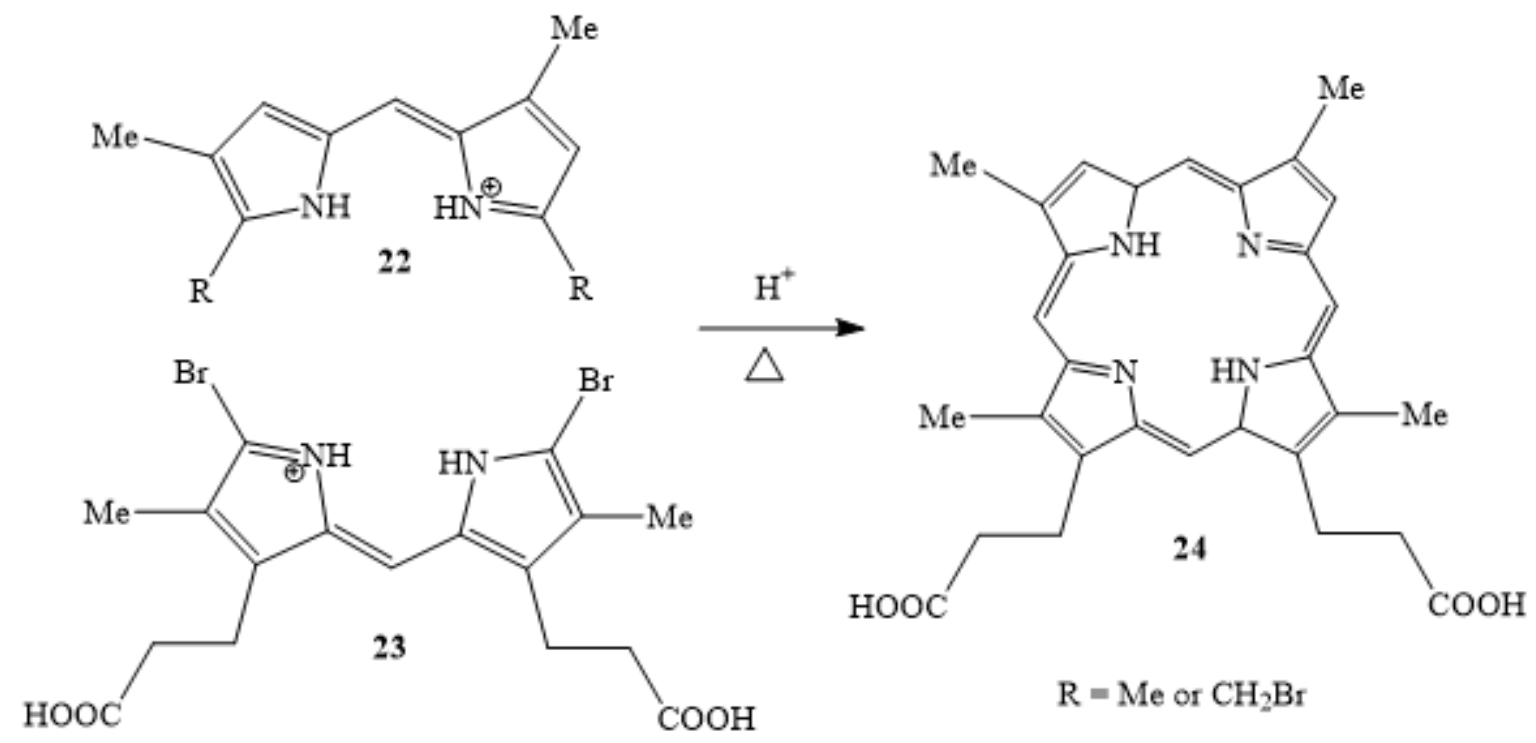

Scheme 6: Fischer Synthesis of Porphyrin 
Although the yields from these reactions were often low, Fischer's dipyrromethene route dominated the field for many years and the potential application of dipyrromethanes $\mathbf{2 0}$ was essentially overlooked. However, in 1960 MacDonald reported a more versatile and higher yielding methodology using dipyrromethene intermediates. Reaction of dipyrromethane $\mathbf{2 5}$ with dialdehyde $\mathbf{2 6}$ under acidic conditions afforded a porphodimethene intermediate. Following air oxidation, porphyrin 27 was generated in $60 \%$ yield (Scheme 7).$^{15}$ The relatively high yields and mild conditions used in these reactions led to MacDonald's ' $2+2$ ' condensation replacing Fischer's pyrromethene route. ${ }^{11}$

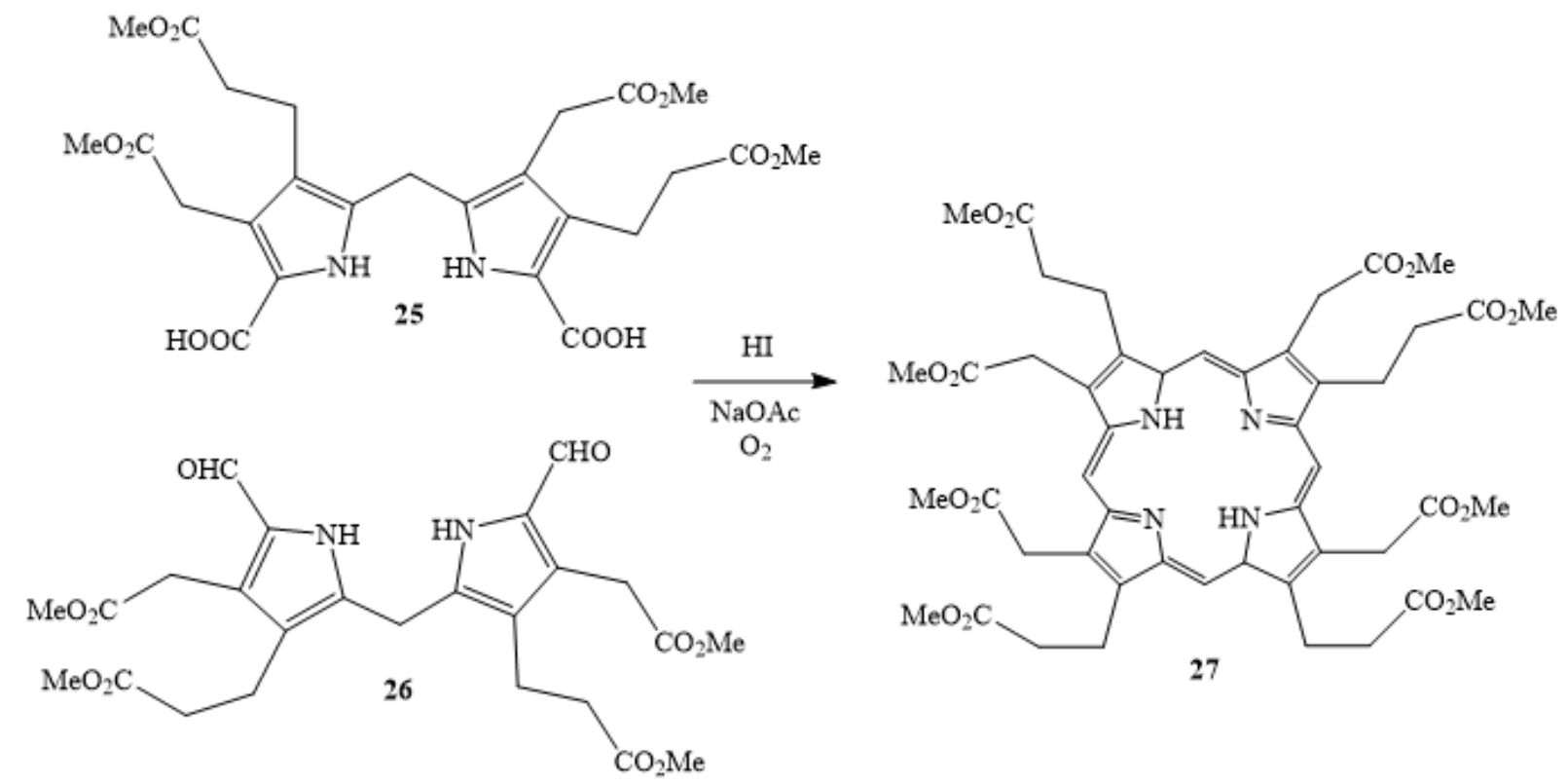

Scheme 7: MacDonald ‘2+2' Porphyrin Condensation

Porphyrins can also be synthesized from oxophlorins, which are cross-conjugated nonaromatic compounds that are the keto tautomers of meso-hydroxyporphyrins. Oxophlorin 28 can be generated by the condensation of dipyrrylketone dialdehyde 29 and dipyrromethane $\mathbf{3 0}$ in 
the presence of an acid catalyst (Scheme 8). The hydroxy tautomer can be trapped by reaction with acetic anhydride and pyridine to afford acetoxyporphyrin $\mathbf{3 1}$. Hydrogenation of $\mathbf{3 1}$ cleaves the acetoxy group to give porphyrinogen 32, and subsequent oxidation with DDQ produced the meso-unsubstituted porphyrin $33{ }^{11}$
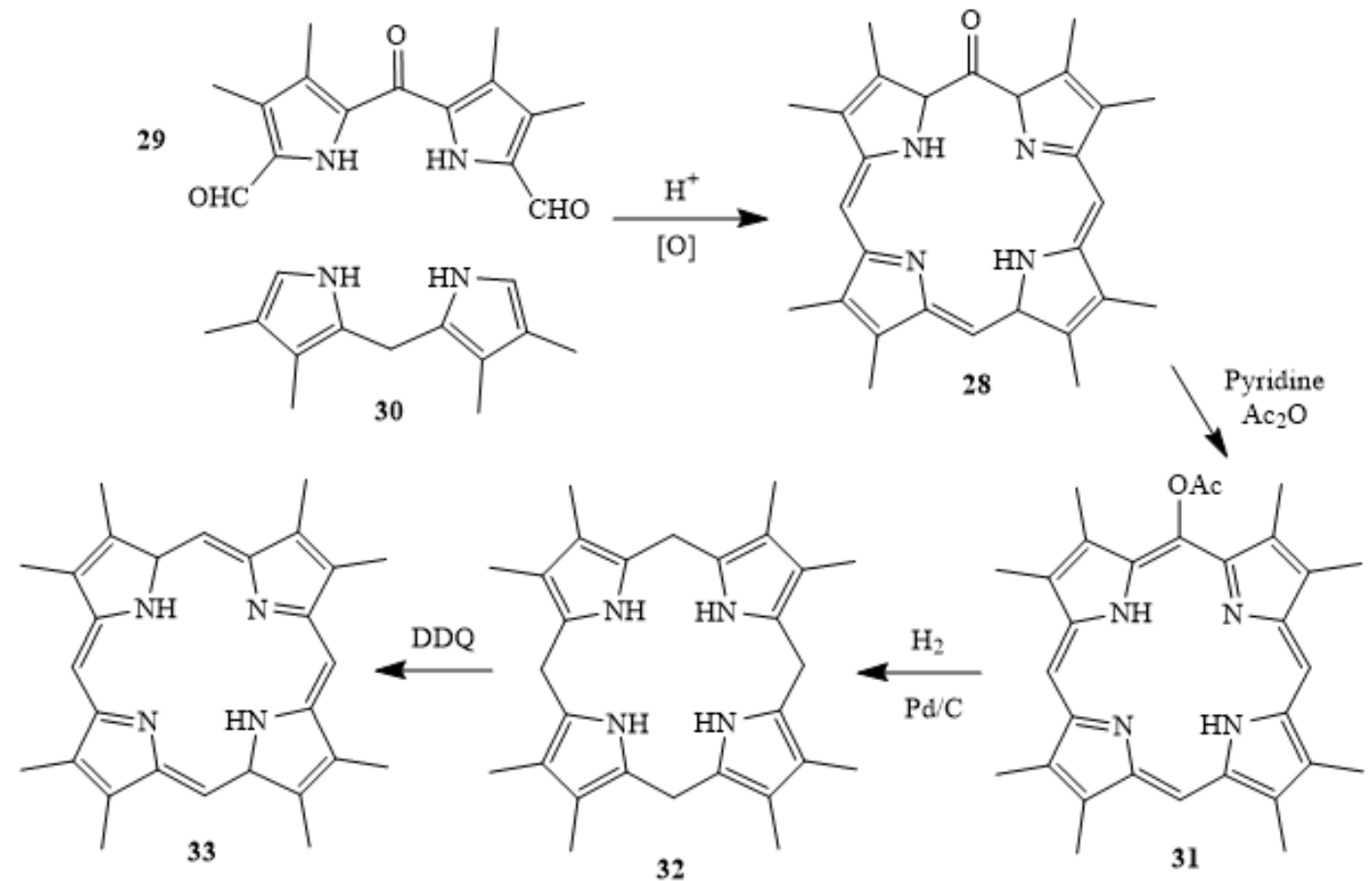

Scheme 8: Synthesis of Porphyrins from Oxophlorins

An important consideration in planning a porphyrin synthesis involves control of symmetry. In the MacDonald ' $2+2$ ' condensation, at least one of the precursors must be symmetrical, otherwise a mixture of isomeric products will be generated. In some cases, these isomers can be separated, but this requires time consuming column chromatography. An alternative MacDonaldtype ' $3+1$ ' condensation has been developed where a tripyrrolic unit is condensed with a pyrrole dialdehyde under acidic conditions, but again one of the condensing fragments must be 
symmetrical in order to avoid isomer formation. In this approach, a tripyrrane $\mathbf{3 4}$ is treated with an acid catalyst, commonly trifluoroacetic acid, and then reacted with a dialdehyde. ${ }^{11}$ This strategy was first introduced by Johnson and his coworkers for the synthesis of oxaporphyrins and thiaporphyrins (Scheme 9). ${ }^{16}$ The tripyrrane was reacted with a thiophene or furan dialdehyde $\mathbf{3 5}$ to generate heteroporphyrins $\mathbf{3 6}$ where one of the nitrogens has been replaced by oxygen or sulfur. Examples of dioxa-, dithia-, and oxathiaporphyrins were also prepared using this strategy.
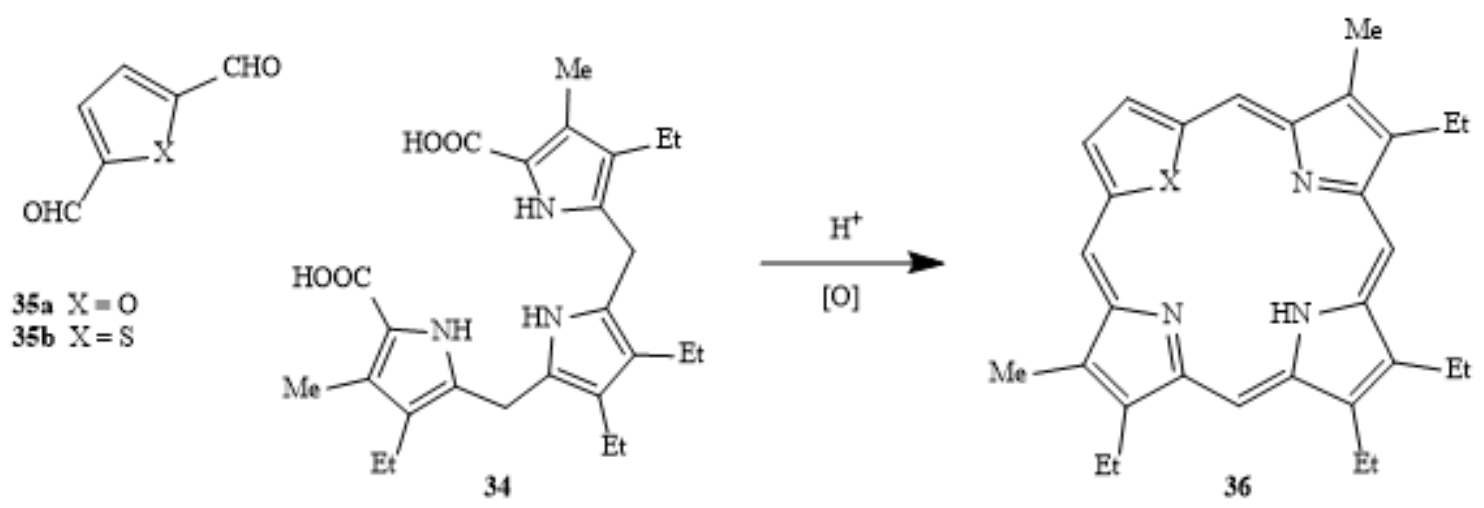

Scheme 9: Synthesis of Thiaporphyrins and Oxaporphyrins

Tripyrranes are crucial intermediates in the ' $3+1$ ' methodology, but the original methods for preparing this system were time consuming and difficult to reproduce. The first tripyrrane intermediate $\mathbf{3 7}$ was created by Kenner and his coworkers by reacting dipyrromethane $\mathbf{3 8}$ with 2acetoxymethylpyrrole 39 in the presence of an acid catalyst (Scheme 10). ${ }^{17}$ 

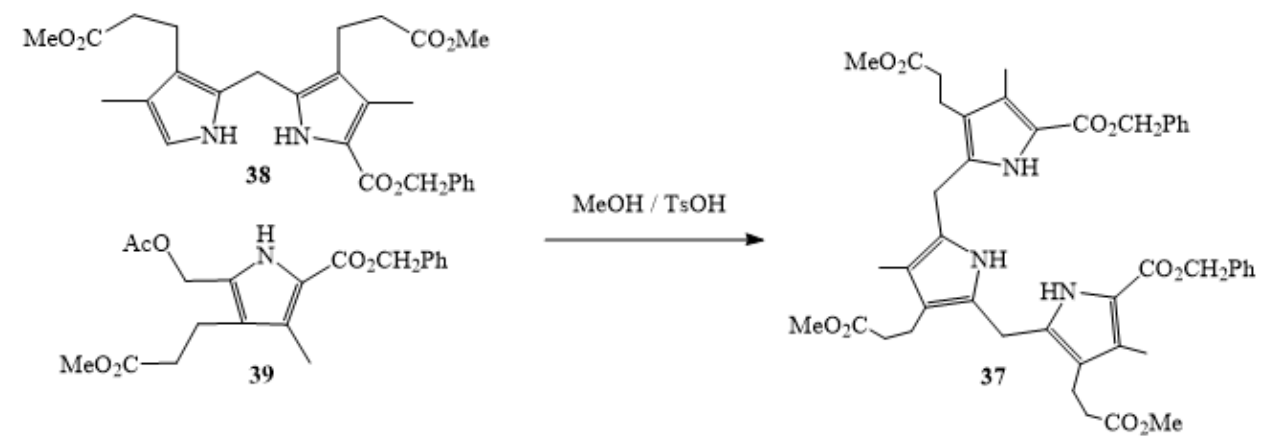

Scheme 10: Synthesis of Kenner's Tripyrrane

In 1987, Sessler et al. reported a far more practical method for the preparation of tripyrranes where an $\alpha$-unsubstituted pyrrole $\mathbf{4 0}$ was reacted with two equivalents of acetoxy methylpyrrole 41 under acidic conditions to give $\mathbf{4 2} .{ }^{18}$ The product precipitated from the reaction solvent to give good yields of pure tripyrrane. These tripyrrolic compounds were commonly prepared as dibenzyl esters. Following hydrogenolysis over Pd/C, the corresponding dicarboxylic acid $\mathbf{4 3}$ was isolated (Scheme 11). ${ }^{18}$

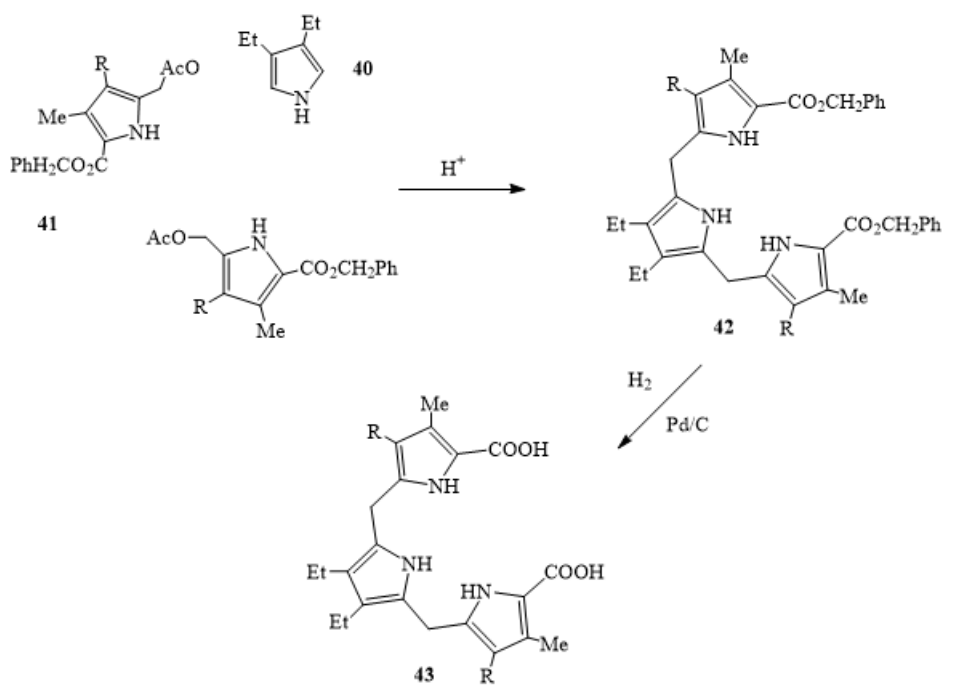

Scheme 11: Optimized Synthesis of Sessler's Tripyrrane 
Modified intermediates where the central pyrrole ring has been replaced by a heterocyclic or carbocyclic ring have also been reported. For instance, the central pyrrolic unit can be replaced with furan, thiophene, azulene ${ }^{19}$ or benzene. ${ }^{20}$ These tripyrrane analogs can be utilized in the synthesis of highly modified porphyrinoid systems though ' $3+1$ ' condensations (Figure 11). ${ }^{19,21,22}$ This type of synthetic method is very powerful and has been used for numerous examples of carbaporphyrins and related systems with further modified porphyrinoid frameworks. ${ }^{23}$ This has enabled the synthesis of many porphyrin-like systems, such as benziporphyrins ${ }^{24}$ and oxybenziporphyrins, ${ }^{25}$ using ' $3+1$ ' MacDonald condensations.

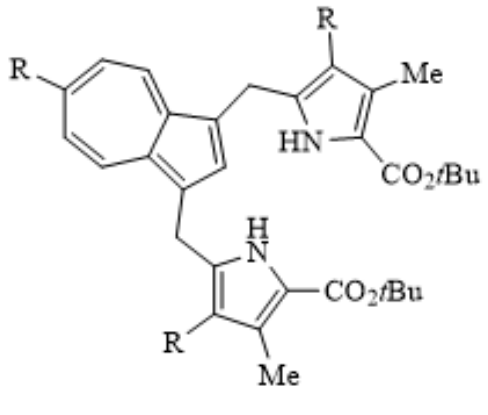

$\mathrm{R}=\mathrm{H}, \mathrm{Bu}, \mathrm{Ph}$

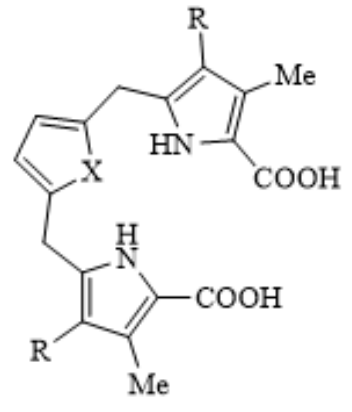

$\mathrm{X}=\mathrm{O}$ or $\mathrm{S}$

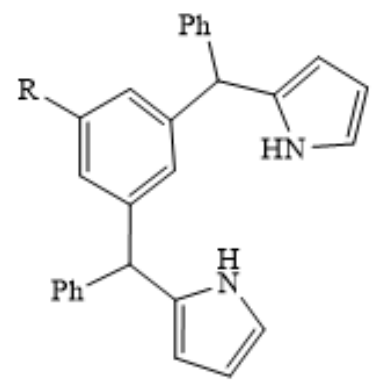

$\mathrm{R}=\mathrm{H}$ or $t \mathrm{Bu}$

Figure 11: Structures of Tripyrrane Analogs with Different Central Rings

Alternative synthetic methods for porphyrin preparation have been developed using openchain tetrapyrroles, such as biladienes and bilanes. The cyclization of tetrapyrrolic compounds are highly condition dependent. Their precursors are highly reactive and can easily undergo decomposition and rearrangement. However, under certain conditions, tetrapyrroles can remain intact and be used to synthesize porphyrins without side reactions creating isomeric mixtures. For instance, dipyrromethanes $\mathbf{4 4}$ and $\mathbf{4 5}$ can be condensed under mild acidic conditions to give 
bilene 46. Cyclization of the bilene with a mixture of TFA and trimethyl orthoformate, followed by air oxidation, affords a pure porphyrin 47 (Scheme 12). ${ }^{11}$
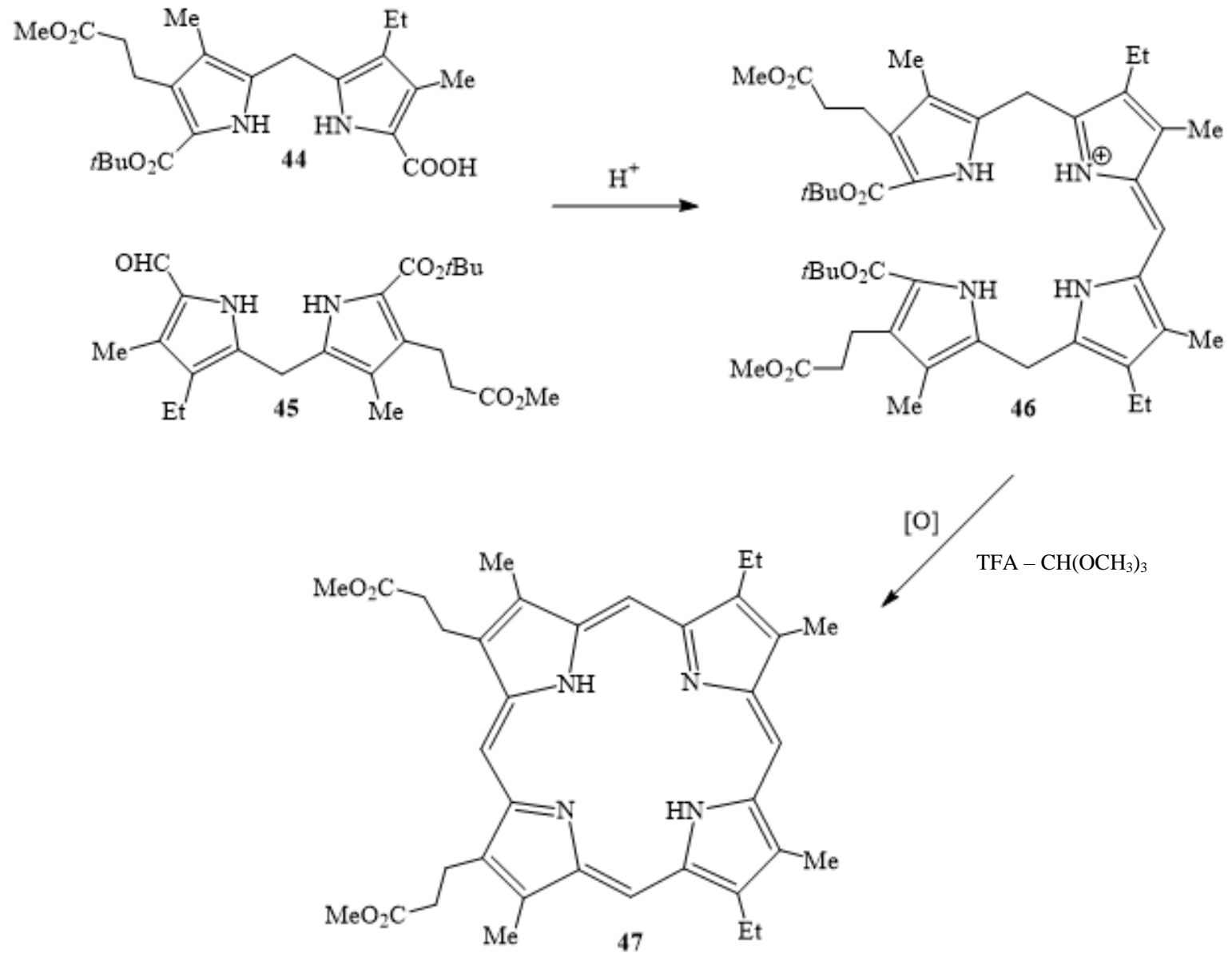

[O]

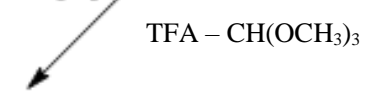

Scheme 12: Synthesis of Porphyrin through a Tetrapyrrolic Intermediate 


\section{Reactivity of Porphyrins and Related Systems}

Metalation is the one of the intriguing properties that testifies to the reactivity of porphyrins. Most of the porphyrins in nature are metal complexes and porphyrins can form complexes with almost all metals. However, the more easily generated metal complexes of porphyrins are formed with first row of transition metals, such as iron. ${ }^{2}$ Carbaporphyrinoids, porphyrin analogs with one or more carbon atoms replacing the core nitrogens, can stabilize unusual oxidation states. For instance, benzocarbaporphyrins can be reacted with silver(I) acetate to form stable silver(III) complexes, and similar gold(III) derivatives have also been reported. Tropiporphyrins also favor silver(III) derivatives. (Figure 12). ${ }^{26}$ Other carbaporphyrinoids have also been shown to yield silver(III) $)^{27,28}$ and palladium(IV) complexes. ${ }^{29}$

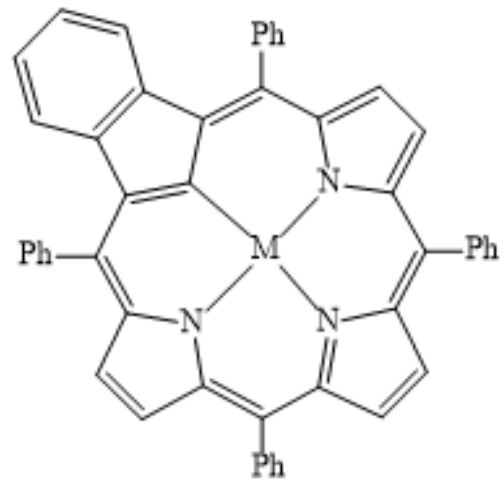

$\mathrm{M}=\mathrm{Au}(\mathrm{III})$ or $\mathrm{Ag}(\mathrm{III})$

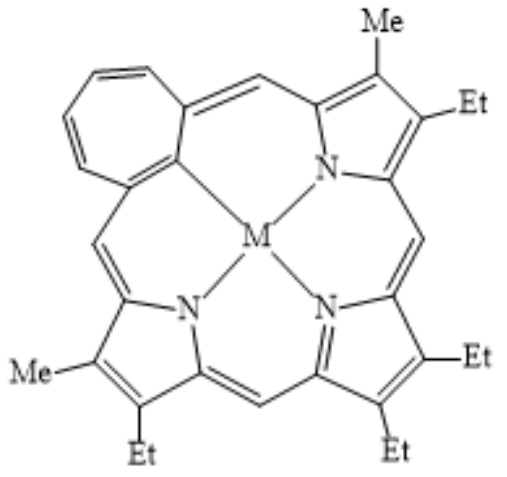

$\mathrm{M}=\mathrm{Ag}(\mathrm{III})$

Figure 12: Metal-Stabilized Carbaporphyrins with Rare Oxidation States on Metals

Porphyrins are aromatic compounds and can undergo electrophilic substitutions, such as halogenation, formylation, nitration, and acylation. Metalloporphyrins prefer to have 
electrophilic substitution at the meso positions, while the free base porphyrins favor reactions on the $\beta$ positions of the pyrrole subunits (Scheme 13). ${ }^{2}$
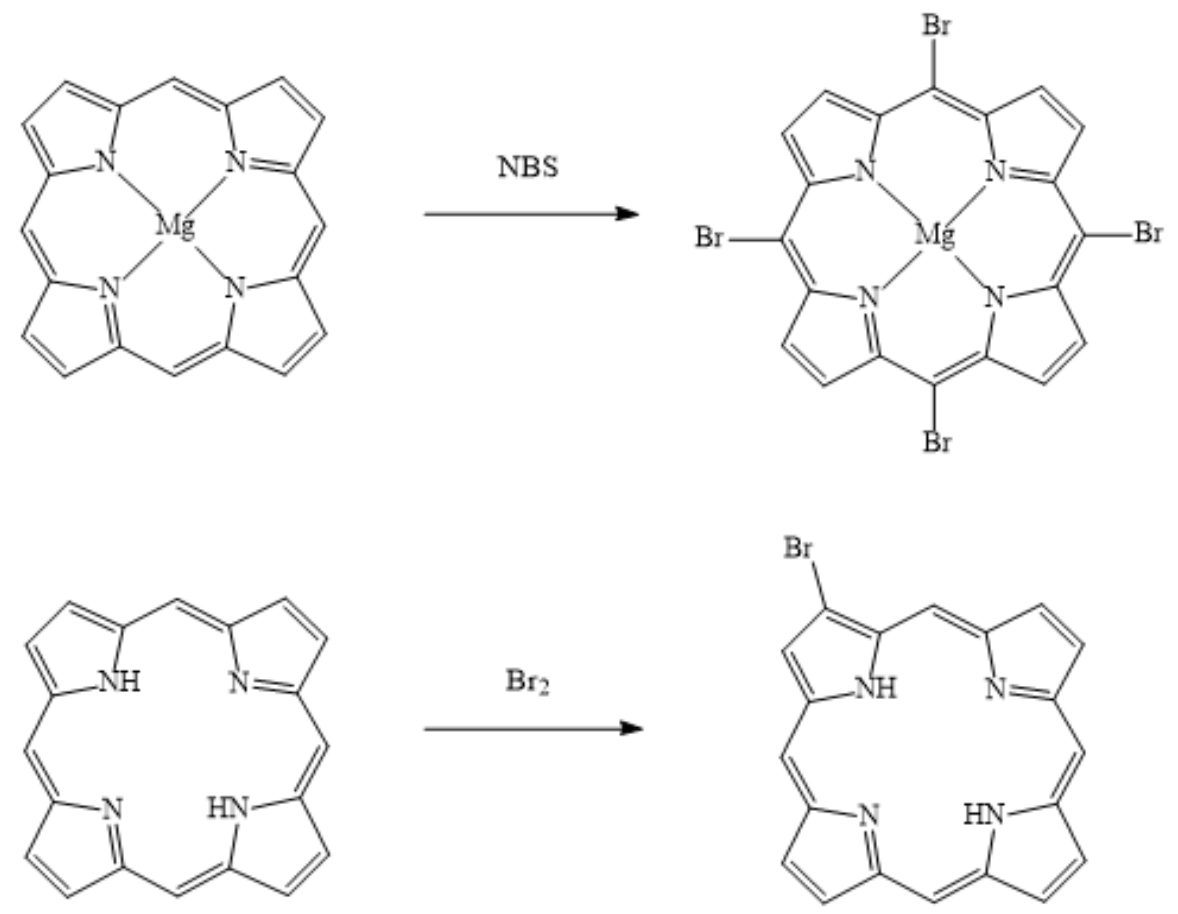

Scheme 13: Bromination of Porphyrins in Different Positions

\section{Applications}

Porphyrins are widely used in a variety of applications, including as ligands in metal catalyzed reactions, and as photosensitizers in photodynamic therapy (PDT). The effectiveness of porphyrinoids in applications of this type is dependent upon the specific structures and can be altered by changing the porpheral substituents, or by changing the core atoms. In PDT, which can be used as a cancer treatment, porphyrins act as photosensitizers that absorb energy from 
light and transfer it to oxygen molecules. The oxygen is then converted to reactive species, such as singlet oxygen, that are destructive to cancer cells. Porphyrins are superior photosensitizers due to their ability to strongly absorb visible light. However, bodily tissues strongly absorb light below $600 \mathrm{~nm}$, and photosensitizers with absorptions between 650 and $800 \mathrm{~nm}$ are favored. Although regular porphyrins do not have absorptions in this region, porphyrin analogs such as $\mathrm{N}-$ confused porphyrins do exhibit absorptions in the far red above $650 \mathrm{~nm}^{23}$

Metalloporphyrins have been widely used in asymmetrical catalysis, such as epoxidation, ${ }^{30}$ cyclopropanation, ${ }^{31}$ and Suzuki-Miyaura cross coupling. ${ }^{32}$ Studies of the cytochrome P450 family of monooxygenases inspired the development of metalloporphyrin catalysts. The heme units acting as cofactors have been shown to exhibit a wide range of functions, such as the elimination of foreign molecules in the body by biotransformation. Groves and his coworkers reported the first examples of cytochrome P450 inspired catalysts. In this work, iron(III) complexes of tetraphenylporphyrin were shown to catalyze olefin epoxidation and alkane hydroxylation. ${ }^{41}$ Woo and coworkers have shown that similar reactions such as cyclopropanation were catalyzed using $\operatorname{Ir}(\mathrm{III})$ tetratolylporphyrin (TTP) (Scheme 14). ${ }^{31}$

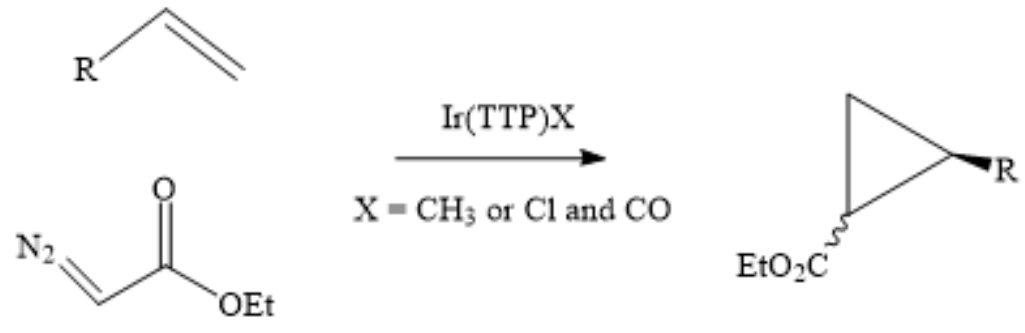

Scheme 14: Metalloporphyrin Catalyzed Cyclopropanation 
Porphyrin analogs have also been shown to catalyze reactions of these types and expanded porphyrins have been used as chemosensors for nuclear waste. An expanded porphyrin-like core can better bind to actinides than true porphyrins. These expanded systems are used for the detection of radioactive metals such as plutonium and uranium, which are sources of nuclear energy. ${ }^{33}$ Moreover, optical sensors containing palladium(II) and platinum(II) metalloporphyrins with phosphorescence properties have been widely investigated for industrial, ecological, and medicinal applications. Alternative optical sensors with high phosphorescence at room temperature have also been discovered using ruthenium(III) and iridium(III) containing metalloporphyrins. ${ }^{34}$

\section{Carbaporphyrins}

It is known that substitution on the porphyrin macrocycle can affect the light absorption and aromaticity of the system. Larger effects can result from replacing the internal nitrogens with oxygen, sulfur, selenium, tellurium, phosphorus or carbon. Carbaporphyrins have one or more of the internal nitrogens on the pyrrolic subunits replaced by carbon. ${ }^{23}$ The first example of a carbaporphyrinoid system was N-confused porphyrin (NCP), which was an isomer of porphyrin that had one of the nitrogens placed on the outside of macrocycle. This derivative was initially discovered as a byproduct from the synthesis of tetraphenylporphyrin. It had been created through a one-pot condensation of benzaldehyde and pyrrole. ${ }^{12-14}$ Furuta and coworkers isolated the byproduct and demonstrated that this aromatic system had a similar UV-vis spectrum to TPP, although the absorptions were shifted to longer wavelengths. Furuta named byproduct $\mathbf{4 8}$ as N-

confused porphyrin due to the relocation of a pyrrolic nitrogen. ${ }^{35}$ It was later demonstrated by 
Geier and Lindsey that yields of NCP could be raised to almost $40 \%$ when benzaldehyde and pyrrole were reacted in the presence of methanesulfonic acid (Scheme 15). ${ }^{36}$

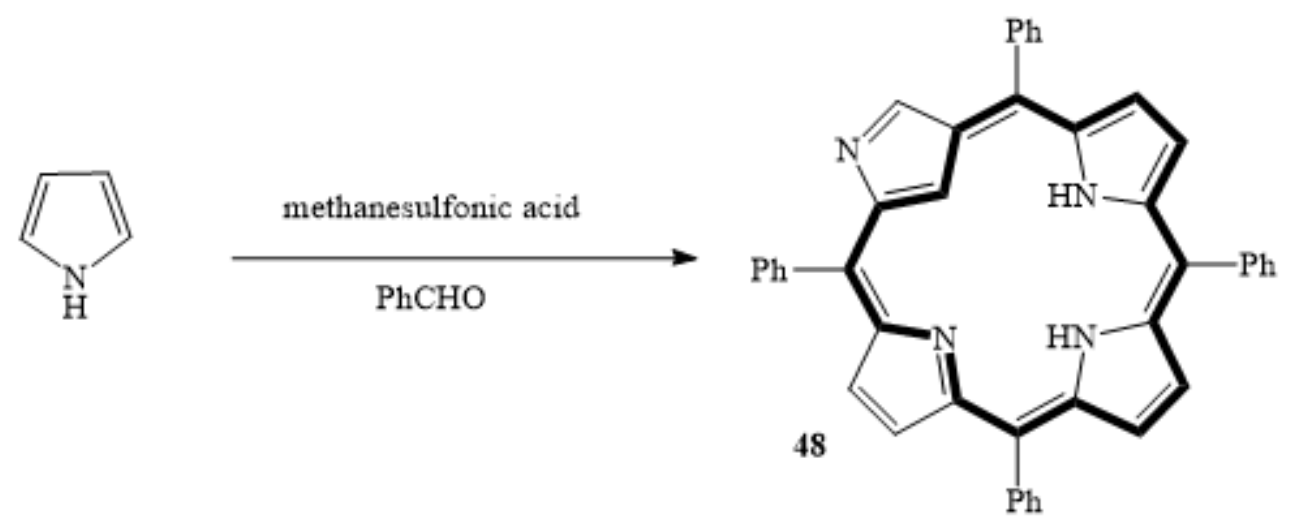

Scheme 15: Synthesis of N-Confused Porphyrin

Recently, a new class of porphyrin isomers called neo-confused porphyrins have been discovered which have one of the nitrogens in a pyrrole ring linked to methine bridge on the macrocycle. ${ }^{37}$ Lash et al. reported the synthesis of neo-confused porphyrin $\mathbf{5 1}$ by a ' $2+2$ ' condensation of dialdehyde 49 and dicarboxylic acid $\mathbf{5 0}$ in the presence of $p$-toluenesulfonic acid ( $p$ - TSA) (Scheme 16). The porphyrin isomer retained aromatic characteristics, although the proton NMR spectrum indicated that the diamagnetic ring current was reduced compared to true porphyrins. ${ }^{37}$ 


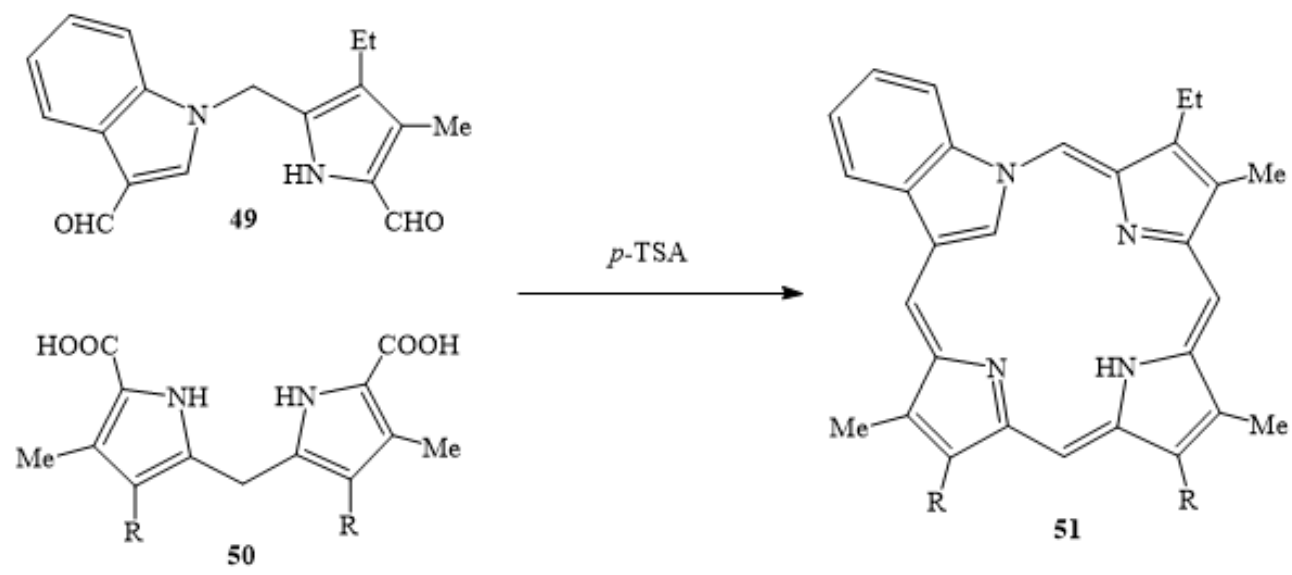

Scheme 16: Synthesis of Neo-Confused Porphyrins

Porphyrinoid macrocycles with inverted furan or thiophene rings have also been prepared. O-confused oxaporphyrin ${ }^{38,39} \mathbf{5 2}$ and S-confused thiaporphyrins ${ }^{40} \mathbf{5 3}$ have heteroatoms at the exterior positions but have greatly reduced aromatic character compared to NCPs due to crossconjugation (Figure 13). ${ }^{38-40}$
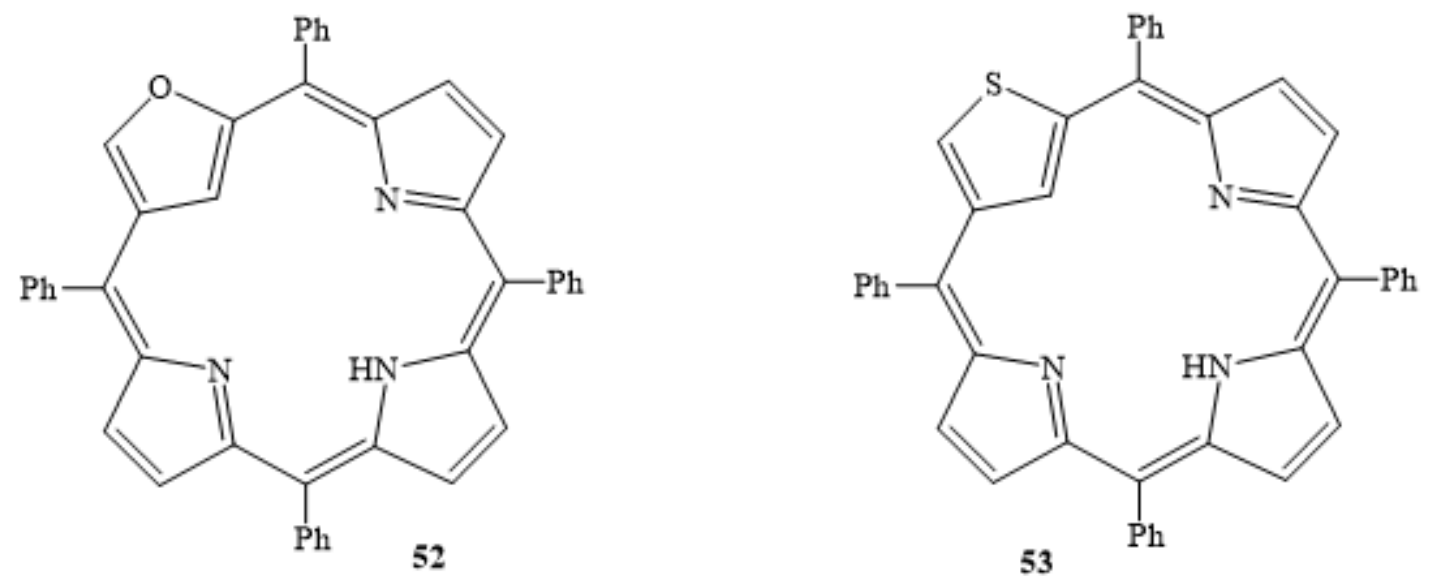

Figure 13: Oxygen-Confused and Sulfur-Confused Porphyrins 
In this thesis, a new class of carbaporphyrinoids with pyrene subunits has been prepared using ' $3+1$ ' condensations. A MacDonald ' $3+1$ ' approach was used to prepare pyreniporphyrin and a related palladium complex was generated. In a separate study, the synthesis of macrocyclic systems from pyrene dicarbinols has been investigated. The pyrene reacted with pyrrole in the presence of a Lewis acid catalyst to give a pyrenitripyrrane and this was further reacted with a thiophene dicarbinol to produce a thiapyreniporphyrin. The aromatic properties of the free base and protonated macrocycles were also assessed. 


\section{CHAPTER II}

\section{PAH-PORPHYRIN HYBRIDS}

\section{Introduction to Benziporphyrins}

Benziporphyrins are porphyrin analogs where a benzene moiety replaces one of pyrrole units in the ring system. The first method used to synthesize benziporphyrin $\mathbf{5 4}$ was a ' $3+1$ ' MacDonald condensation of a tripyrrane 55 with a dialdehyde 56 under acidic condition (Scheme 17). ${ }^{24}$
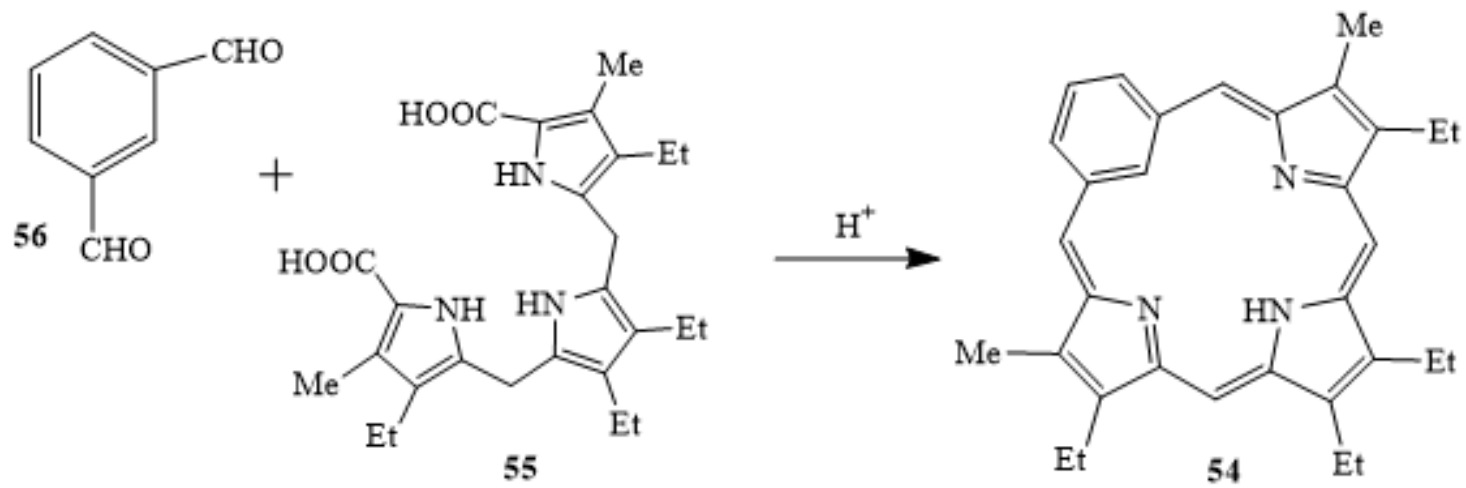

Scheme 17: Synthesis of Benziporphyrin

The initial report appeared to show that two tautomers of benziporphyrin (54a and $\mathbf{5 4 b}$ ) could be observed in the NMR spectrum, but Lash et al. ${ }^{21}$ later demonstrated that only tautomer 54a was actually observable by proton and ${ }^{13} \mathrm{C}$ NMR spectroscopy. The initial result was attributed to the 
presence of isomeric impurities that were mistakenly assigned to tautomeric forms of benziporphyrins. Although benziporphyrin was somewhat unstable in solution, the compound could be isolated in a $28 \%$ yield as a purple powder. ${ }^{21}$

Cross - conjugation interrupts potential $18 \pi$ electron pathways, and benziporphyrins are not considered to be aromatic. A hypothetical tautomer $\mathbf{5 4} \mathbf{c}$ with a continuous $18 \pi$ electron conjugation pathway has been proposed, but this would disrupt the aromaticity of the six membered ring (Figure 14). Moreover, the proton NMR spectrum confirms that benziporphyrins are not aromatic due to the absence of a diamagnetic ring current. The internal and external benzene protons all resonate between 7.6 and $8.0 \mathrm{ppm} .{ }^{25}$ Tautomer $\mathbf{5 4 a}$ appears to predominate in solution, although $\mathbf{5 4 b}$ may be in equilibrium with this species. The internal $\mathrm{NH}$ resonate at $8.9 \mathrm{ppm}$, again indicating the absence of macrocyclic aromaticity. However, in the presence of acid, a dicationic species is generated that shows a weak diamagnetic ring current and the internal $\mathrm{CH}$ shifted upfield to 5.2 ppm. ${ }^{21}$

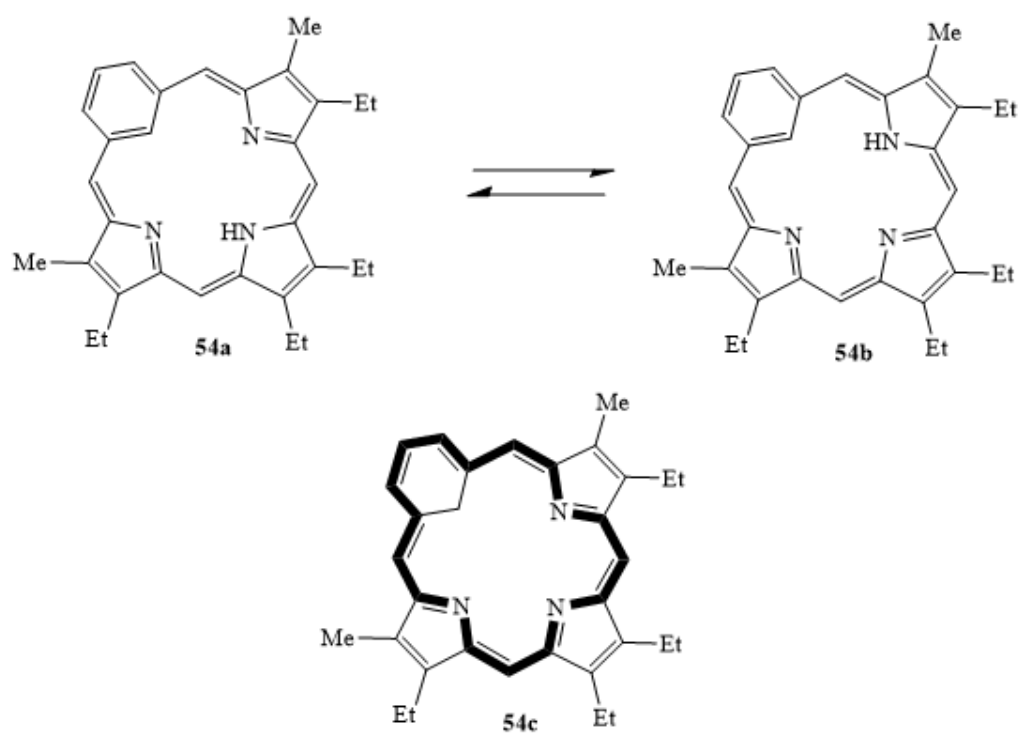

Figure 14: Tautomers of Benziporphyrin 
Even though benziporphyrins are not aromatic, the addition of substituents, such as electron donating methoxy groups, on the benzene ring can significantly affect the diatropic character of the system. In addition, 2-hydroxybenziporphyrin $\mathbf{5 8}$ tautomerizes to give an aromatic semiquinone 57. Condensation of a tripyrrane with dialdehyde $\mathbf{5 9}$ gave the hydroxybenziporphyrin $\mathbf{5 8}$, and this underwent a keto-enol tautomerization to give an oxybenziporphyrin 57 . This modified porphyrinoid possesses an $18 \pi$ electron pathway and has aromatic characteristics (Scheme 18). The UV-vis spectra of oxybenziporphyrins were porphyrin-like and gave two Soret bands and a series of Q bands. The proton NMR spectrum for 57 also demonstrated strong upfield shifts for the internal $\mathrm{CH}$ and $\mathrm{NH}$ to give resonances at -7.3 and -4 ppm, respectively. ${ }^{21,25}$

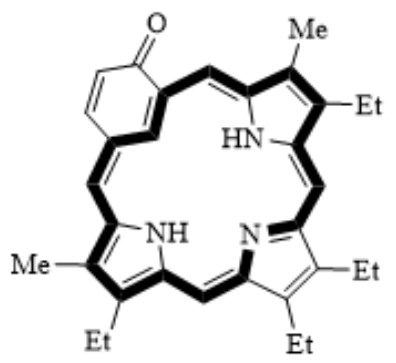

57
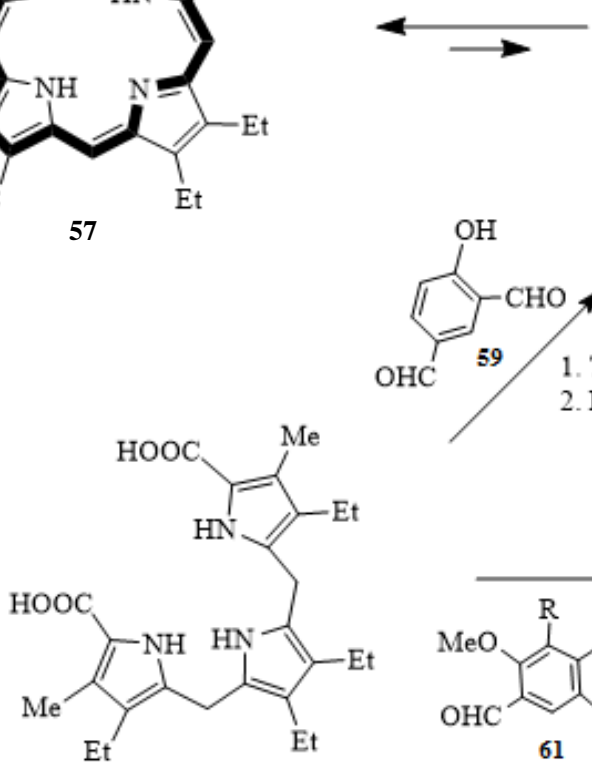
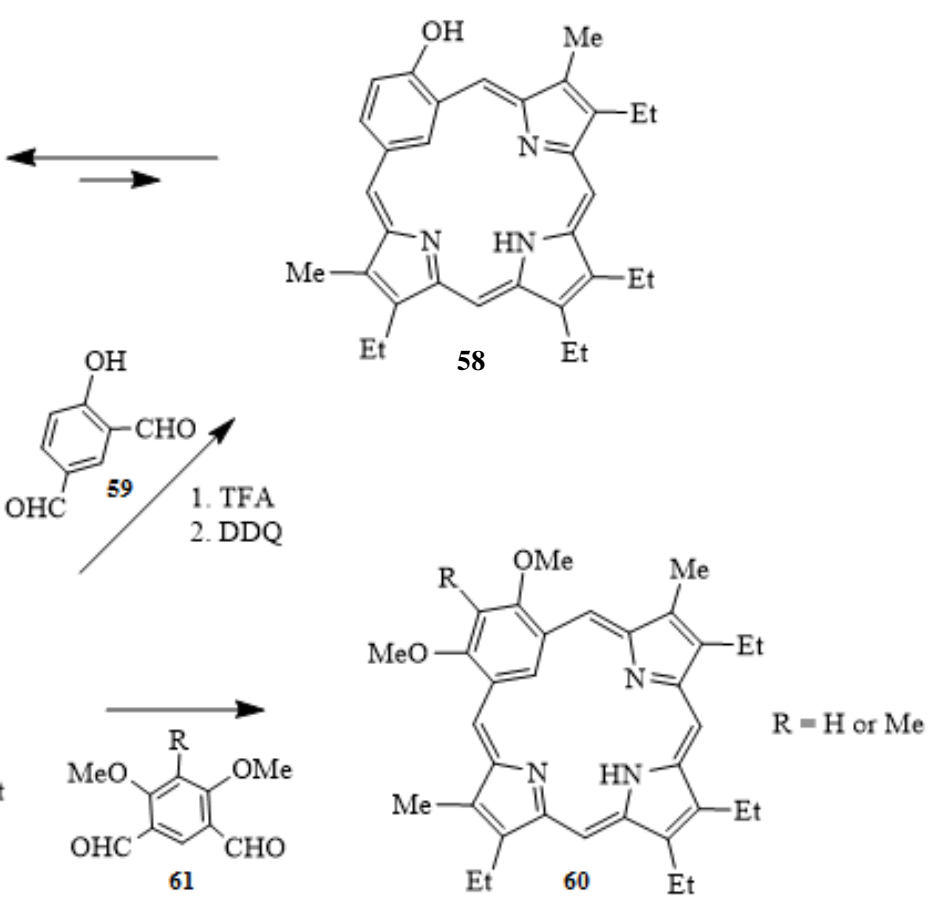

Scheme 18: Synthesis of Methoxybenziporphyrins and Oxybenziporphyrins 
In order to investigate the influence of electron donating substituents on the aromatic character of benziporphyrins, two examples of dimethoxybenziporphyrin $\mathbf{6 0}$ were prepared (Scheme 18). These substituted benziporphyrins were prepared by reacting dimethoxybenzene dialdehyde 61 with a tripyrrane under standard ' $3+1$ ' conditions. Tetraphenyl dimethoxybenziporphyrins were synthesized by reacting dicarbinol 63 with benzaldehyde and pyrrole in the presence of catalytic boron trifluoride etherate (Scheme 19). In the proton NMR spectrum of tetraphenylbenziporphyrin without methoxy substituents, the chemical shift for the internal $\mathrm{CH}$ appeared at $7.3 \mathrm{ppm}$, while the $\mathrm{NH}$ appeared at $10.3 \mathrm{ppm}$. The addition of electrondonating substituents in 62a led to the chemical shifts on the $\mathrm{CH}$ and $\mathrm{NH}$ being moved upfield to 6.4 and 9.2 ppm, respectively. Addition of TFA to 62 gave the corresponding dications $62 \mathbf{H}$. In the proton NMR spectrum for $\mathbf{6 2} \mathbf{a H}$, the internal $\mathrm{CH}$ shifted to $3.5 \mathrm{ppm}$, indicating that the diatropicity for the macrocycle had been greatly enhanced. ${ }^{41}$<smiles>[R]c1c(OC)c(C(O)c2ccccc2)cc(C(O)c2ccccc2)c1OC</smiles>
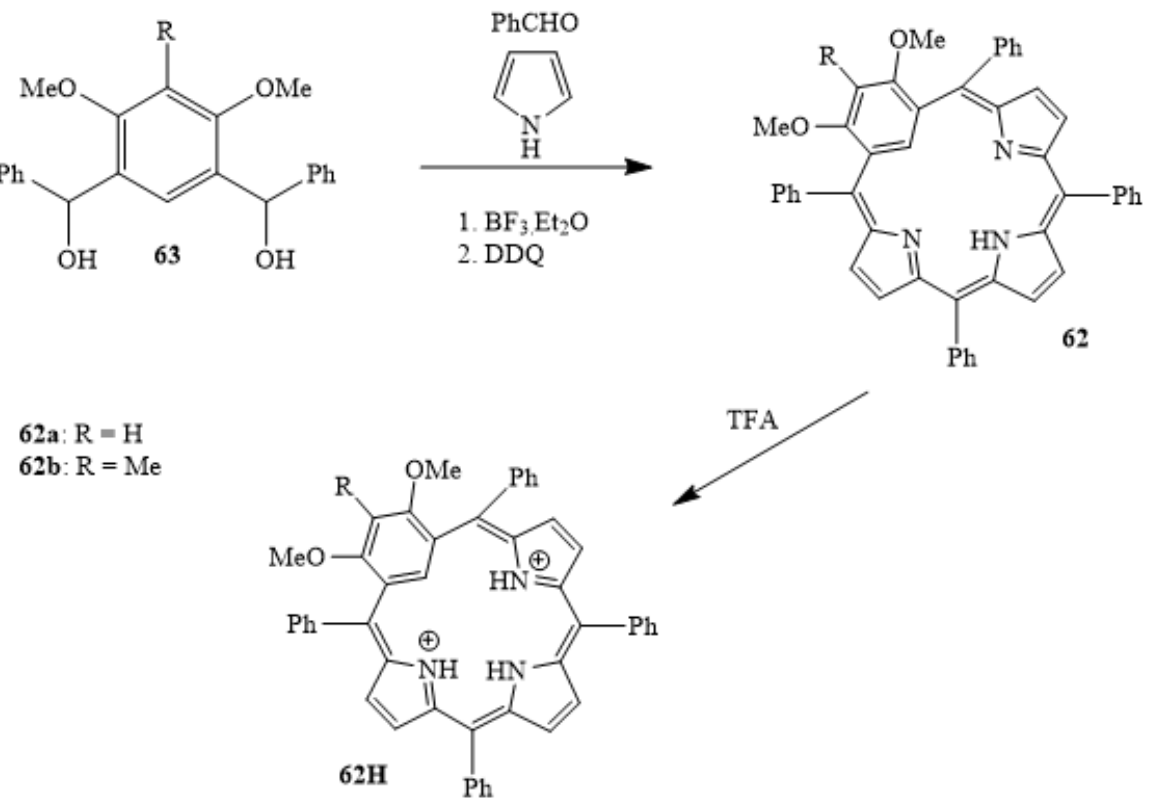

Scheme 19: Synthesis and Protonation of Dimethoxy Benziporphyrins 
Cleavage of a methoxy group from dimethoxybenziporphyrins 60a and 60b was achieved by treatment with excess boron tribromide $\left(\mathrm{BBr}_{3}\right)$. This gave the related methoxy oxybenziporphyrins 64 which proved to be fully aromatic porphyrinoids (Scheme 20). ${ }^{42}$
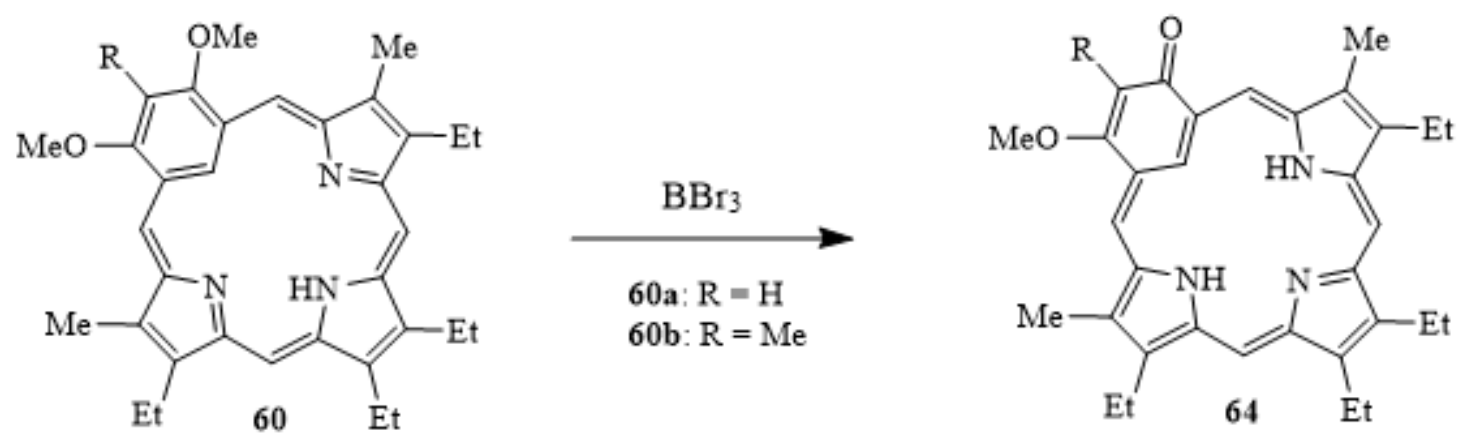

Scheme 20: Synthesis of Oxybenziporphyrin through Methoxy Cleavage

The cleavage of both methoxy groups was achieved by refluxing $\mathbf{6 0}$ with hydrobromic acid and acetic acid. When $\mathbf{6 0 a}$ was treated with this mixture of acids, both methoxy groups were cleaved to give hydroxy oxybenziporphyrin $\mathbf{6 5}$. The free base compound was highly insoluble, but protonation with TFA gave a soluble dication (Scheme 21). After protonation, $65 \mathbf{H}$ showed an upfield chemical shift for the internal $\mathrm{CH}$ to $-2.4 \mathrm{ppm}$. When $\mathbf{6 0 b}$ was reacted under the same conditions, the resulting product underwent an unexpected oxidation to afford hydroxy diketone 66. This unusual porphyrinoid exhibited greatly increased diatropicity and the proton NMR spectrum showed the internal $\mathrm{CH}$ at $-8.5 \mathrm{ppm} .{ }^{42}$ 

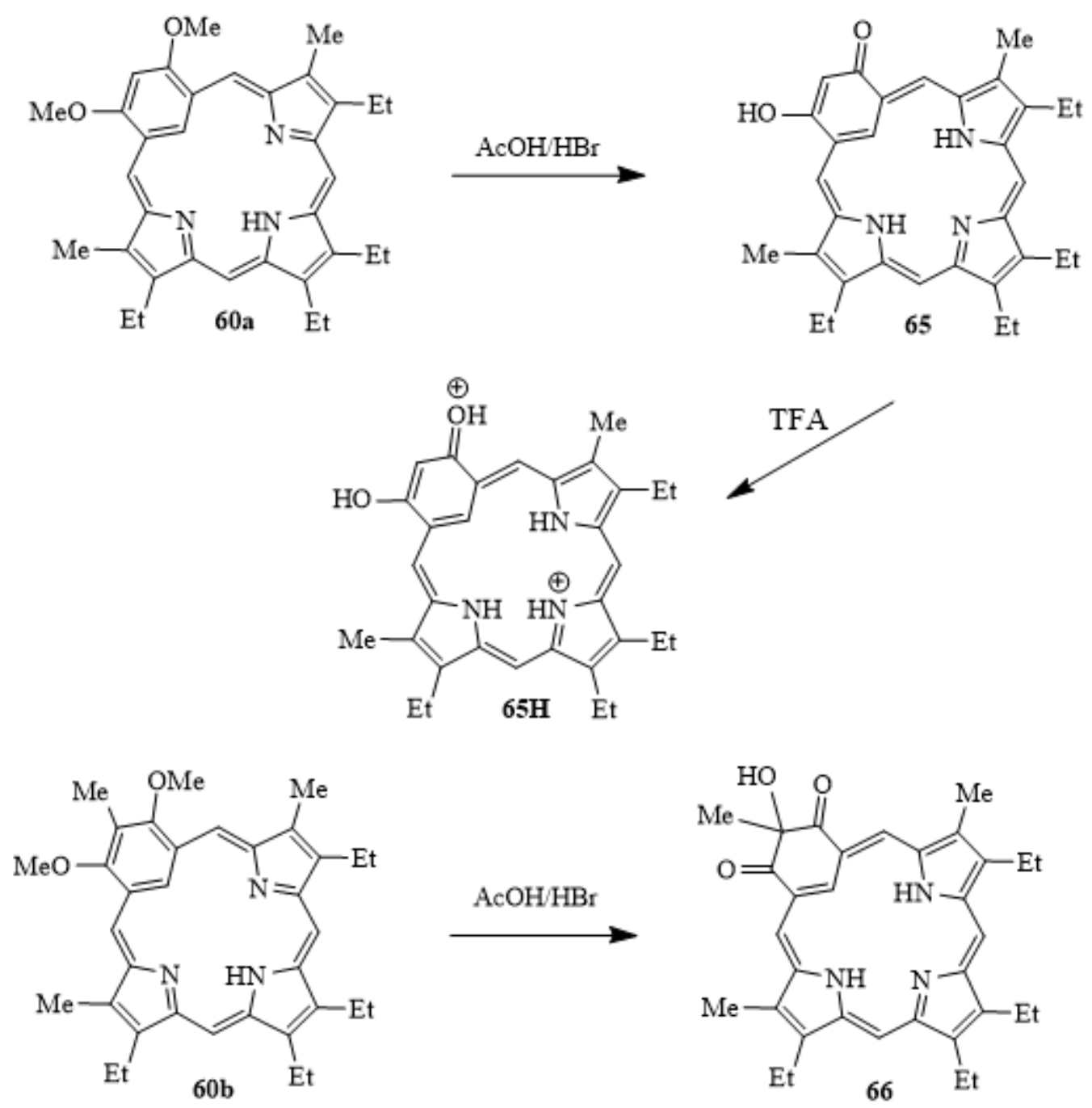

Scheme 21: Cleavage of the Methoxy Units in Dimethoxybenziporphyrins with HBr in Refluxing Acetic Acid

\section{Introduction of Polycyclic Aromatic Compounds}

Heteroaromatic chemistry is a wide field that has been pursued to hundreds of years. The intense interest in heterocyclic chemistry has led to the development of synthetic methodologies, and research into natural products, molecular biology, and material science. ${ }^{43}$ Initial interests in 
polycyclic heteroaromatic (PHA) compounds was due to their applications as synthetic dyes. ${ }^{44}$ The first PHA compound (Figure 15) flavanthrone was reported by Roland Scholl in $1907 .{ }^{45}$ This unique eight-ring structure represented an important discovery with potential industrial applications. In the following decades, research continued on PHAs and diverse polycyclic structures, such as tricycloquinazoline, xylindein, and tetrabenzo-tetraoxa[8]circulene, were discovered. ${ }^{46}$
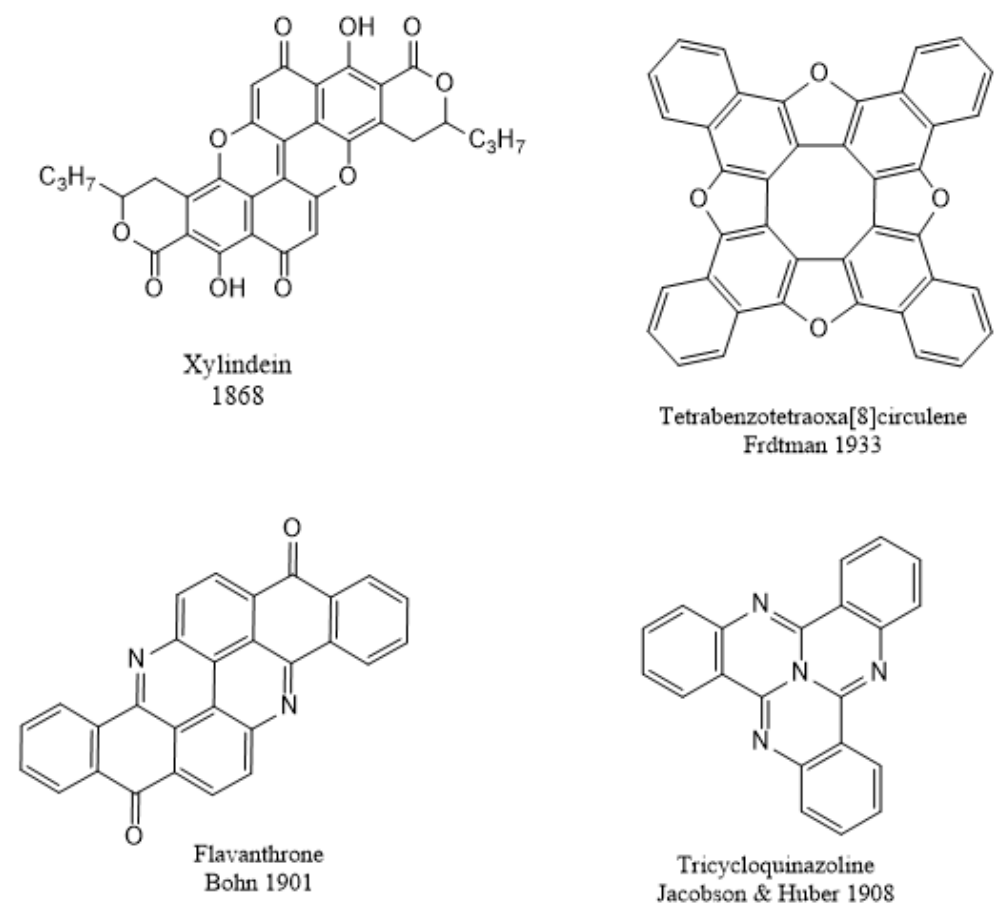

Figure 15: Early Examples of PHAs

The term of PAH stands for polycyclic aromatic hydrocarbon. The differences between PAHs and PHAs are essentially due to the presence of at least one non-carbon atom in the rings, such as nitrogen, oxygen, and sulfur. Initially, the major motivation for investigating PAHs related to their role as carcinogens. ${ }^{47}$ However, more recently investigations in this area have 
been explored due to the relationship of these structures with graphene. Furthermore, extended aromatic systems incorporating porphyrin rings have been synthesized that possess unusual properties. Although initial studies in this area made use of complicated reaction conditions that gave poor yields of PHAs, more sophisticated routes to highly functionalized derivatives have now been developed. In particular, metal catalyzed reactions have become important synthetic methods in the synthesis of PHAs and related highly conjugated porphyrin systems. This method also enables the installation of functional groups and provides routes to novel precursors. Porphyrins with fused aromatic rings (Scheme 22) have been widely investigated and can be further modified by metalation of the macrocyclic core. This type of modification significantly changes the UV-visible spectra and can modify the aromatic properties for the system. ${ }^{48}$
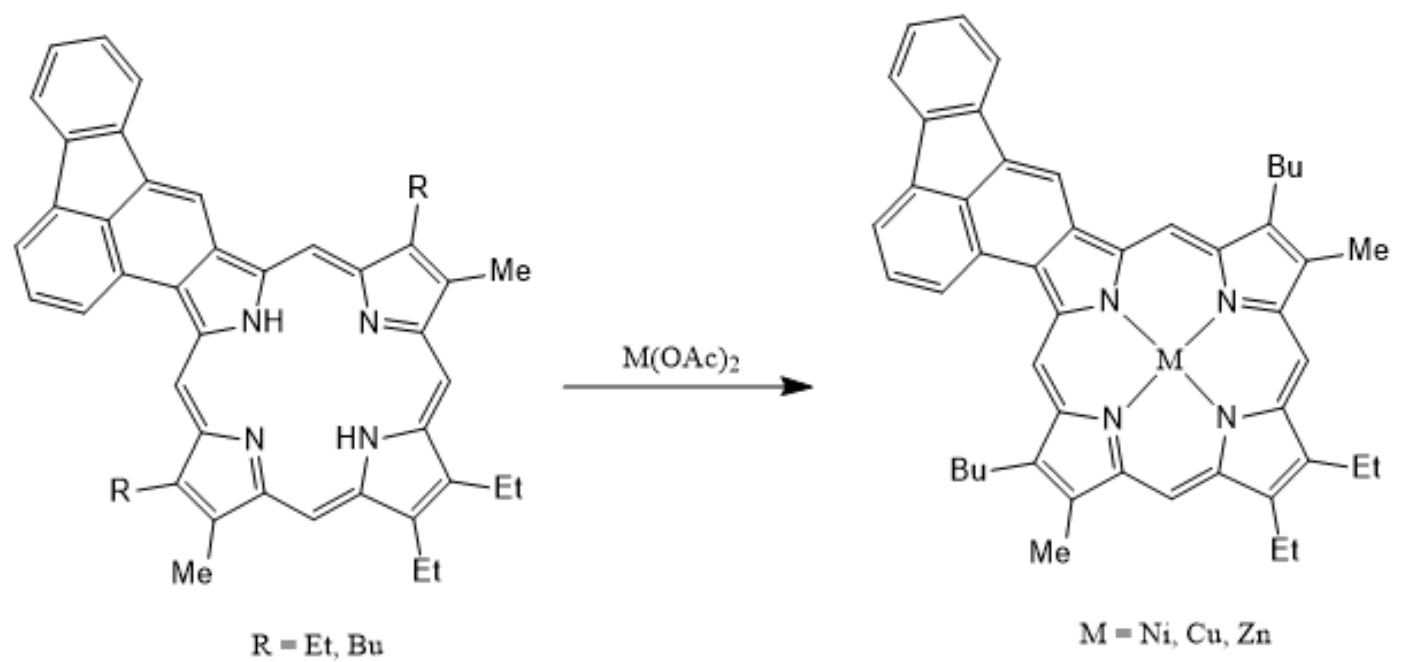

Scheme 22: Example of the Metalation of a Porphyrin with a Fused PAH Unit ${ }^{48}$

Porphyrin analogues with carbocyclic rings in place of one or more pyrrole subunits can also be further extended to produce PAH-porphyrin hybrids. Benziporphyrins can be extended to form naphthiporphyrins $67^{49}$ that have slightly modified properties. In order to further investigate 
this phenomenon, benziporphyrins with further extended conjugation have been investigated. Specifically, the synthesis of pyreniporphyrin $\mathbf{6 8}$, a pyrene-containing porphyrin analogue, from pyrene dialdehyde 69 and tripyrrane 55 has been achieved (Scheme 23).

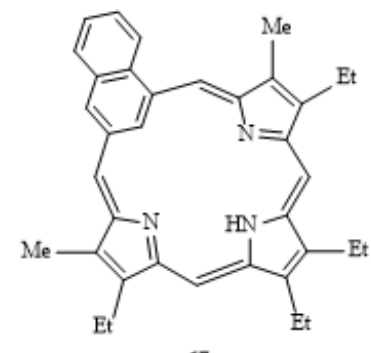

67

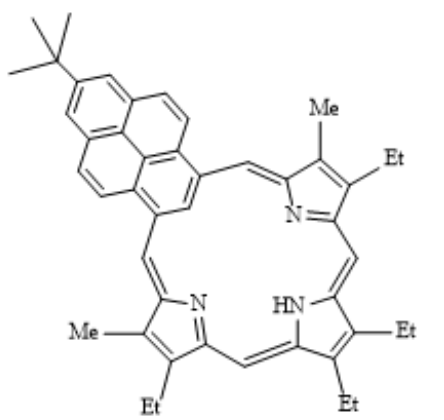

68

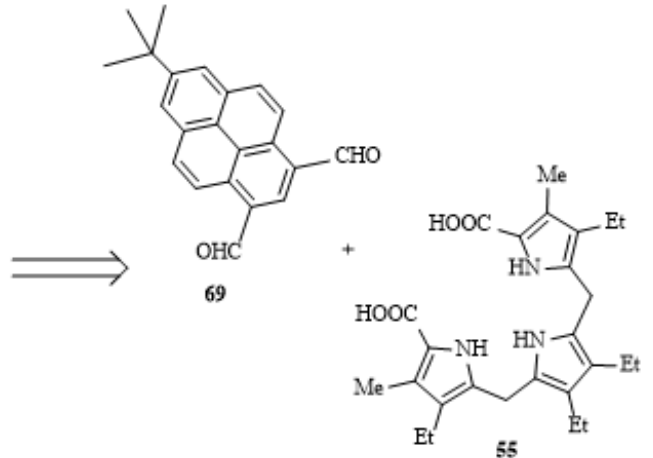

Scheme 23: Naphthiporphyrin 67 and Retrosynthetic Analysis of Pyreniporphyrin 68

The details of this synthesis of the properties of the resulting PAH-porphyrin hybrid are described below. In addition, a thiapyreniporphyrin has been prepared and investigations into related systems are described.

\section{Results and Discussion}

In this study, a ' $3+1$ ' MacDonald condensation was used to prepare a pyreniporphyrin. The MacDonald ' $3+1$ ' condensation has been shown to be an effective method for preparing carbaporphyrinoids such as benziporphyrins. ${ }^{19,21,42,48}$ In order to utilize this synthetic method, a tripyrrane intermediate was required. In addition, a pyrene dialdehyde was also needed. The tripyrrane was prepared from pyrrolic precursors that were obtained via Knorr or Barton-Zard condensations. Reaction of diethyl malonate with sodium nitrite and acetic acid afforded oxime $\mathbf{7 0}$ and this was reduced with hydrogen over $10 \% \mathrm{Pd} / \mathrm{C}$ to give diethyl aminomalonate (71). 
Alkylation of 2,4-pentanedione with ethyl iodide and potassium carbonate in refluxing acetone gave 72, and this condensed with $\mathbf{7 1}$ in refluxing acetic acid to produce pyrrole ethyl ester $\mathbf{7 3}$ (Scheme 24).<smiles>CCOC(=O)CC(=O)OCC(C)C(=O)OCC</smiles><smiles>CCC(C(C)=O)C(C)=O</smiles><smiles>CCOC(=O)C(N)C(=O)OCC</smiles>

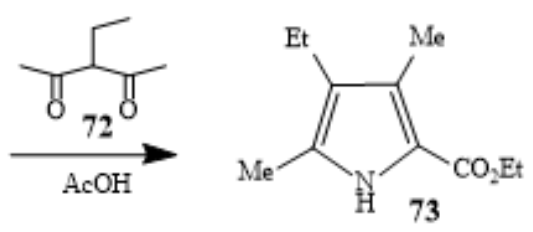

Scheme 24: Preparation of Pyrrole Ester 73 using a Knorr-Type Pyrrole Synthesis ${ }^{2}$

Another pyrrole precursor, 3,4-diethylpyrrole 74, was prepared using the Barton-Zard reaction (Scheme 25). Glycine ethyl ester hydrochloride and triethylamine were refluxed in methyl formate to afford $\mathrm{N}$-formylglycinate 75. Ethyl isocyanoacetate 76 was subsequently prepared by carefully adding phosphorus oxychloride and triethylamine at $0{ }^{\circ} \mathrm{C}$. Nitro alcohol 77 was prepared by reacting propionaldehyde with 1-nitropropane in the presence of potassium fluoride (Henry Reaction). Treatment of $\mathbf{7 7}$ with acetic anhydride under acidic conditions afforded the corresponding nitro acetate 78. Barton-Zard condensation of $\mathbf{7 8}$ with ethyl 
isocyanoacetate in the presence of two equivalents of the base 1,8-diazabicyclo[5.4.0]undec-7ene (DBU) resulted in the formation of pyrrole ethyl ester 79. The crude reaction product was refluxed with sodium hydroxide in ethylene glycol. This resulted in saponification and decarboxylation to give diethyl pyrrole 74. The dialkyl pyrrole is moderately unstable and was stored in the freezer for future use.

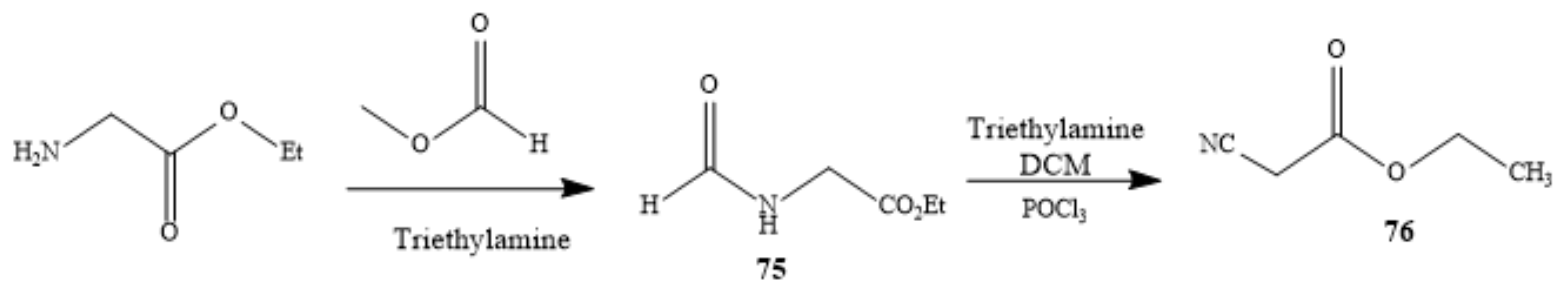

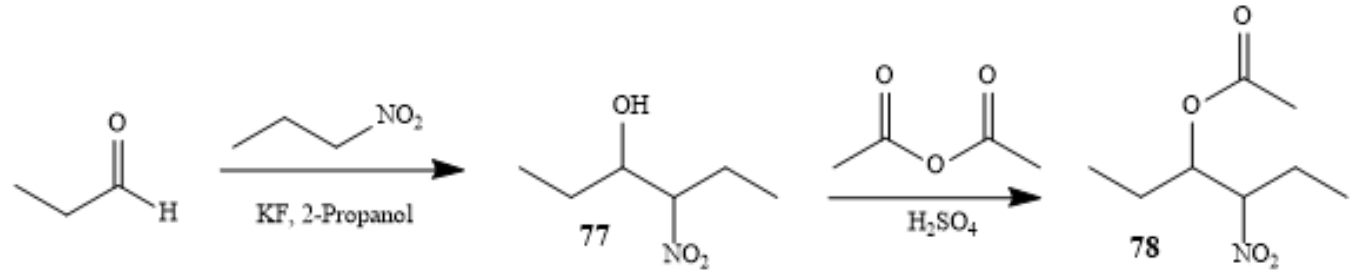<smiles>CCOC(=O)CC#N</smiles>

Scheme 25: Preparation of 3,4-Diethylpyrrole via a Barton-Zard Synthesis ${ }^{53}$

Pyrrole ethyl ester $\mathbf{7 3}$ was transesterified with benzyl alcohol in the presence of sodium benzyloxide to give the corresponding benzyl ester $\mathbf{8 0}$. Further reaction with lead tetraacetate afforded acetoxymethyl pyrrole $\mathbf{8 1}$. Two equivalent of $\mathbf{8 1}$ were reacted with 3,4-diethylpyrrole and acetic acid in refluxing ethanol to give tripyrrane dibenzyl ester $\mathbf{8 2}$ in $92 \%$ yield (Scheme 
26). The benzyl ester protective groups were cleaved by hydrogenolysis over $10 \% \mathrm{Pd} / \mathrm{C}$ to give the corresponding dicarboxylic acid $\mathbf{5 5}$. This product is relatively unstable and was generally had to be used within one week even when it was stored in the freezer.
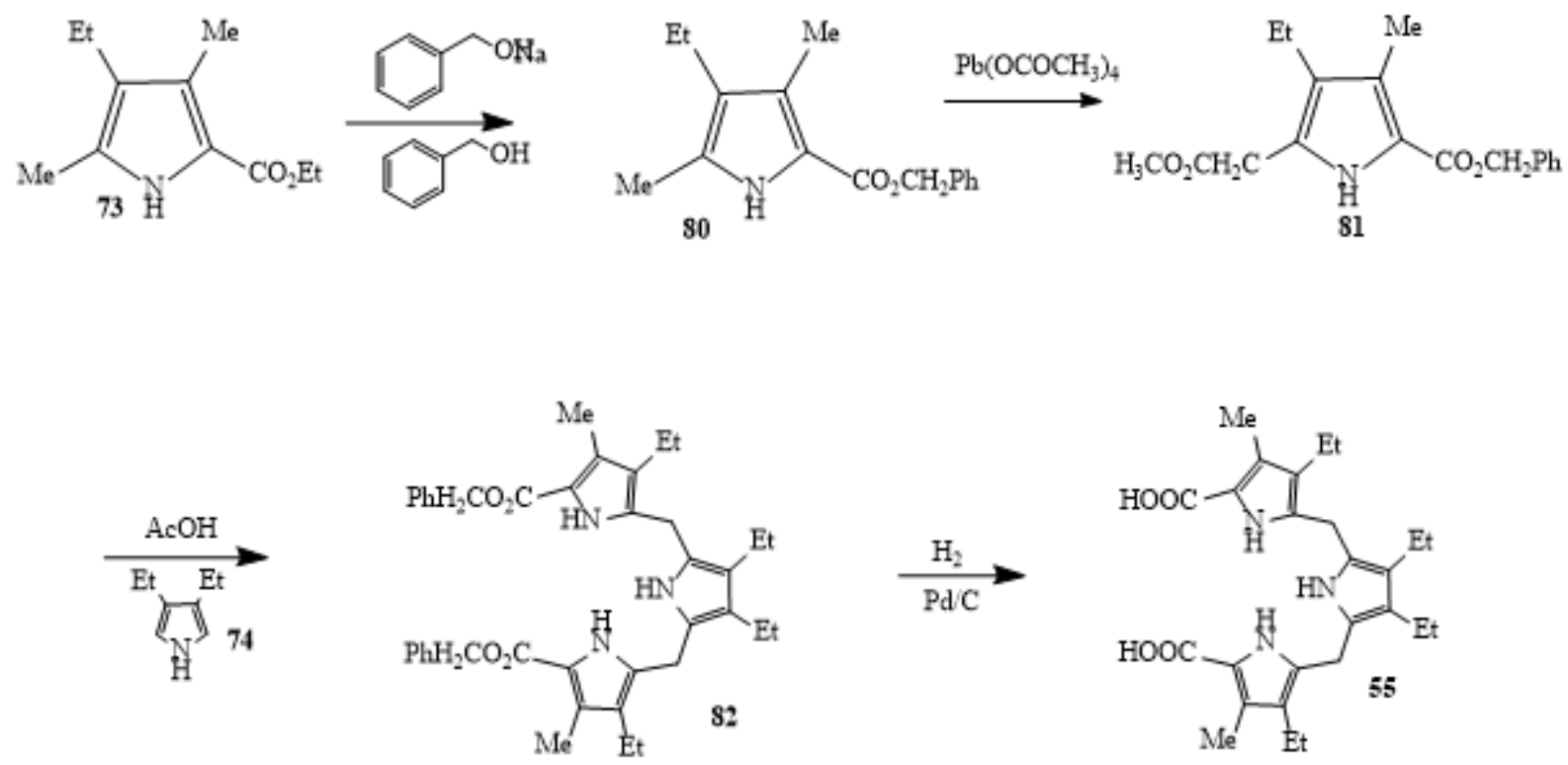

Scheme 26: Preparation of a Tripyrrane

\section{tert-Butylpyrene Dialdehyde}

Dialdehyde 69 was also required as a precursor for the synthesis of pyreniporphyrin (Scheme 27). tert-Butylpyrene $\mathbf{8 3}$ was prepared by reacting pyrene with tert-buyl chloride in the presence of aluminum chloride. Further treatment with three equivalents of bromine gave 1,6,8tribromo-2-tert-butylpyrene 84. Metal-halogen exchange with $n$-butyllithium generated a trilithium species in situ, and this was reacted with dimethylformamide (DMF). Following hydrolysis, dialdehyde 69 was isolated in $72 \%$ yield. 

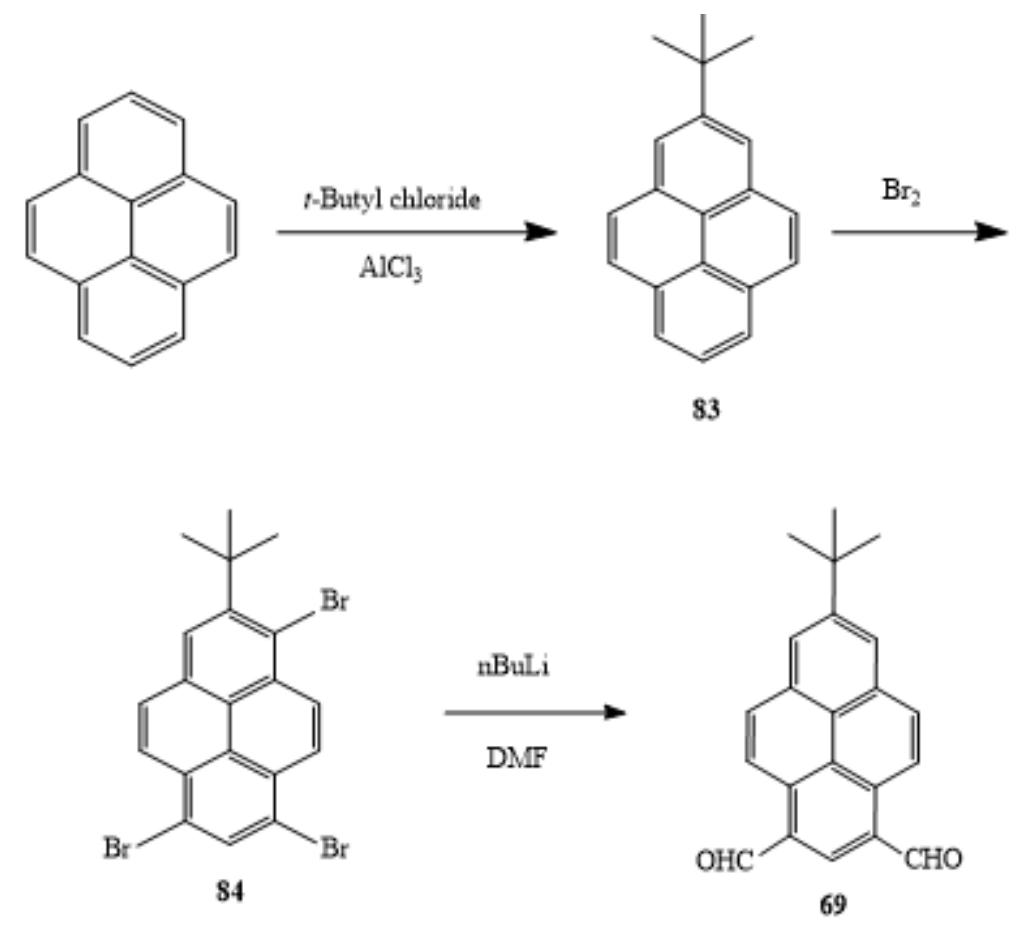

Scheme 27: Preparation of tert-Butylpyrene Dialdehyde

\section{tert-Butylpyreniporphyrin}

Using the ' $3+1$ ' MacDonald condensation, tripyrrane 55 was reacted with dialdehyde 69 in the presence of trifluoroacetic acid. Following oxidation with DDQ and purification by column chromatography, pyreniporphyrin $\mathbf{6 8}$ was isolated in 38\% yield (Scheme 28). 

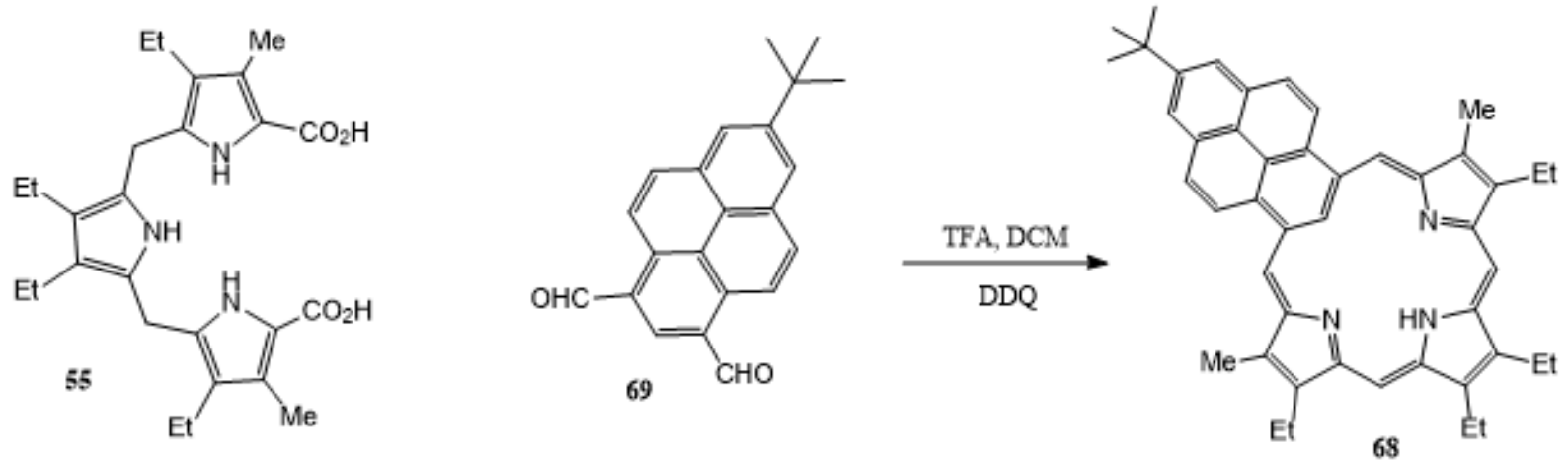

Scheme 28: Synthesis of Pyreniporphyrin

The reaction conditions involved using dichloromethane as a solvent and carrying out the acid catalyzed condensation for 5 hours, followed by oxidation with DDQ for 3 hours. Column chromatography on alumina gave a dark green band that was further purified using a second alumina column. Recrystallization from chloroform and methanol afforded the target product as a dark green powder (Scheme 28).

As was the case for benziporphyrins, pyreniporphyrin $\mathbf{6 8}$ did not show any evidence for macrocyclic aromatic character due to the presence of the polycyclic aromatic hydrocarbon component. In the proton NMR spectrum of $\mathbf{6 8}$ (Figure 16), the four meso protons resonate as two singlets due to symmetrical structure at 8.24 and $6.42 \mathrm{ppm}$. The meso-protons adjacent to the pyrene moiety were relatively deshielded, as would be expected, but these results were consistent with a non-aromatic porphyrinoid. The pyrrole $\mathrm{NH}$ proton gave a chemical shift at $9.82 \mathrm{ppm}$ as a broad singlet, while the internal $\mathrm{CH}$ proton also appeared downfield at $8.40 \mathrm{ppm}$. These results clearly show that no shielding due to a porphyrin-like ring current is present in the pyreniporphyrin system. 


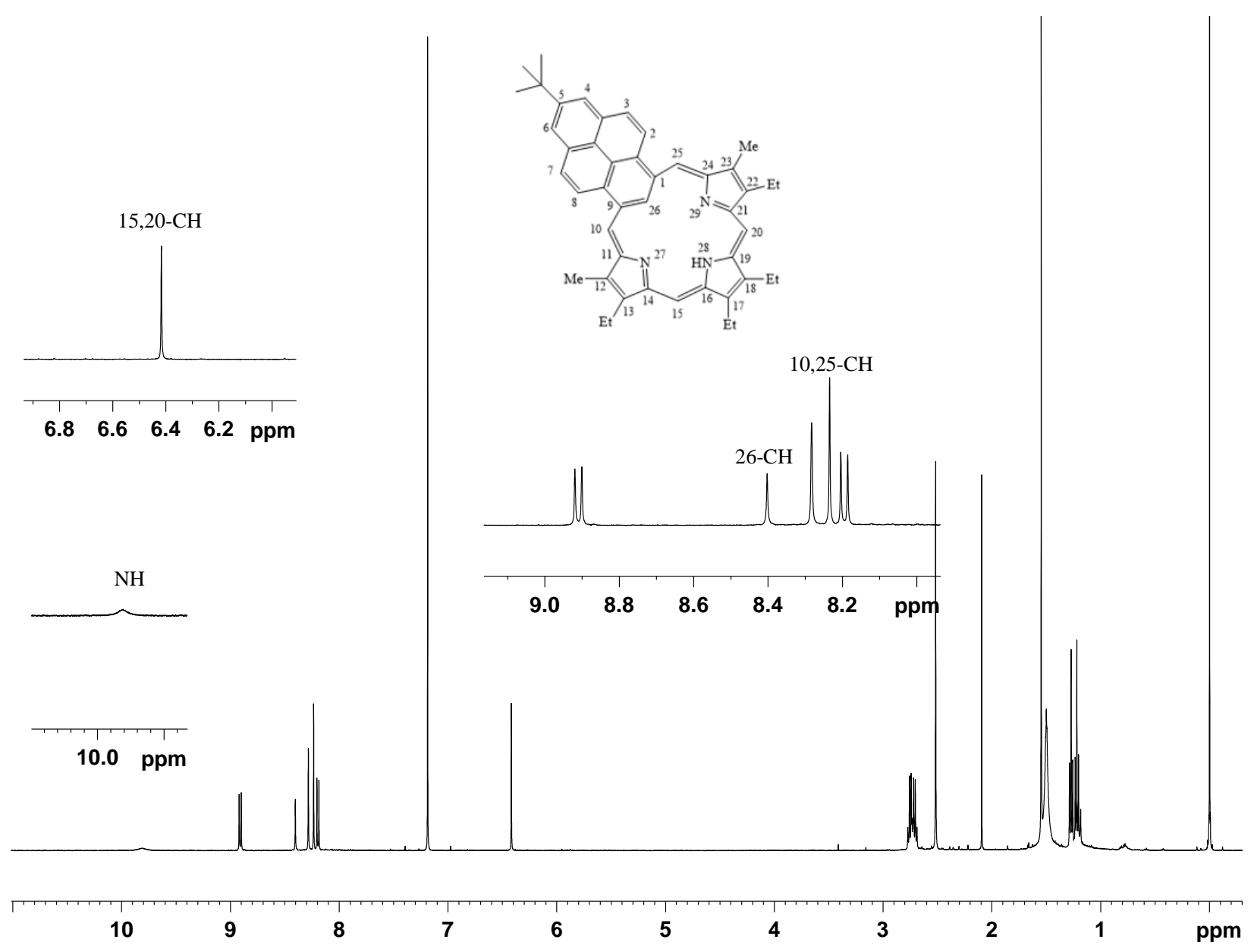

Figure 16: $500 \mathrm{MHz}$ Proton NMR Spectrum of 68 in $\mathrm{CDCl}_{3}$

Pyreniporphyrin 68 was also assessed by UV-vis spectroscopy. In $1 \%$ triethylaminedichloromethane, pyreniporphyrin 68 showed two absorption bands at $343 \mathrm{~nm}$ and $446 \mathrm{~nm}$ and additional broad bands at higher wavelengths (Figure 17). Addition of 1 equivalent of TFA generated a monocationic species with a strong absorption at $677 \mathrm{~nm}$. Further addition of TFA resulted in the formation of a dication $68 \mathrm{H}_{2}{ }^{2+}$ with strong absorptions near $750 \mathrm{~nm}$ (Scheme 29). 


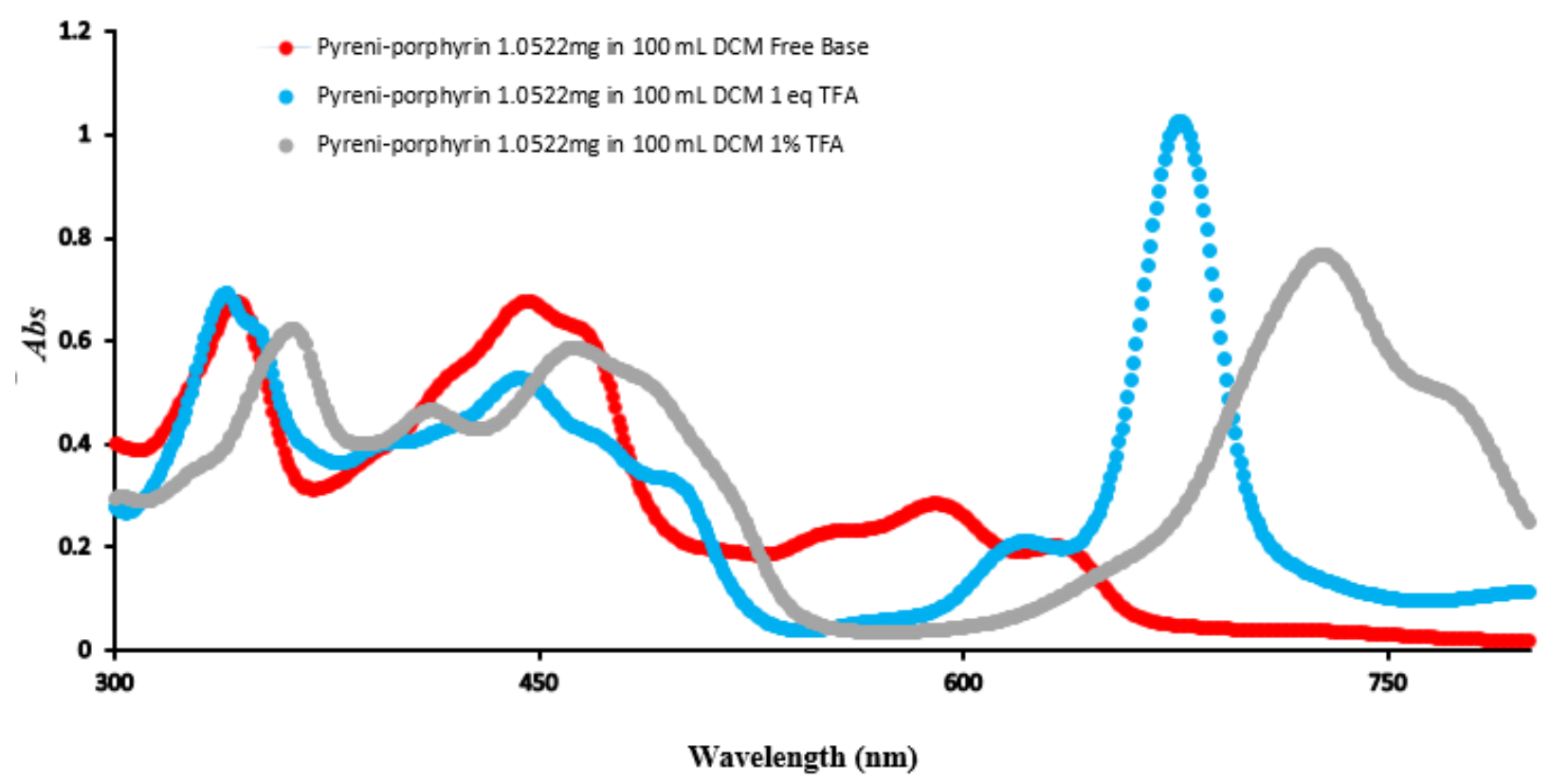

Figure 17: UV-vis Spectra of $\mathbf{6 8}$ in $1 \% \mathrm{Et}_{3} \mathrm{~N}-\mathrm{CH}_{2} \mathrm{Cl}_{2}, 1$ equivalent TFA- $\mathrm{CH}_{2} \mathrm{Cl}_{2}$, and $1 \%$ TFA$\mathrm{CH}_{2} \mathrm{Cl}_{2}$

Protonation is a fundamental chemical process, which is essentially the addition of a proton to an atom, ion, or molecule to generate the conjugate acid. Some molecules and ions that can undergo more than one protonation are labeled polybasic, and this is commonly observed for many biological systems. Protonation alters many properties of the chemical species, such as hydrophilicity, optical properties, reduction potential, and spectroscopy. ${ }^{55}$ Protonation is often rapid due to the high mobility of protons in many organic solvents. ${ }^{56}$ In order to run the NMR of protonated pyreniporphyrin, six drops of TFA were added to a solution of 68 in $\mathrm{CDCl}_{3}$. 

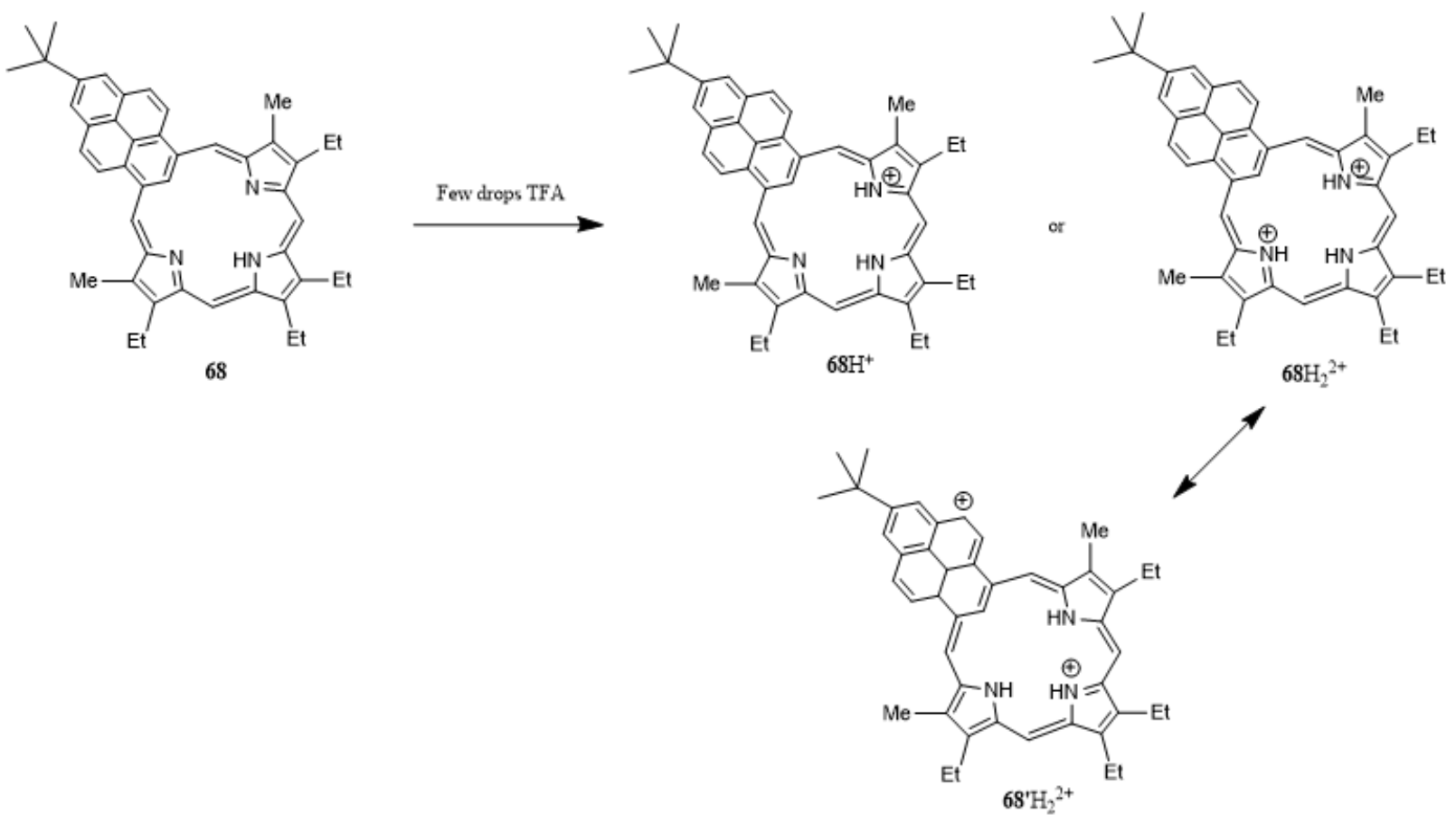

Scheme 29: Protonation of Pyreniporphyrin

The protonation of pyreniporphyrin provided interesting information about the aromatic character of dication $68 \mathrm{H}_{2}{ }^{2+}$. In the proton NMR spectrum of $68 \mathrm{H}_{2}{ }^{2+}$, the four meso protons showed up as two singlets at $8.65 \mathrm{ppm}$ and $7.69 \mathrm{ppm}$, and these are significantly shifted downfield compared to the free base $\mathbf{6 8}$ where the meso-protons appeared at $8.24 \mathrm{ppm}$ and 6.42 ppm. More importantly, the internal proton of $68 \mathrm{H}_{2}{ }^{2+}$ was strongly shifted upfield to $2.93 \mathrm{ppm}$. Moreover, the NH proton after protonation was shifted to $4.63 \mathrm{ppm}$. These results indicate that protonation results in significant diatropic characteristics (Figure 18), in contrast to the nonaromatic free base form. The aromatic charater noted for $68 \mathrm{H}_{2}^{2+}$ can be attributed to resonance contributors such as $\mathbf{6 8}^{\prime} \mathrm{H}_{2}{ }^{2+}$ that possess $18 \pi$ electron delocalization pathways (Scheme 29). 


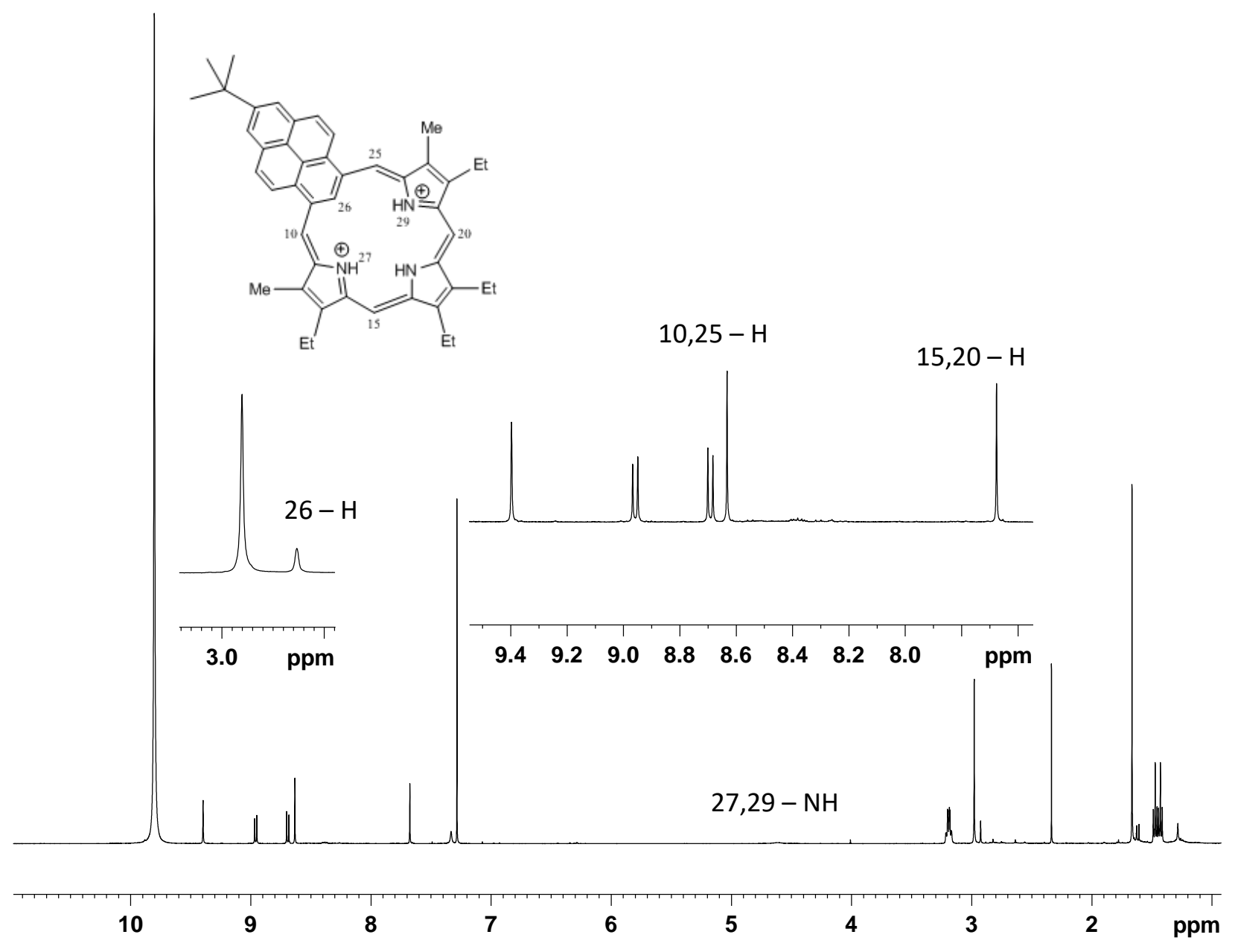

Figure 18: $500 \mathrm{MHz}$ Proton NMR Spectrum of $\mathbf{6 8 \mathrm { H } _ { 2 }}{ }^{2+}$ in $\mathrm{CDCl}_{3}$

Metalation of pyreniporphyrin 68 was briefly investigated. Palladium complex 85 was synthesized by refluxing a solution of pyreniporphyrin $\mathbf{6 8}$ and palladium(II) acetate in mixture of chloroform and acetonitrile for two hours (Scheme 30). Following purification by alumina column chromatography and recrystallization, the palladium(II) complex $\mathbf{8 5}$ was obtained as a dark green powder in $85 \%$ yield. Attempts to prepare other metal complexes were unsuccessful. Reactions were attempted using nickel(II) acetate or silver acetate, as these reactants had been 
successfully used to prepare organometallic derivatives for other carbaporphyrinoids, but no reaction was observed with 68 .

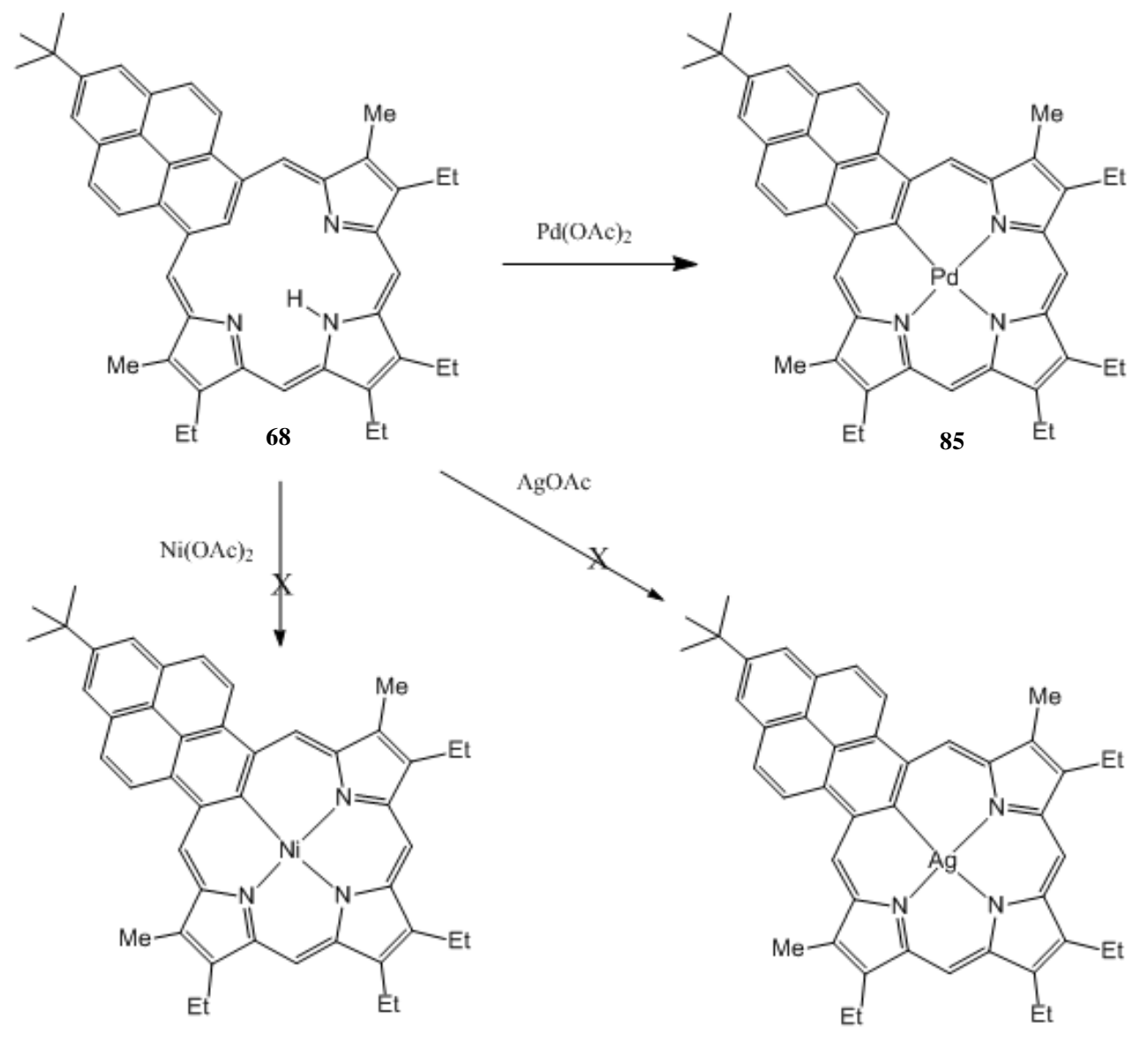

Scheme 30: Synthesis of a Pyreniporphyrin Metal Complex

The UV-vis spectrum for palladium complex $\mathbf{8 5}$ gave three intense absorption bands at 348, 454, and $620 \mathrm{~nm}$ (Figure 19). Due to the absence of an internal proton, it was difficult to assess the aromaticity of $\mathbf{8 5}$. However, its proton NMR spectrum, the meso-protons appeared as two $2 \mathrm{H}$ singlets at 8.20 and $8.65 \mathrm{ppm}$, while pyreniporphyrin 68 showed the meso-protons at 
6.43 and $8.29 \mathrm{ppm}$. Hence, metalation leads to significant deshielding that may be due to the emergence of aromatic character.

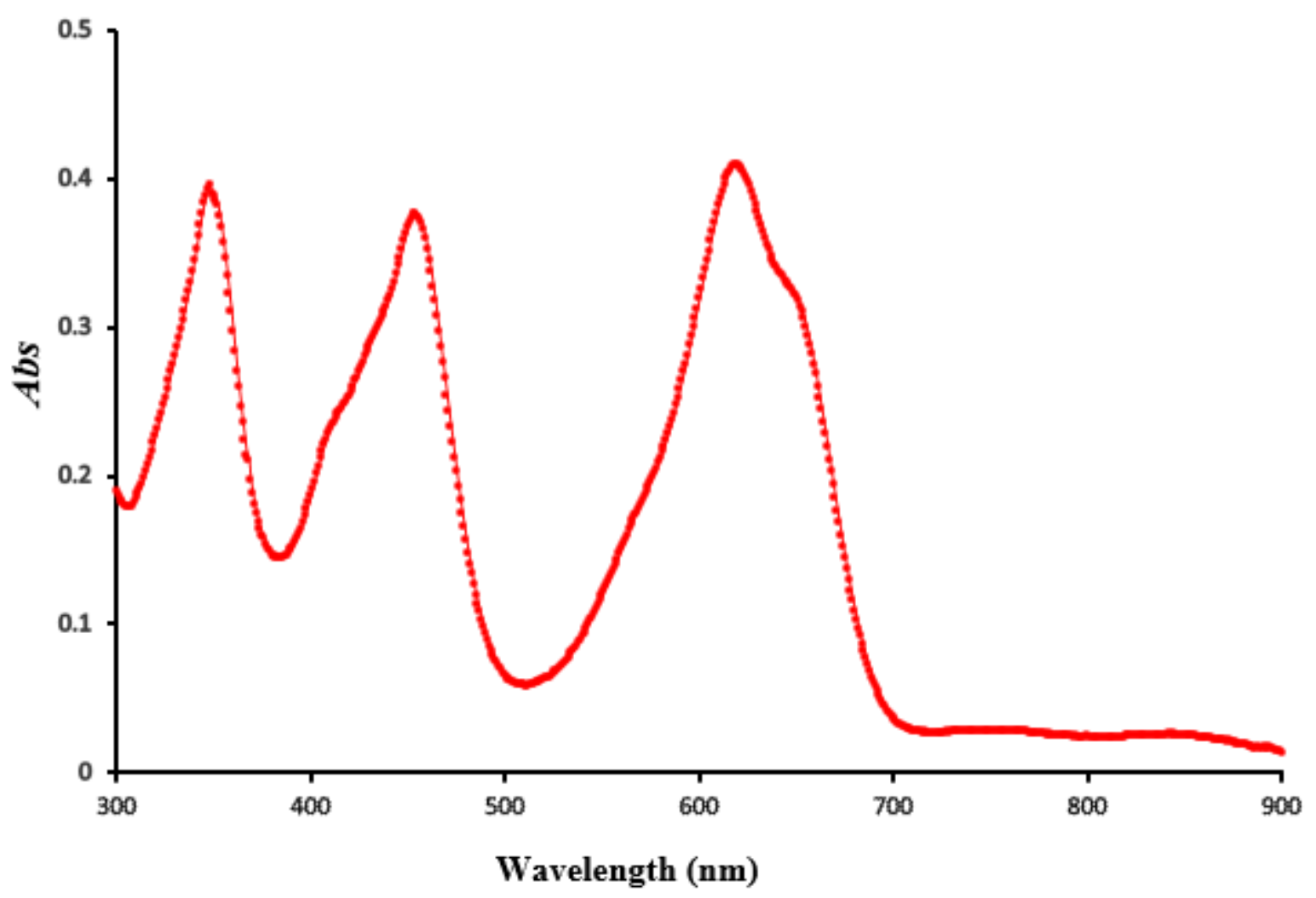

Figure 19: UV-Vis Spectrum of $\mathbf{8 5}$ in Dichloromethane

\section{Thiapyreniporphyrin}

As it had been observed that the protonation and metalation of pyreniporphyrin induced macrocyclic diatropic character and aromaticity, it was of interest to know how these effects would influence related porphyrinoid systems. In order to assess a related system, the synthesis of a thiapyreniporphyrin was targeted. This synthesis made use of a slightly different approach 
and required the formation of a pyrene-contaning tripyrrane analogue. Pyrene dialdehyde 69 was reacted with phenylmagnesium bromide to generate pyrene dicarbinol 86 (Scheme 31).

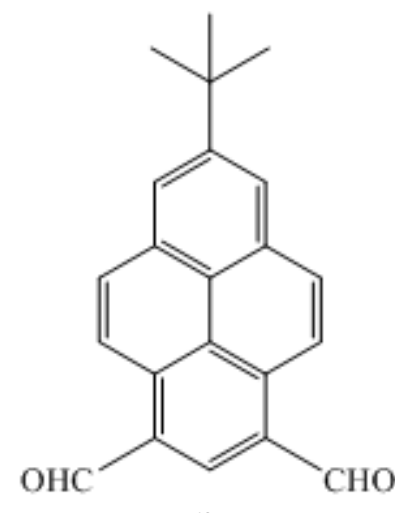

69
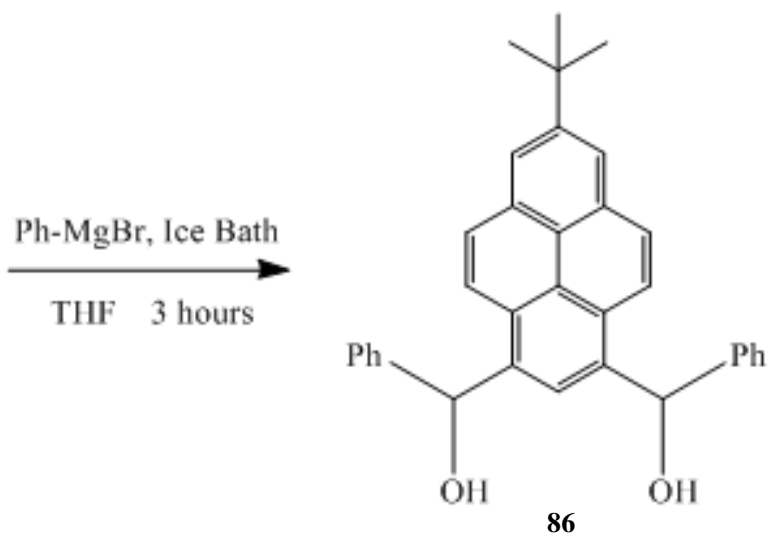

Scheme 31: Preparation of a Pyrene Dicarbinol

Diphenyl tripyrrane analog 87 was prepared by condensing pyrene dicarbinol 86 with excess pyrrole in the presence of a Lewis acid catalyst in refluxing 1,2-dichloroethane for 24 hours. The solvent was removed and the residue was purified by silica column chromatography, eluting with dichloromethane, to afford pyrenitripyrrane $\mathbf{8 7}$ as a pale yellow oil (Scheme 32). The fractions obtained by column chromatography were monitored by TLC. The plate was conveniently visualized in the presence of bromine vapor. Normally, a yellow band eluted off the column due to residual pyrrole and this would turn blue on the TLC plate in the presence of bromine. Pyrenitripyrrane 87 appeared as two red spots on the TLC plate due to the formation of diastereomers. It was only possible to partially separate the diastereomeric mixtures by column chromatography; however, the stereochemistry of intermediates did not affect the formation of the macrocyclic system, and it was unnecessary to carry out the separation. The tripyrrane analog 
was obtained as a mixture of two diastereomers in $80 \%$ yield. In order to prevent decomposition, the tripyrrane was stored in the freezer.
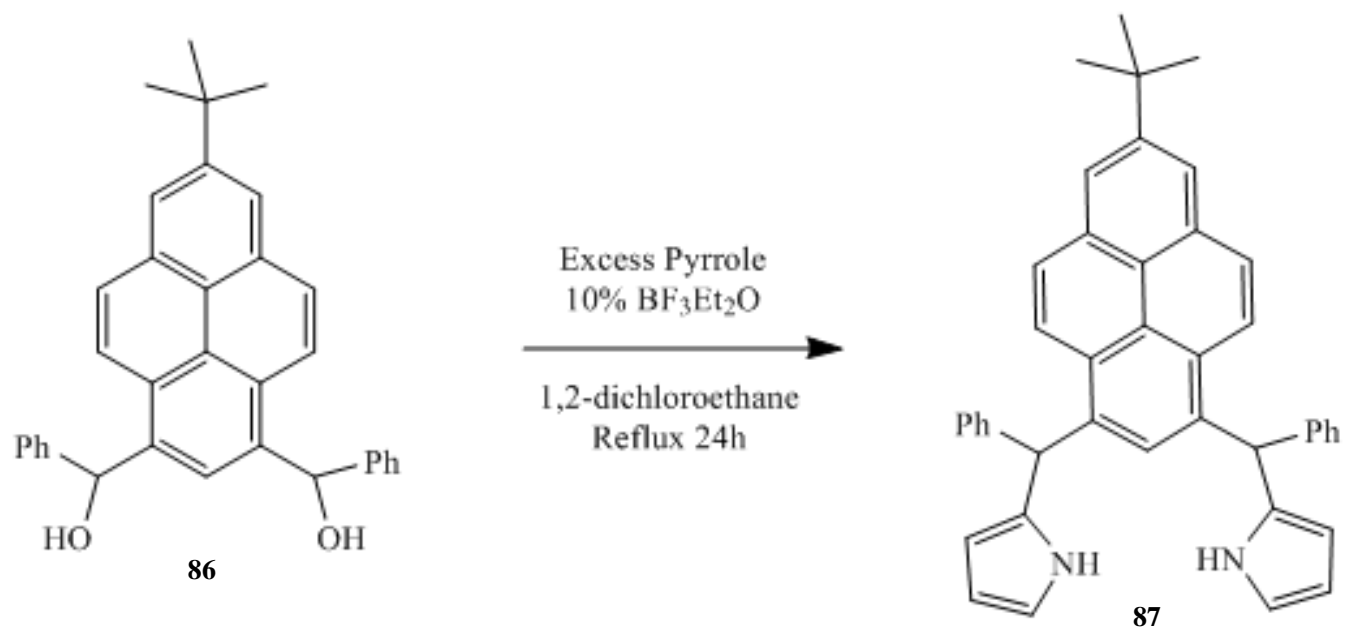

Scheme 32: Preparation of Diphenyl Pyrenitripyrrane

Thiapyreniporphyrin $\mathbf{8 8}$ was synthesized by reacting pyrenitripyrrane $\mathbf{8 7}$ and thiophene dicarbinol 89 in the presence of catalytic boron trifluoride etherate in chloroform at room temperature under an atmosphere of nitrogen for three hours. Following oxidation with DDQ for a further 1.5-hours, thiapyreniporphyrin was isolated in 6.6\% yield (Scheme 33). 

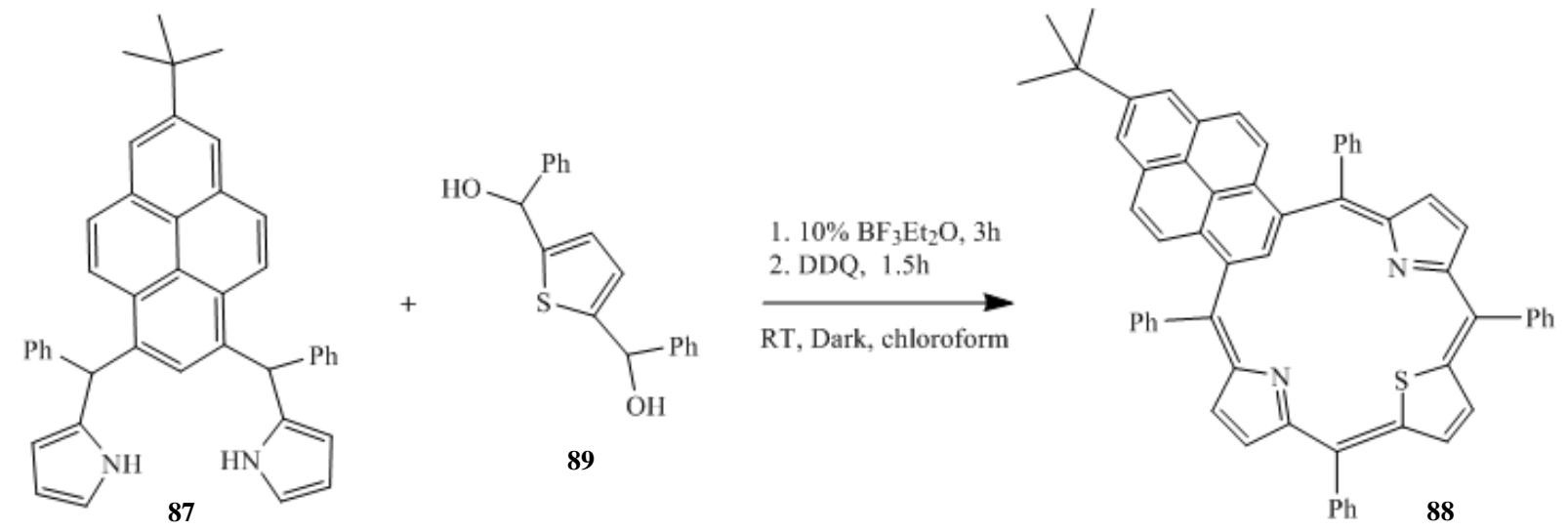

Scheme 33: Synthesis of a Thiapyreniporphyrin

The solvent was evaporated under reduced pressure, and the residue purified by column chromatography eluting with dichloromethane, and then on a second column eluting with a mixture of dichloromethane / hexanes in ratio of 3:2. The desired product $\mathbf{8 8}$ was recrystallized from chloroform and methanol to give a dark green powder.

The polycyclic aromatic hydrocarbon porphyrin hybrid has been generated with four mesophenyl substituents and a thiophene ring has also been introduced. The proton NMR spectrum for 88 shows the internal $\mathrm{CH}$ peak on at $7.51 \mathrm{ppm}$ (Figure 20 and 21). Although this is slightly upfield from the value observed for pyreniporphyrin $\mathbf{6 8}$, this result is consistent with a nonaromatic porphyrinoid system. In fact, the meso-phenyl substituents lead to steric crowding that is likely to distort the macrocycle and reduce the possibility of the system taking on aromatic character. 


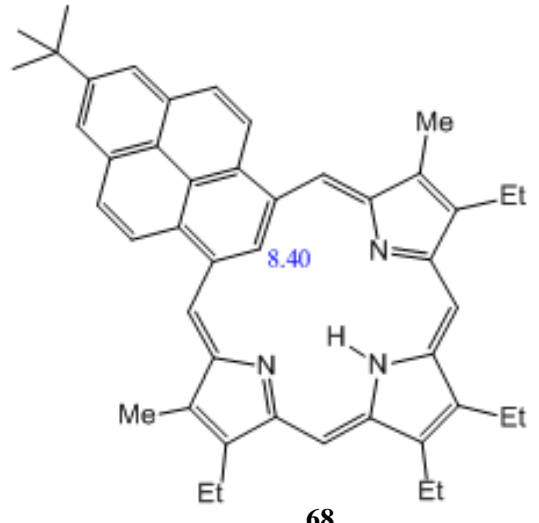

68

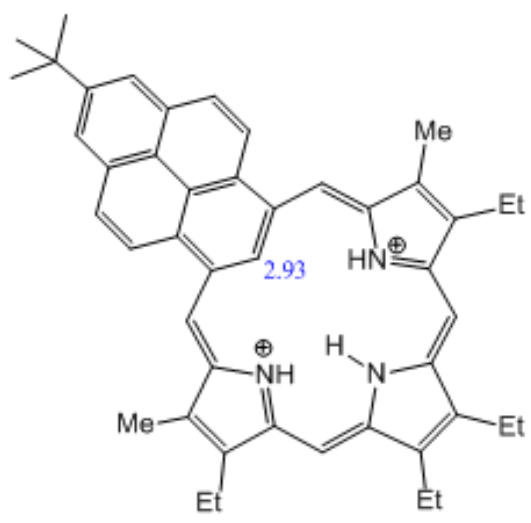

$68 \mathrm{H}_{2}{ }^{2+}$

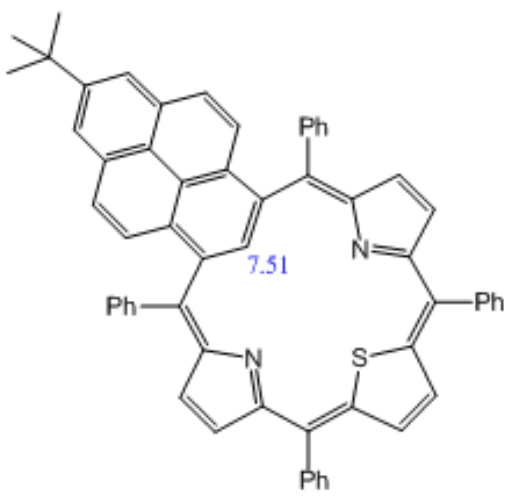

88

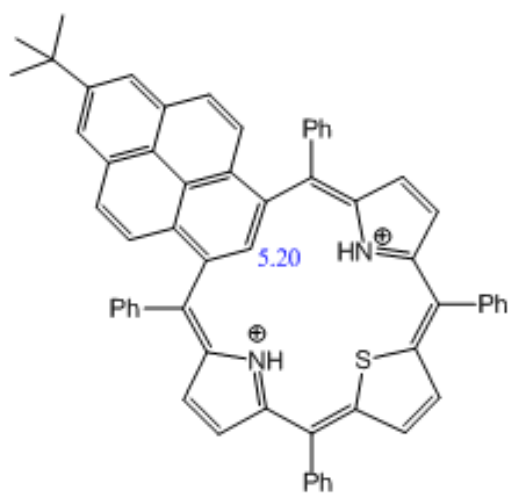

$\mathbf{8 8 H}_{2}{ }^{2+}$

Figure 20: Internal Proton Chemical Shifts for Pyreniporphyrin Systems 

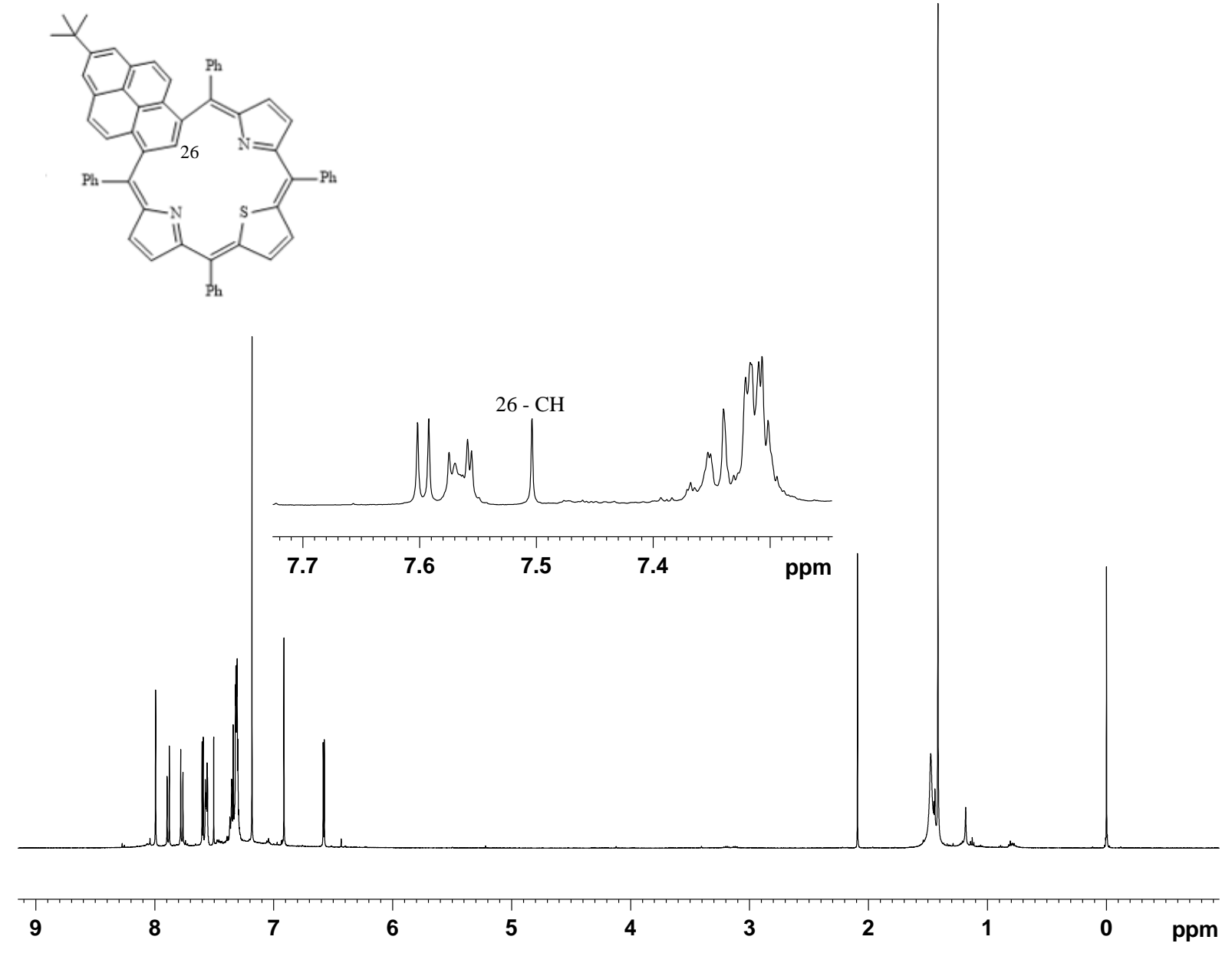

Figure 21: Proton NMR of Tetraphenyl Thiapyreniporphyrin

Addition of TFA to a solution of $\mathbf{8 8}$ in $\mathrm{CDCl}_{3}$ gave a dication species that took on a more distinctly green coloration. In the presence of trace amounts of TFA, $\mathbf{8 8}$ was somewhat insoluble, possibly due to the formation of a monocation, but at higher acid concentration $\mathbf{8 8} \mathrm{H}_{2}{ }^{2+}$ was reasonably soluble. The proton NMR spectrum for this species gave a resonance for the internal $\mathrm{CH}$ proton at $5.20 \mathrm{ppm}$. This result indicates that the dication has taken on some diatropic character, but the shift is much smaller than the one observed for $\mathbf{6 8} \mathrm{H}_{2}{ }^{2+}$ (Figure 22). 


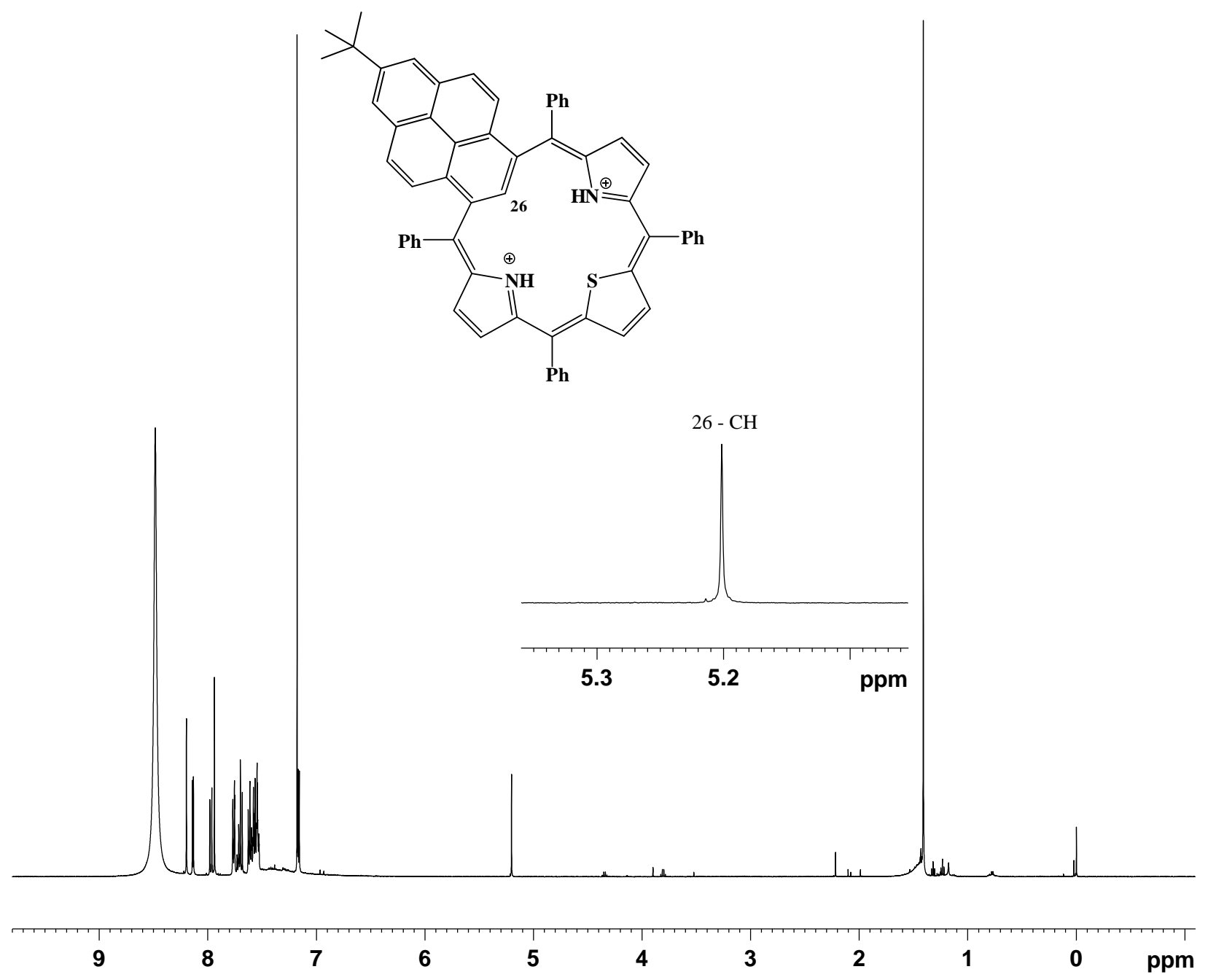

Figure 22: Proton NMR for Protonated Thiapyreniporphyrin

Thiapyreniporphyrin $\mathbf{8 8}$ was also examined by UV-vis spectroscopy. It exhibited a Soret-like absorption band at $348 \mathrm{~nm}$ and another band in the red region at $631 \mathrm{~nm}$. The monocation species showed bathochromic and hypochromic shifts to the Soret-like band, and gave peaks at 343, 440, and $636 \mathrm{~nm}$. The dication species gave similar absorptions at 343, 460, and $635 \mathrm{~nm}$ (Figure 23). 


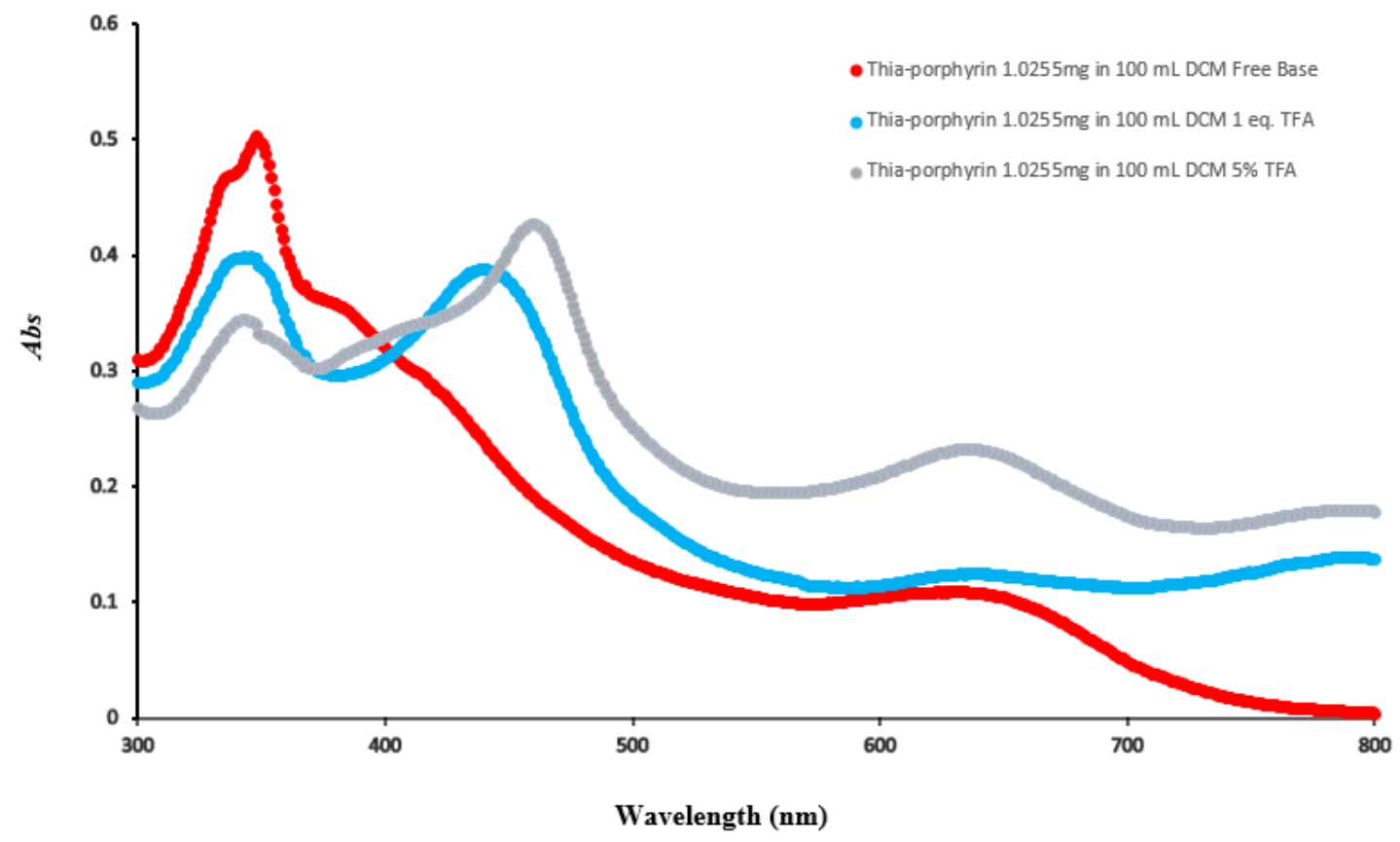

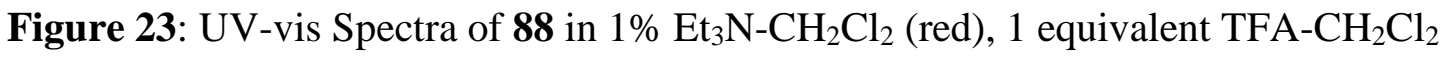
(blue), and 5\% TFA- $\mathrm{CH}_{2} \mathrm{Cl}_{2}$ (grey) 


\section{Tetraphenylpyreniporphyrin}

A series attempts were made to react $\mathbf{8 6}$ or $\mathbf{8 7}$ with pyrrole, benzaldehyde, and $10 \%$ $\mathrm{BF}_{3} \mathrm{Et}_{2} \mathrm{O}$ in chloroform in an attempt to synthesize tetraphenylpyreniporphyrin $\mathbf{9 0}$. However, none of the conditions investigated afforded the desired macrocycle. Many alternative reactions are possible and the formation of tetraphenylporphyrin was observed. Due to these problems, the synthesis of $\mathbf{9 0}$ was abandoned (Scheme 34).
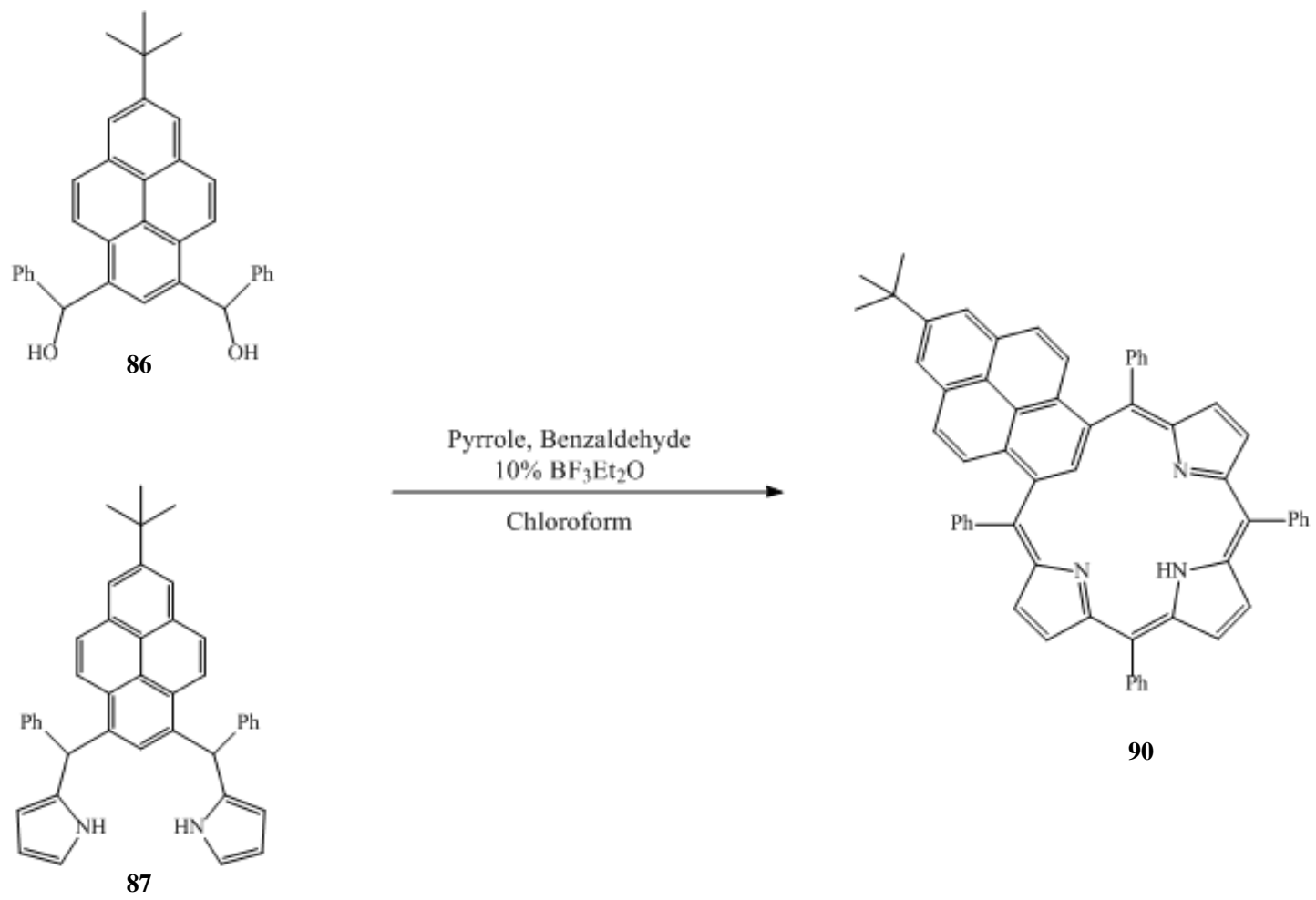

90

Scheme 34: Possible Synthetic Routes to Tetraphenylpyreniporphyrin 


\section{Conclusion}

Although benziporphyrins are not aromatic compounds, it was hypothesized that the incorporation of polycyclic aromatic hydrocarbons might enhance the aromaticity of these systems. In order to assess this possibility, a novel pyrene-containing porphyrinoid was synthesized. Using the ' $3+1$ ' strategy, good yields of pyreniporphyrin $\mathbf{6 8}$ were obtained by reacting a pyrene dialdehyde with a tripyrrane. Pyreniporphyrin showed no indication of aromatic character by NMR spectroscopy and the UV-vis spectra for this porphyrin analog did not resemble the spectra for aromatic porphyrinoids. However, addition of acid generated a dicationic species that exhibited significant diatropic character. Although a similar effect had previously been observed for benziporphyrins, the shifts were substantially larger for the PAHporphyrin hybrid. The NMR spectrum for the palladium(II) complex for $\mathbf{8 5}$ also showed the presence of a diamagnetic ring current. A tetraphenyl thiapyreniporphyrin was also prepared and this compound showed no sign of macrocyclic aromaticity. However, addition of acid led to the formation of a weakly diatropic dication. The reduced aromatic character of the thiapyreniporphyrin compared to pyreniporphyrin 68 can be attributed to the presence of mesosubstituents that disrupt the planarity of the macrocycle.

Future work should focus on oxidation of pyreniporphyrin systems using appropriate oxidants to form quinone-type products, or aromatic systems related to oxybenziporphyrins. The discovery of synthetic methods to generate fully aromatic porphyrinoids will improve the stability of these compounds. 


\section{CHAPTER III}

\section{EXPERIMENTAL}

All chemicals were purchased from Acros Organic and Sigma Aldrich. Grade III basic alumina and silica gel were used for column chromatography. The ${ }^{1} \mathrm{H}$ and ${ }^{13} \mathrm{C}-\mathrm{NMR}$ spectra were obtained using a Bruker Avance III $500 \mathrm{MHz}$ NMR spectrometer at $25^{\circ} \mathrm{C}$. Chemical shifts, relative to $\mathrm{CDCl}_{3}$ (residual chloroform at $\delta 7.26 \mathrm{ppm}$ ) in proton NMR spectra and the $\mathrm{CDCl}_{3}$ triplet at $\delta 77.23 \mathrm{ppm}$ in ${ }^{13} \mathrm{C}$-NMR spectra, were recorded in parts per million (ppm). UV-vis spectra were collected by Cary 100 Bio spectrophotometer. Melting point were gathered using a Mel-Temp apparatus.

Diethyl Oximinomalonate (70)

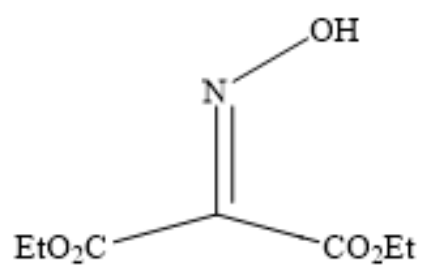

Sodium hydroxide pellets $(25.1 \mathrm{~g}, 0.628 \mathrm{~mol})$ were added to acetic acid in a 2 -L three neck round bottom flask attached an addition funnel, a condenser, and a glass stopper. The mixture was 
stirred until the solid had completely dissolved. Diethyl malonate (131.68 g, $125 \mathrm{~mL})$ was added to thehot solution, and then sodium nitrite in water $(139.2 \mathrm{~g}$ in $190 \mathrm{~mL})$ was added dropwise over 90 minutes. The resulting mixture was stirred at room temperature overnight. An oily layer developed when sodium hydroxide in water $(63.0 \mathrm{~g}$ in $190 \mathrm{~mL})$ was added to the mixture. The aqueous layer was discarded after it was back extracted twice with cold diethyl ether. The combined organic layers were washed with water and saturated sodium bicarbonate, and dried over magnesium sulfate. The solvent was then removed using a rotary evaporator to yield diethyl oximinomalonate $(107.8 \mathrm{~g}, 69.3 \%)$ as a clear oil. ${ }^{1} \mathrm{H} \mathrm{NMR}\left(500 \mathrm{MHz}, \mathrm{CDCl}_{3}\right): \delta 1.32(6 \mathrm{H}, \mathrm{t},-$ $\left.\mathrm{OCH}_{2} \mathrm{CH}_{3}\right), 4.36$ (4H, two overlapping quartets, $\left.-\mathrm{OCH}_{2} \mathrm{CH}_{3}\right), 11.0(1 \mathrm{H}, \mathrm{s},-\mathrm{OH})$.

Diethyl Aminomalonate (71)

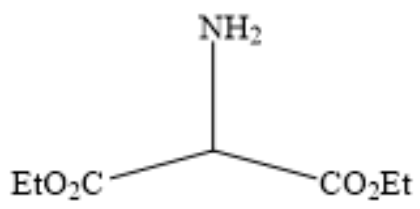

Diethyl oximinomalonate (108 g, $0.617 \mathrm{~mol})$ was dissolved in absolute ethanol $(175 \mathrm{~mL})$ and placed in a hydrogenation vessel. The mixture was purged with nitrogen, and $10 \%$ palladiumcharcoal (2.0 g) was added. The resulting mixture was shaken under hydrogen with $45 \mathrm{psi}$ at room temperature overnight. The palladium catalyst was filtered and the solvent removed under reduced pressure to give diethyl aminomalonate $(95.4 \mathrm{~g}, 88.3 \%)$ as a pale yellow oil. ${ }^{1} \mathrm{H}$ NMR $\left(500 \mathrm{MHz}, \mathrm{CDCl}_{3}\right): \delta 1.23\left(6 \mathrm{H}, \mathrm{t},-\mathrm{OCH}_{2} \mathrm{CH}_{3}\right), 1.92\left(2 \mathrm{H}, \mathrm{s},-\mathrm{NH}_{2}\right), 4.00(1 \mathrm{H}, \mathrm{s},-\mathrm{CH}), 4.15-4.20$ (4H, q, $-\mathrm{OCH}_{2} \mathrm{CH}_{3}$ ). 


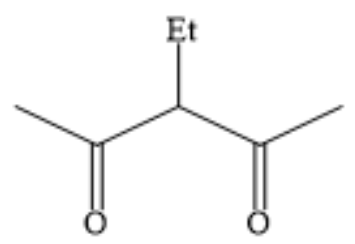

Potassium carbonate (168 g) and 2,4-pentanedione $(102 \mathrm{~mL})$ were mixed with reagent grade acetone $(250 \mathrm{~mL})$ in $1-\mathrm{L}$ three neck flask equipped with a mechanical stirrer, condenser, and an addition funnel contained iodoethane $(80 \mathrm{~mL})$. Iodoethane was added dropwise and the resulting mixture stirred under reflux overnight. The resulting precipitate was filtered and washed three times with acetone. The solvent was removed under reduced pressure, and the residue was distilled to give 3-ethyl-2,4-pentanedione $(108.3 \mathrm{~g}, 84.6 \%)$ as a yellow oil, b.p. $173-177^{\circ} \mathrm{C}$ (lit. b.p. $\left.{ }^{57} 179-180{ }^{\circ} \mathrm{C}\right)$. This product existed as a mixture of keto and enol tautomers.

Ethyl 4-Ethyl-3,5-Dimethylpyrrole-2-Carboxylate (73)

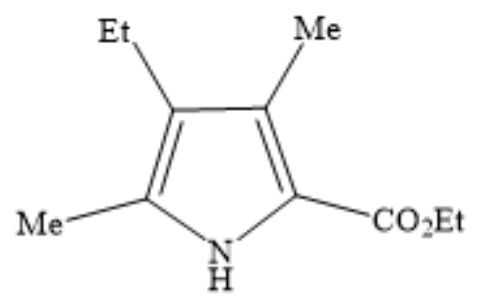

A mixture of diethyl aminomalonate (58.72 g) and 3-ethyl-2,4-pentanedione (42.61 g) was added to gently boiling acetic acid $(200 \mathrm{~mL})$, and the mixture refluxed for 2 hours. The resulting solution was poured into an ice-water mixture $(1500 \mathrm{~mL})$ and allowed to stand overnight. The 
resulting precipitate was filtered and recrystallized from absolute ethanol to give ethyl 4-ethyl3,5-dimethylpyrrole-2-carboxylate $(26.82 \mathrm{~g}, 41.5 \%)$ as white crystals, m.p. $92-95{ }^{\circ} \mathrm{C}$ (lit. m.p. ${ }^{58}$ $\left.89-90{ }^{\circ} \mathrm{C}\right) .{ }^{1} \mathrm{H}$ NMR $\left(500 \mathrm{MHz}, \mathrm{CDCl}_{3}\right): \delta 1.03\left(3 \mathrm{H}, \mathrm{t}\right.$, pyrrole- $\left.\mathrm{CH}_{2} \mathrm{CH}_{3}\right), 1.32(3 \mathrm{H}, \mathrm{t},-$ $\left.\mathrm{OCH}_{2} \mathrm{CH}_{3}\right), 2.20\left(3 \mathrm{H}, \mathrm{s},-\mathrm{CH}_{3}\right), 2.25\left(3 \mathrm{H}, \mathrm{s},-\mathrm{CH}_{3}\right), 2.39\left(2 \mathrm{H}, \mathrm{q}\right.$, pyrrole- $\left.\mathrm{CH}_{2} \mathrm{CH}_{3}\right), 4.31(2 \mathrm{H}, \mathrm{q},-$ $\left.\mathrm{OCH}_{2} \mathrm{CH}_{3}\right), 8.51(1 \mathrm{H}$, broad s, $\mathrm{NH})$.

Benzyl 4-Ethyl-3,5-Dimethylpyrrole-2-Carboxylate $(\mathbf{8 0})$

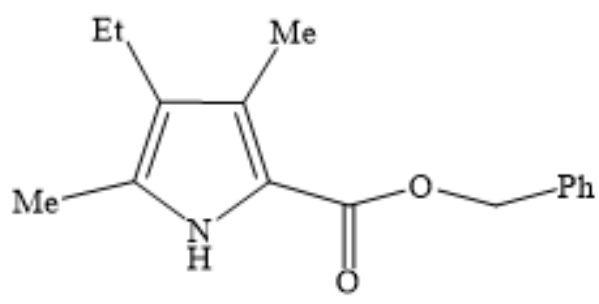

Ethyl 4-ethyl-3,5-dimethylpyrrole-2-carboxylate (20.0 g), was dissolved in benzyl alcohol (25 $\mathrm{mL}$ ) and slowly heated from room temperature to $230{ }^{\circ} \mathrm{C}$ over 90 minutes. A solution of sodium benzyloxide, prepared by reacting sodium metal $(0.20 \mathrm{~g})$ with benzyl alcohol $(10 \mathrm{~mL})$, was added dropwise periodically over this period. When the temperature of the vapor above the reaction solution reached $175^{\circ} \mathrm{C}$, a final portion of sodium benzyloxide solution was added. After heating for a further 5 minutes, the hot solution was poured into a chilled mixture of methanol $(80 \mathrm{~mL})$, glacial acetic acid $(1.0 \mathrm{~mL})$, and water $(50 \mathrm{~mL})$. The resulting precipitate was collected by suction filtration and recrystallized from 95\% ethanol to afford benzyl 4-ethyl-3,5dimethylpyrrole-2-carboxylate $(23.4 \mathrm{~g}, 89 \%)$ as white crystals, m.p. $102-104{ }^{\circ} \mathrm{C}$ (lit. m.p. ${ }^{59} 102$ $\left.-103{ }^{\circ} \mathrm{C}\right) .{ }^{1} \mathrm{H} \mathrm{NMR}\left(500 \mathrm{MHz}, \mathrm{CDCl}_{3}\right): \delta 1.10\left(3 \mathrm{H}, \mathrm{t}\right.$, pyrrole- $\left.\mathrm{CH}_{2} \mathrm{CH}_{3}\right), 2.24(3 \mathrm{H}, \mathrm{s}$, pyrrole- 
$\left.\mathrm{CH}_{3}\right), 2.43\left(2 \mathrm{H}, \mathrm{q}\right.$, pyrrole- $\left.\mathrm{CH}_{2} \mathrm{CH}_{3}\right), 5.32\left(2 \mathrm{H}, \mathrm{s},-\mathrm{OCH}_{2}\right), 7.30-7.46(5 \mathrm{H}, \mathrm{m}$, phenyl), 8.52 $(1 \mathrm{H}$, br s, $-\mathrm{NH})$.

Benzyl 5-Acetoxymethyl-4-ethyl-3-methylpyrrole-2-carboxylate $(\mathbf{8 1})$

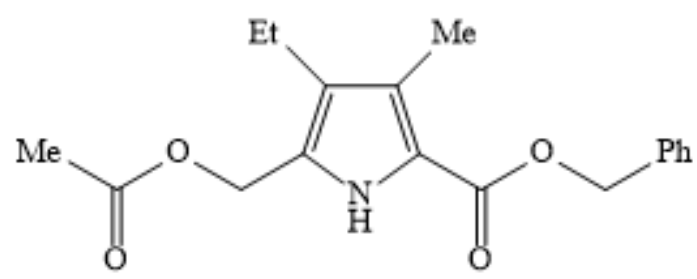

A mixture of benzyl 4-ethyl-3,5-dimethylpyrrole-2-carboxylate (10.81 g), glacial acetic acid $(320 \mathrm{~mL})$, acetic anhydride $(16 \mathrm{~mL})$, and lead tetraacetate $(18.0 \mathrm{~g})$ was stirred at room temperature overnight. The resulting orange solution was poured into ice-water $(1000 \mathrm{~mL})$ to give a white precipitate. The compound was collected by suction filtration, dissolved in dichloromethane, dried over sodium sulfate, and the solvent removed on a rotary evaporator. Recrystallization from chloroform/ligroin gave benzyl 5-acetoxymethyl-4-ethyl-3methylpyrrole-2-carboxylate (11.27 g, 85\%), m.p. $123{ }^{\circ} \mathrm{C}$ (lit. m.p. $\left.{ }^{60} 122{ }^{\circ} \mathrm{C}\right) ;{ }^{1} \mathrm{H}$ NMR (500 $\left.\mathrm{MHz}, \mathrm{CDCl}_{3}\right): \delta 1.08\left(3 \mathrm{H}, \mathrm{t},-\mathrm{CH}_{2} \mathrm{CH}_{3}\right), 2.07\left(3 \mathrm{H}, \mathrm{s},-\mathrm{OCOCH}_{3}\right), 2.30\left(3 \mathrm{H}, \mathrm{s}\right.$, pyrrole- $\left.\mathrm{CH}_{3}\right), 2.45$ $\left(2 \mathrm{H}, \mathrm{q},-\mathrm{CH}_{2} \mathrm{CH}_{3}\right), 5.08\left(2 \mathrm{H}, \mathrm{s},-\mathrm{CH}_{2} \mathrm{OAc}\right), 5.30\left(2 \mathrm{H}, \mathrm{s},-\mathrm{OCH}_{2}\right), 7.30-7.48(5 \mathrm{H}, \mathrm{m}, \mathrm{Ph}), 8.97$ (1H, broad s, -NH). 


\section{Ethyl N-Formylglycinate (75)}

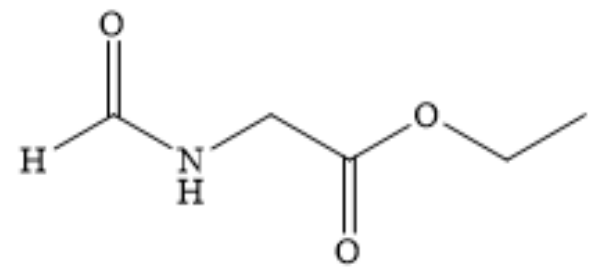

A solution of glycine ethyl ester hydrochloride $(139.0 \mathrm{~g})$ in methyl formate $(500 \mathrm{~mL})$ was added to a 2-L three neck round bottom flask, mounted with a mechanical stirrer, an addition funnel, and a condenser with a calcium chloride drying tube. Triethylamine (100.0 g) was added dropwise to the stirred refluxing solution, and reflux was continued for 24 hours after the addition was completed. The mixture was cooled and suction filtered, and the excess methyl formate was evaporated under reduced pressure. Vacuum distillation yielded ethyl Nformylglycinate $(85.0 \mathrm{~g}, 65 \%)$ as a clear oil, b.p. $115-119^{\circ} \mathrm{C}$ at 1 torr (lit. b.p. ${ }^{61} 119-120^{\circ} \mathrm{C}$ at 1 torr). ${ }^{1} \mathrm{H}$ NMR (500 MHz, $\left.\mathrm{CDCl}_{3}\right): \delta 1.23\left(3 \mathrm{H}, \mathrm{t},-\mathrm{OCH}_{2} \mathrm{CH}_{3}\right), 3.96\left(2 \mathrm{H}, \mathrm{d},-\mathrm{CH}_{2} \mathrm{NH}\right), 4.10$ $\left(2 \mathrm{H}, \mathrm{q},-\mathrm{OCH}_{2} \mathrm{CH}_{3}\right), 6.86(1 \mathrm{H}$, broad s, $-\mathrm{NH}), 8.15(1 \mathrm{H}, \mathrm{s},-\mathrm{CHO})$. 


\section{Ethyl Isocyanoacetate (76)}

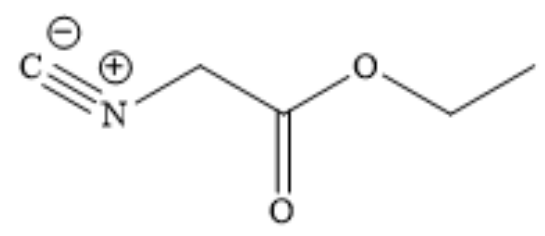

A mixture of triethylamine (135.0 g), $\mathrm{N}$-formylglycine ethyl ester $(70.0 \mathrm{~g})$, and dichloromethane $(550 \mathrm{~mL})$ was placed in a 3-L three-neck flask fitted with a mechanical stirrer, thermometer, and an addition funnel. The mixture was cooled to $0^{\circ} \mathrm{C}$ with the aid of a salt-ice bath. Freshly distilled phosphorus oxychloride $(82.0 \mathrm{~g})$ was added dropwise while maintaining the reaction temperature at $0{ }^{\circ} \mathrm{C}$. The mixture was stirred for a further 1 hour at $0{ }^{\circ} \mathrm{C}$ and then a solution of sodium carbonate $(106.0 \mathrm{~g})$ in water $(425 \mathrm{~mL})$ was gradually added, keeping the temperature below $20^{\circ} \mathrm{C}$. The aqueous layer was diluted to $1 \mathrm{~L}$ with water, the organic layer was separated and the aqueous phase was back extracted with dichloromethane. The combined organic layers were washed with brine and dried over potassium carbonate. The residue was vacuum distilled to yield ethyl isocyanoacetate as a yellow oil $(38.70 \mathrm{~g}, 64 \%)$, b.p. $90-94^{\circ} \mathrm{C}$ at 18 torr (lit. b.p. ${ }^{62} 76$ $-78^{\circ} \mathrm{C}$ at 4 torr) after solvent was removed under reduced pressure. ${ }^{1} \mathrm{H}$ NMR $(500 \mathrm{MHz}$, $\left.\mathrm{CDCl}_{3}\right): \delta 1.31\left(3 \mathrm{H}, \mathrm{t},-\mathrm{CH}_{2} \mathrm{CH}_{3}\right), 4.17\left(2 \mathrm{H}, \mathrm{s},-\mathrm{CH}_{2}\right), 4.21\left(2 \mathrm{H}, \mathrm{q},-\mathrm{OCH}_{2} \mathrm{CH}_{3}\right)$. 


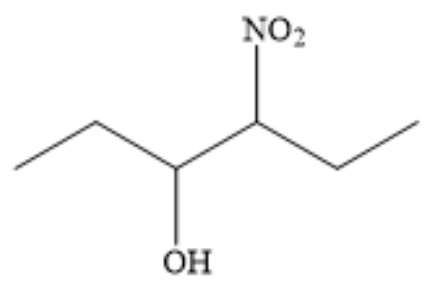

2-Propanol $(450 \mathrm{~mL})$ and propionaldehyde $(220 \mathrm{~mL})$ were combined in a $2 \mathrm{~L}$ three necked flask equipped with a mechanical stirrer, thermometer, and an addition funnel with a drying tube. Fresh potassium fluoride $(25.0 \mathrm{~g})$ was added to the solution, and 1-nitropropane $(280 \mathrm{~mL})$ was added dropwise while keeping the solution temperature below $40{ }^{\circ} \mathrm{C}$ with the aid of an ice-bath. The ice-bath was removed and stirring was continued overnight. The solution was filtered and the solvent removed under reduced pressure. Water $(500 \mathrm{~mL})$ was added to the residue and the solution was extracted three times with ethyl ether. The extracts were combined and dried over sodium sulfate. The solvent was removed on a rotary evaporator and the residue was vacuum distilled to yield 4-nitro-3-hexanol (156.38 g, 36\%) as a yellow oil, b.p. $92-94{ }^{\circ} \mathrm{C}$ at 18 torr (lit. b.p. ${ }^{63} 89{ }^{\circ} \mathrm{C}$ at 2 torr). The proton NMR indicated the presence of two different diastereomers due to the presence of two chiral centers. 


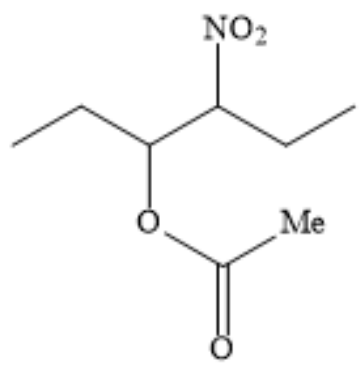

Concentrated sulfuric acid $(0.5 \mathrm{~mL})$ was added to 4-nitro-3-hexanol $(130 \mathrm{~mL})$ that had been cooled in an ice bath. Acetic anhydride $(100 \mathrm{~mL})$ was added in portions, keeping the solution temperature below $60^{\circ} \mathrm{C}$. The solution was stirred for 1 hour and vacuum distilled to remove acetic acid and acetic anhydride. The residue was then redistilled to yield 4-acetoxy-3nitrohexane (176.8 g, $94.6 \%$ ) as a yellow oil, b.p. $110-114^{\circ} \mathrm{C}$ at 18 torr (lit. b.p. ${ }^{64} 95-98{ }^{\circ} \mathrm{C}$ at 5 torr). The proton NMR indicated that two different diastereomers were presented.

\section{3,4-Diethylpyrrole (74)}

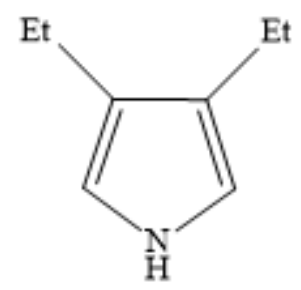

A solution of ethyl isocyanoacetate (36.26 g) and 3-acetoxy-4-nitrohexane (73.18 g) in THF (230 $\mathrm{mL}$ ) and 2-propanol $(93 \mathrm{~mL})$ was placed in a 1-L three neck flask equipped with a thermometer, 
drying tube, and addition funnel. DBU (120.0 g) was added dropwise, while maintaining the temperature between $20-30{ }^{\circ} \mathrm{C}$, and the mixture was stirred at room temperature overnight. The solvent was evaporated under reduced pressure and the residue diluted with warm water. The aqueous layer was extracted three times with ether, washed with $10 \%$ hydrochloric acid, and dried over magnesium sulfate. The solvent was evaporated under reduced pressure to afford crude ethyl 3,4-diethylpyrrole-2-carboxylate. The crude product was mixed with sodium hydroxide pellets $(30.0 \mathrm{~g})$ in ethylene glycol $(300 \mathrm{~mL})$ and heated for 1 hour at $190^{\circ} \mathrm{C}$. The solution was cooled, diluted with water and extracted twice with hexanes. The combined organic layers were dried over magnesium sulfate, filtered and the solvent removed under reduced pressure. The residue was vacuum distilled to give 3,4-diethylpyrrole $(20.56 \mathrm{~g}, 52 \%)$ as a clear oil, b.p. $115-122{ }^{\circ} \mathrm{C}$ at 18 torr (lit. b.p. ${ }^{65} 82-85{ }^{\circ} \mathrm{C}$ at 9 torr). $\left.{ }^{1} \mathrm{H} \mathrm{NMR} \mathrm{(500} \mathrm{MHz,} \mathrm{CDCl}_{3}\right): \delta$ $1.23\left(6 \mathrm{H}, \mathrm{t}, 2 \mathrm{x}-\mathrm{CH}_{2} \mathrm{CH}_{3}\right), 2.57\left(4 \mathrm{H}, \mathrm{q}, 2 \mathrm{x}-\mathrm{CH}_{2} \mathrm{CH}_{3}\right), 6.58(2 \mathrm{H}, \mathrm{d}, 2 \mathrm{x}-\mathrm{CH}), 7.92(1 \mathrm{H}, \mathrm{s},-\mathrm{NH})$.

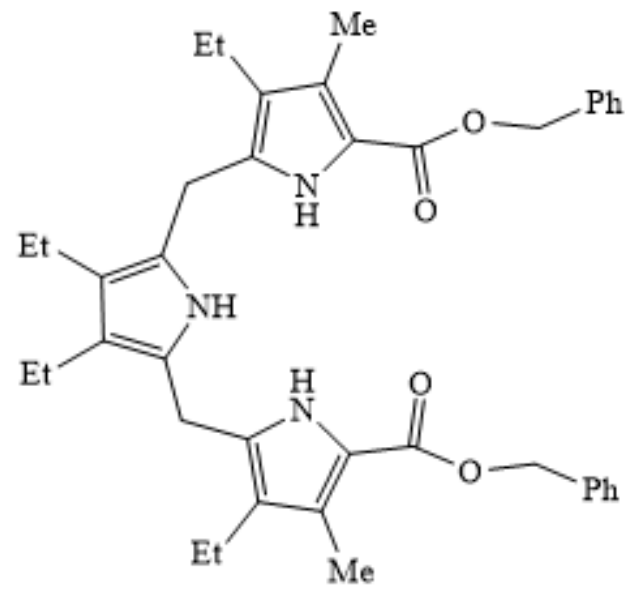


Benzyl 5-acetoxymethyl-4-ethylpyrrole-2-carboxylate (2.56 g) and 3,4-diethylpyrrole ( $0.6 \mathrm{~mL})$ were mixed with absolute ethanol $(30 \mathrm{~mL})$ and glacial acetic acid $(2 \mathrm{~mL})$. The mixture was refluxed under nitrogen overnight. The resulting solution was cooled to room temperature and further cooled in an ice bath until precipitation was completed. The precipitate was then filtered and dried in a vacuum desiccator overnight to give the tripyrrane $(2.36 \mathrm{~g}, 92 \%)$ as a white powder, m.p. $205-208^{\circ} \mathrm{C}$ (lit. m.p. ${ }^{66} 211^{\circ} \mathrm{C}$ ). This compound was somewhat unstable and was stored in the refrigerator. ${ }^{1} \mathrm{H} \mathrm{NMR}\left(500 \mathrm{MHz}, \mathrm{CDCl}_{3}\right): \delta 1.01\left(6 \mathrm{H}, \mathrm{t},-\mathrm{CH}_{2} \mathrm{CH}_{3}\right), 1.12(6 \mathrm{H}, \mathrm{t},-$ $\left.\mathrm{CH}_{2} \mathrm{CH}_{3}\right), 2.26\left(6 \mathrm{H}, \mathrm{s}\right.$, pyrrole- $\left.\mathrm{CH}_{3}\right), 2.35\left(4 \mathrm{H}, \mathrm{q},-\mathrm{CH}_{2} \mathrm{CH}_{3}\right), 2.48\left(4 \mathrm{H}, \mathrm{q},-\mathrm{CH}_{2} \mathrm{CH}_{3}\right), 3.60(4 \mathrm{H}$, broad s, bridge- $\left.\mathrm{CH}_{2}\right), 4.63\left(4 \mathrm{H}, \mathrm{s},-\mathrm{OCH}_{2}\right), 7.25\left(5 \mathrm{H}, \mathrm{m},-\mathrm{C}_{6} \mathrm{H}_{5}\right), 10.86(2 \mathrm{H}$, broad s, $-\mathrm{NH})$.

Tripyrrane dicarboxylic acid (55)

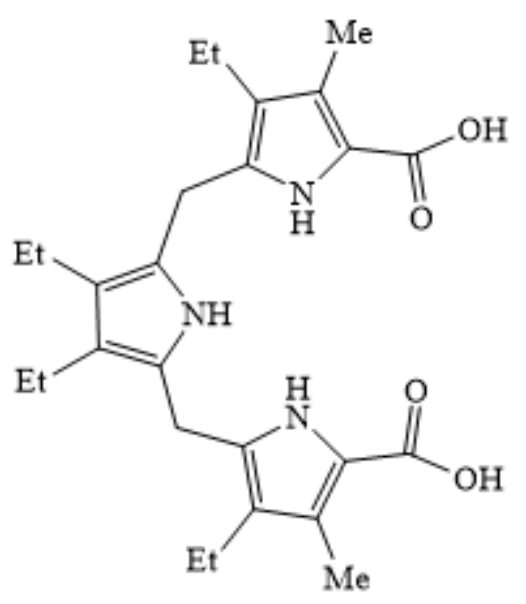

In a hydrogenation vessel, the foregoing tripyrrane dibenzyl ester $(1.00 \mathrm{~g})$ was dissolved in reagent grade acetone $(150 \mathrm{~mL})$ and methanol $(50 \mathrm{~mL})$, and 20 drops of triethylamine was 
added. The solution was purged with nitrogen and $10 \%$ palladium-charcoal $(200 \mathrm{mg})$ was added. The vessel was shaken on a hydrogenation apparatus under 40 psi hydrogen at room temperature overnight. The catalyst was removed by suction filtration, and the solvent evaporated under reduced pressure. The residue was dissolved in 5\% ammonium hydroxide and diluted with water up to $50 \mathrm{~mL}$. The solution was cooled in a salt-ice bath and acidified with glacial acetic acid while maintaining the temperature below $5{ }^{\circ} \mathrm{C}$. Once precipitation was completed, the product was collected by suction filtration, washed with cold water 10 times to remove traces of acetic acid, and vacuum dried overnight to yield the dicarboxylic acid tripyrrane $(0.706 \mathrm{~g}, 99 \%)$ as a purple powder. The tripyrrane was used without further purification.

2-tert-Butylpyrene (83)

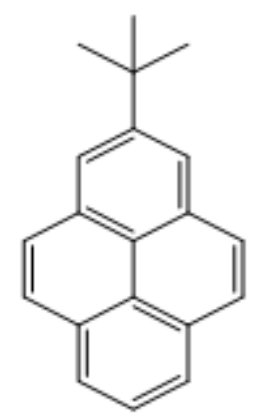

A solution of pyrene $(25.0 \mathrm{~g}, 0.124 \mathrm{~mol})$ and tert-butyl chloride $(13.8 \mathrm{~g}, 0.149 \mathrm{~mol})$ in methylene chloride $(100 \mathrm{~mL})$ was cooled to $0{ }^{\circ} \mathrm{C}$, anhydrous aluminum chloride $(17.6 \mathrm{~g})$ added in one portion, and the resulting mixture stirred for 3 hours. The mixture was poured into a large amount of ice-water and the precipitate was collected by suction filtration. The organic layer was separated, washed with brine, dried over magnesium sulfate, and the solvent removed under 
reduced pressure. The residue was recrystallized from methanol to afford a mixture $(22.4 \mathrm{~g})$ containing 2,7-di-tert-butylpyrene and 2-tert-butylpyrene. Further crystallization from hexanes gave 2-tert-butylpyrene (22.93 g, 71\%) as yellow/silver plates, m.p. $108-112^{\circ} \mathrm{C}$ (lit. m.p. ${ }^{51} 110$ $\left.-112{ }^{\circ} \mathrm{C}\right) .{ }^{1} \mathrm{H}$ NMR $\left(500 \mathrm{MHz}, \mathrm{CDCl}_{3}\right): \delta 1.58\left(9 \mathrm{H}, \mathrm{s},-\mathrm{CH}_{3}\right), 7.93-8.30(9 \mathrm{H}, \mathrm{m}$, pyrene).

\section{1,6,8-Tribromo-2-tert-butylpyrene $(\mathbf{8 4})$}

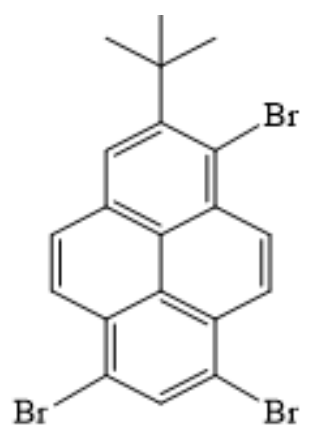

Bromine (10.0 mL, $194 \mathrm{mmol})$ was added to a stirred solution of 2-tert-butylpyrene (13.0 g, 50.3 mmol) in methylene chloride $(300 \mathrm{~mL})$ and the resulting mixture stirred at room temperature for 24 hours. The precipitate was collected by suction filtration and extracted with hot toluene in a Soxhlet extractor overnight. Upon cooling, a precipitate was formed. The toluene extract was cooled in an ice bath and suction filtered to give the tribromopyrene $(17.6 \mathrm{~g}, 71 \%)$ as a greenishwhite powder, m.p. $276-279^{\circ} \mathrm{C}$ (lit. m.p. $\left..^{52} 277-279{ }^{\circ} \mathrm{C}\right) .{ }^{1} \mathrm{H}$ NMR $\left(500 \mathrm{MHz}, \mathrm{CDCl}_{3}\right): \delta 1.79$ (9H, s, -tert-butyl), $8.10-8.90$ (6H, m, pyrene). 


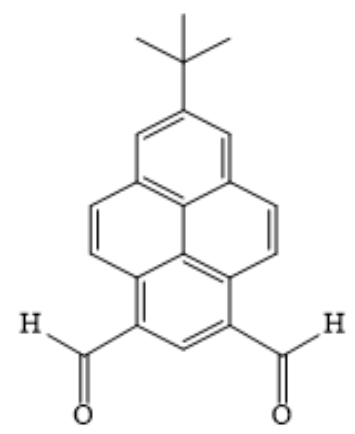

A mixture of tribromopyrene $84(5.56 \mathrm{~g}, 11.3 \mathrm{mmol})$ in $\mathrm{THF}(120 \mathrm{~mL})$ was cooled to $-70{ }^{\circ} \mathrm{C}$ with the aid of a dry ice-acetone bath. $n$-Butyllithium (2.56 M in hexane, $100 \mathrm{~mL}, 164 \mathrm{mmol}$ ) was added and the resulting mixture stirred at $-70^{\circ} \mathrm{C}$ for 3 hours. Dimethylformamide $(20 \mathrm{~mL}, 259$ mmol) was added in one portion and the resulting solution was stirred for 40 minutes under the same conditions. A saturated ammonium chloride solution $(30 \mathrm{~mL})$ was added to quench the reaction. After filtration, the aqueous layer was extracted with dichloromethane three times and the combined organic layers were washed with saturated sodium bicarbonate and sodium chloride. The extracts were dried over sodium sulfate, filtered, evaporated, and purified by column chromatography on alumina eluting with toluene. Evaporation of the product fractions gave the diformylpyrene $(2.56 \mathrm{~g}, 72.2 \%)$ as a yellow powder, m.p. $264-268{ }^{\circ} \mathrm{C}$ (lit. m.p. ${ }^{52} 267$ $\left.{ }^{\circ} \mathrm{C}\right) .{ }^{1} \mathrm{H} \mathrm{NMR}\left(500 \mathrm{MHz}, \mathrm{CDCl}_{3}\right): \delta 1.63(9 \mathrm{H}, \mathrm{s}$, -tert-butyl), $8.54-9.56(7 \mathrm{H}, \mathrm{m}$, pyrene), 10.8 (2H, s, -CHO). 


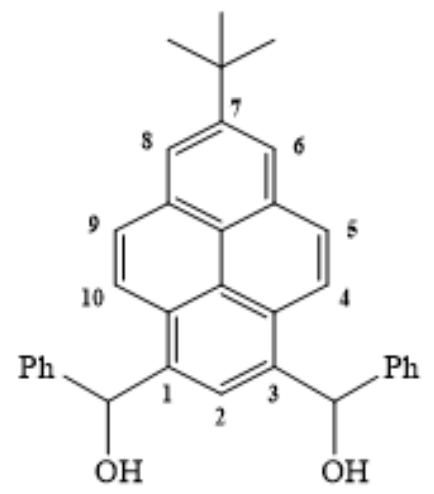

Dialdehyde $69(0.50 \mathrm{~g})$ was dissolved in THF $(75 \mathrm{~mL})$ and the solution was cooled to $0{ }^{\circ} \mathrm{C}$. Phenylmagnesium bromide $(5 \mathrm{~mL})$ was added dropwise via syringe. The resulting mixture was stirred at $0{ }^{\circ} \mathrm{C}$ for 3 hours. Saturated ammonium chloride was used to quench mixture. The organic layer was diluted with ethyl ether, washed three times with water, dried over sodium sulfate, and the solvent evaporated under reduced pressure. The resulting solid was recrystallized from chloroform / hexane to yield the dicarbinol $(0.395 \mathrm{~g}, 50 \%)$ as a pale yellow powder, m.p. $231-233{ }^{\circ} \mathrm{C} .{ }^{1} \mathrm{H}$ NMR $\left(500 \mathrm{MHz}, \mathrm{CDCl}_{3}\right): \delta 1.48(9 \mathrm{H}, \mathrm{s}$, -tert-butyl), $6.78(2 \mathrm{H}, \mathrm{s},-\mathrm{CH}), 7.20-$ $7.42(10 \mathrm{H}, \mathrm{m}$, phenyl), $7.95-8.38$ (7H, m, pyrene). 


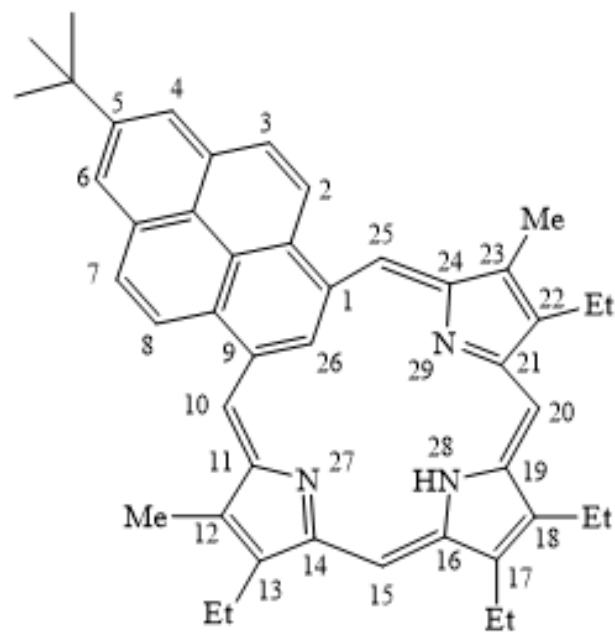

In a pear-shaped flask, freshly prepared dicarboxylic acid $\mathbf{5 5}(50.0 \mathrm{mg}, 0.110 \mathrm{mmol})$ was stirred with trifluoroacetic acid $(1.0 \mathrm{~mL})$ under nitrogen for 2 minutes. Dichloromethane $(30.0 \mathrm{~mL})$ was added, followed immediately by dialdehyde $69(35.0 \mathrm{mg}, 0.110 \mathrm{mmol})$, and the mixture was stirred under nitrogen at room temperature for a further 5 hours. DDQ $(27.0 \mathrm{mg}, 0.119 \mathrm{mmol})$ was added and the resulting solution was stirred under the same conditions for 3 hours. The mixture was washed with water and chromatographed twice on alumina (Grade 3), eluting with a 7:3 mixture of dichloromethane and hexanes. A dark green fraction was collected and recrystallized from chloroform and methanol to give pyreniporphyrin 68 (27 mg, $0.042 \mathrm{mmol}$, $38 \%)$ as a dark green powder, m.p. $>300{ }^{\circ} \mathrm{C} .{ }^{1} \mathrm{H} \mathrm{NMR}\left(500 \mathrm{MHz}, \mathrm{CDCl}_{3}\right): \delta 1.22(6 \mathrm{H}, \mathrm{t}, 17,18-$ $\left.\mathrm{CH}_{2} \mathrm{CH}_{3}, J=7.7 \mathrm{~Hz}\right), 1.28\left(6 \mathrm{H}, \mathrm{t}, 13,22-\mathrm{CH}_{2} \mathrm{CH}_{3}, J=7.7 \mathrm{~Hz}\right), 1.55(9 \mathrm{H}, \mathrm{s}, t$-butyl), $2.52(6 \mathrm{H}, \mathrm{s}$, $\left.12,23-\mathrm{CH}_{3}\right), 2.72\left(4 \mathrm{H}, \mathrm{q}, 17,18-\mathrm{CH}_{2} \mathrm{CH}_{3}, J=7.6 \mathrm{~Hz}\right), 2.75\left(4 \mathrm{H}, \mathrm{q}, 13,22-\mathrm{CH}_{2} \mathrm{CH}_{3}, J=7.6 \mathrm{~Hz}\right)$, $6.42(2 \mathrm{H}, \mathrm{s}, 15,20$-meso-CH), $8.20(2 \mathrm{H}, \mathrm{d}, 2,8$-pyrene- $\mathrm{CH}, J=9.1 \mathrm{~Hz}), 8.24(2 \mathrm{H}, \mathrm{s}, 10,25$-meso$\mathrm{CH}), 8.28(2 \mathrm{H}, \mathrm{s}, 4,6-$ pyrene-CH), $8.41(1 \mathrm{H}, \mathrm{s}$, internal $-\mathrm{CH}), 8.91(2 \mathrm{H}, \mathrm{d}, 3,7$-pyrene $-\mathrm{CH}, J=$ 
9.5 Hz), $9.81\left(1 \mathrm{H}\right.$, br s, NH); UV-Vis $\left(1 \% \mathrm{Et}_{3} \mathrm{~N}-\mathrm{CH}_{2} \mathrm{Cl}_{2}\right): \lambda_{\max }(\log \varepsilon): 343$ (4.61), 446 (4.62), 464 (4.58), 553 (4.15), 590 (4.24), $632 \mathrm{~nm}$ (4.09); UV-Vis (1 equivalent TFA- $\left.\mathrm{CH}_{2} \mathrm{Cl}_{2}\right): \lambda_{\max }(\log$ ع): 339 (4.62), 396 (4.39), 443 (4.51), 469 (4.41), 496 (4.31), 621 (4.11), 677 (4.80), 803 (3.84); UV-Vis (1\% TFA-CH $\left.\mathrm{Cl}_{2}\right): \lambda_{\max }(\log \varepsilon): 363$ (4.58), 412 (4.45), 462 (4.55), 486 (4.50), 727 (4.67), $770 \mathrm{~nm}(4.48) ;{ }^{13} \mathrm{C} \mathrm{NMR}\left(500 \mathrm{~Hz}, \mathrm{CDCl}_{3}\right): \delta 9.61,14.23,14.88,16.95,17.33,30.80$, $92.04,115.24,118.10,122.62,123.50,126.45,129.11,129.90,132.94,139.04,139.73,140.52$, 147.01, 155.95, 168.64 ppm; ${ }^{1} \mathrm{H}$ NMR (dication $\left.68 \mathrm{H}_{2}{ }^{+}, 500 \mathrm{MHz}, \mathrm{TFA}-\mathrm{CDCl}_{3}\right): \delta 1.43(6 \mathrm{H}, \mathrm{t}$, 17,18- $\left.\mathrm{CH}_{2} \mathrm{CH}_{3}, J=7.5 \mathrm{~Hz}\right), 1.47\left(6 \mathrm{H}, \mathrm{t}, 13,22-\mathrm{CH}_{2} \mathrm{CH}_{3}, J=7.5 \mathrm{~Hz}\right), 1.67$ (9H, s, $t$-butyl), 2.93 (1H, s, internal proton), $2.98\left(6 \mathrm{H}, \mathrm{s}, 12,23-\mathrm{CH}_{3}\right), 3.18\left(4 \mathrm{H}, \mathrm{q}, 17,18-\mathrm{CH}_{2} \mathrm{CH}_{3}, J=7.1 \mathrm{~Hz}\right), 3.21$ (4H, q, 13,22- $\left.\mathrm{CH}_{2} \mathrm{CH}_{3}, J=7.1 \mathrm{~Hz}\right), 4.61(2 \mathrm{H}$, br s, $\mathrm{NH}), 7.68(2 \mathrm{H}, \mathrm{s}, 15,20-$ meso-CH), $8.64(2 \mathrm{H}$, s, 10,25-meso-CH), 8.69 (2H, d, 2,8-pyrene-CH, $J=9.1 \mathrm{~Hz}), 8.96(2 \mathrm{H}, \mathrm{d}, 3,7-$ pyrene-CH, $J=$ $8.6 \mathrm{~Hz}$ ), $9.40\left(2 \mathrm{H}, \mathrm{s}, 4,6\right.$-pyrene-CH); ${ }^{13} \mathrm{C} \mathrm{NMR}$ (dication $68 \mathrm{H}_{2}{ }^{+}, 500 \mathrm{~Hz}, \mathrm{TFA}-\mathrm{CDCl}_{3}$ ): $\delta 11.01$, $14.60,15.55,18.39,18.59,31.54,93.62,102.36,120.35,125.73,126.31,130.77,136.48,138.92$, $140.85,142.37,145.64,146.23,150.43,158.00 \mathrm{ppm}$. 


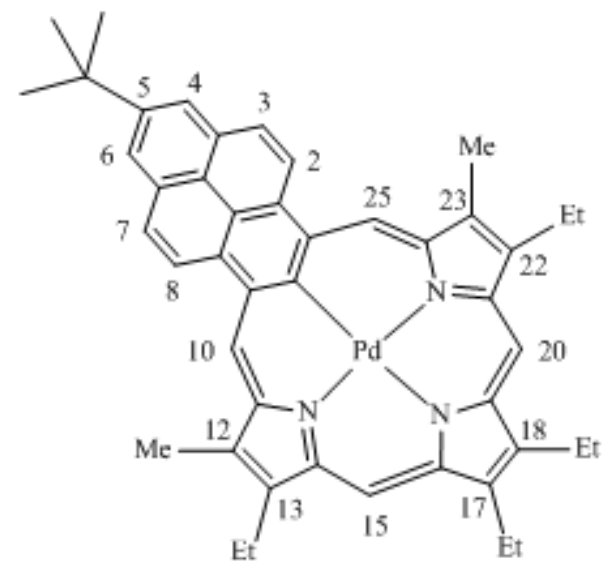

Pyreniporphyrin $68(8.0 \mathrm{mg}, 0.013 \mathrm{mmol})$ and palladium(II) acetate $(6.0 \mathrm{mg}, 0.027 \mathrm{mmol})$ in a 1:1 mixture of chloroform and acetonitrile $(20 \mathrm{~mL})$ were stirred under reflux for 2 hours. The solution was allowed to cool to room temperature, washed with water, and extracted with dichloromethane. The combined organic layers were evaporated under reduced pressure. The residue was purified by column chromatography on grade III basic alumina, eluting with a mixture of dichloromethane and hexanes in a ratio of 4:1, and a bluish-green fraction was collected. The solvent was evaporated under reduced pressure and the residue recrystallized from chloroform and methanol to afford the palladium complex $85(8.5 \mathrm{mg}, 0.011 \mathrm{mmol}, 85 \%)$ as a dark green powder, m.p. > $300{ }^{\circ} \mathrm{C} .{ }^{1} \mathrm{H} \mathrm{NMR}\left(500 \mathrm{MHz}, \mathrm{CDCl}_{3}\right): \delta 1.33\left(6 \mathrm{H}, \mathrm{t}, 17,18-\mathrm{CH}_{2} \mathrm{CH}_{3}, J\right.$ $=7.6 \mathrm{~Hz}), 1.37\left(6 \mathrm{H}, \mathrm{t}, 13,22-\mathrm{CH}_{2} \mathrm{CH}_{3}, J=7.6 \mathrm{~Hz}\right), 1.55\left(9 \mathrm{H}, \mathrm{s}, t\right.$-butyl), $2.64\left(6 \mathrm{H}, \mathrm{s},-\mathrm{CH}_{3}\right), 2.90$ (4H, q, 17,18- $\left.\mathrm{CH}_{2} \mathrm{CH}_{3}, J=6.4 \mathrm{~Hz}\right), 2.93\left(4 \mathrm{H}, \mathrm{q}, 13,22-\mathrm{CH}_{2} \mathrm{CH}_{3}, J=6.4 \mathrm{~Hz}\right), 7.26(2 \mathrm{H}, \mathrm{s}, 15,20-$ meso-CH), $8.14(2 \mathrm{H}, \mathrm{d}, 2,8-$ pyrene-CH, $J=9.1 \mathrm{~Hz}), 8.20(2 \mathrm{H}, \mathrm{s}, 10,25-$ meso-CH), $8.65(2 \mathrm{H}, \mathrm{s}$, 4,6-pyrene-CH), $8.92(2 \mathrm{H}, \mathrm{d}, 3,7$-pyrene-CH, $J=9.0 \mathrm{~Hz}) ;{ }^{13} \mathrm{C} \mathrm{NMR}\left(500 \mathrm{~Hz}, \mathrm{CDCl}_{3}\right): \delta 10.44$, $15.19,16.45,18.35,18.62,29.69,31.80,95.69,118.60,125.26,127.48,129.70,130.81,138.34$ 
139.92, 140.56, 143.41, 144.52, 152.37 ppm; UV-Vis $\left(1 \% \mathrm{Et}_{3} \mathrm{~N}-\mathrm{CH}_{2} \mathrm{Cl}_{2}\right): \lambda_{\max }(\log \varepsilon): 348$

(4.45), 454 (4.43), 620 (4.47), 650 (4.36).

\section{1,3-Bis(phenylpyrrolylmethyl)-7-tert-butylpyrene (87)}

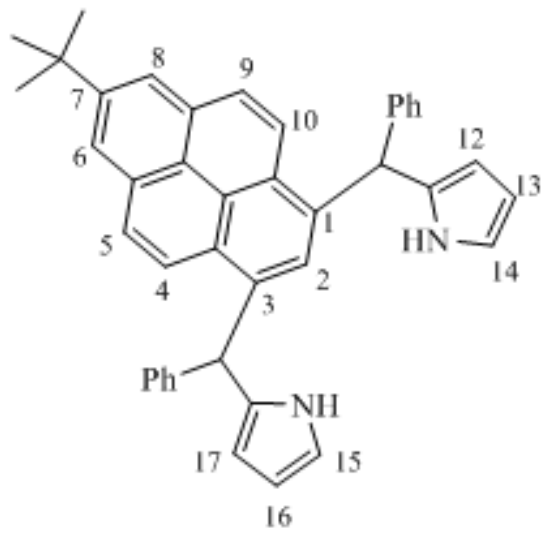

Nitrogen was bubbled through a solution of dicarbinol $86(150.0 \mathrm{mg}, 0.336 \mathrm{mmol})$ and pyrrole (4 $\mathrm{mL}$ ) in 1,2-dichloroethane ( $20 \mathrm{~mL}$ ) for 20 minutes, after which $60 \mu \mathrm{L}$ of a $10 \%$ boron trifluoride etherate solution in methylene chloride was added, and the resulting mixture was stirred under reflux for 24 hours. The solution was cooled to room temperature and quenched by addition of triethylamine $(2 \mathrm{~mL})$. The solvent was evaporated on a rotary evaporator at aspiration pressure, and excess pyrrole was removed with the aid of a vacuum pump. The product was purified by column chromatography on silica, eluting with methylene chloride. Evaporation of product fractions gave the pyrenitripyrrane (145 $\mathrm{mg}, 0.268 \mathrm{mmol}, 80 \%)$ as a pale yellow oil. ${ }^{1} \mathrm{H}$ NMR $\left(500 \mathrm{MHz}, \mathrm{CDCl}_{3}\right): \delta 1.48(9 \mathrm{H}, \mathrm{s}, t$-butyl), $5.66(1 \mathrm{H}, \mathrm{d}, 12-\mathrm{CH}, J=9.3 \mathrm{~Hz}), 5.68(1 \mathrm{H}, \mathrm{d}, 17-\mathrm{CH}$, $J=9.3 \mathrm{~Hz}), 5.99(1 \mathrm{H}, \mathrm{q}, 13-\mathrm{CH}, J=3.3 \mathrm{~Hz}), 6.03(1 \mathrm{H}, \mathrm{q}, 17-\mathrm{CH}, J=3.3 \mathrm{~Hz}), 6.34(2 \mathrm{H}, \mathrm{s},-$ CHPh), $6.47(1 \mathrm{H}, \mathrm{q}, 14-\mathrm{CH}, J=1.5 \mathrm{~Hz}), 6.50(1 \mathrm{H}, \mathrm{q}, 15-\mathrm{CH}, J=1.5 \mathrm{~Hz}), 7.05(10 \mathrm{H}, \mathrm{m}$, phenyl), 
$7.20(2 \mathrm{H}, \mathrm{s}, 2-\mathrm{CH}), 7.54(2 \mathrm{H}$, br s, 2 x NH), $7.88(2 \mathrm{H}, \mathrm{d}, 5,9-\mathrm{CH}, J=9.7 \mathrm{~Hz}), 8.07$ (2H, s, 6, 8$\mathrm{CH}), 8.12(2 \mathrm{H}, \mathrm{d}, 4,10-\mathrm{CH}, J=9.7 \mathrm{~Hz})$.

$\underline{10,15,20,25-t e t r a p h e n y l-5-t e r t-b u t y l-28-t h i a p y r e n i p o r p h y r i n}(\mathbf{8 8})$

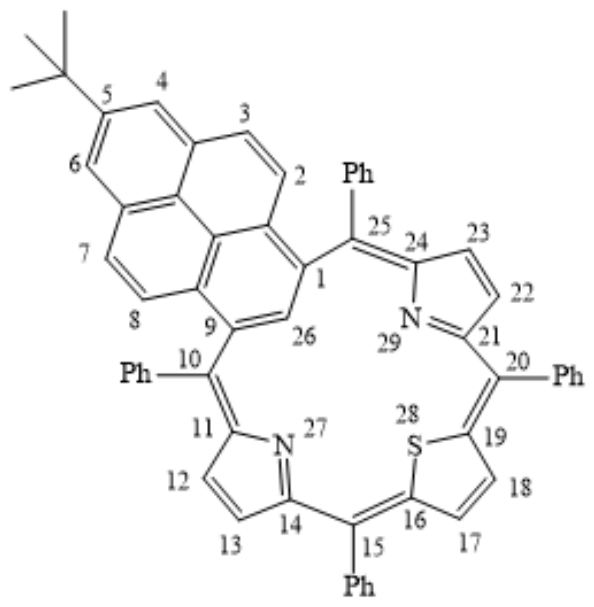

Nitrogen was bubbled through a solution of diphenyl tripyrrane 87 (54 mg, $0.095 \mathrm{mmol}$ ) and thiophene dicarbinol 89 (30 mg, $0.101 \mathrm{mmol})$ in chloroform (30 mL) for 10 minutes. A $10 \%$ solution of $\mathrm{BF}_{3} \mathrm{Et}_{2} \mathrm{O}$ in chloroform $(50 \mu \mathrm{L})$ was added by syringe, and the solution was allowed to stir under nitrogen in the dark at room temperature for 3 hours. DDQ (65 mg, $0.286 \mathrm{mmol})$ was added and stirring was continued for a further 1.5 hours. The solvent was removed under reduced pressure, and the residue purified by column chromatography on grade III neutral alumina eluting with dichloromethane. The product was further purified on grade III neutral alumina, eluting with a mixture of dichloromethane and hexanes in ratio of 3:2. A dark green band was collected and the solvent was evaporated under reduced pressure. The residue was recrystallized from chloroform and methanol to afford thiapyreniporphyrin $\mathbf{8 8}(6.0 \mathrm{mg}, 0.006$ 
mmol, 7\%) as a dark green powder, m.p. $>300{ }^{\circ} \mathrm{C} .{ }^{1} \mathrm{H}$ NMR $\left(500 \mathrm{MHz}, \mathrm{CDCl}_{3}\right): \delta 1.42(9 \mathrm{H}, \mathrm{s}, t$ Butyl), 6.58 (2H, d, 13,22-CH, J = 4.8 Hz), 6.91 (1H, s, 17-CH), 7.33 (16H, m, 15,20-phenyl), $7.51(1 \mathrm{H}, \mathrm{s}, 26-\mathrm{CH}), 7.57(4 \mathrm{H}, \mathrm{m}, 10,25-$ phenyl), $7.60(2 \mathrm{H}, \mathrm{d}, 12,23-\mathrm{CH}, J=4.8 \mathrm{~Hz}), 7.77(2 \mathrm{H}$, d, 2,8-CH, $J=9.1 \mathrm{~Hz}), 7.89(2 \mathrm{H}, \mathrm{d}, 3,7-\mathrm{CH}, J=9.1 \mathrm{~Hz}), 8.00(2 \mathrm{H}, \mathrm{s}, 4,6-\mathrm{CH}) ;{ }^{13} \mathrm{C}$ NMR $(500$ $\left.\mathrm{Hz}, \mathrm{CDCl}_{3}\right): \delta 31.87,117.73,122.82,126.12,127.71,128.02,128.17,128.40,129.08,129.79$, $130.55,130.97,131.66,135.31,135.76,138.61,141.59,146.24,149.22,154.91,156.98,170.93$ ppm; UV-Vis (1\% $\left.\mathrm{Et}_{3} \mathrm{~N}-\mathrm{CH}_{2} \mathrm{Cl}_{2}\right): \lambda_{\max }(\log \varepsilon): 348$ (4.51), 387 (4.35), $631 \mathrm{~nm}$ (3.85); UV-Vis (1 equivalent TFA- $\left.\mathrm{CH}_{2} \mathrm{Cl}_{2}\right)$ : $\lambda_{\max }(\log \varepsilon): 343$ (4.41), 440 (4.40), $636 \mathrm{~nm}$ (3.90); UV-Vis (5\% TFACH2Cl2): $\lambda_{\max }(\log \varepsilon): 343$ (4.34), 460 (4.44), $635 \mathrm{~nm}(4.18) ;{ }^{1} \mathrm{H}$ NMR (dication $\mathbf{8 8} \mathrm{H}_{2}{ }^{2+}, 500$ $\left.\mathrm{MHz}, \mathrm{TFA}-\mathrm{CDCl}_{3}\right): \delta 1.41$ (9H, s, $t$-Butyl), 5.20 (1H, s, 26-CH), 7.58 (16H, m, 15,20-phenyl), 7.60 (4H, m, 10,25-phenyl), 7.69 (2H, d, 13,22-CH, $J=9.2 \mathrm{~Hz}), 7.76(2 \mathrm{H}, \mathrm{d}, 2,8-\mathrm{CH}, J=8.0$ $\mathrm{Hz}), 7.94(1 \mathrm{H}, \mathrm{s}, 17-\mathrm{CH}), 7.97(2 \mathrm{H}, \mathrm{d}, 3,7-\mathrm{CH}, J=9.2 \mathrm{~Hz}), 8.14(2 \mathrm{H}, \mathrm{d}, 12,23-\mathrm{CH}, J=5.3 \mathrm{~Hz})$, $8.20(2 \mathrm{H}, \mathrm{s}, 4,6-\mathrm{CH}), 10.67(2 \mathrm{H}, \mathrm{s}, \mathrm{NH}) ;{ }^{13} \mathrm{C}$ NMR (dication $\left.\mathbf{8 8} \mathrm{H}_{2}{ }^{2+}, 500 \mathrm{MHz}, \mathrm{TFA}-\mathrm{CDCl}_{3}\right): \delta$ $31.54,35.36,99.38,121.54,127.46,127.64,128.46,128.91,129.50,129.96,131.27,132.27$, $132.59,133.32,133.86,134.32,135.13,138.95,140.26,141.08,143.94,152.06,153.83,162.96$ ppm. 


\section{REFERENCES}

1. Smith, K. M., ed.; Porphyrins and Metalloporphyrins; Elsevier Scientific Pub. Co, 1975.

2. Milgrom, L. R. The Colours of Life: An Introduction to the Chemistry of Porphyrins and Related Compounds; Oxford University Press, 1997.

3. Loudon, G. M. Organic Chemistry; Roberts and Company, 2009.

4. Hofmann, A. W. Proc. R. Soc. Lond. 1856, 8, 1-3.

5. Sondheimer, F.; Wolovsky, R.; Amiel, Y. J Am. Chem. Soc. 1962, 84, $274-284$.

6. Lash, T. D. in The Porphyrin Handbook: Heteroporphyrins, Expanded Porphyrins and Related Macrocycles; Kadish, K. M.; Smith, K. M.; Guilard, R. Academic Press, 2000; Vol. 2, pp 125 - 199.

7. Soret, J. L. Compt. Rend. 1883, 97, 1267.

8. Malinski, T. in The Porphyrin Handbook: Applications Past, Present, and Future; Kadish, K. M.; Smith, K. M.; Guilard, R. Academic Press, 2000; Vol. 6, pp $232-255$.

9. Kuster, W.; Deihle, P. Z. Physiol. Chem. 1912, 82.

10. Fischer, H.; Zeile, K. Justus Liebigs Ann. Der Chem. 1929, 468, 98 - 116.

11. Smith, K. M. in The Porphyrin Handbook: Synthesis and Organic Chemistry; Kadish, K. M.; Smith, K. M.; Guilard, R Academic Press, 2000; Vol. 1, pp 2 - 43.

12. Rothemund, P. J. Am. Chem. Soc. 1936, 58, 625 - 627.

13. Adler, A. D.; Longo, F. R.; Finarelli, J. D.; Goldmacher, J.; Assour, J.; Korsakoff, L. J. Org. Chem. 1967, 32, $476-477$.

14. Lindsey, J. S.; Schreiman, I. C.; Hsu, H. C.; Kearney, P. C.; Marguerettaz, A. M. J. Org. Chem. 1987, 52, $827-836$.

15. Arsenault, G. P.; Bullock, E.; MacDonald, S. F. J. Am. Chem. Soc. 1960, 82, $4384-$ 4389.

16. Broadhurst, M. J.; Grigg, R.; Johnson, A. W. J. Chem. Soc. 1971, 3681 - 3690.

17. Cavaleiro, J. A. S.; Gonsalves, A. M. d'A R.; Kenner, G. W.; Smith, K. M. J. Chem. Soc Perkin Trans. 1973, 1, 2471. 
18. Sessler, J. L.; Johnson, M. R.; Lynch, V. J. Org. Chem. 1987, 52, 4394 - 4397.

19. Lash, T. D.; Toney, A. M.; Castans, K. M.; Ferrence, G. M. J. Org. Chem. 2013, 78, 9143 $-9152$.

20. Graham, S. R.; Colby, D. A.; Lash, T. D. Angew. Chem. Int. Ed. 2002, 41, 1371 - 1374.

21. Lash, T. D.; Chaney, S. T.; Richter, D. T. J. Org. Chem. 1998, 63, 9076 - 9088.

22. Sessler, J. L.; Cyr, M.; Burrell, A, K. Tetrahedron, 1992, 48, 9661 - 9672.

23. Lash, T. D. Eur. J. Org. Chem. 2007, 33, 5461 - 5481.

24. Berlin, K.; Breitmaier, E. Angew. Chem. Int. Ed. Engl. 1994, 33, 1246 - 1247.

25. Lash, T. D. Angew. Chem. Int. Ed. Engl. 1995, 34, 2533 - 2535.

26. Muckey, M. A.; Szczepura, L. F.; Ferrence, G. M.; Lash, T. D. Inorg. Chem. 2002, 41, $4840-4842$.

27. Lash, T. D.; Rasmussen, J. M.; Bergman, K. M; Colby, D. A. Org. Lett. 2004, 6, 549 552.

28. Araki, K.; Winnischofer, H; Toma, H. E.; Maeda, H.; Osuka, A.; Furuta, H. Inorg. Chem. 2001, 40, $2020-2025$.

29. AbuSalim, D. I.; Ferrence, G. M.; Lash, T. D. J. Am. Chem. Soc. 2014, 136, 6763 - 6772.

30. Collman, J. P.; Brauman, J. I.; Meunier, B.; Raybuck, S. A.; Kodadek, T. Proc Natl. Acad Sci. 1984, 81, $3245-3248$.

31. Anding, B. J.; Ellern, A.; Woo, L. K. Organometallics, 2012, 31, 3628 - 3635.

32. Kostas, I. D.; Coutsolelos, A G; Charalambidis, G; Skondra, A. Tetrahedron Lett. 2007, $48,6688-6691$.

33. Rambo, B. M.; Sessler, J. L. Chem. -Eur. J. 2011, 17, 4946 - 4959.

34. Amao, T.; Okura, I. J. Porphyrins Phthalocyanines 2009, 13, 1111 - 1122.

35. Furuta, H.; Asano, T.; Ogawa, T. J. Am. Chem. Soc. 1994, 116, $767-768$.

36. Geier, G. R.; Lindsey, J. S. J. Org. Chem. 1999, 64, 1596 - 1603. 
37. Lash, T. D.; Lammer, A. D.; Ferrence, G. M. Angew. Chem. Int. Ed. 2011, 50, 9718 9712.

38. Pawlicki, M.; Latos-Grazynski, L. J. Org. Chem. 2005, 70, 9123 - 9130.

39. Pawlicki, M.; Latos-Grazynski, L. Chem. -Eur. J. 2003, 9, 4650-4660.

40. Sprutta, N.; Latos-Grazynski, L. Tetrahedron Lett. 1999, 40, 8457 - 8460.

41. Lash, T. D.; Szymanski, J. T.; Ferrence, G. M. J. Org. Chem. 2007, 72, $6481-6492$.

42. Richter, D. T.; Lash, T. D. Tetrahedron 2001, 57, 3657 - 3671.

43. Allen, R. L. M. Colour Chemistry; Springer US: Boston, MA, 1971.

44. The Chemistry and Application of Dyes; Waring, D. R., Hallas, G., Eds.; Springer: Boston, MA, 1990.

45. Scholl, R. Konstitution und Synthese des Flavanthrens. Ber. Dtsch. Chem. Ges. 1907, 40 (2), $1691-1702$.

46. Stepien, M.; Gonka, E.; Zyla, M.; Sprutta, N. Chem. Rev. 2016, doi: 10.1021/acs.chemrev.6b00076.

47. Harvey, R. G. Polycyclic Aromatic Hydrocarbons: Chemistry and Carcinogenicity; Cambridge University Press: Cambridge, 1991.

48. Lash, T. D.; Werner, T. M.; Thompson, M. L.; Manley, J. M. J. Org. Chem. 2001, 66, $3152-3159$

49. Lash, T. D. J. Porphyrins Phthalocyanines, 1997, 1, 29-44.

50. Lash, T. D. Chem. Eur. J. 1996, 2, 1197-1200.

51. Miura, Y.; Yamano, E.; Tanaka, A. J. Org. Chem. 1994, 59, 3294-3300.

52. Inoue, J.; Fukui, K.; Kubo, T.; Nakazawa, S.; Sato, K.; Shiomi, D.; Morita, Y.;

Yamamoto, K.; Takui, T.; Nakasuji, K. J. Am. Chem. Soc. 2001, 123, 12702-12703. 
53. Barton, D. H. R.; Zard, S. Z. J. Chem. Soc. 1985, 16, 1098.

54. Lash, T. D.; Chaney, S. T.; Richter, D. T. J. Org. Chem. 1998, 63, 9076-9088.

55. Zumdahl, S. S. Chemistry; Health: Lexington, MA, 1986.

56. Kramarz, K. W.; Norton, J. R. Prog. Inorg. Chem. 1994, 42, 1-65.

57. Gnichtel, H.; Schoenherr, H.-J. Chem. Ber. 1966, 99, 618 - 624.

58. Kleinspehn, G. G.; Corwin, A. H. J. Org. Chem. 1960, 25, 1048 - 1050.

59. Mironov, A. F.; Naumova, B. S.; Evstigneeva, R. P.; Preobrazhenskii, N. A. Zh. Obshch. Khim. 1964, 34, 3312 - 3314.

60. Johnson, A. W.; Kay, I. T.; Markham, E.; Price, R.; Shaw, K. B. J. Chem. Soc. 1959, $3416-3424$

61. Morell, S. A.; Vonkorff, R. W. Penaldic Acids and Their Derivatives. U.S. Patent 2,516,900, August 1, 1950; SciFinder Scholar 1951: 3664.

62. Ugi, I.; Fetzer, U.; Eholzer, U.; Knupfer, H.; Offerman, K. Angew. Chem. 1965, 77, 492 504.

63. Nightingale, D. V.; Janes, J. R. J. Am. Chem. Soc. 1944, 66, 352 - 354.

64. Parham, W. E.; Bleasdale, J. L. J. Am. Chem. Soc. 1950, 72, 3843 - 3846.

65. Eisner, U.; Lichtarowicz, A.; Linstead, R. P. J. Chem. Soc. 1957, 733 - 739.

66. Sessler, J. L.; Johnson, M. R.; Lynch, V. J. Org. Chem. 1987, 52, 4394. 


\section{APPENDIX A}

\section{SELECTED NMR SPECTRA AND CHEMICAL SHIFT ASSIGNMENTS}
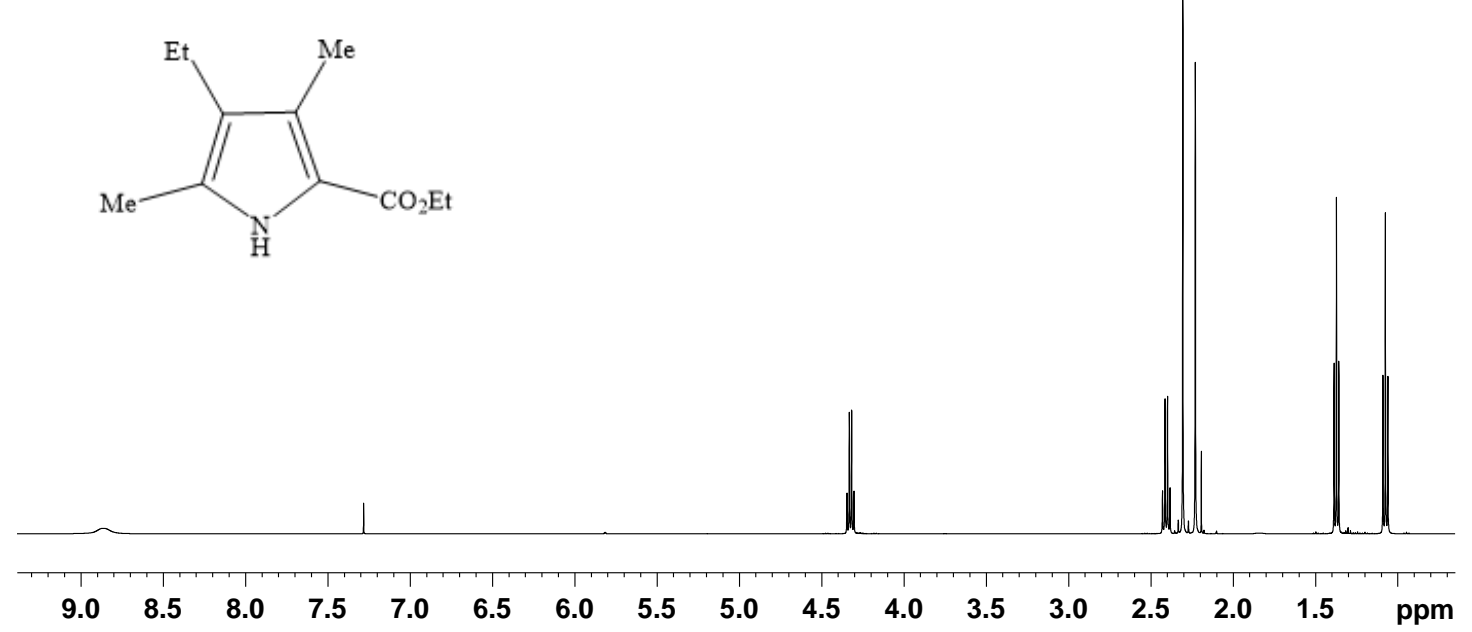

Figure A - 1: $500 \mathrm{MHz}{ }^{1} \mathrm{H}$ NMR Spectrum of Pyrrole Ester 73 in $\mathrm{CDCl}_{3}$

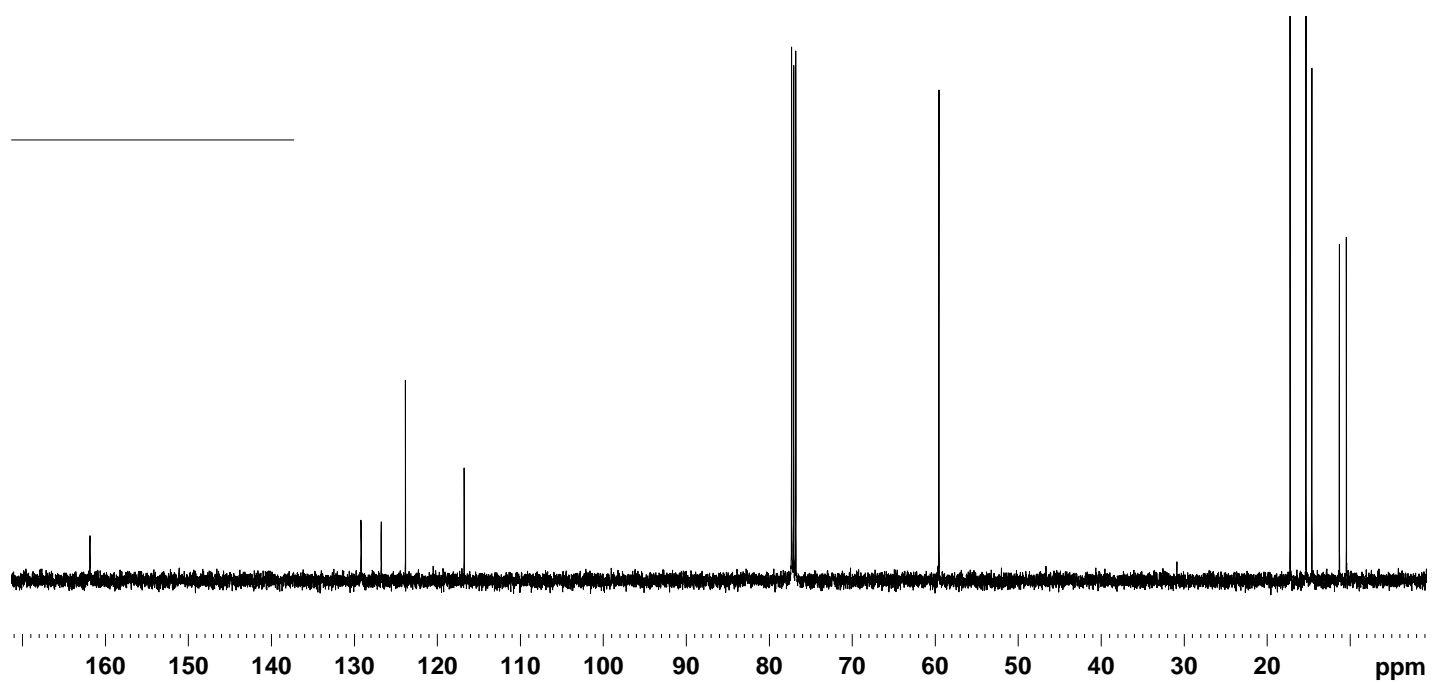

Figure A - 2: $125 \mathrm{MHz}{ }^{13} \mathrm{C}$ NMR Spectrum of Pyrrole Ester 73 in $\mathrm{CDCl}_{3}$ 
<smiles>CCc1c(C)[nH]c(C(=O)OCc2ccccc2)c1C</smiles>

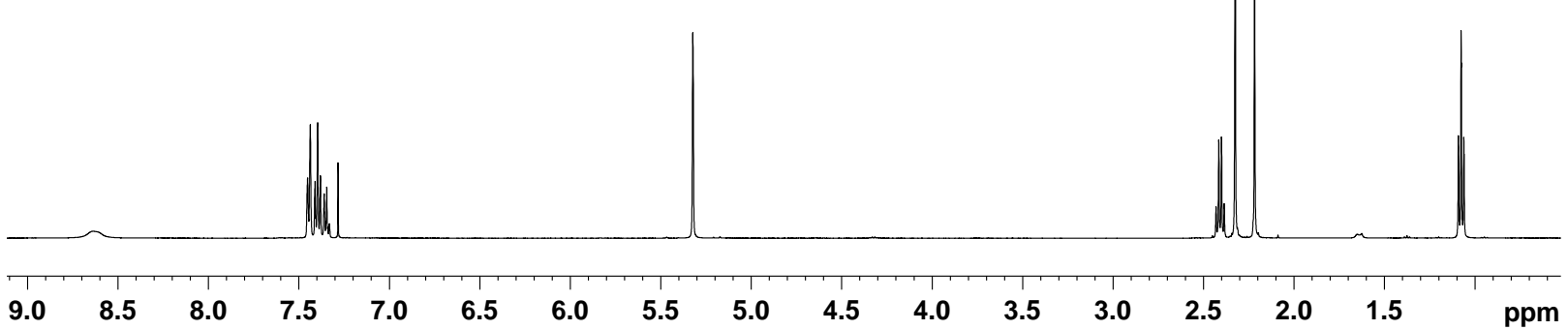

Figure A - 3: $500 \mathrm{MHz}{ }^{1} \mathrm{H}$ NMR Spectrum of Benzyl Pyrrole Carboxylate 80 in $\mathrm{CDCl}_{3}$

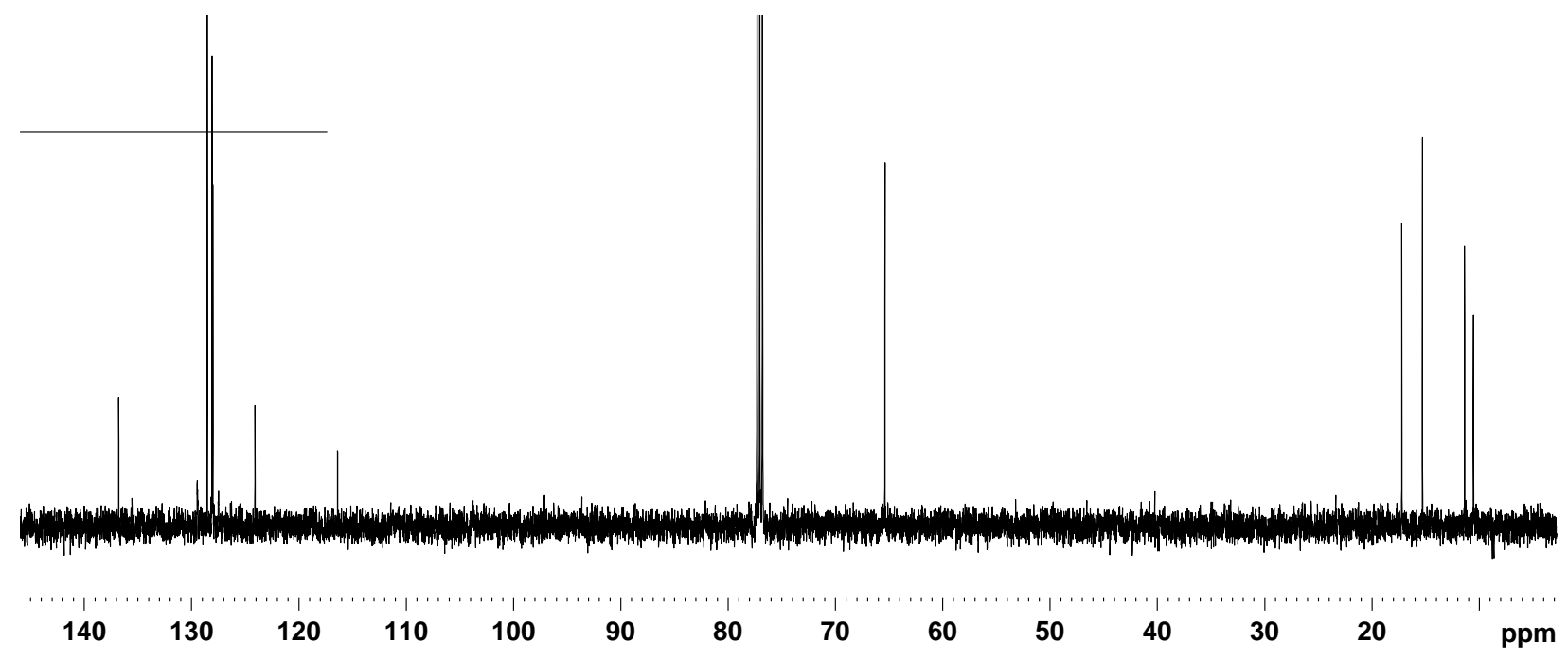

Figure A - 4: $125 \mathrm{MHz}{ }^{13} \mathrm{C}$ NMR Spectrum of Benzyl Pyrrole Carboxylate 80 in $\mathrm{CDCl}_{3}$ 


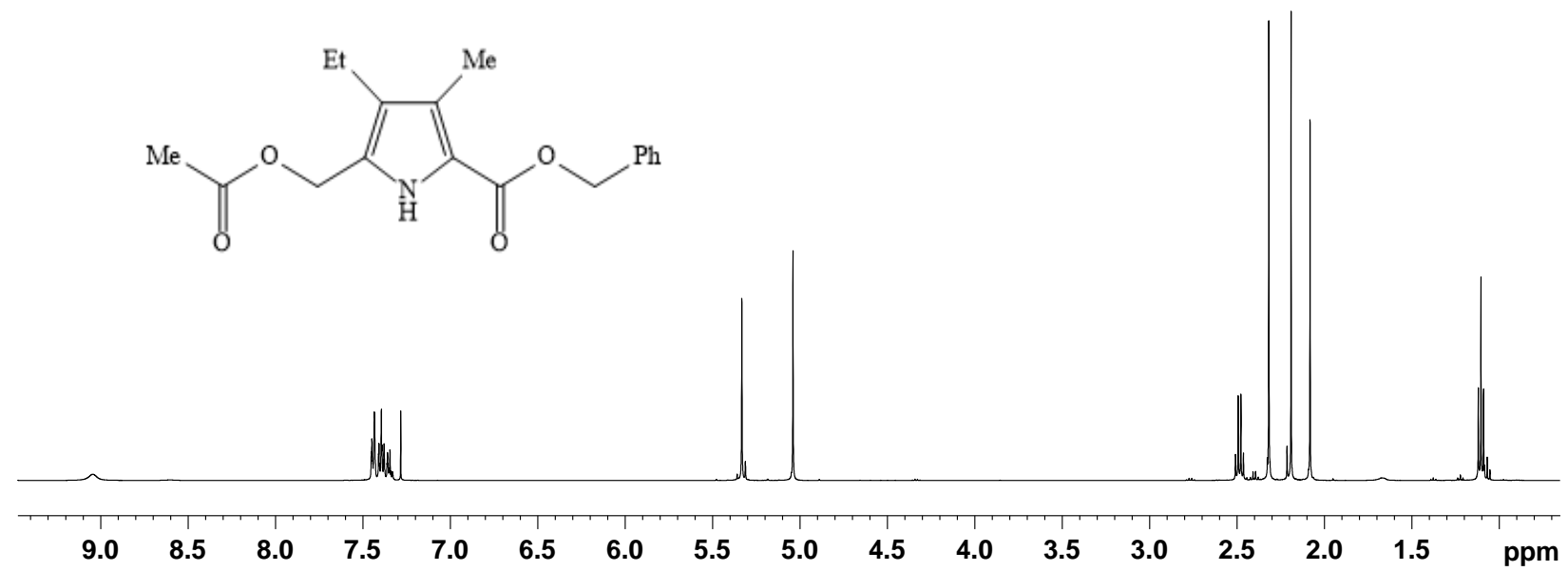

Figure A - 5: $500 \mathrm{MHz}{ }^{1} \mathrm{H}$ NMR Spectrum of Acetoxymethylpyrrole 81 in $\mathrm{CDCl}_{3}$

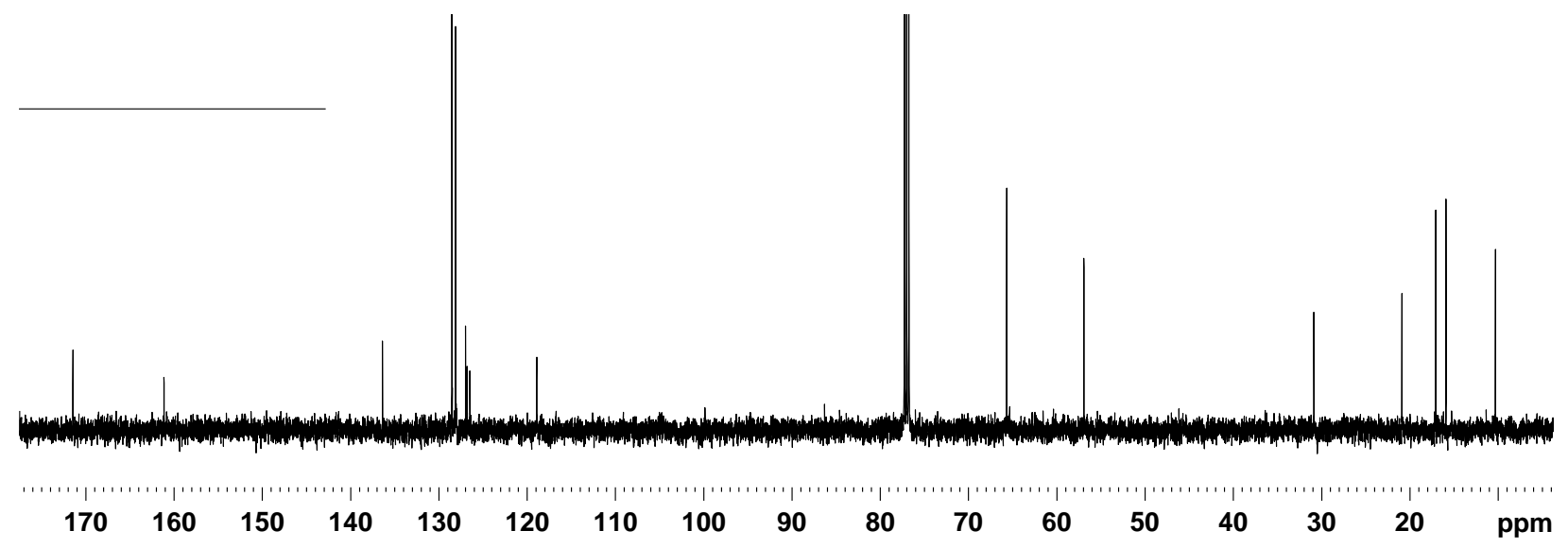

Figure A - 6: $125 \mathrm{MHz}{ }^{13} \mathrm{C}$ NMR Spectrum of Acetoxymethylpyrrole 81 in $\mathrm{CDCl}_{3}$ 


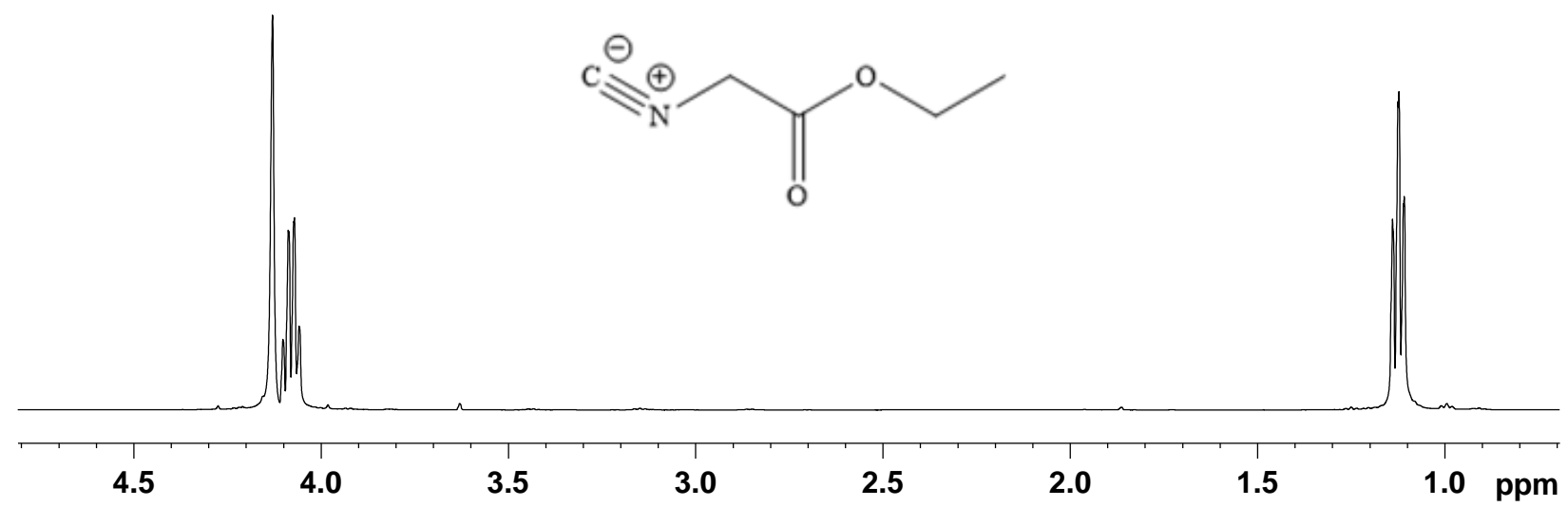

Figure A - 7: $500 \mathrm{MHz}{ }^{1} \mathrm{H}$ NMR Spectrum of Ethyl Isocyanoacetate 76 in $\mathrm{CDCl}_{3}$

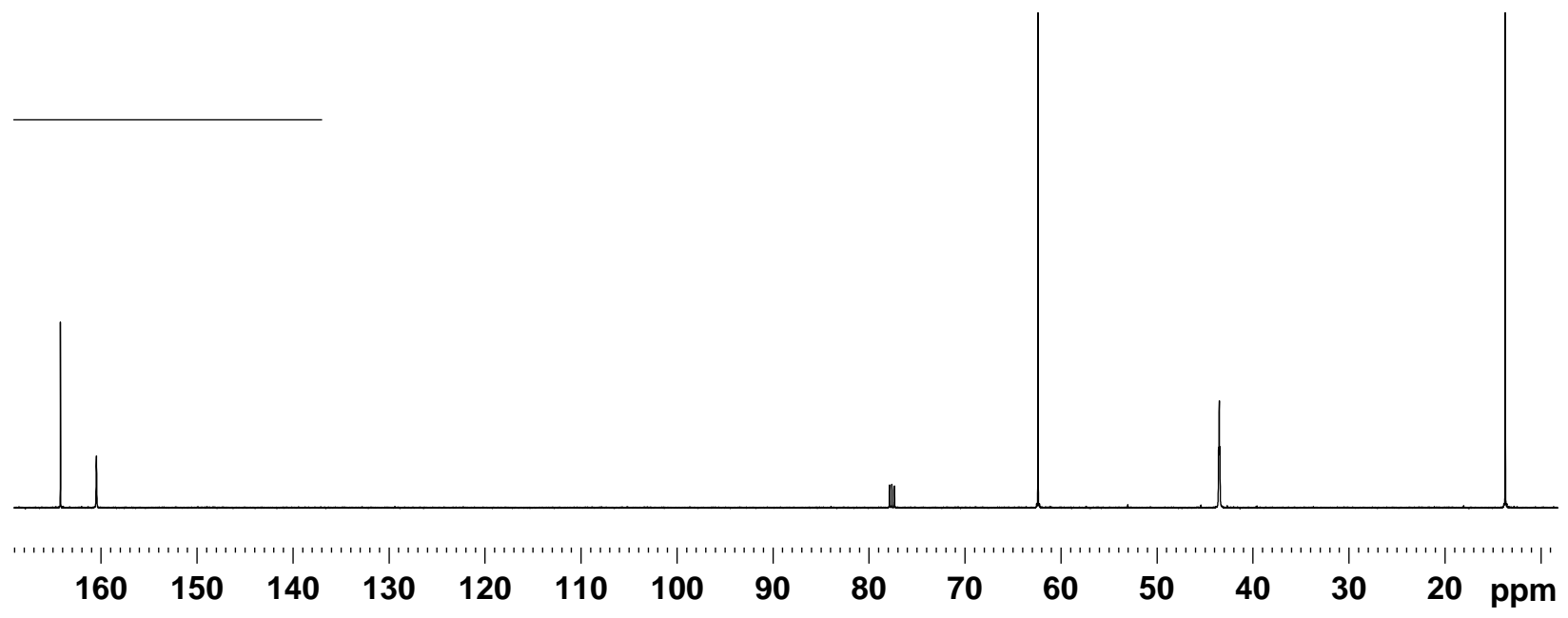

Figure A - 8: $125 \mathrm{MHz}{ }^{13} \mathrm{C}$ NMR Spectrum of Ethyl Isocyanoacetate 76 in $\mathrm{CDCl}_{3}$ 


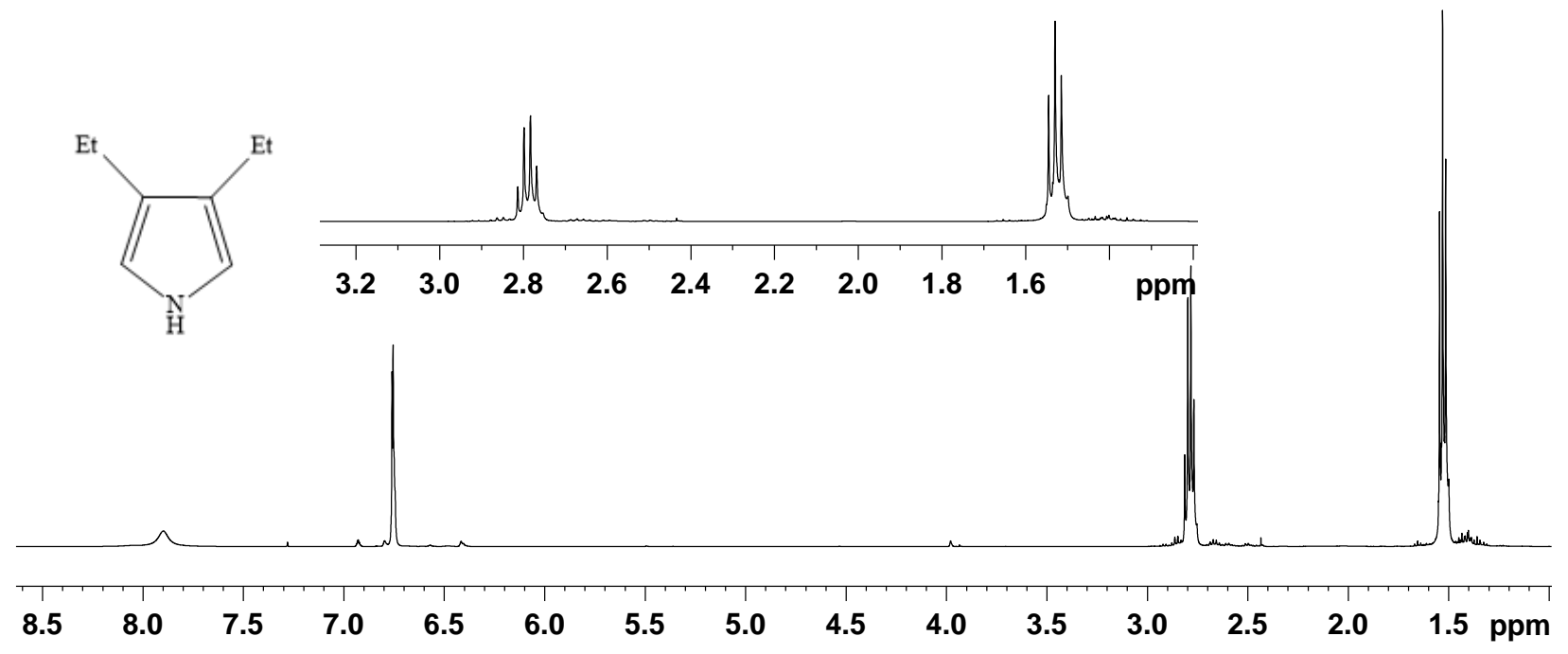

Figure A - 9: $500 \mathrm{MHz}{ }^{1} \mathrm{H}$ NMR Spectrum of Diethyl Pyrrole 74 in $\mathrm{CDCl}_{3}$

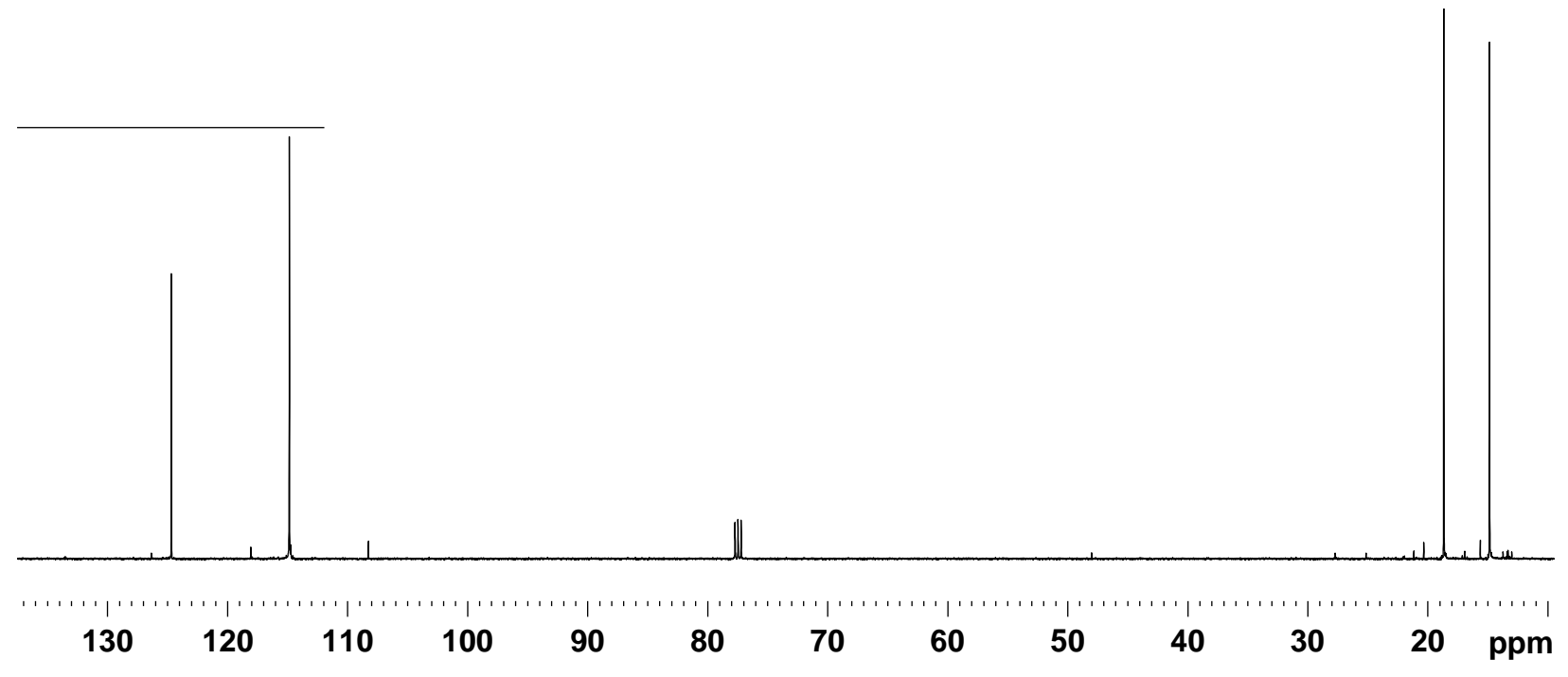

Figure A - 10: $125 \mathrm{MHz}{ }^{13} \mathrm{C}$ NMR Spectrum of Diethyl Pyrrole 74 in $\mathrm{CDCl}_{3}$ 

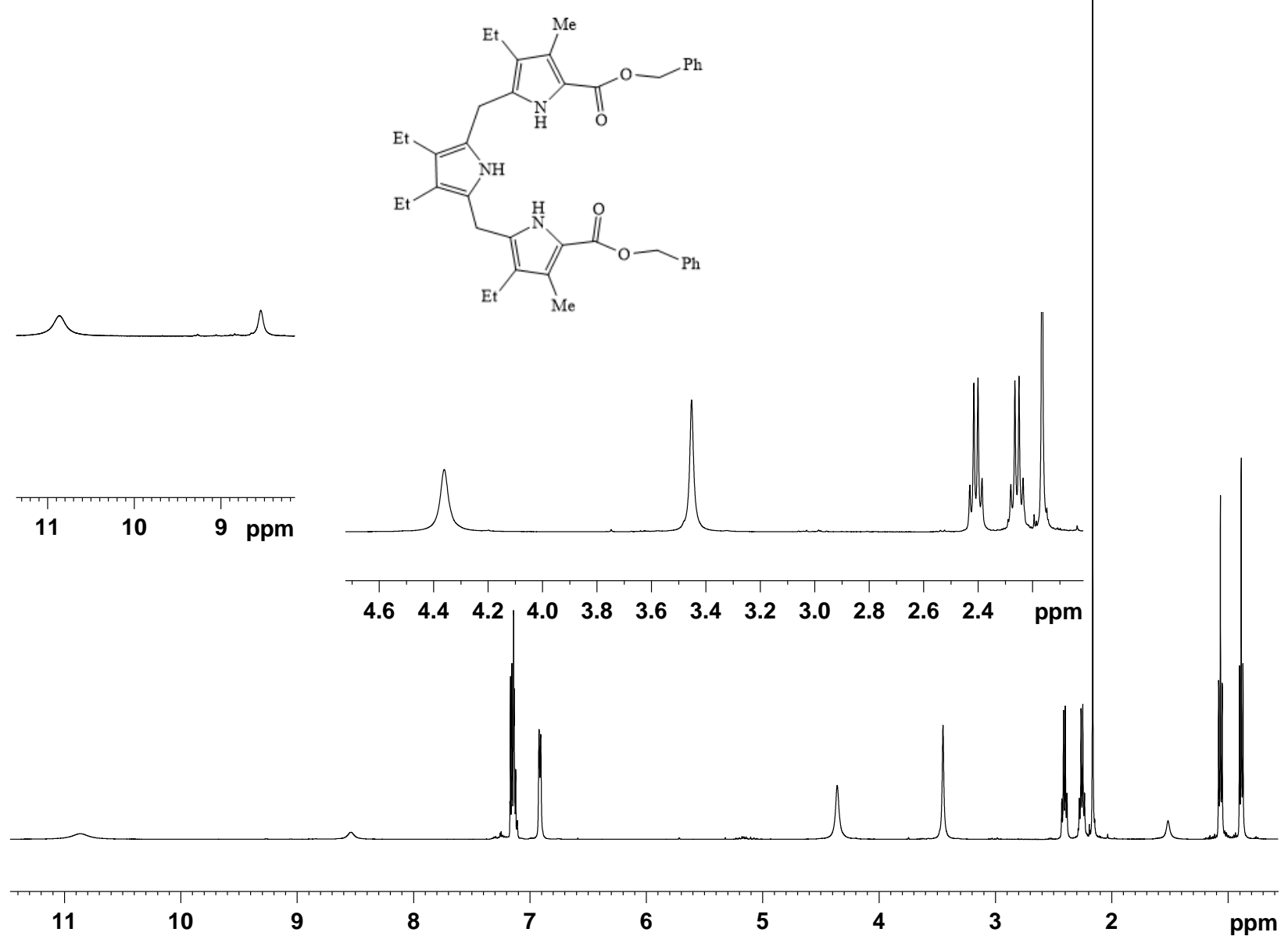

Figure A - 11: $500 \mathrm{MHz}{ }^{1} \mathrm{H}$ NMR Spectrum of Tripyrrane Dibenzyl Ester 82 in $\mathrm{CDCl}_{3}$ 


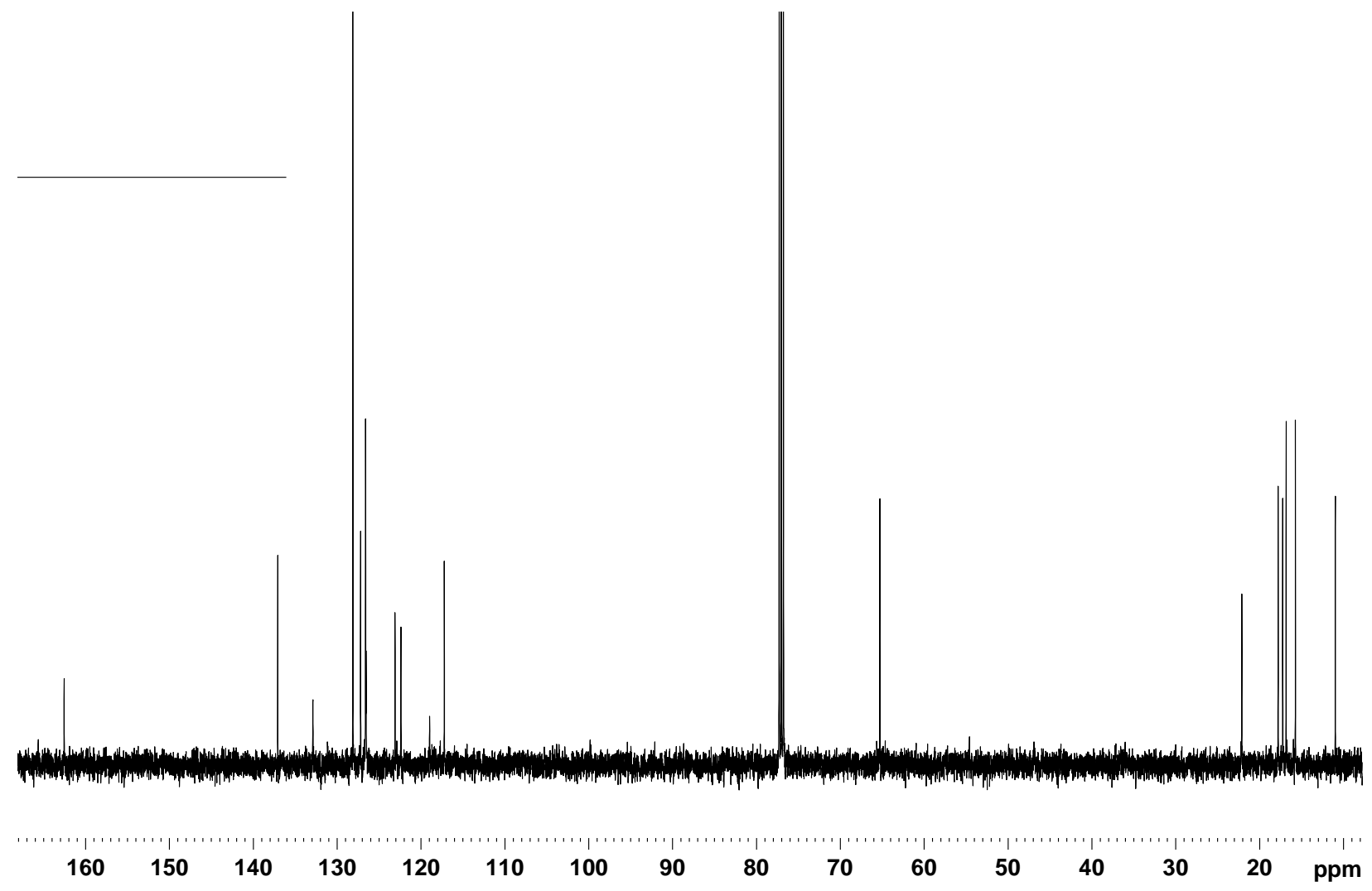

Figure A - 12: $125 \mathrm{MHz}{ }^{13} \mathrm{C}$ NMR Spectrum of Tripyrrane Dibenzyl Ester 82 in $\mathrm{CDCl}_{3}$ 


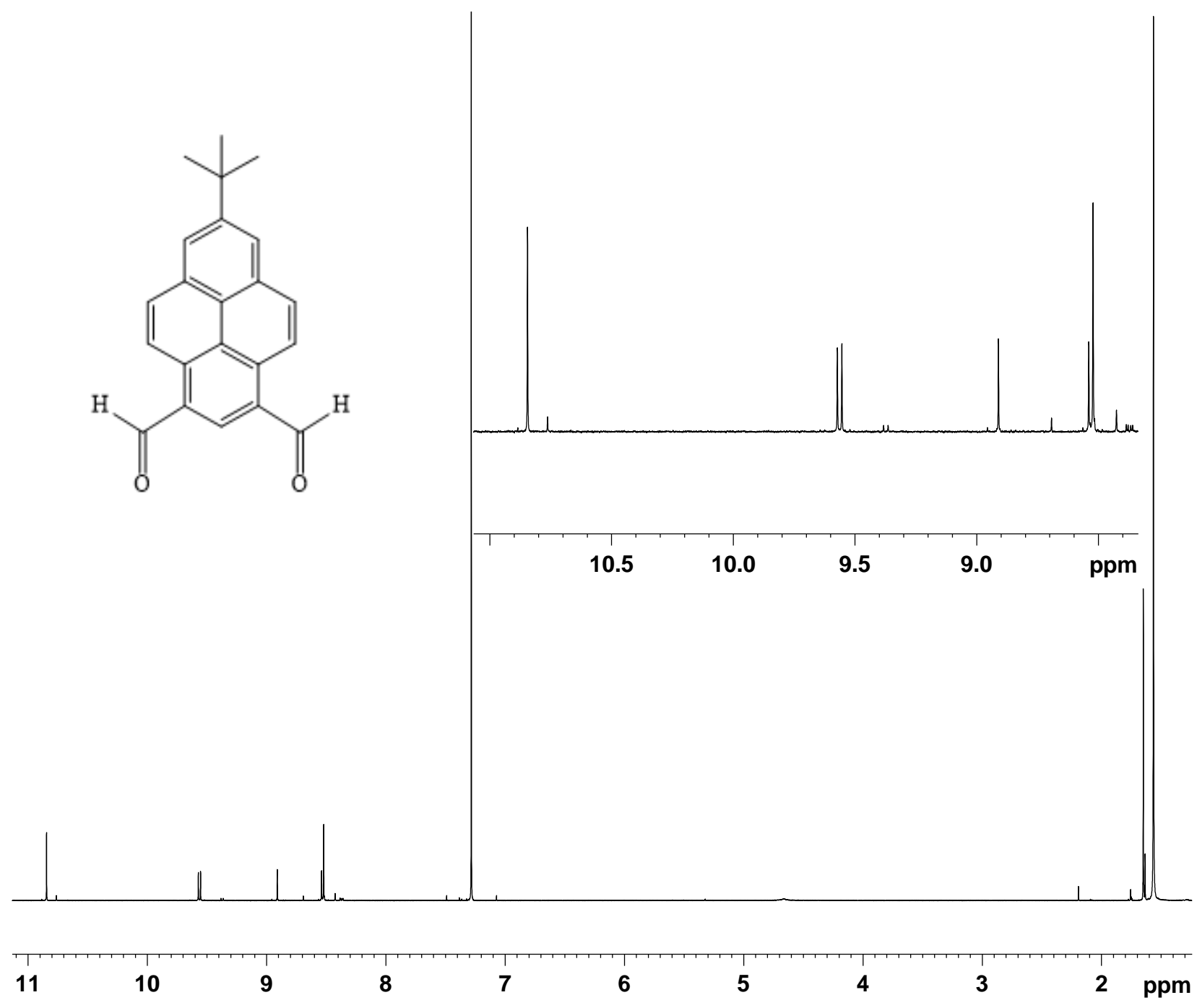

Figure A - 13: $500 \mathrm{MHz}{ }^{1} \mathrm{H}$ NMR Spectrum of Pyrene Dialdehyde 83 in $\mathrm{CDCl}_{3}$ 


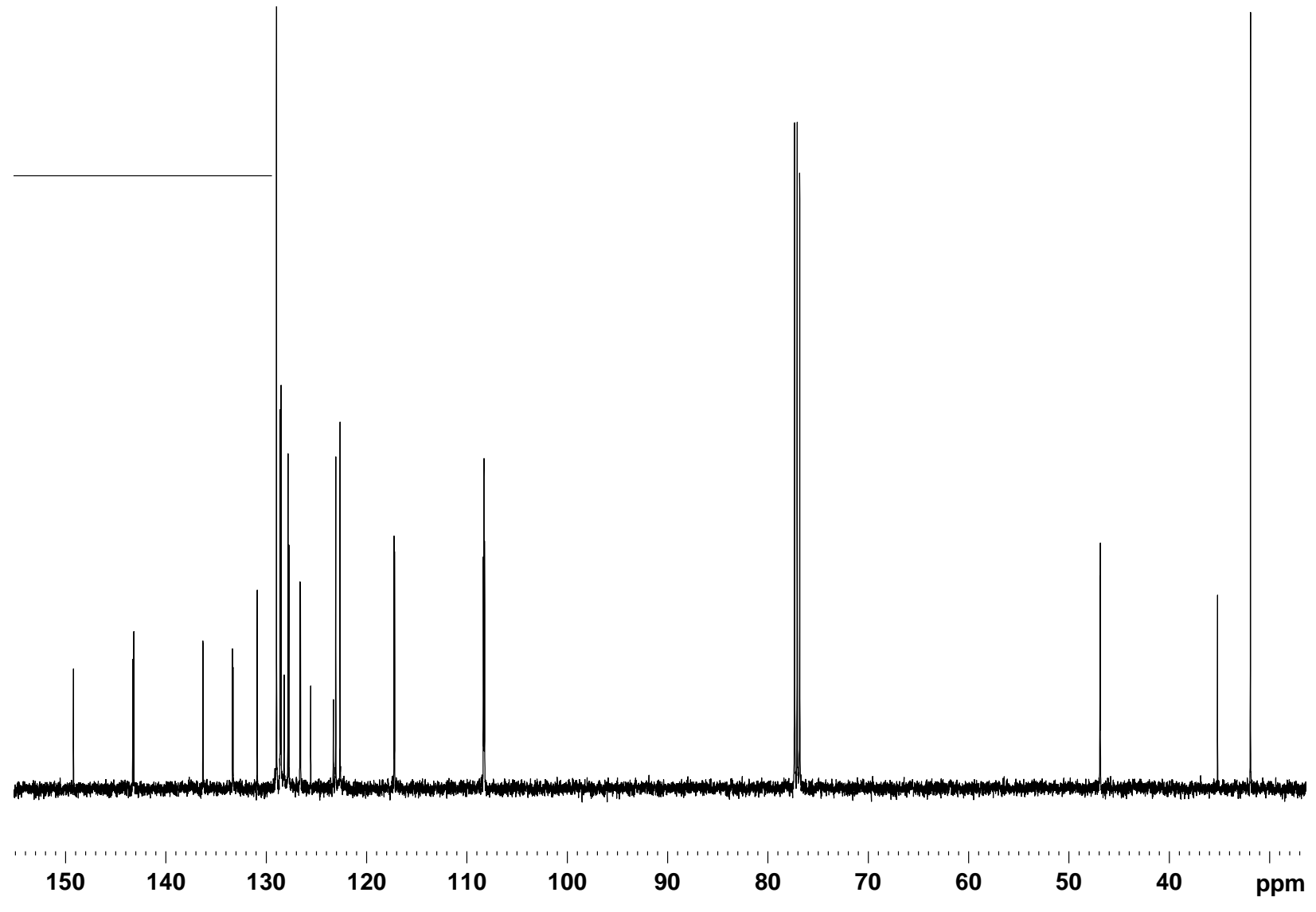

Figure A - 14: $125 \mathrm{MHz}{ }^{13} \mathrm{C}$ NMR Spectrum of Pyrene Dialdehyde 83 in $\mathrm{CDCl}_{3}$ 


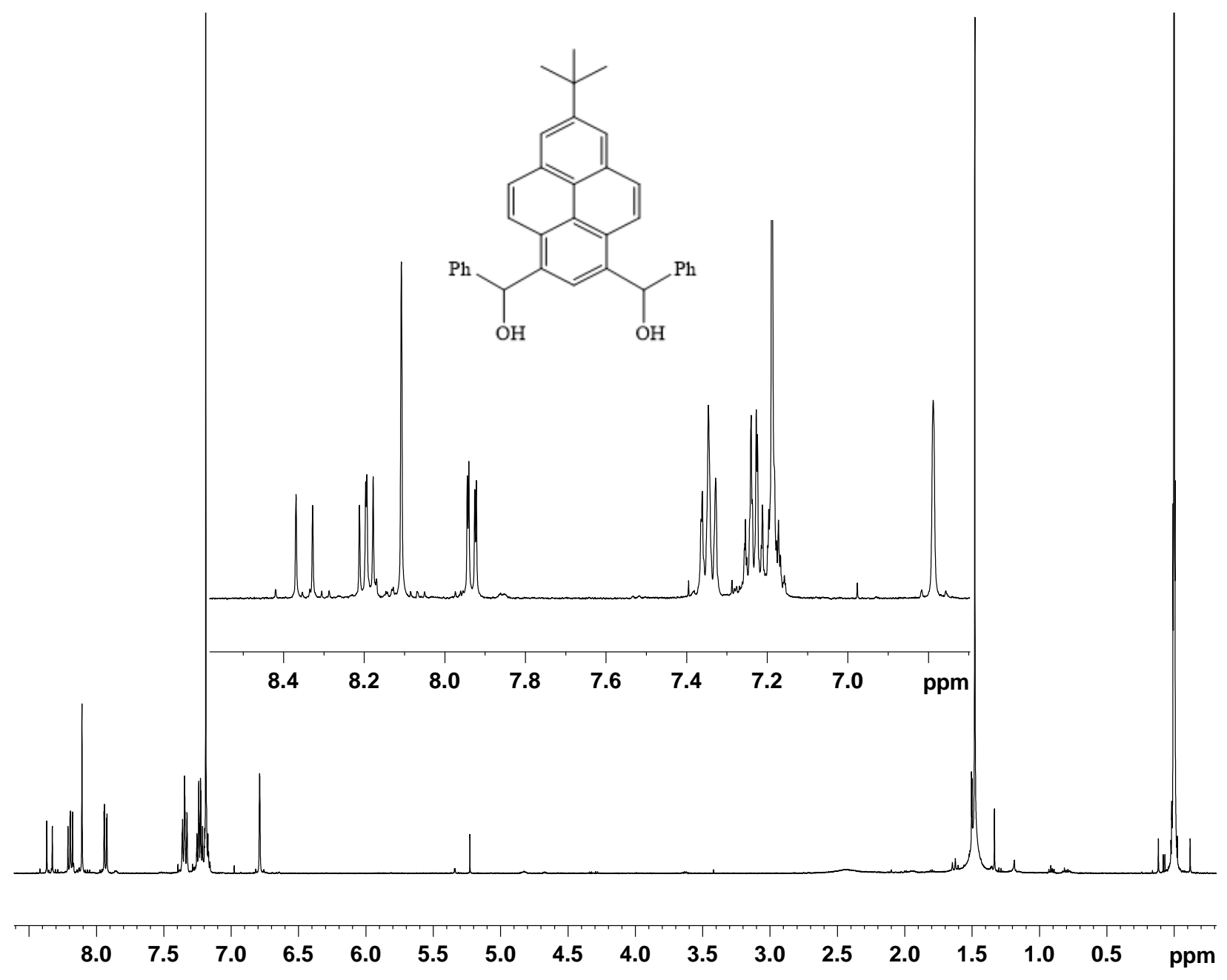

Figure A - 15: $500 \mathrm{MHz}{ }^{1} \mathrm{H}$ NMR Spectrum of Pyrene Dicarbinol 84 in $\mathrm{CDCl}_{3}$ 


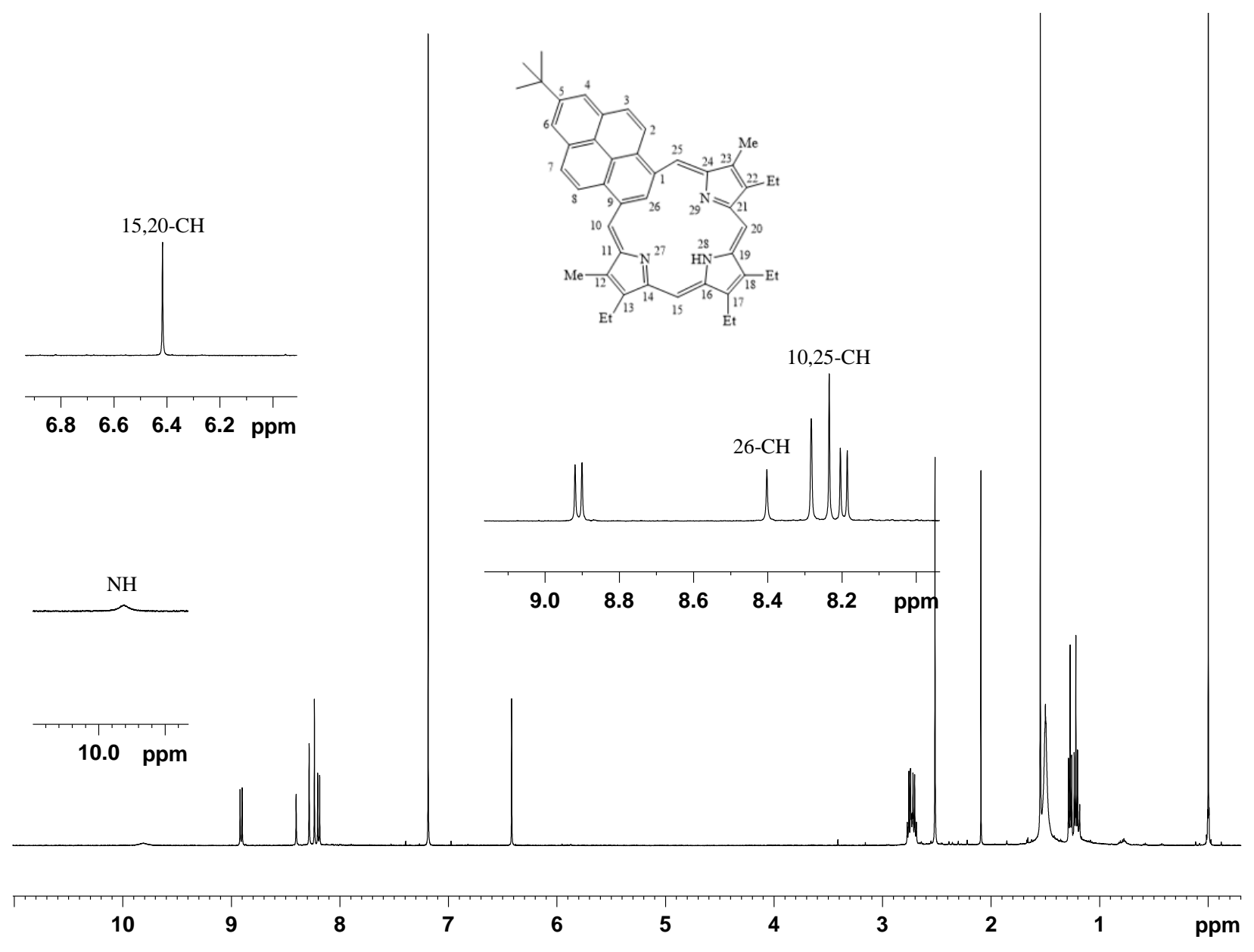

Figure A - 16: $500 \mathrm{MHz}{ }^{1} \mathrm{H}$ NMR Spectrum of Pyreniporphyrin 68 in $\mathrm{CDCl}_{3}$ 


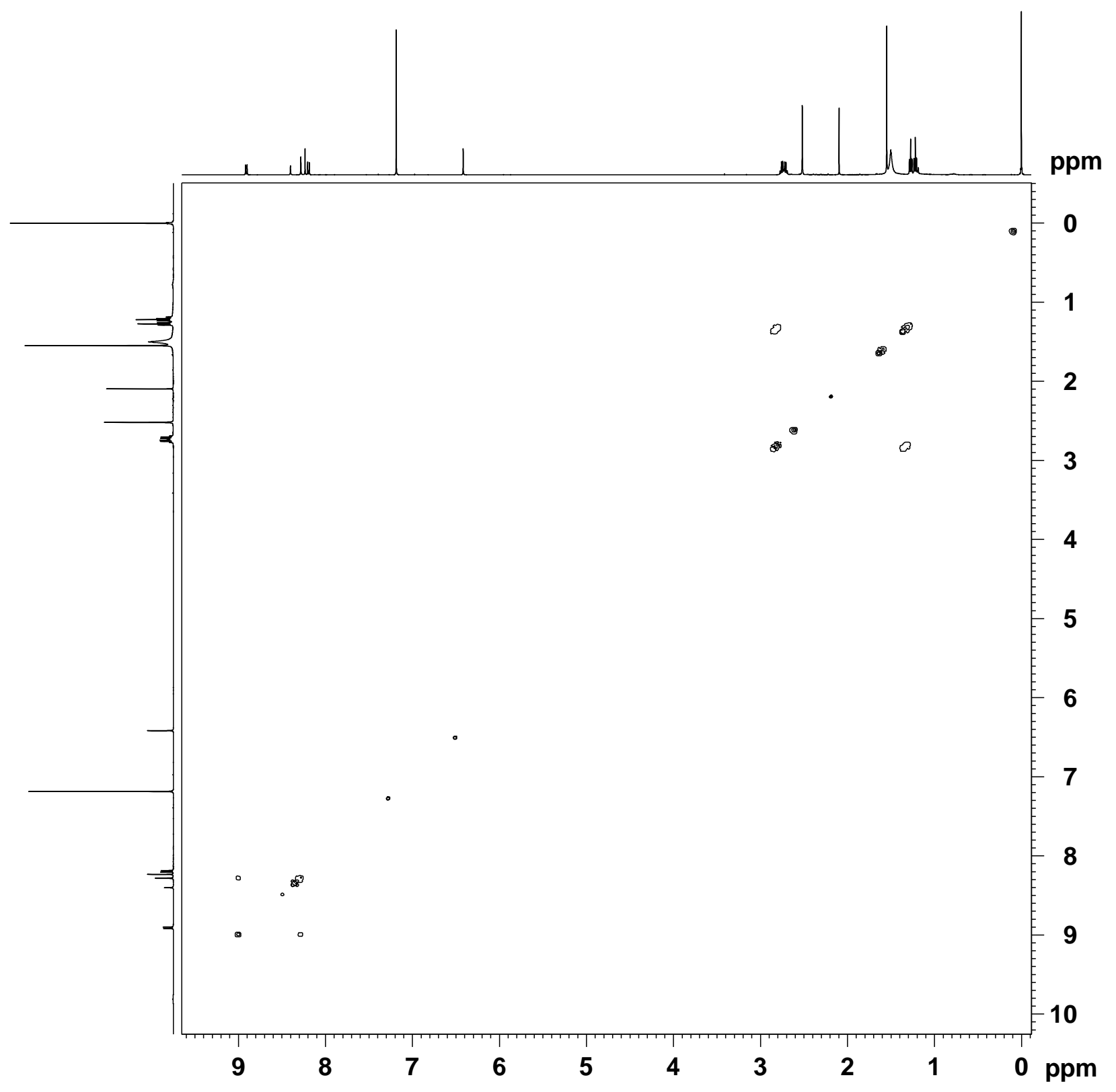

Figure A - 17: $500 \mathrm{MHz}{ }^{1} \mathrm{H}-{ }^{1} \mathrm{H}$ COSY NMR Spectrum of Pyreniporphyrin 68 in $\mathrm{CDCl}_{3}$ 


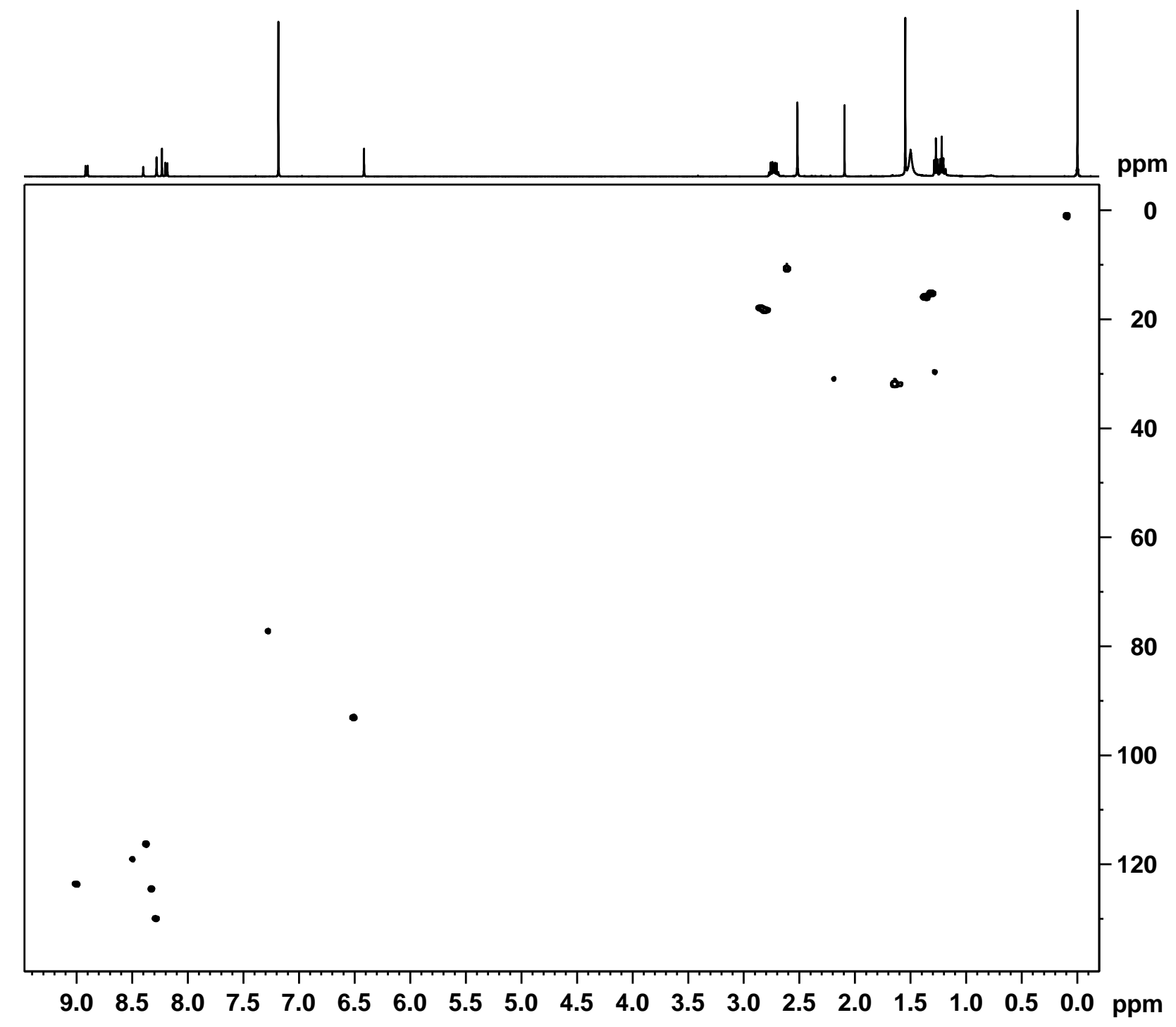

Figure A - 18: 500 MHz HSQC NMR Spectrum of Pyreniporphyrin 68 in $\mathrm{CDCl}_{3}$ 


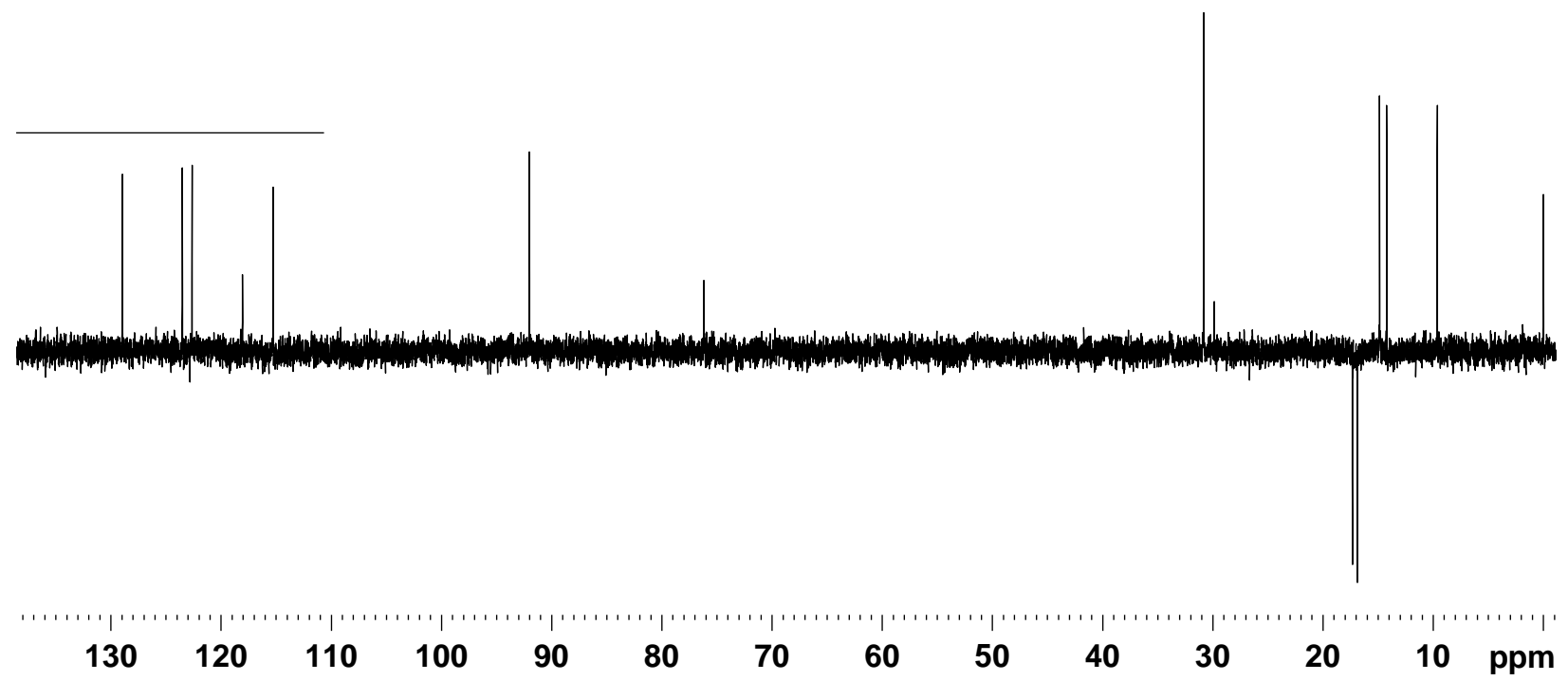

Figure A - 19: DEPT-135 NMR Spectrum of Pyreniporphyrin 68 in $\mathrm{CDCl}_{3}$

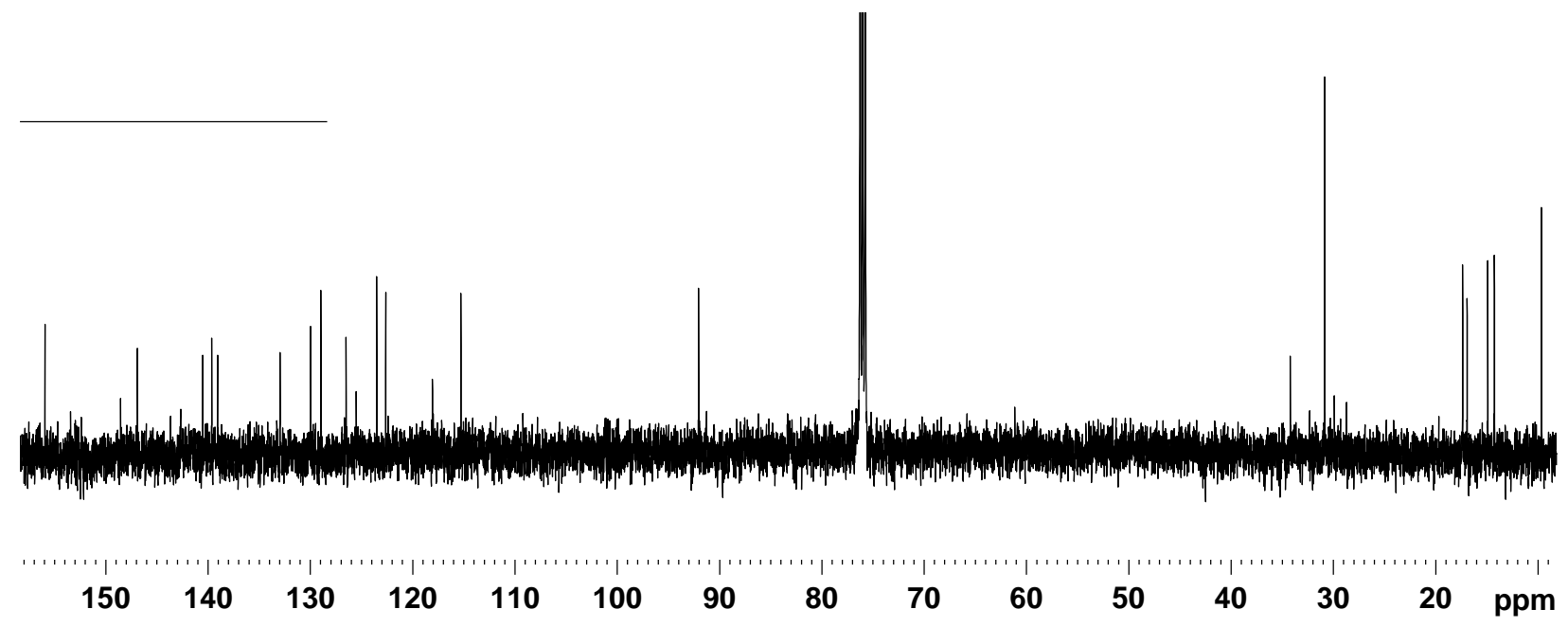

Figure A - 20: $125 \mathrm{MHz}{ }^{13} \mathrm{C}$ NMR Spectrum of Pyreniporphyrin 68 in $\mathrm{CDCl}_{3}$ 

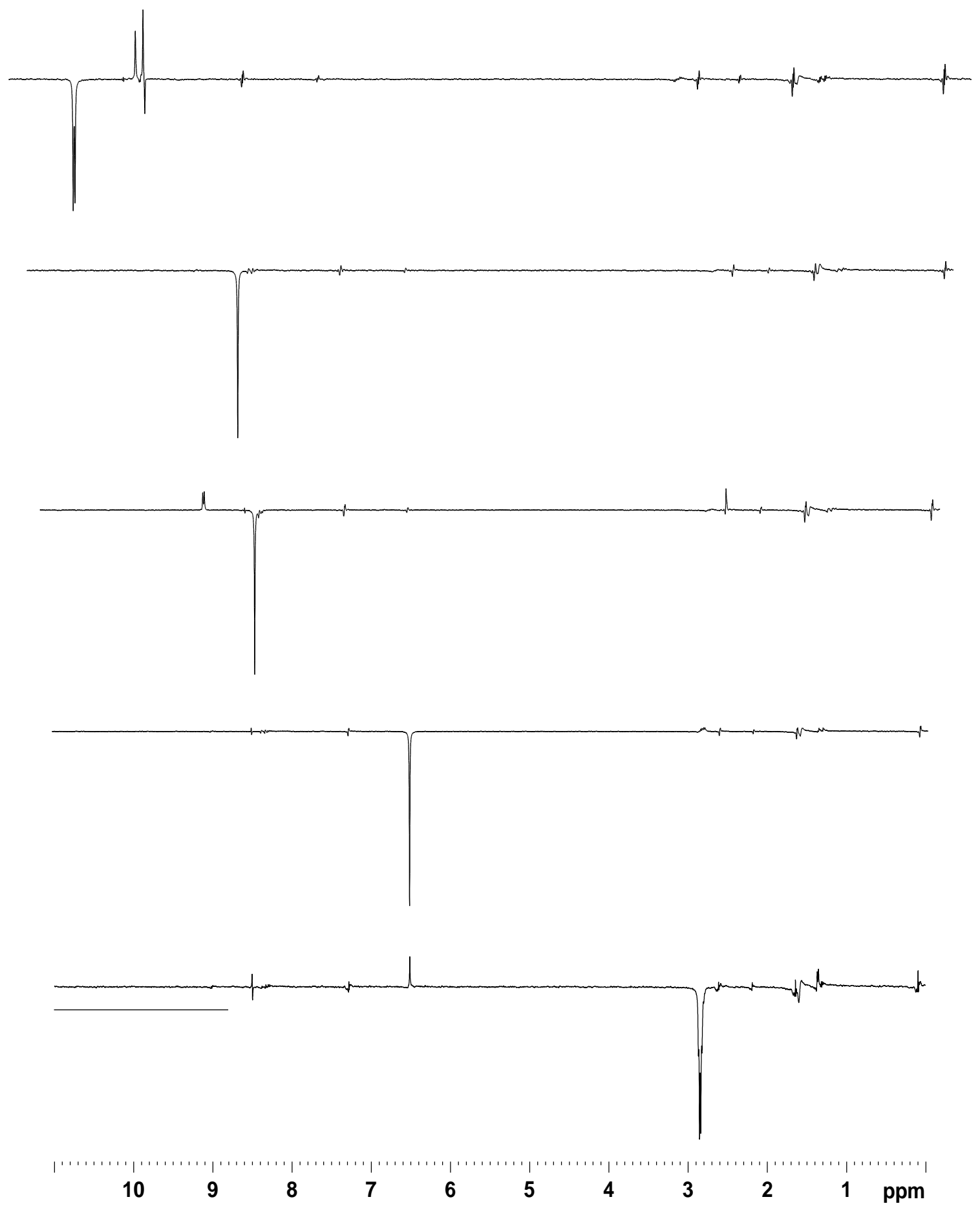

Figure A - 21: Selected nOe Difference NMR Spectra of Pyreniporphyrin 68 in $\mathrm{CDCl}_{3}$ 


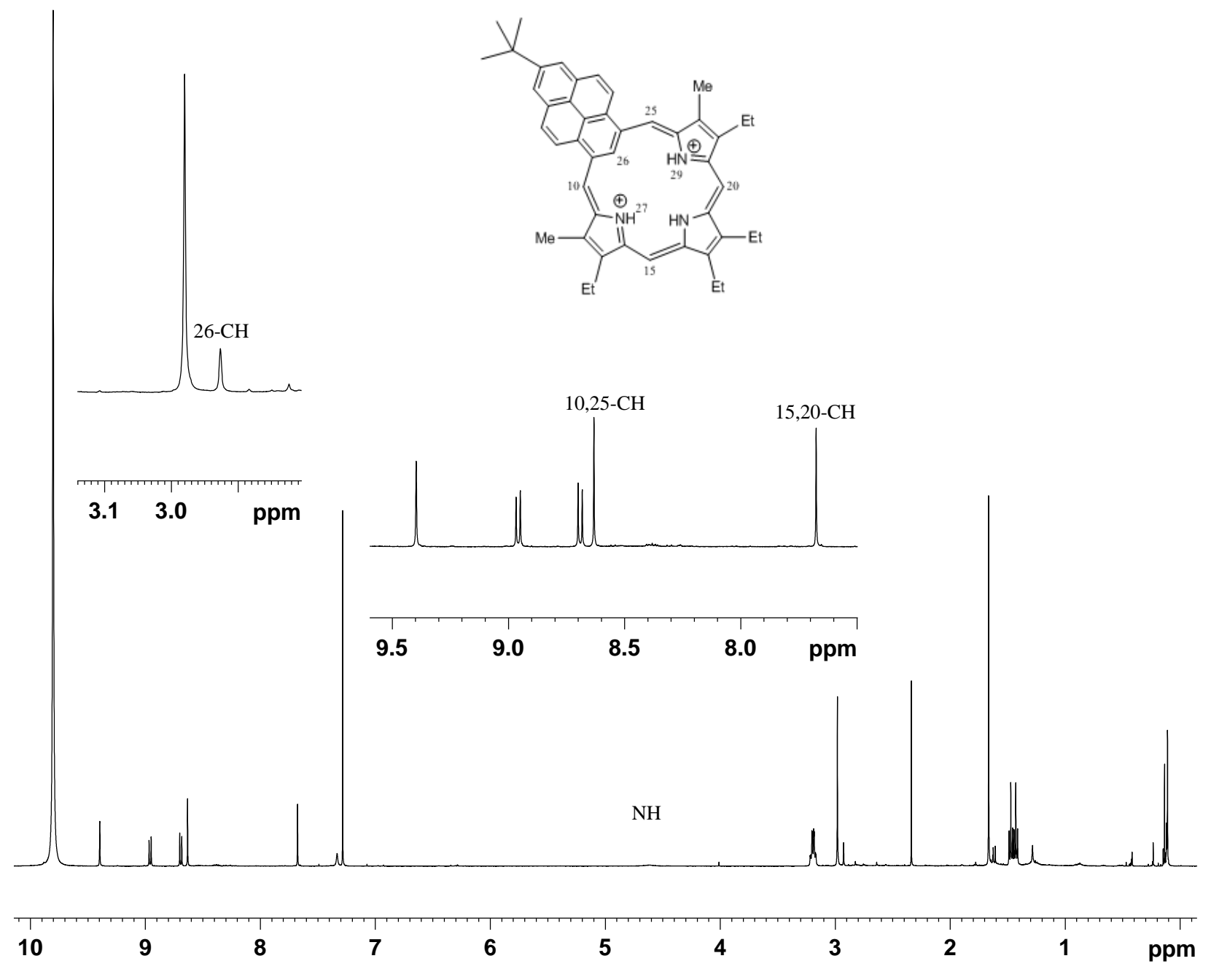

Figure A - 22: $500 \mathrm{MHz}{ }^{1} \mathrm{H}$ NMR Spectrum of Pyreniporphyrin Dication $68 \mathrm{H}_{2}{ }^{2+}$ in $\mathrm{TFA}-\mathrm{CDCl}_{3}$ 


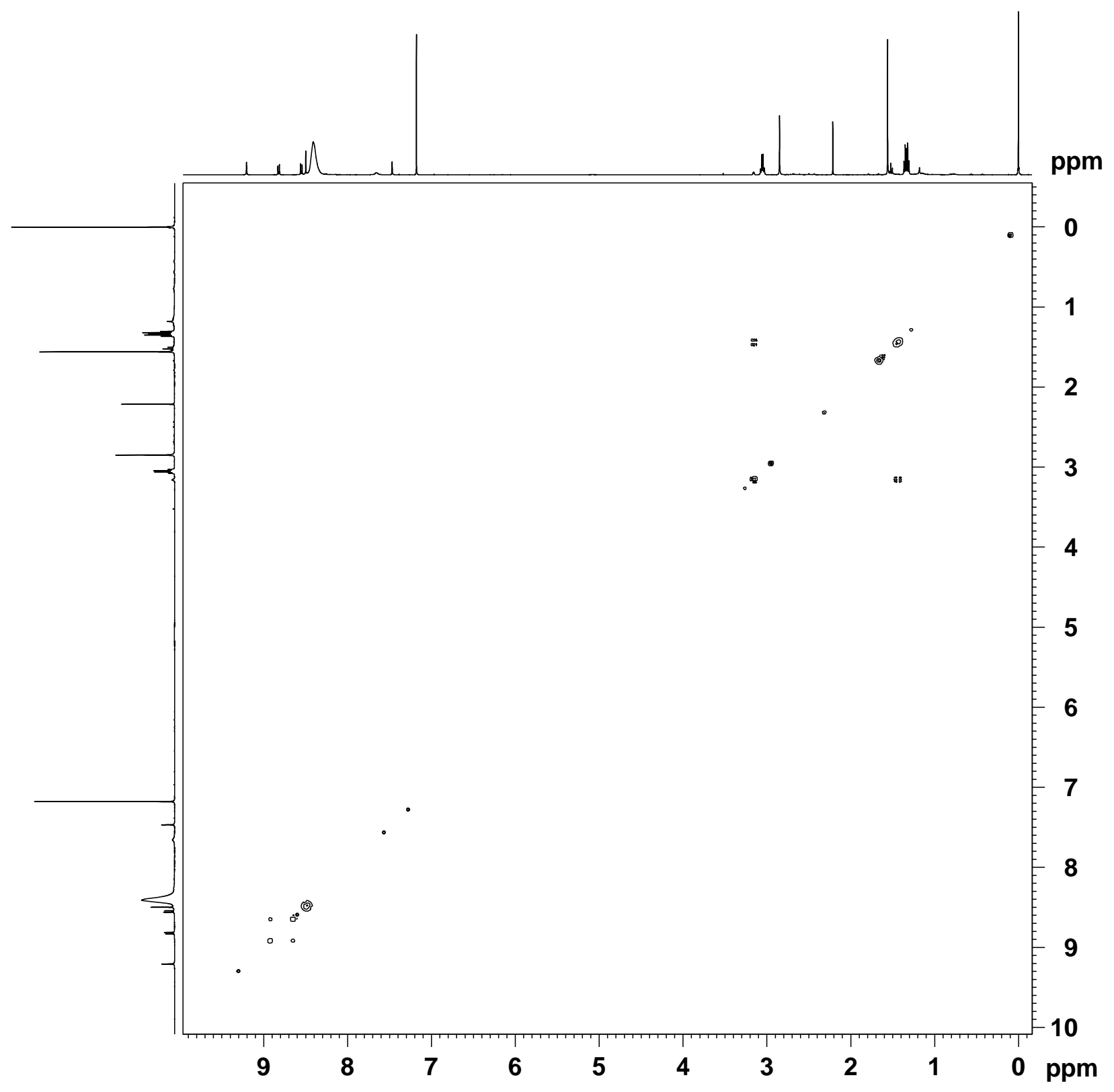

Figure A - 23: $500 \mathrm{MHz}{ }^{1} \mathrm{H}-{ }^{1} \mathrm{H}$ COSY NMR Spectrum of Pyreniporphyrin Dication $68 \mathrm{H}_{2}{ }^{2+}$ in TFA-CDCl ${ }_{3}$ 


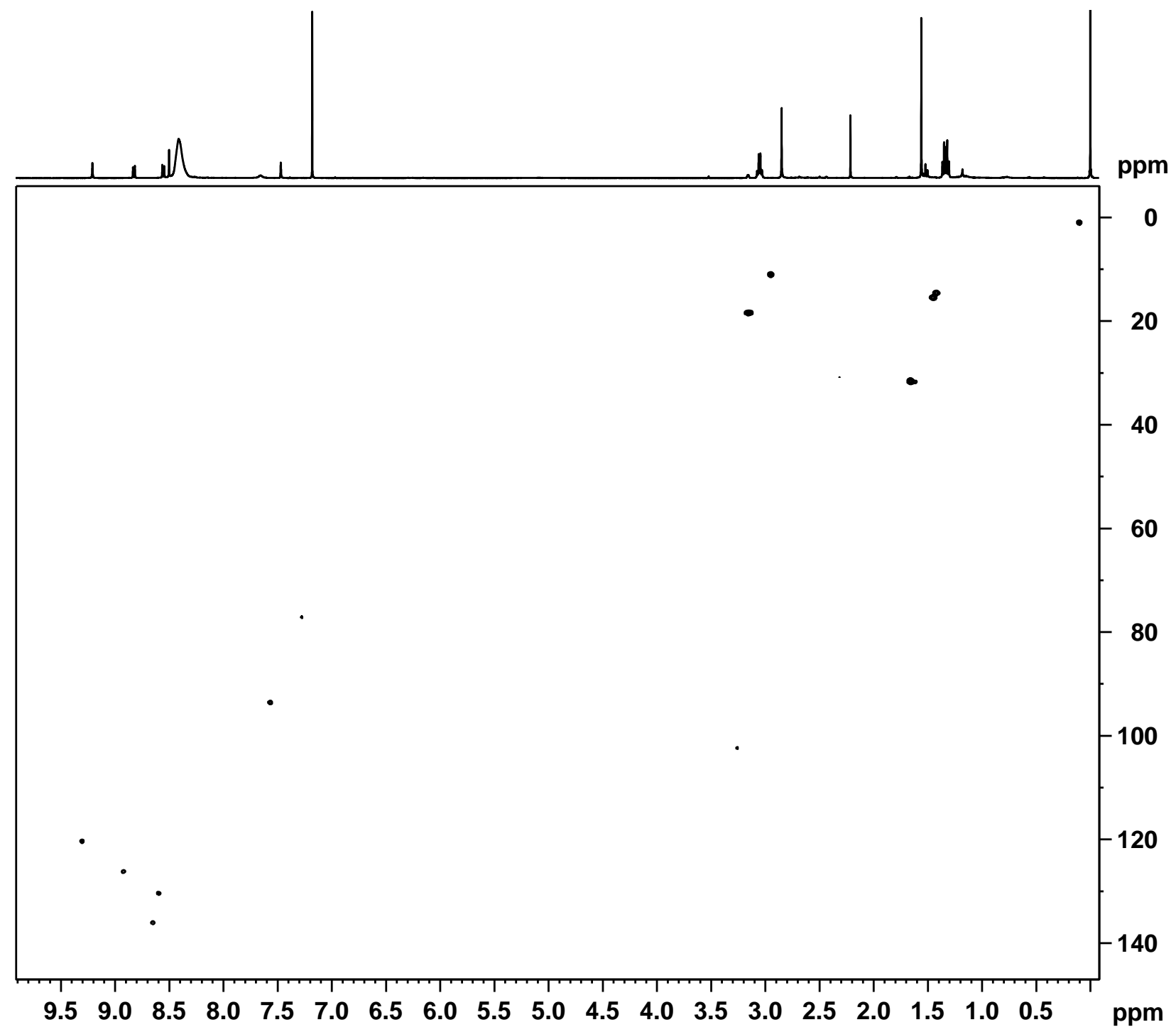

Figure A - 24: 500 MHz HSQC NMR Spectrum of Pyreniporphyrin Dication $68 \mathrm{H}_{2}{ }^{2+}$ in TFA$\mathrm{CDCl}_{3}$ 


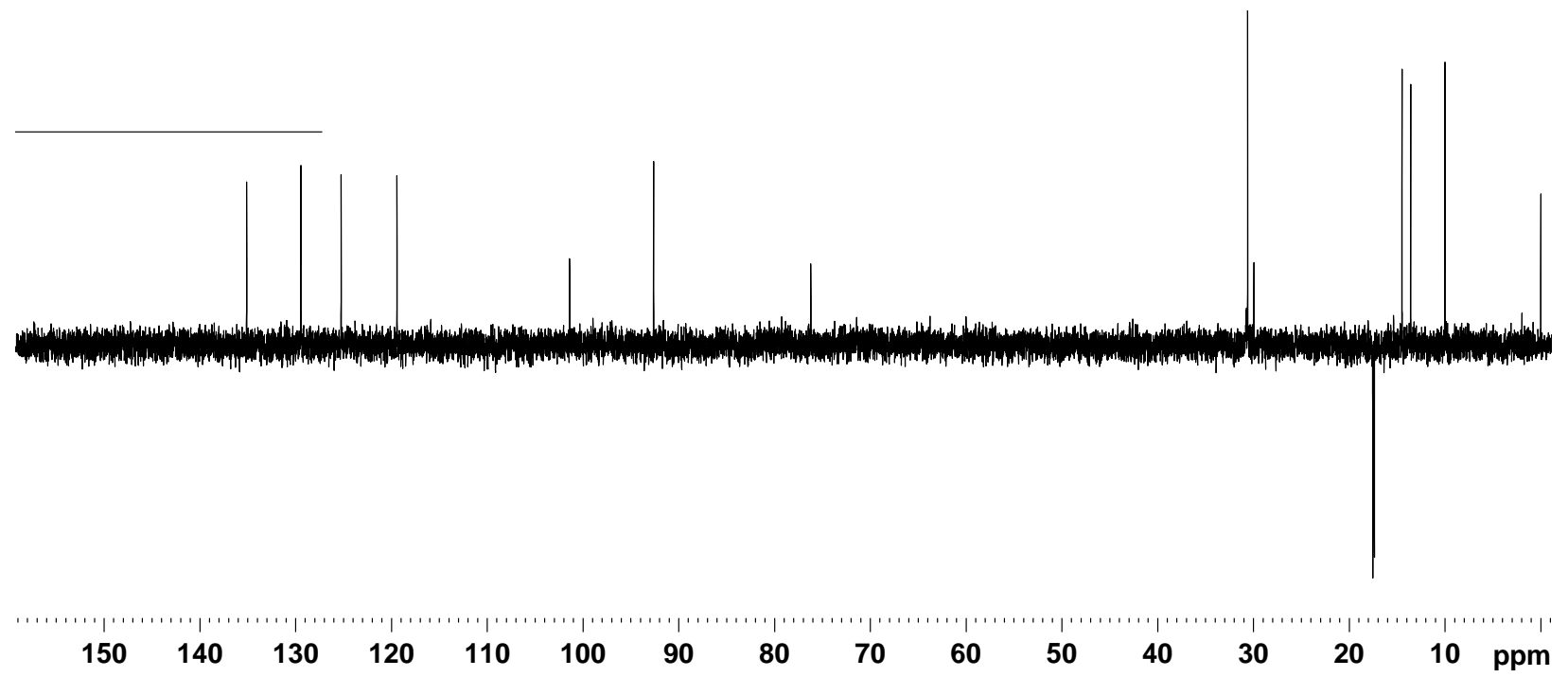

Figure A - 25: DEPT-135 NMR Spectrum of Pyreniporphyrin Dication $68 \mathrm{H}_{2}{ }^{2+}$ in TFA-CDCl 3

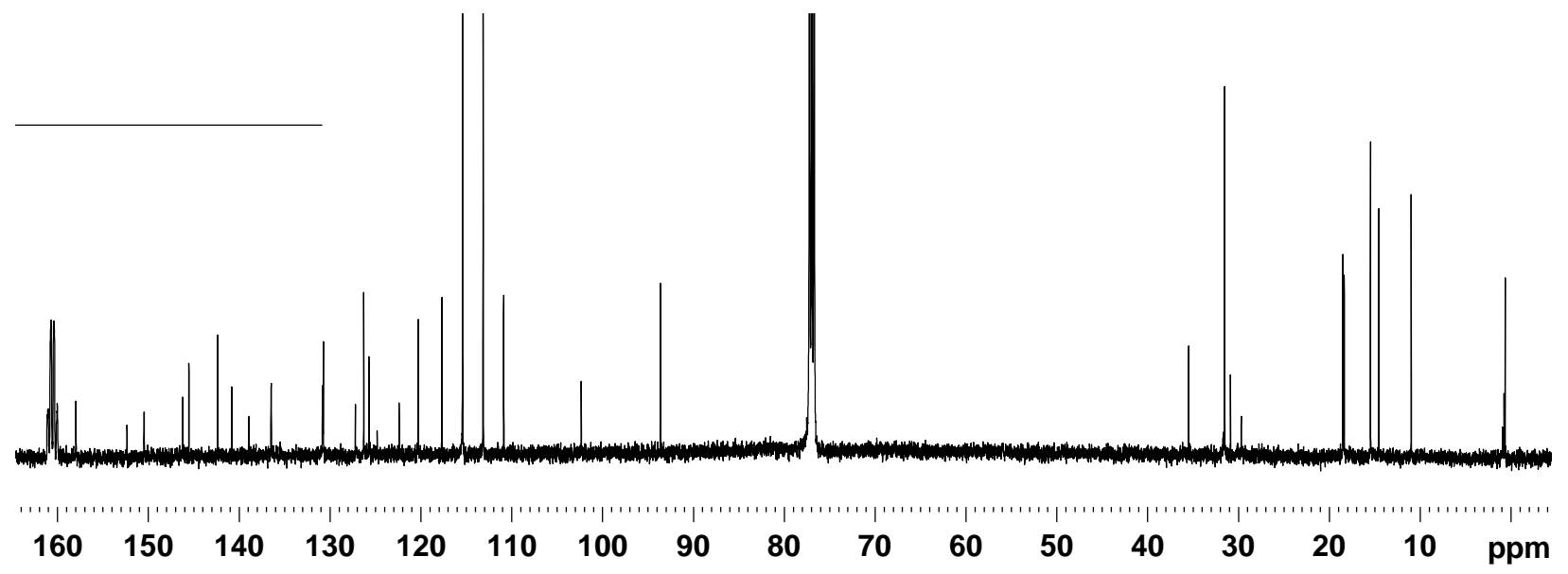

Figure A - 26: $125 \mathrm{MHz}{ }^{13} \mathrm{C}$ NMR Spectrum of Pyreniporphyrin Dication $68 \mathrm{H}_{2}^{2+}$ in TFA$\mathrm{CDCl}_{3}$ 

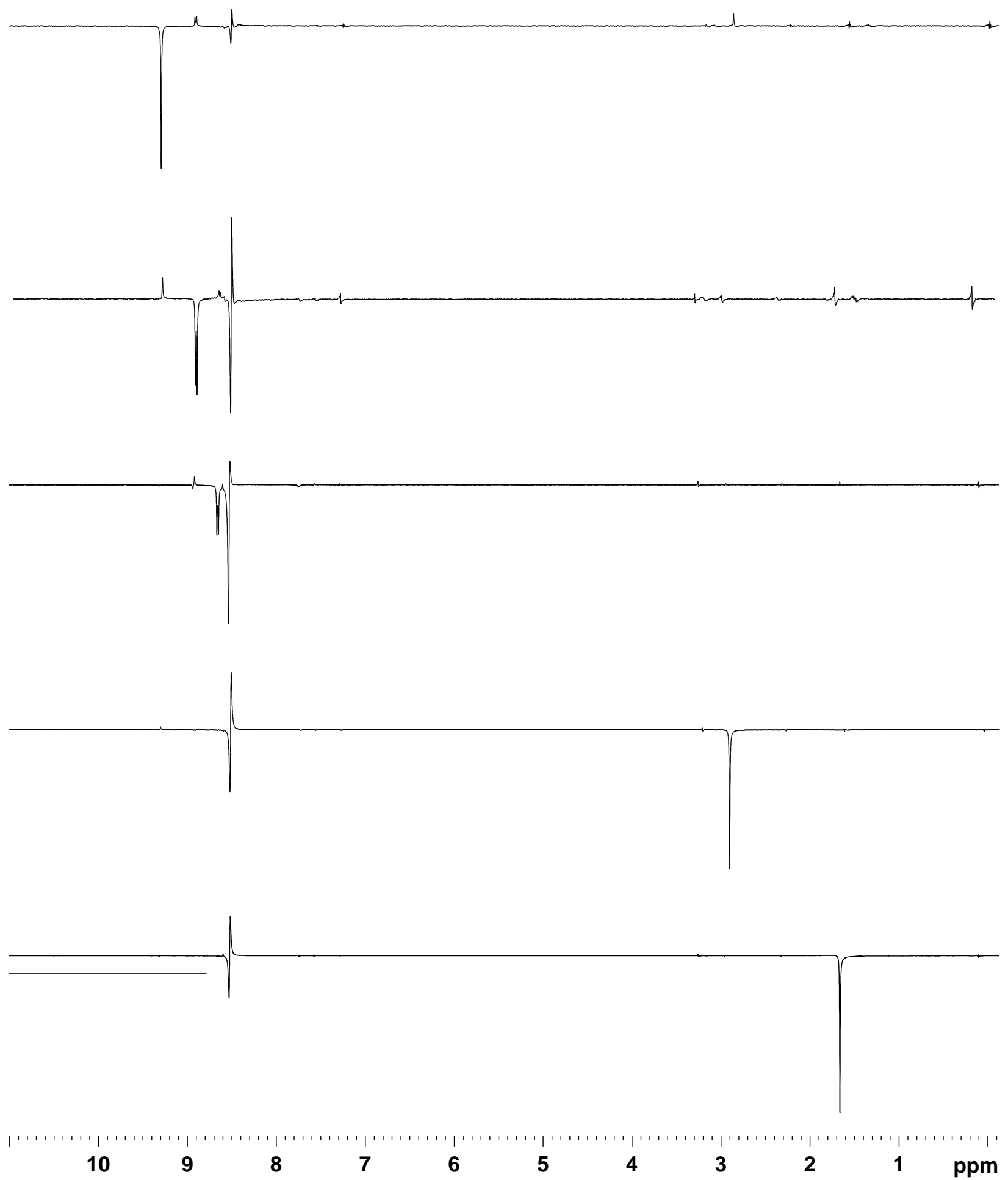

Figure A - 27: Selected nOe Difference NMR Spectra of Pyreniporphyrin Dication $68 \mathrm{H}_{2}{ }^{2+}$ in

TFA- $\mathrm{CDCl}_{3}$ 

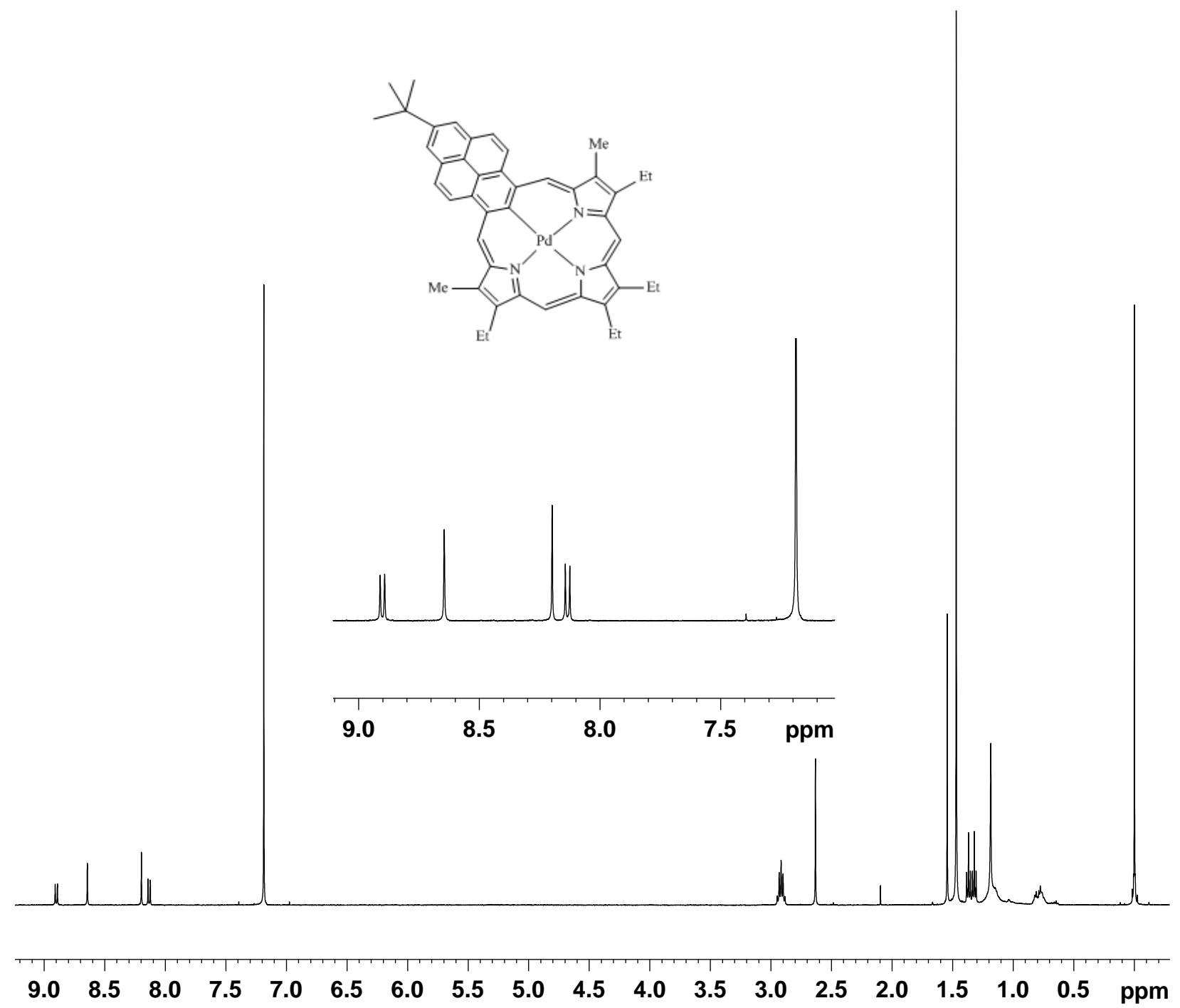

Figure A - 28: $500 \mathrm{MHz}{ }^{1} \mathrm{H}$ NMR Spectrum of Palladium Complex 85 in $\mathrm{CDCl}_{3}$ 


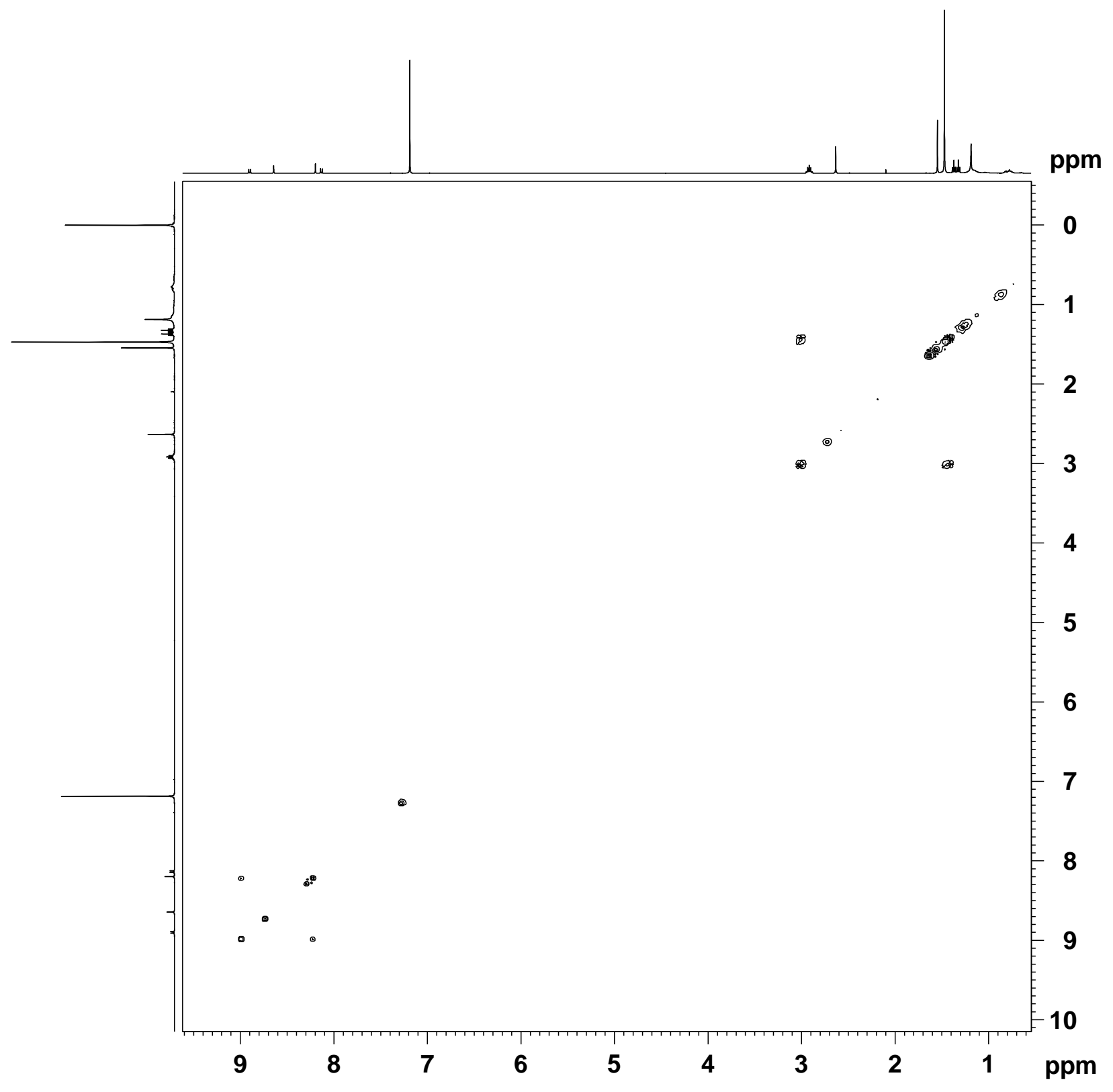

Figure A - 29: $500 \mathrm{MHz}{ }^{1} \mathrm{H}-{ }^{1} \mathrm{H}$ COSY NMR Spectrum of Palladium Complex 85 in $\mathrm{CDCl}_{3}$ 


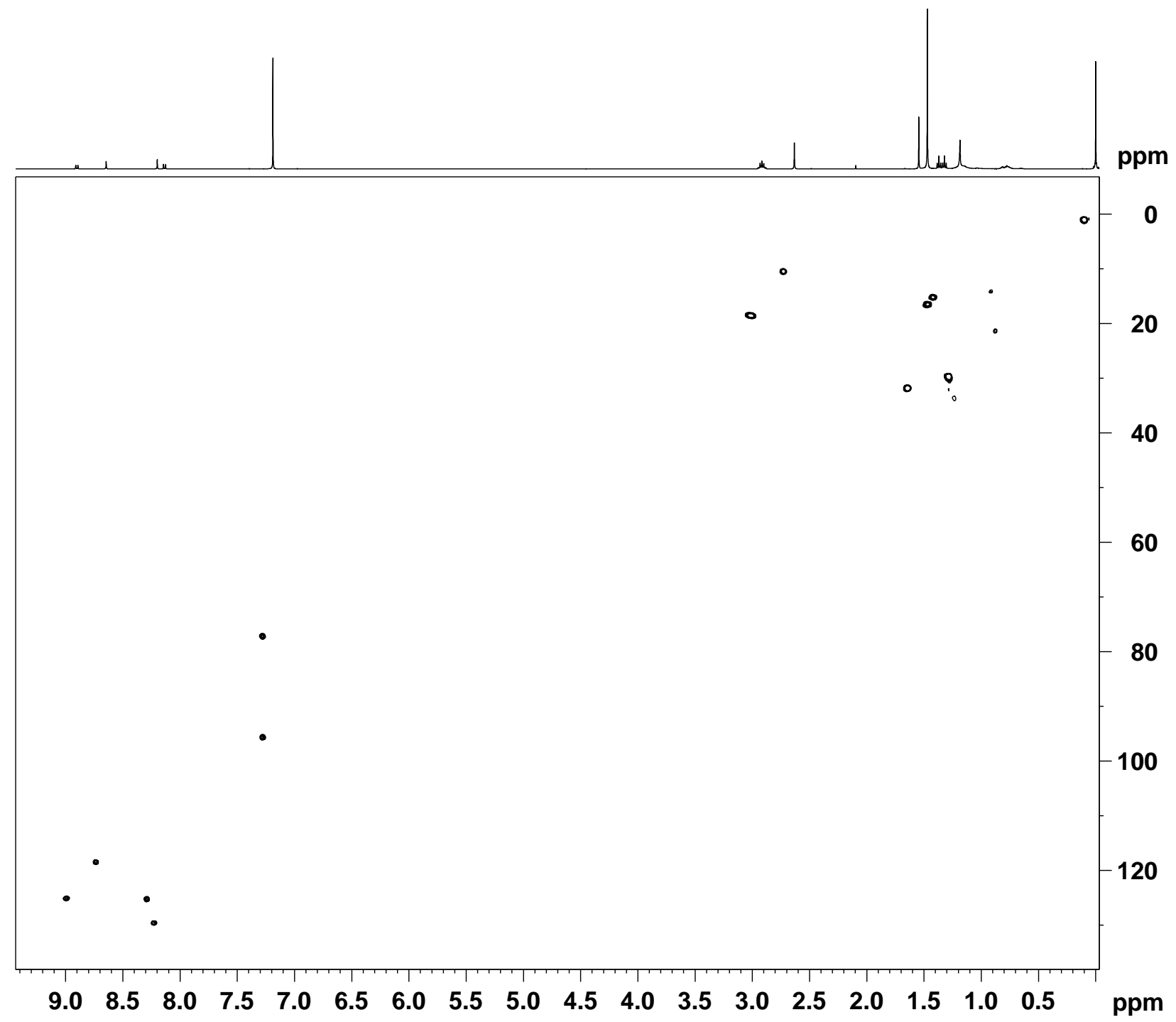

Figure A - 30: 500 MHz HSQC NMR Spectrum of Palladium Complex 85 in $\mathrm{CDCl}_{3}$ 


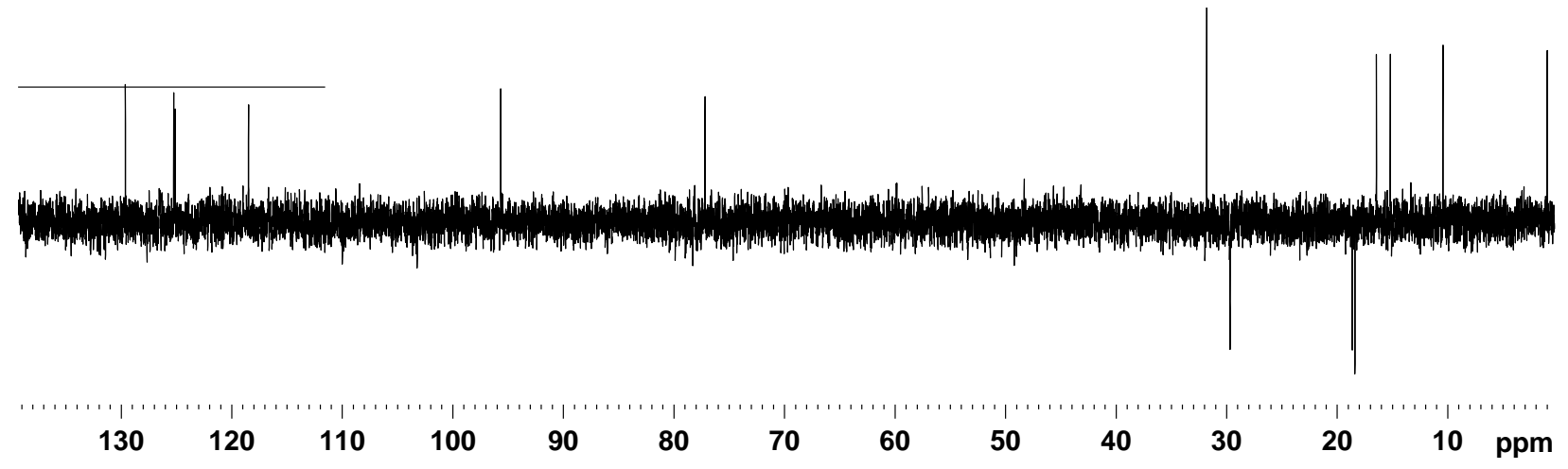

Figure A - 31: DEPT-135 NMR Spectrum of Palladium Complex 85 in $\mathrm{CDCl}_{3}$

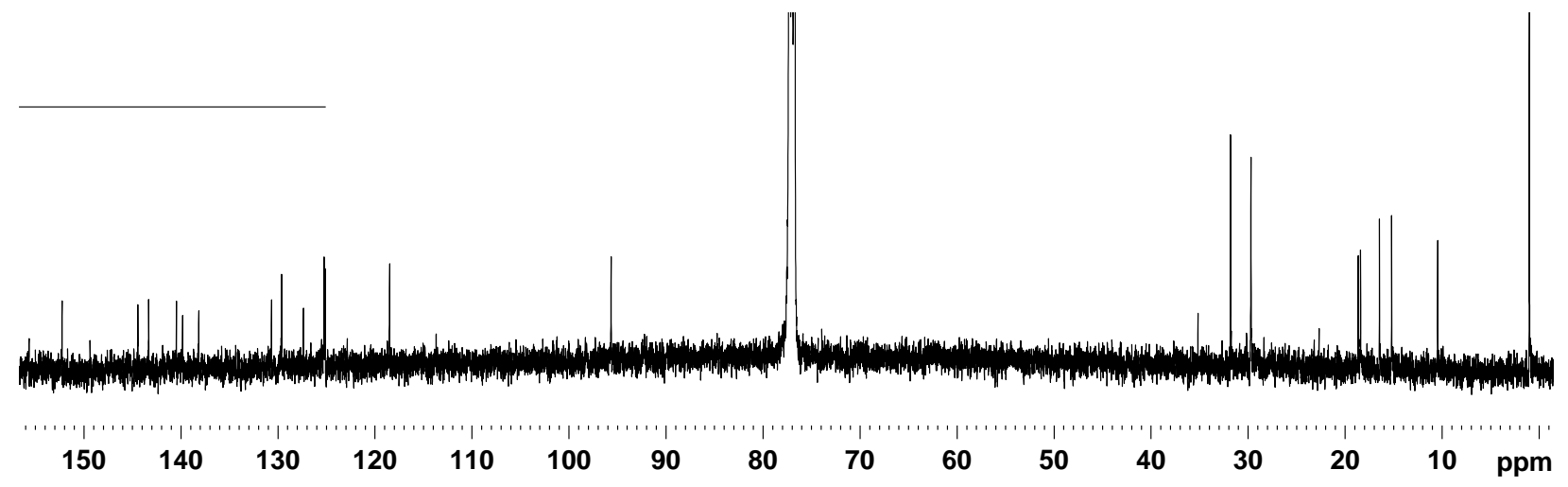

Figure A - 32: $125 \mathrm{MHz}{ }^{13} \mathrm{C}$ NMR Spectrum of Palladium Complex 85 in $\mathrm{CDCl}_{3}$ 

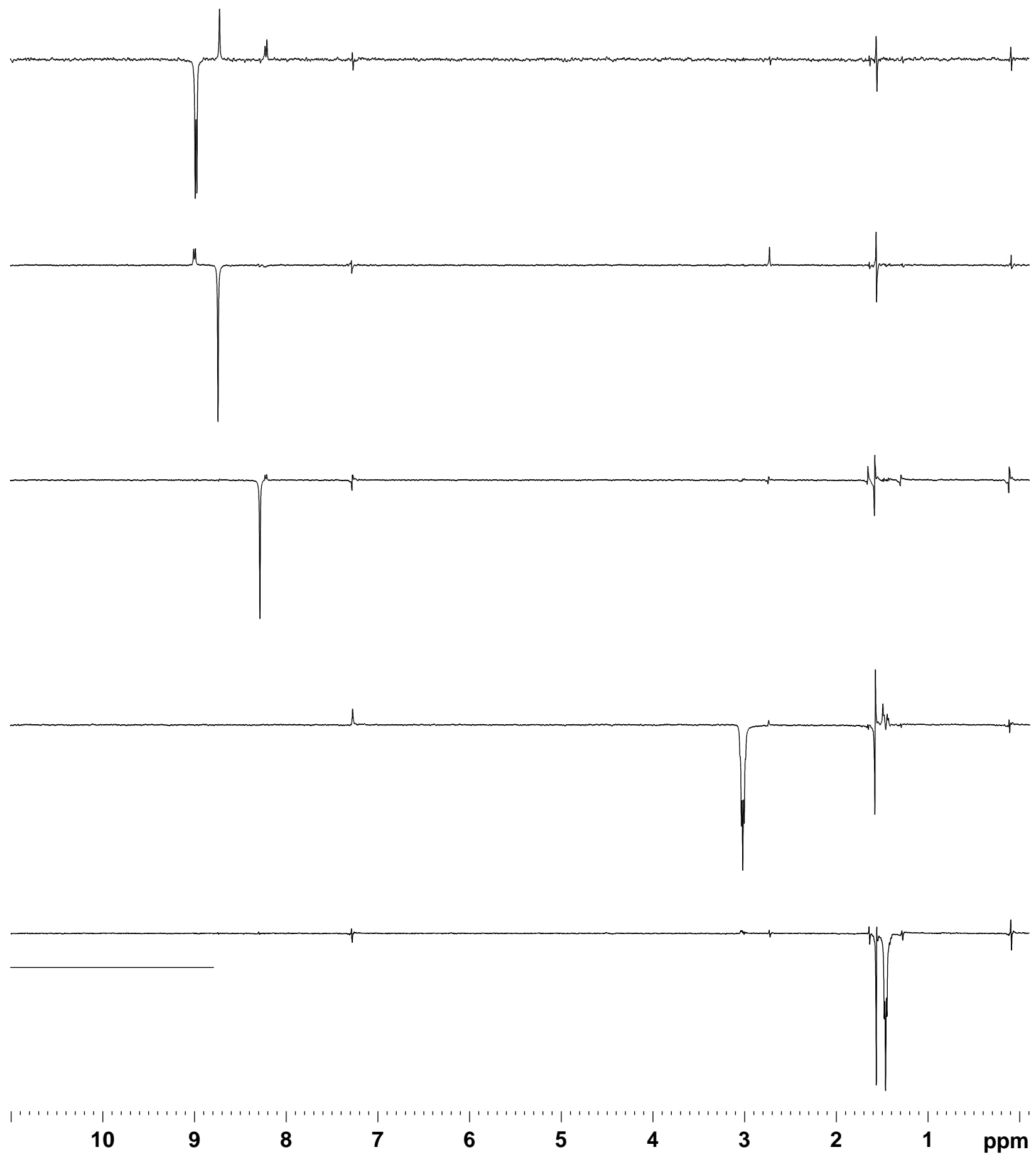

Figure A - 33: Selected nOe Difference NMR Spectra of Palladium Complex 85 in $\mathrm{CDCl}_{3}$ 


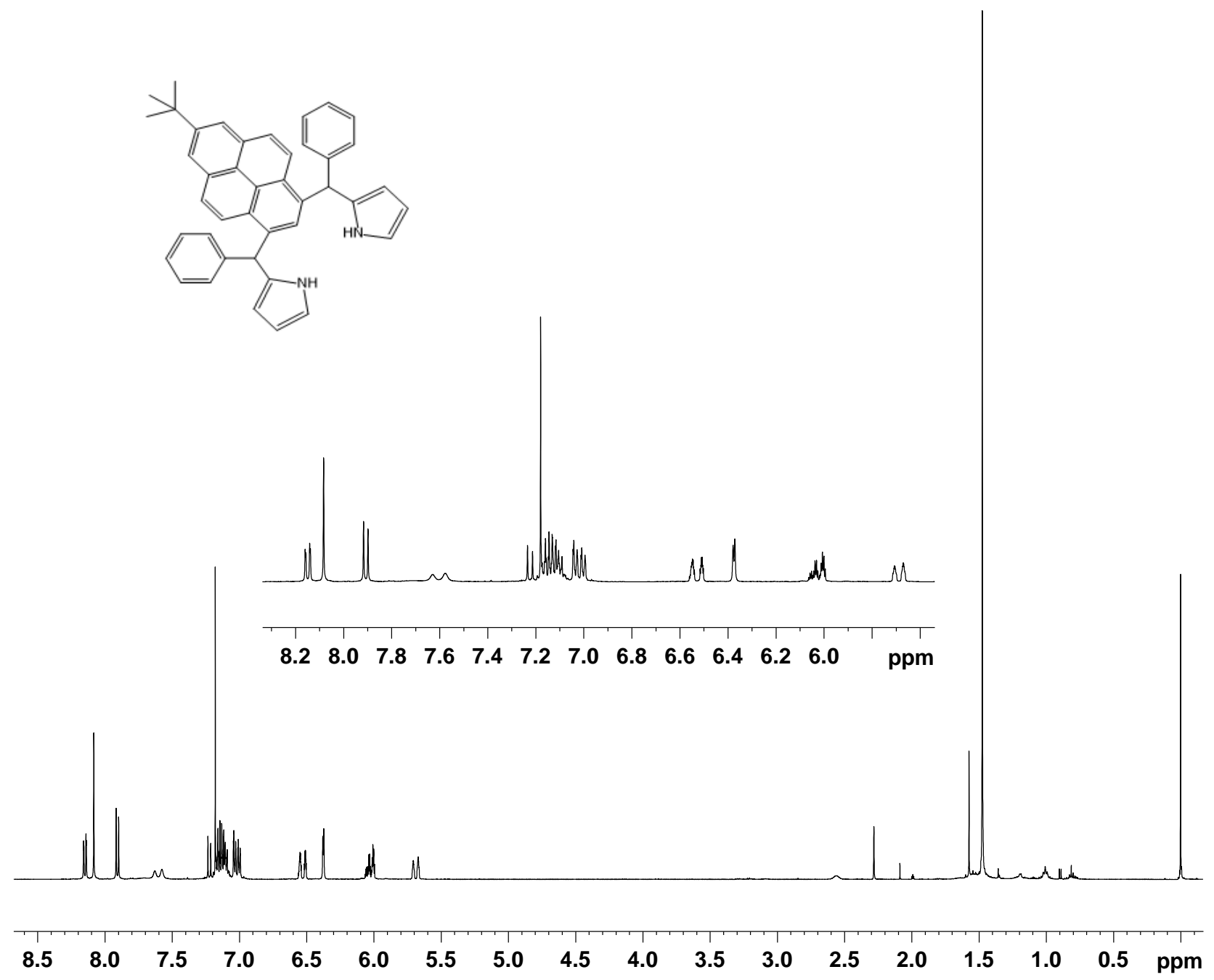

Figure A - 34: $500 \mathrm{MHz}{ }^{1} \mathrm{H}$ NMR Spectrum of Diphenyl Pyrenitripyrrane 87 in $\mathrm{CDCl}_{3}$ 


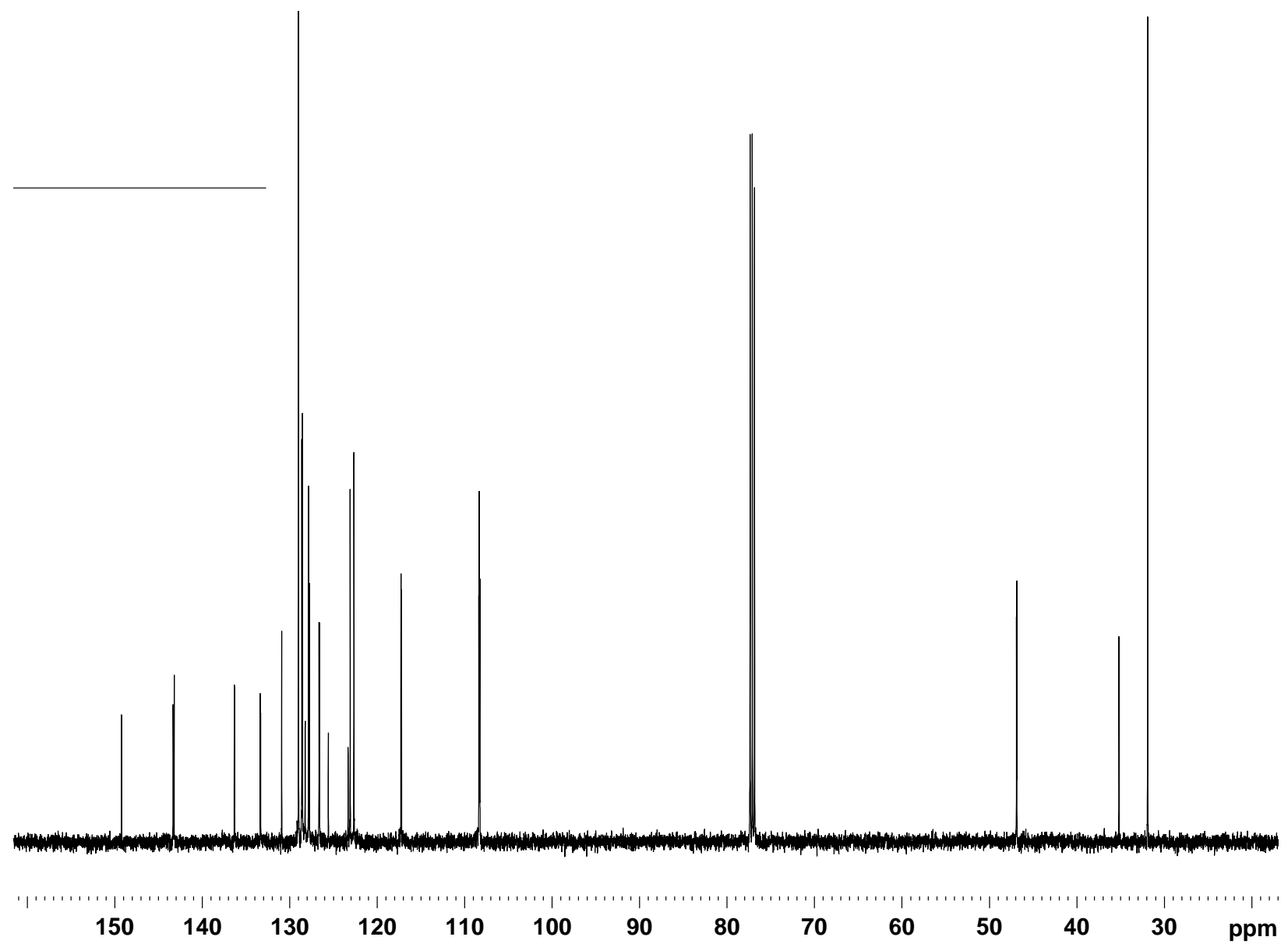

Figure A - 35: $125 \mathrm{MHz}{ }^{13} \mathrm{C}$ NMR Spectrum of Diphenyl Pyrenitripyrrane 87 in $\mathrm{CDCl}_{3}$ 


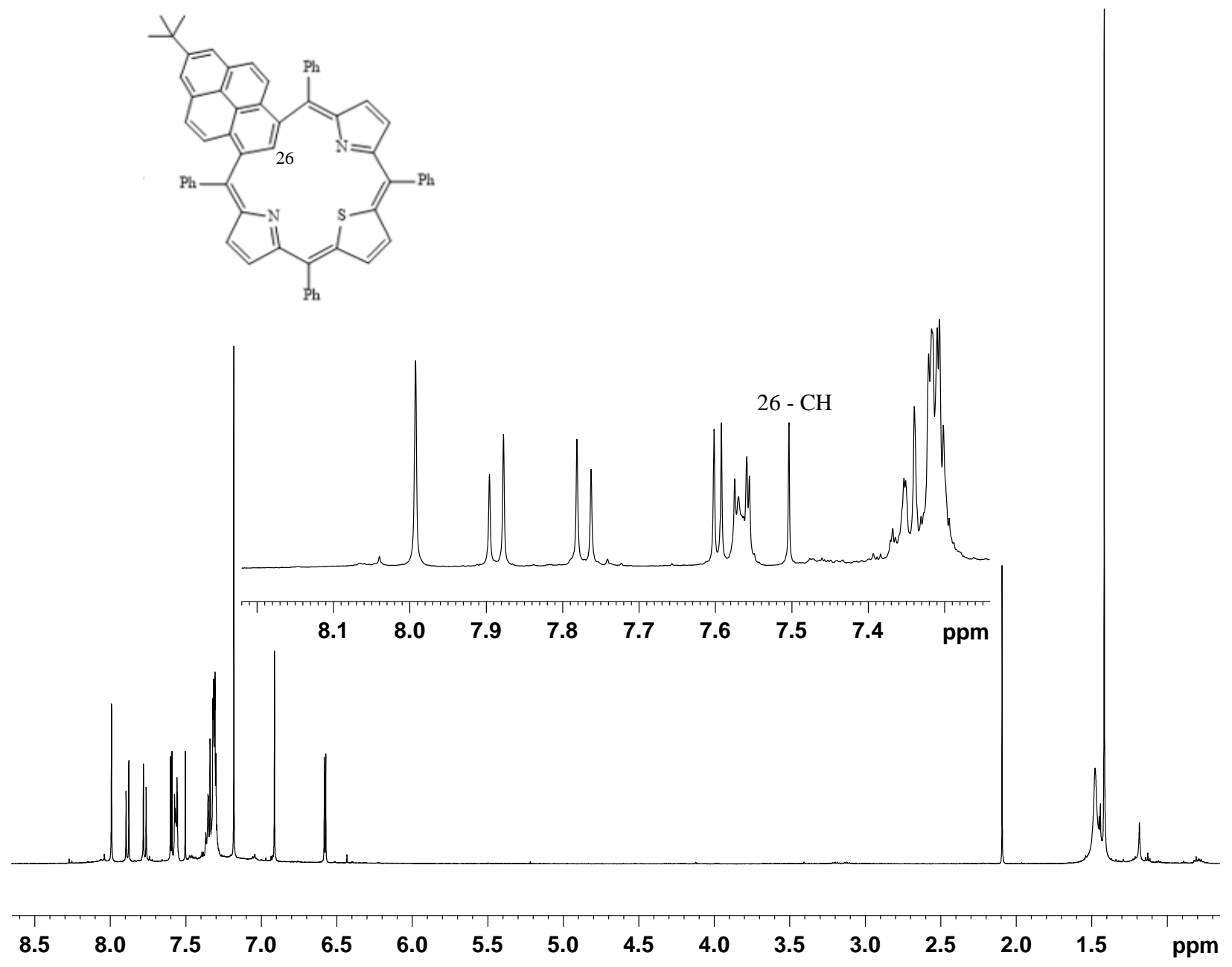

Figure A - 36: $500 \mathrm{MHz}{ }^{1} \mathrm{H}$ NMR Spectrum of Thiapyreniporphyrin 88 in $\mathrm{CDCl}_{3}$ 


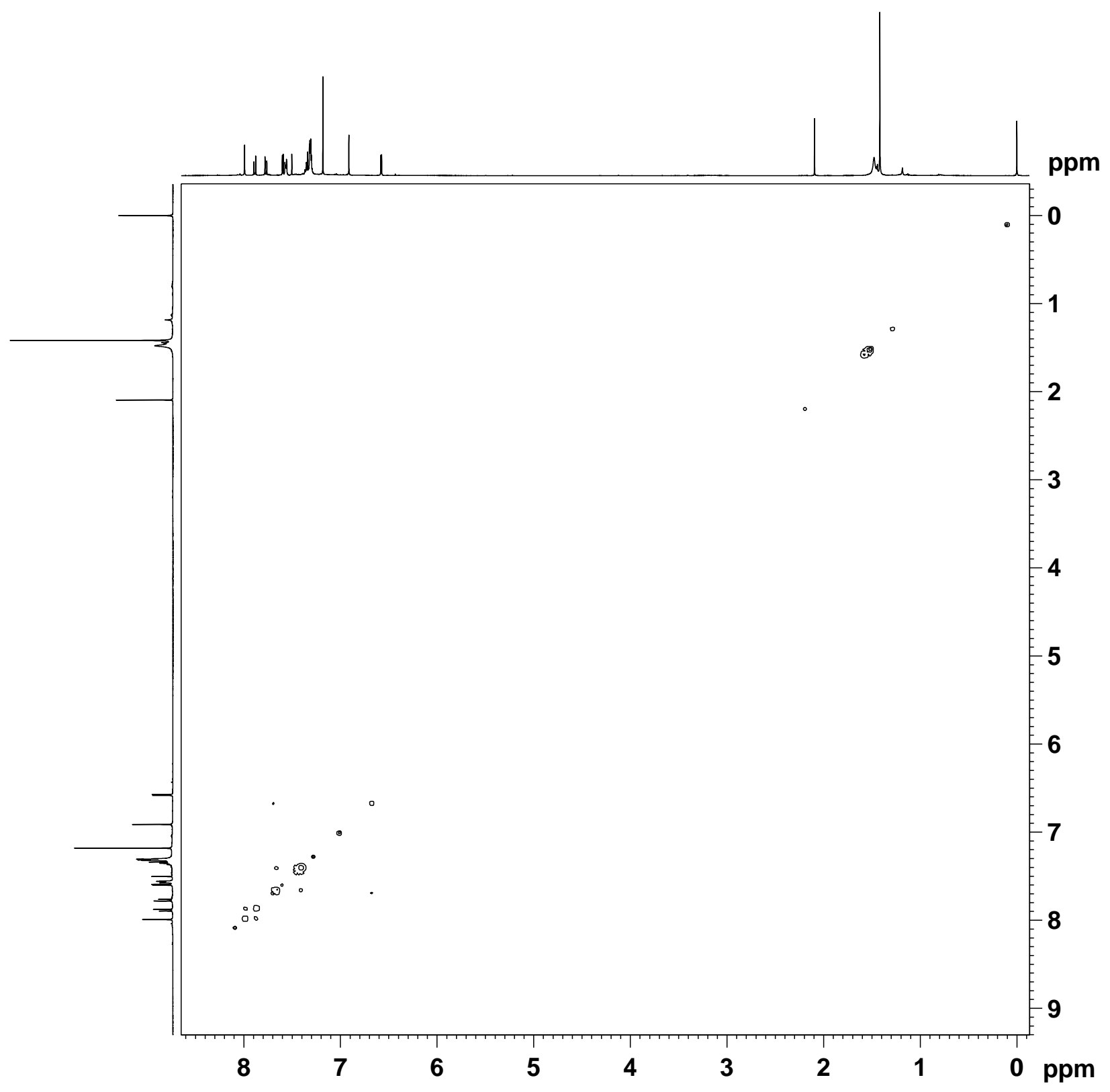

Figure A - 37: $500 \mathrm{MHz}{ }^{1} \mathrm{H}-{ }^{1} \mathrm{H}$ COSY NMR Spectrum of Thiapyreniporphyrin 88 in $\mathrm{CDCl}_{3}$ 


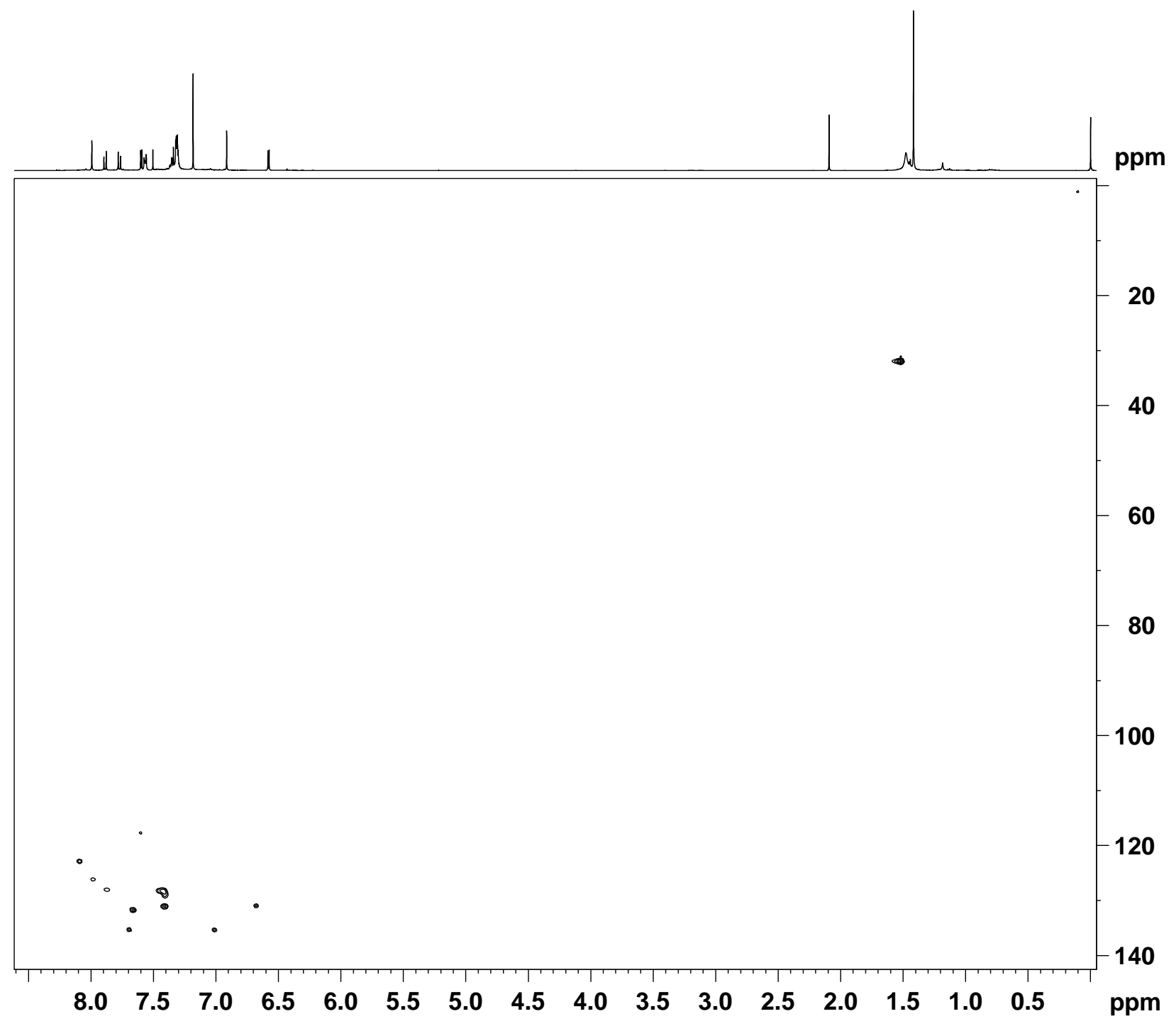

Figure A - 38: $500 \mathrm{MHz}$ HSQC NMR Spectrum of Thiapyreniporphyrin 88 in $\mathrm{CDCl}_{3}$ 


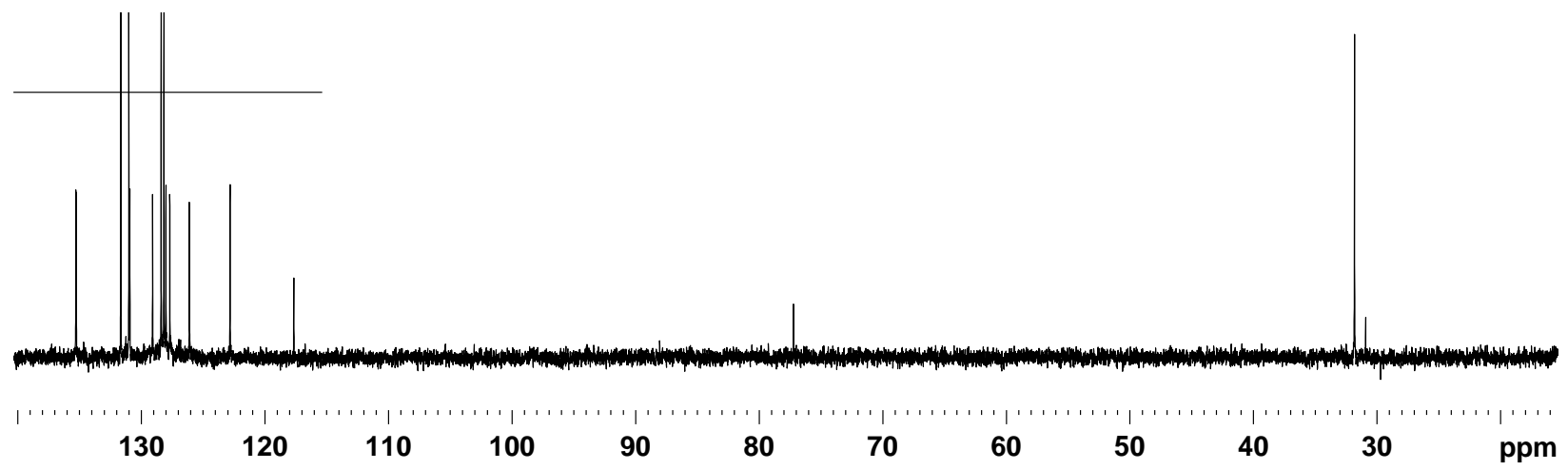

Figure A - 39: DEPT-135 NMR Spectrum of Thiapyreniporphyrin 88 in $\mathrm{CDCl}_{3}$

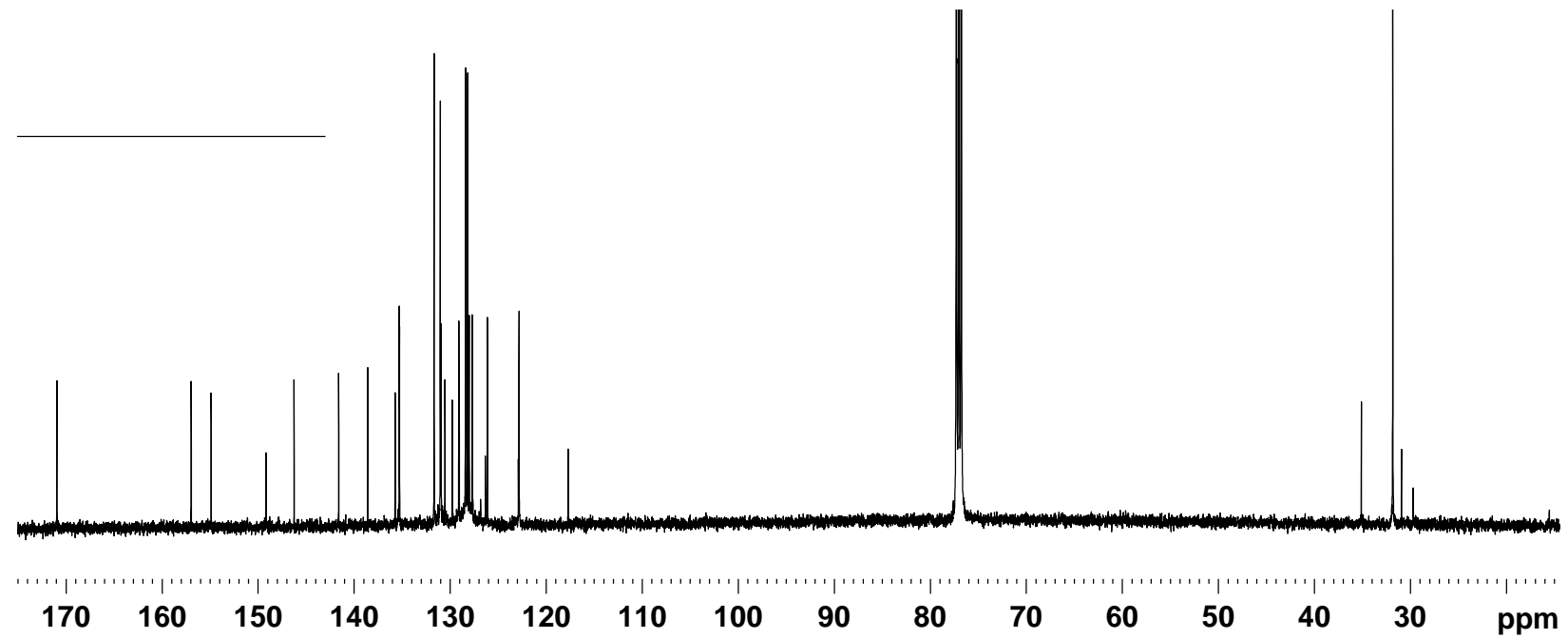

Figure A - 40: $125 \mathrm{MHz}{ }^{13} \mathrm{C}$ NMR Spectrum of Thiapyreniporphyrin 88 in $\mathrm{CDCl}_{3}$ 

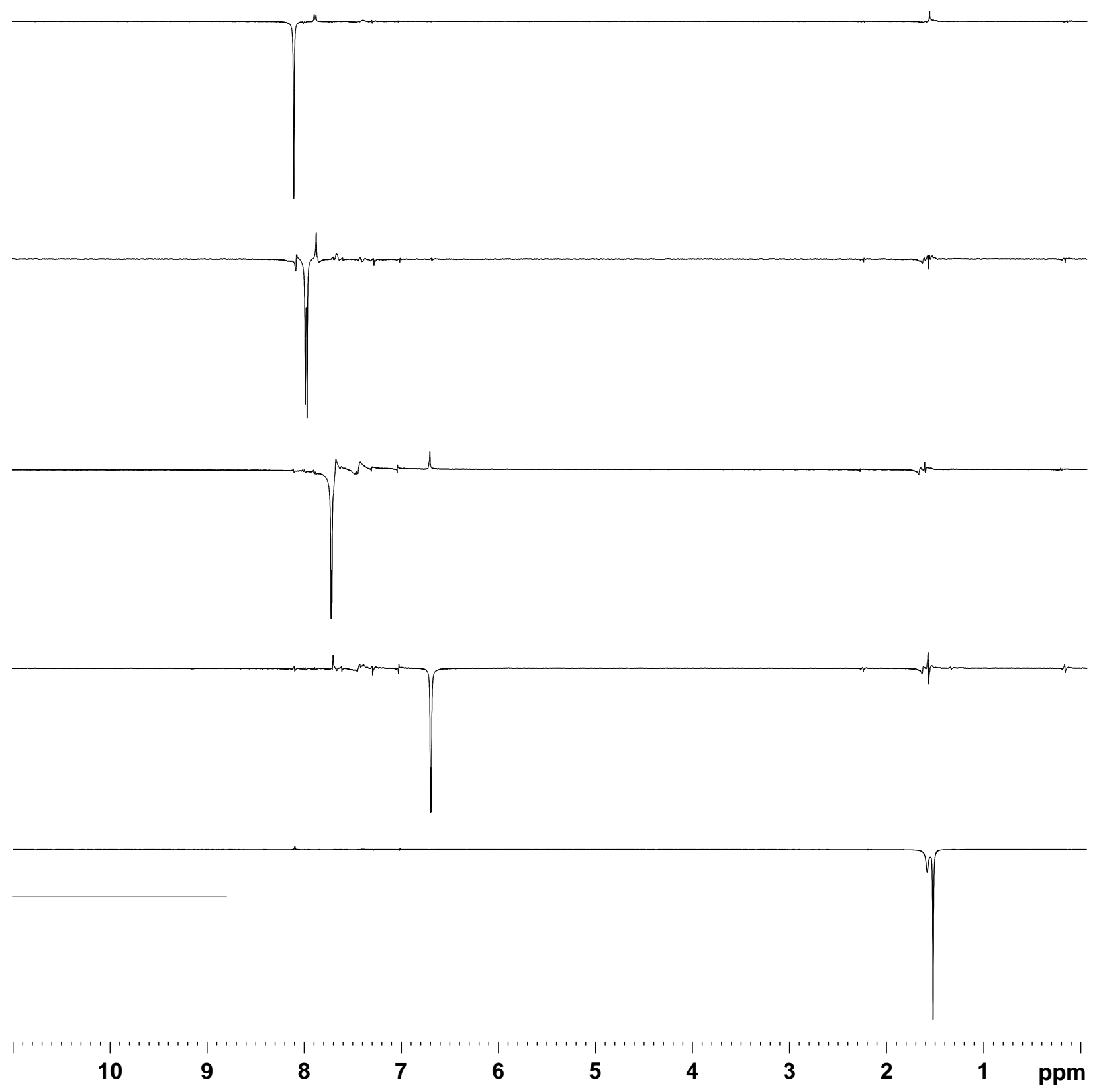

Figure A - 41: Selected nOe Difference NMR Spectra of Thiapyreniporphyrin 88 in $\mathrm{CDCl}_{3}$ 


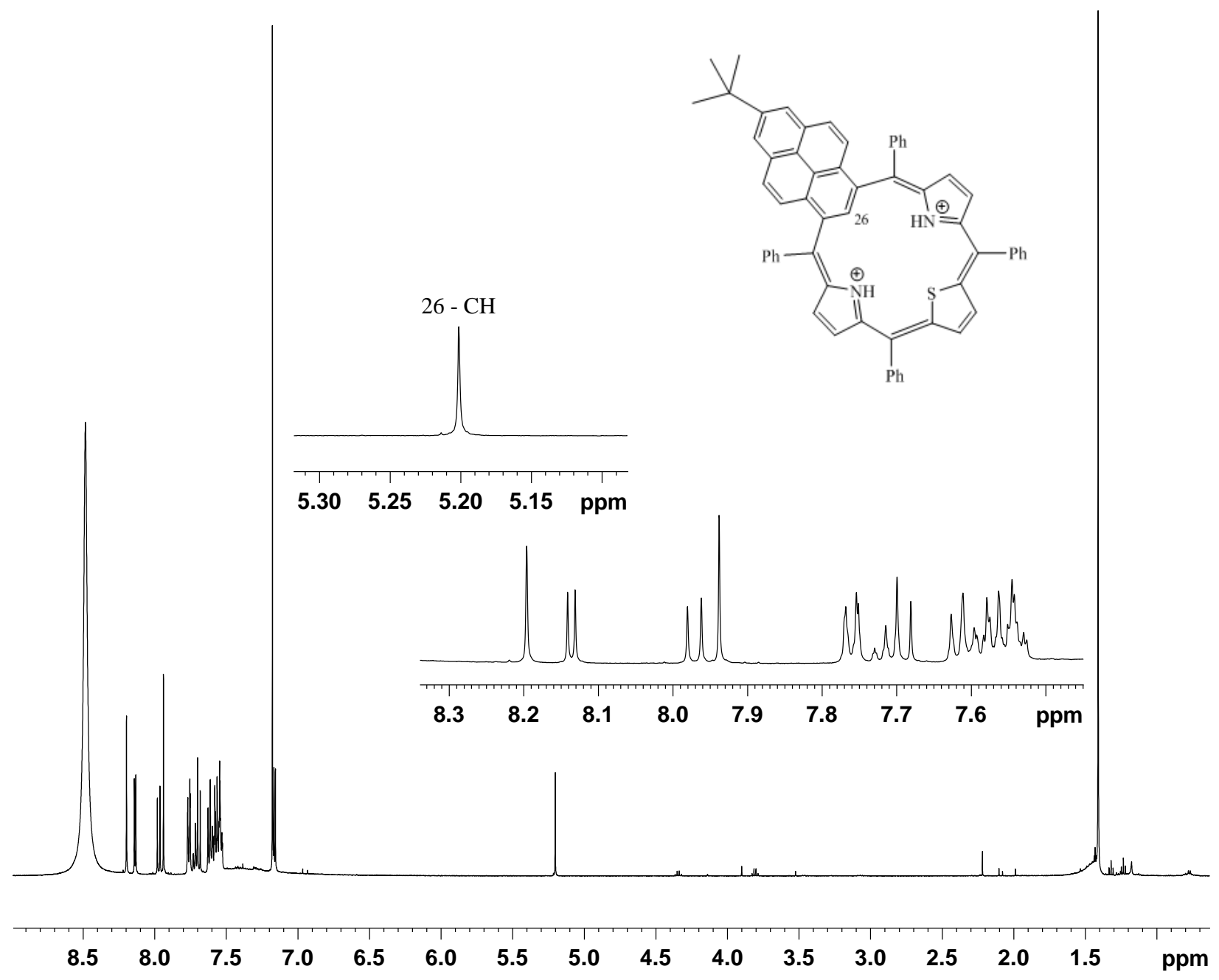

Figure A - 42: $500 \mathrm{MHz}{ }^{1} \mathrm{H}$ NMR Spectrum of Thiapyreniporphyrin Dication $\mathbf{8 8 H}_{2}{ }^{2+}$ in TFA$\mathrm{CDCl}_{3}$ 


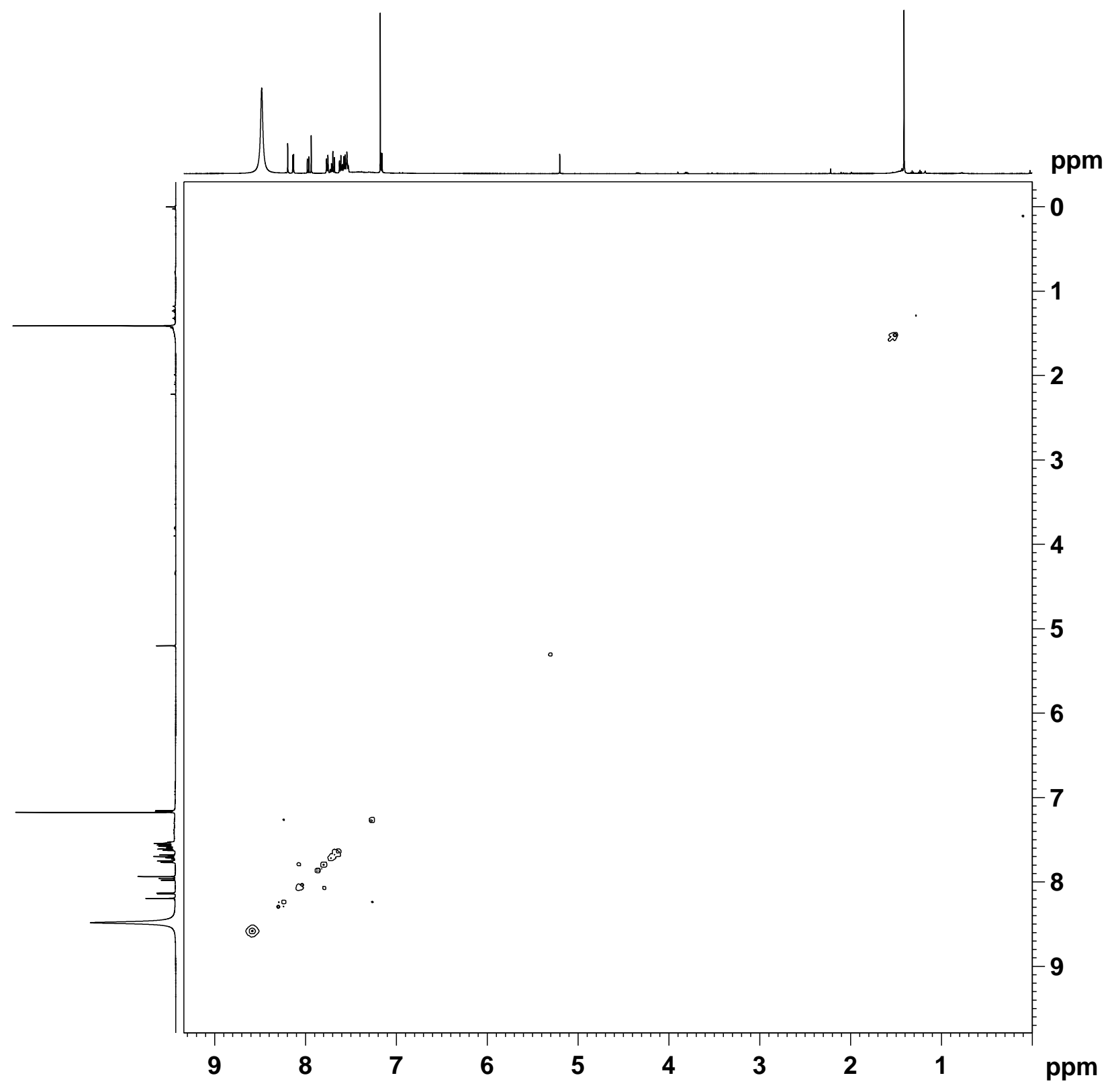

Figure A - 43: $500 \mathrm{MHz}{ }^{1} \mathrm{H}-{ }^{1} \mathrm{H}$ COSY NMR Spectrum of Thiapyreniporphyrin Dication $\mathbf{8 8} \mathrm{H}_{2}{ }^{2+}$ in TFA-CDCl 3 


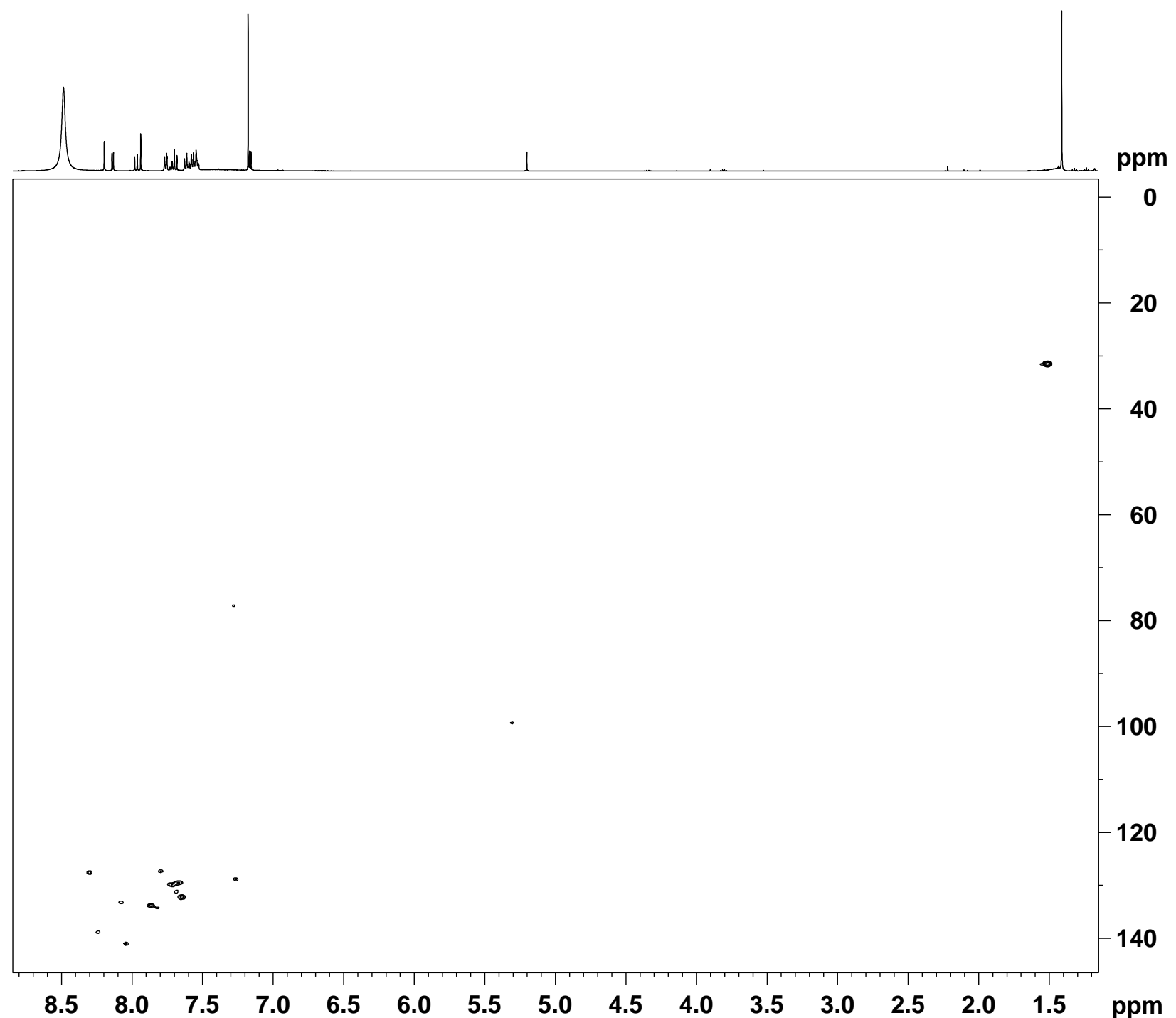

Figure A - 44: $500 \mathrm{MHz}$ HSQC NMR Spectrum of Thiapyreniporphyrin Dication $\mathbf{8 8} \mathrm{H}_{2}^{2+}$ in TFA-CDCl 3 


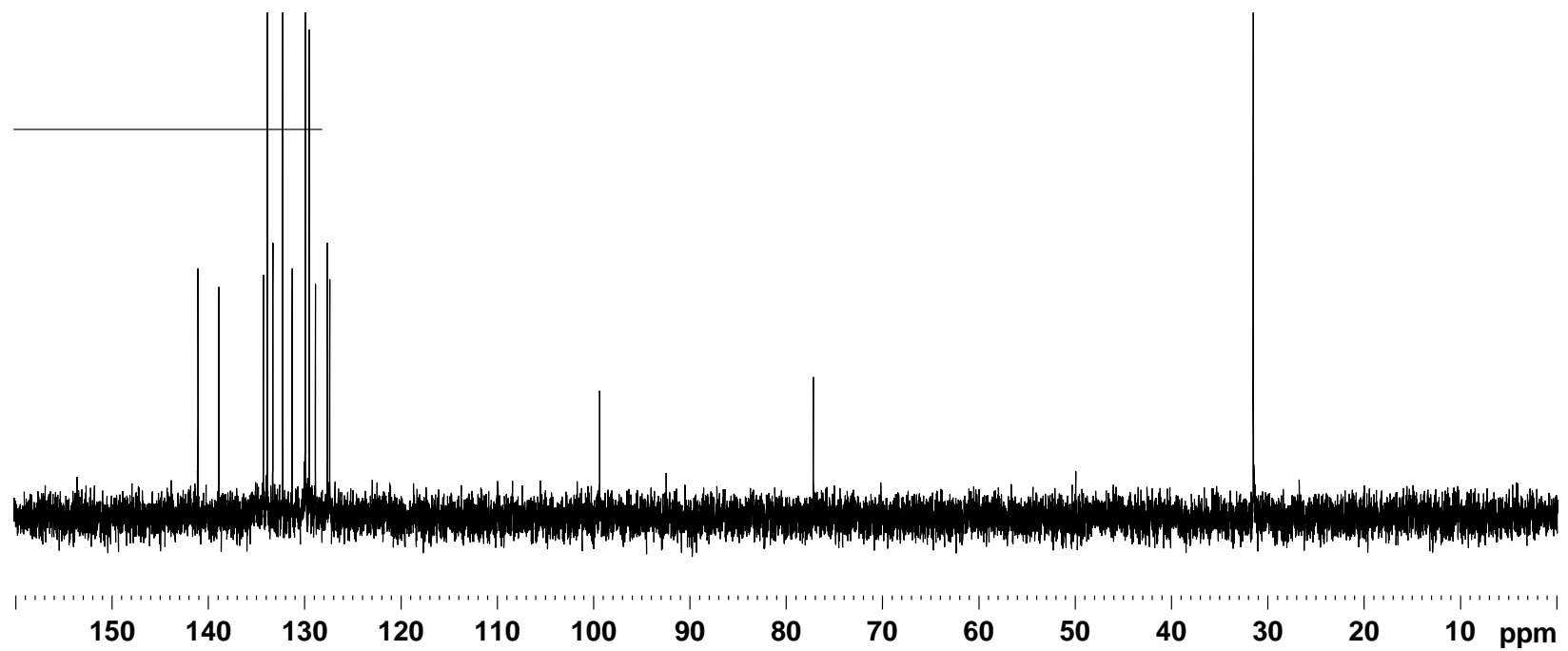

Figure A - 45: DEPT-135 NMR Spectrum of Thiapyreniporphyrin Dication $\mathbf{8 8} \mathrm{H}_{2}{ }^{2+}$ in TFA-

$\mathrm{CDCl}_{3}$

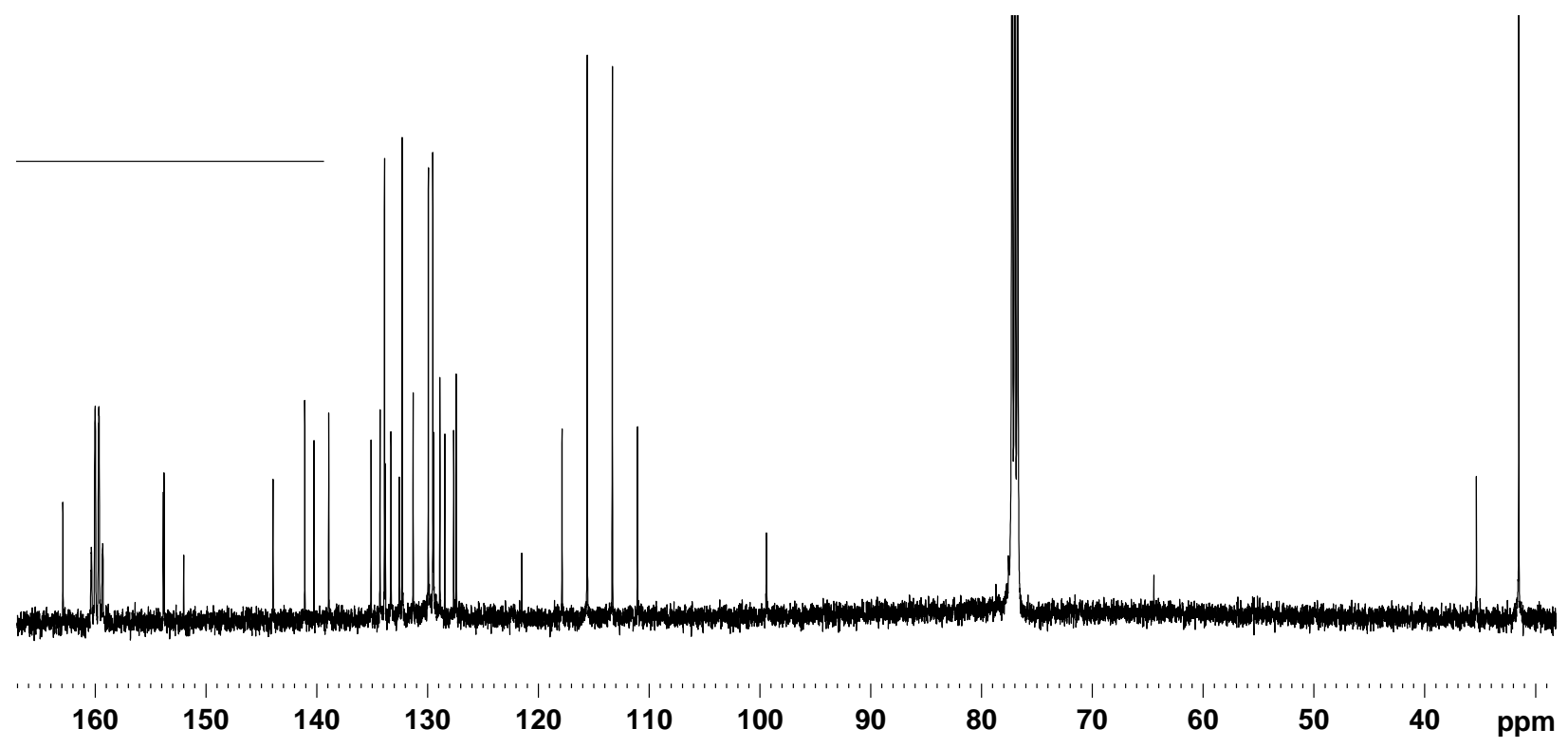

Figure A - 46: $125 \mathrm{MHz}{ }^{13} \mathrm{C}$ NMR Spectrum of Thiapyreniporphyrin Dication $\mathbf{8 8} \mathrm{H}_{2}{ }^{2+}$ in TFA$\mathrm{CDCl}_{3}$ 

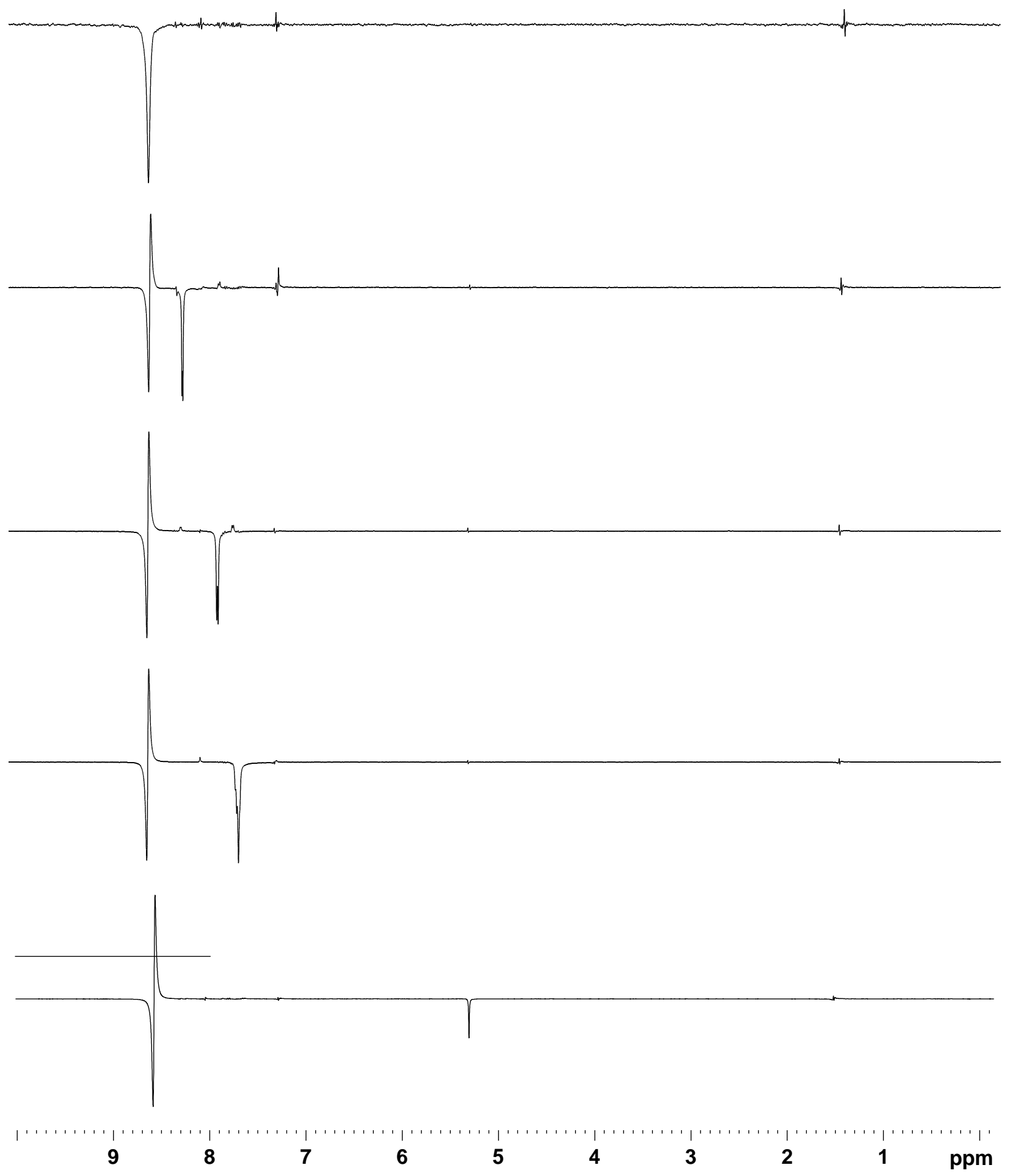

Figure A - 47: Selected nOe Difference NMR Spectra of Thiapyreniporphyrin Dication $\mathbf{8 8} \mathrm{H}_{2}{ }^{2+}$ in TFA-CDCl 3 


\section{APPENDIX B}

\section{SELECTED UV-VIS SPECTRA}

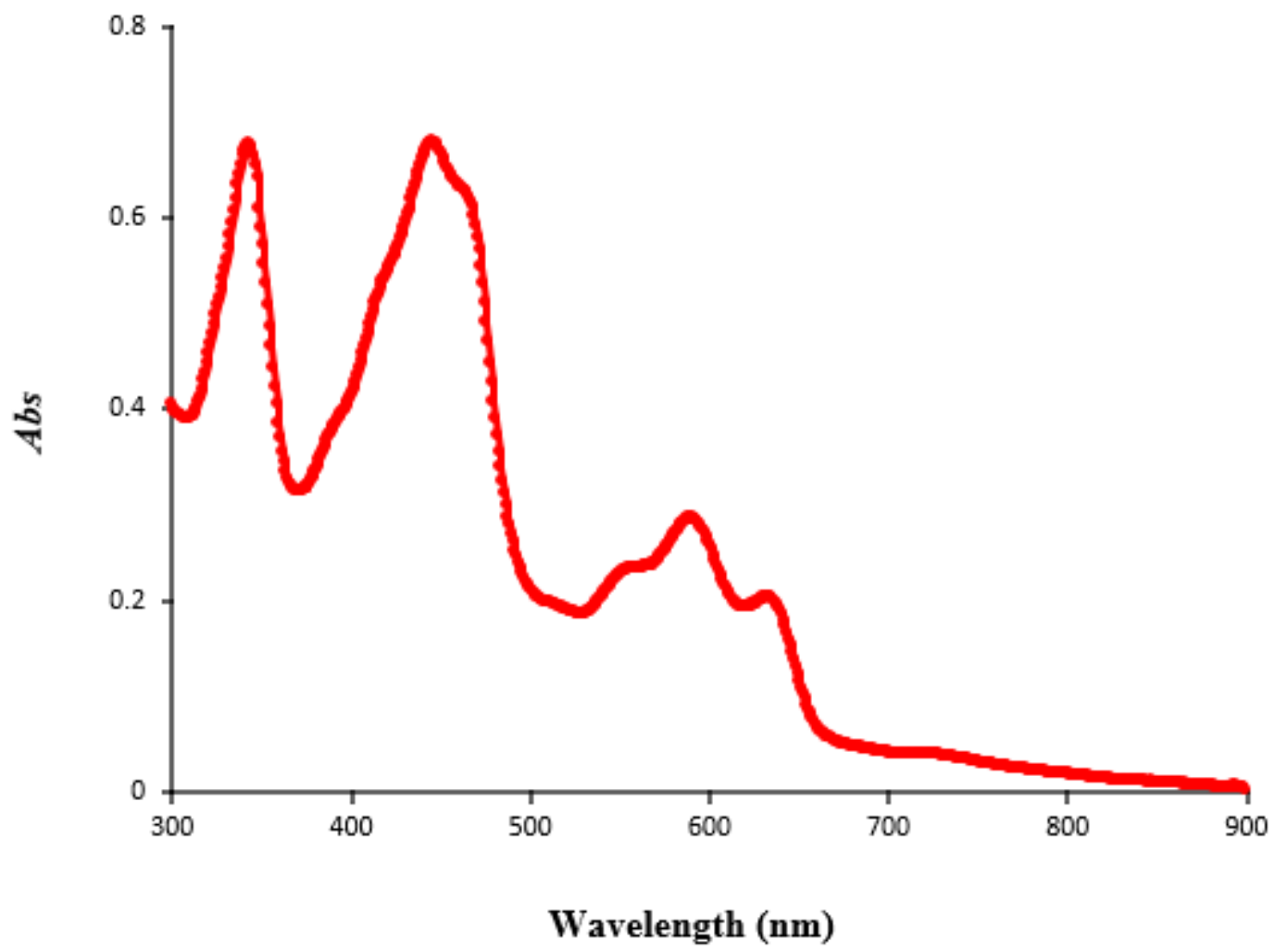

Figure B - 1: UV-Vis Spectrum of 68 in $1 \%$ TEA-CH${ }_{2} \mathrm{Cl}_{2}$ 


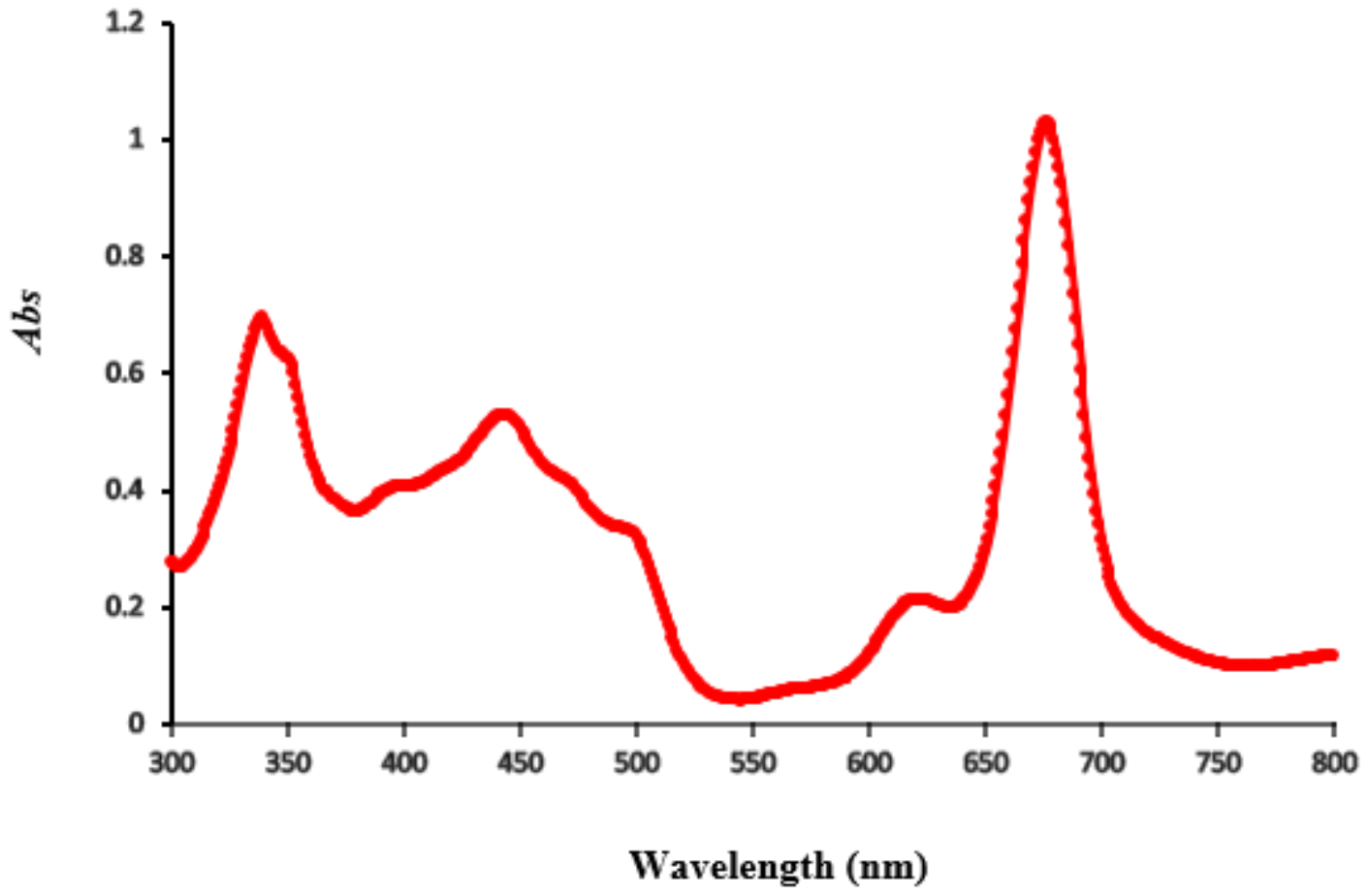

Figure B - 2: UV-Vis Spectrum of $\mathbf{6 8}$ in 1 equivalent TFA- $\mathrm{CH}_{2} \mathrm{Cl}_{2}$ 


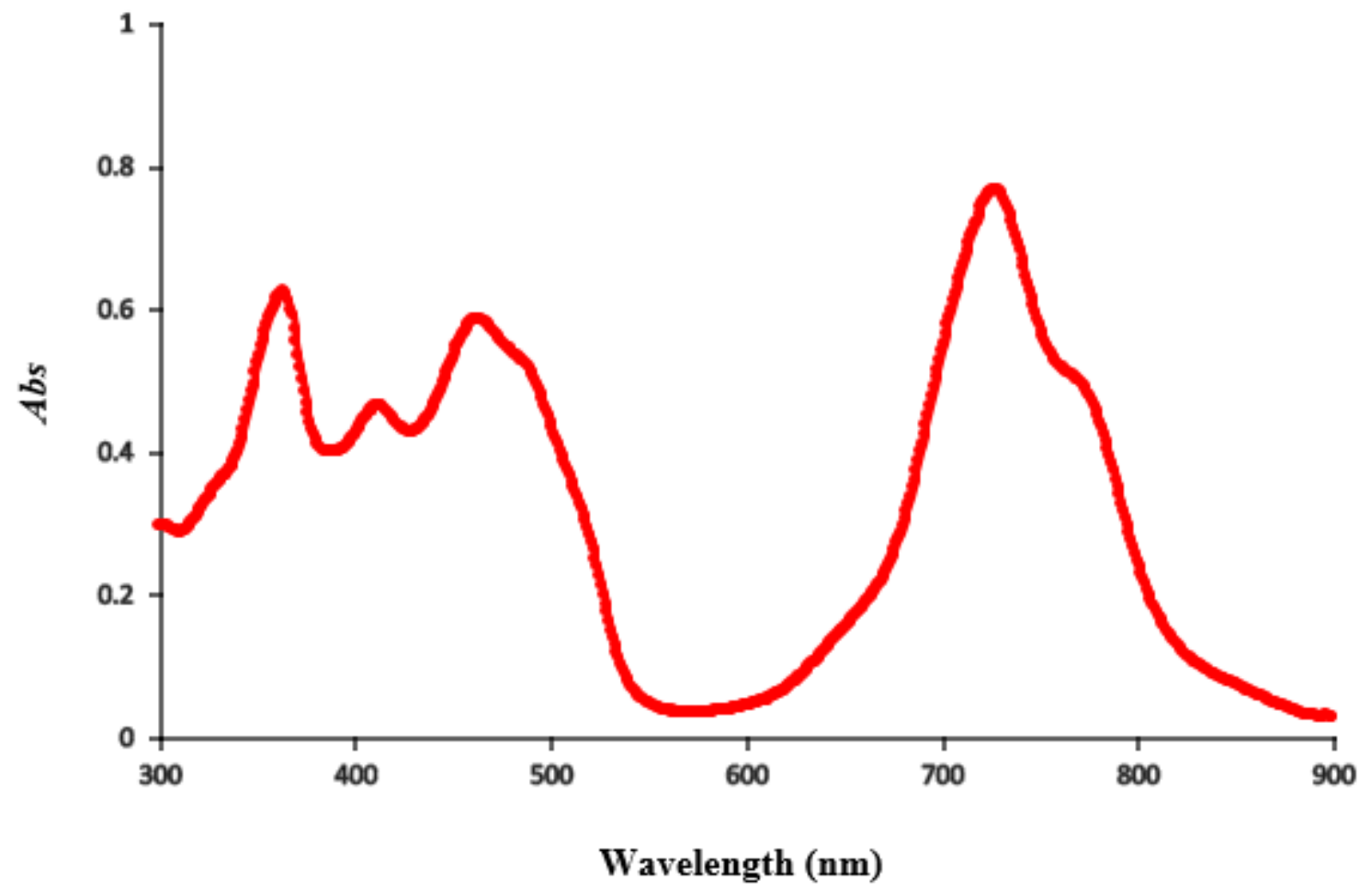

Figure B - 3: UV-Vis Spectrum of 68 in $1 \%$ TFA- $\mathrm{CH}_{2} \mathrm{Cl}_{2}$ 


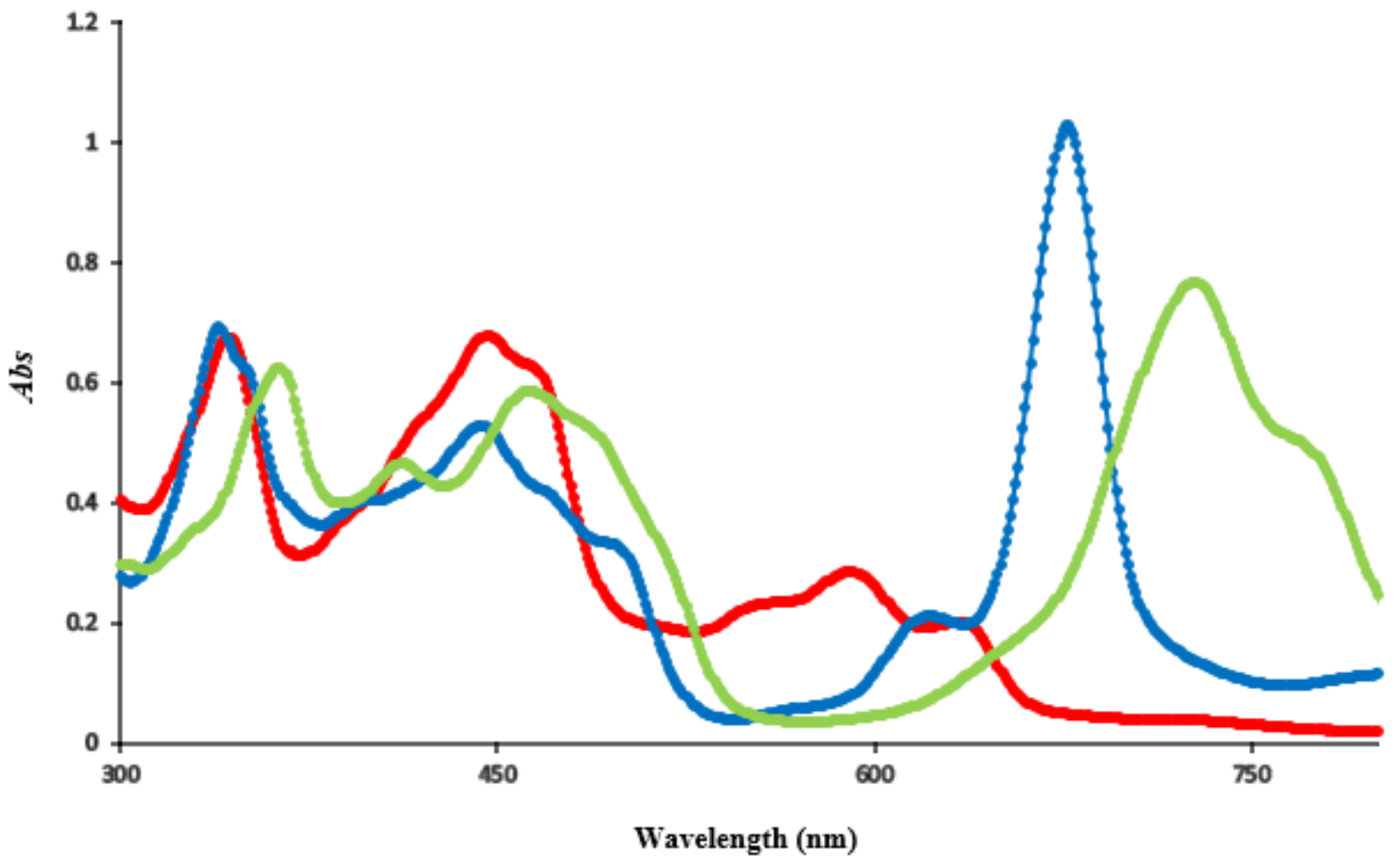

Figure B - 4: UV-Vis Spectra of $\mathbf{6 8}$ in $1 \%$ TEA- $\mathrm{CH}_{2} \mathrm{Cl}_{2}$ (red), 1 equivalent $\mathrm{TFA}-\mathrm{CH}_{2} \mathrm{Cl}_{2}$ (blue), and $1 \%$ TFA- $\mathrm{CH}_{2} \mathrm{Cl}_{2}$ (green) 


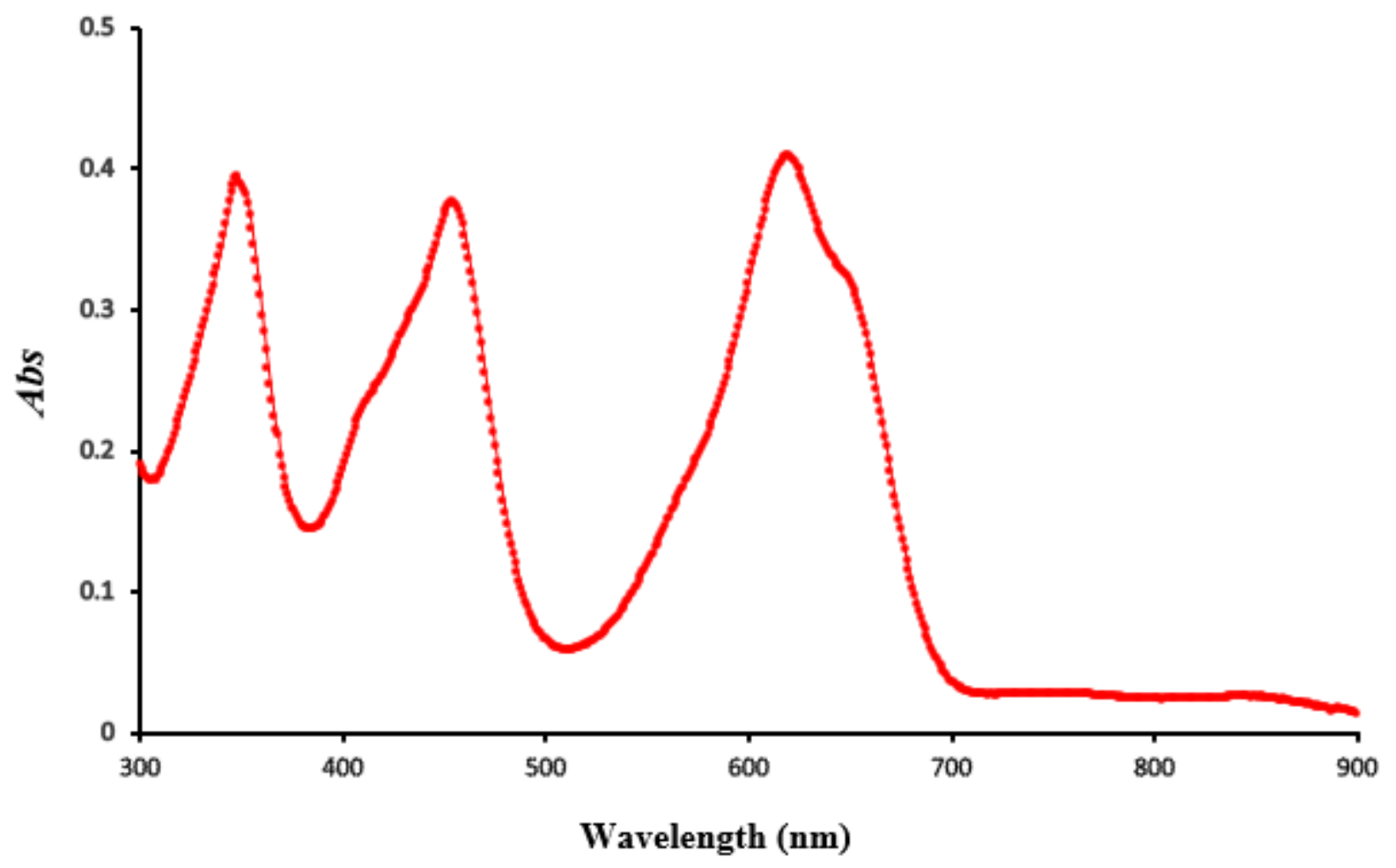

Figure B - 5: UV-Vis Spectrum of 85 in $1 \%$ TEA-CH${ }_{2} \mathrm{Cl}_{2}$ 


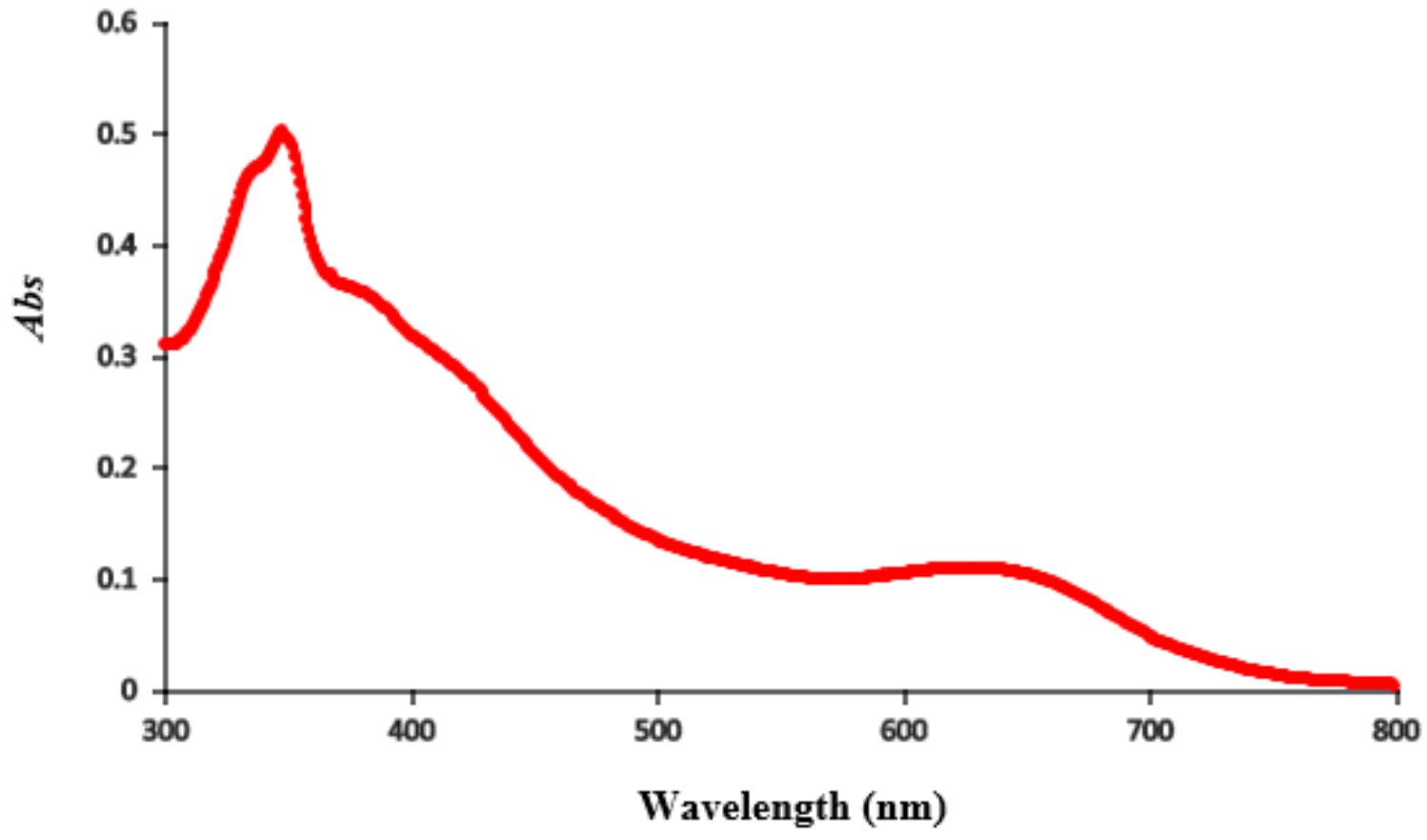

Figure B - 6: UV-Vis Spectrum of $\mathbf{8 8}$ in $1 \% \mathrm{TEA}-\mathrm{CH}_{2} \mathrm{Cl}_{2}$ 


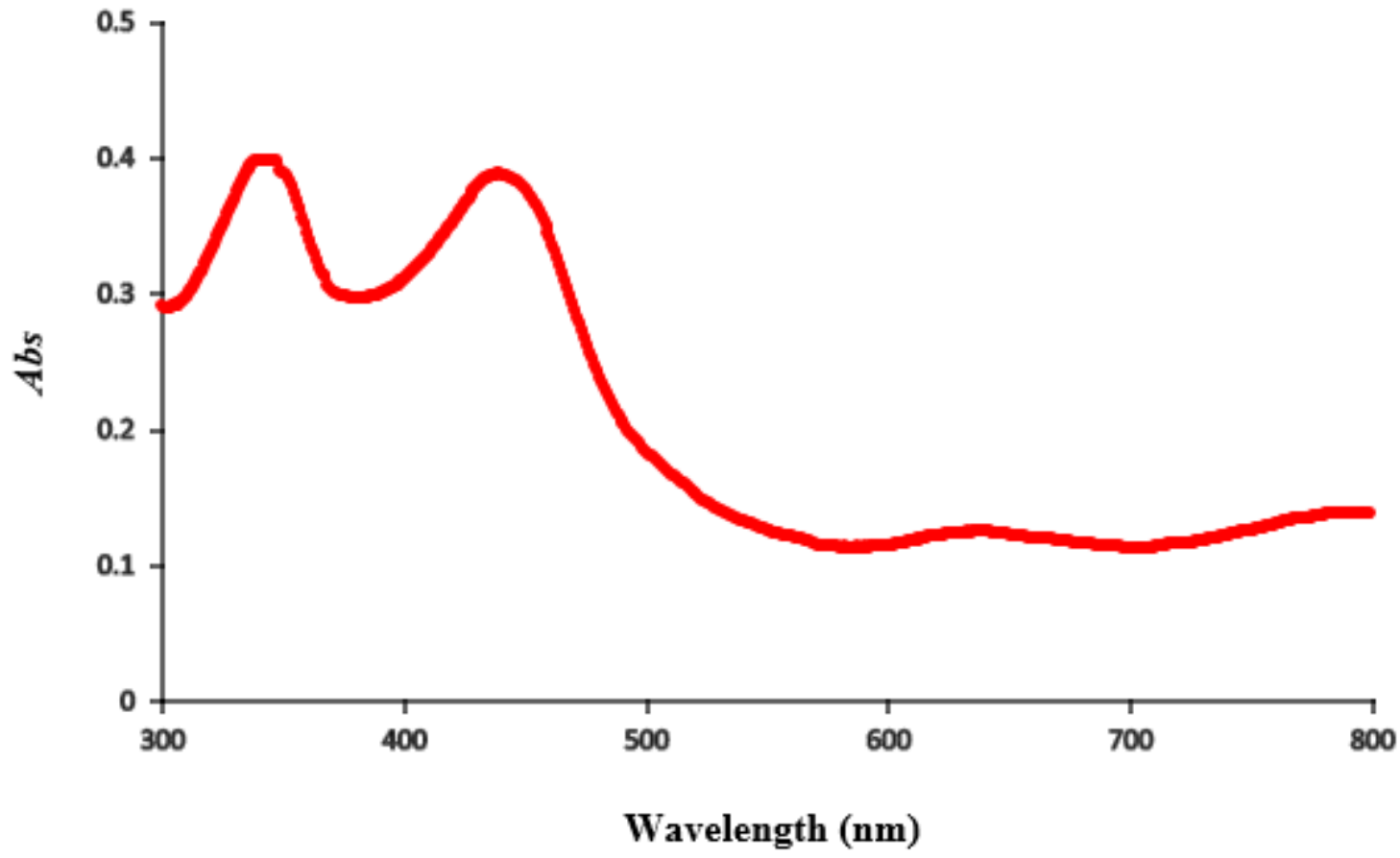

Figure B - 7: UV-Vis Spectrum of $\mathbf{8 8}$ in 1 equivalent TFA- $\mathrm{CH}_{2} \mathrm{Cl}_{2}$ 


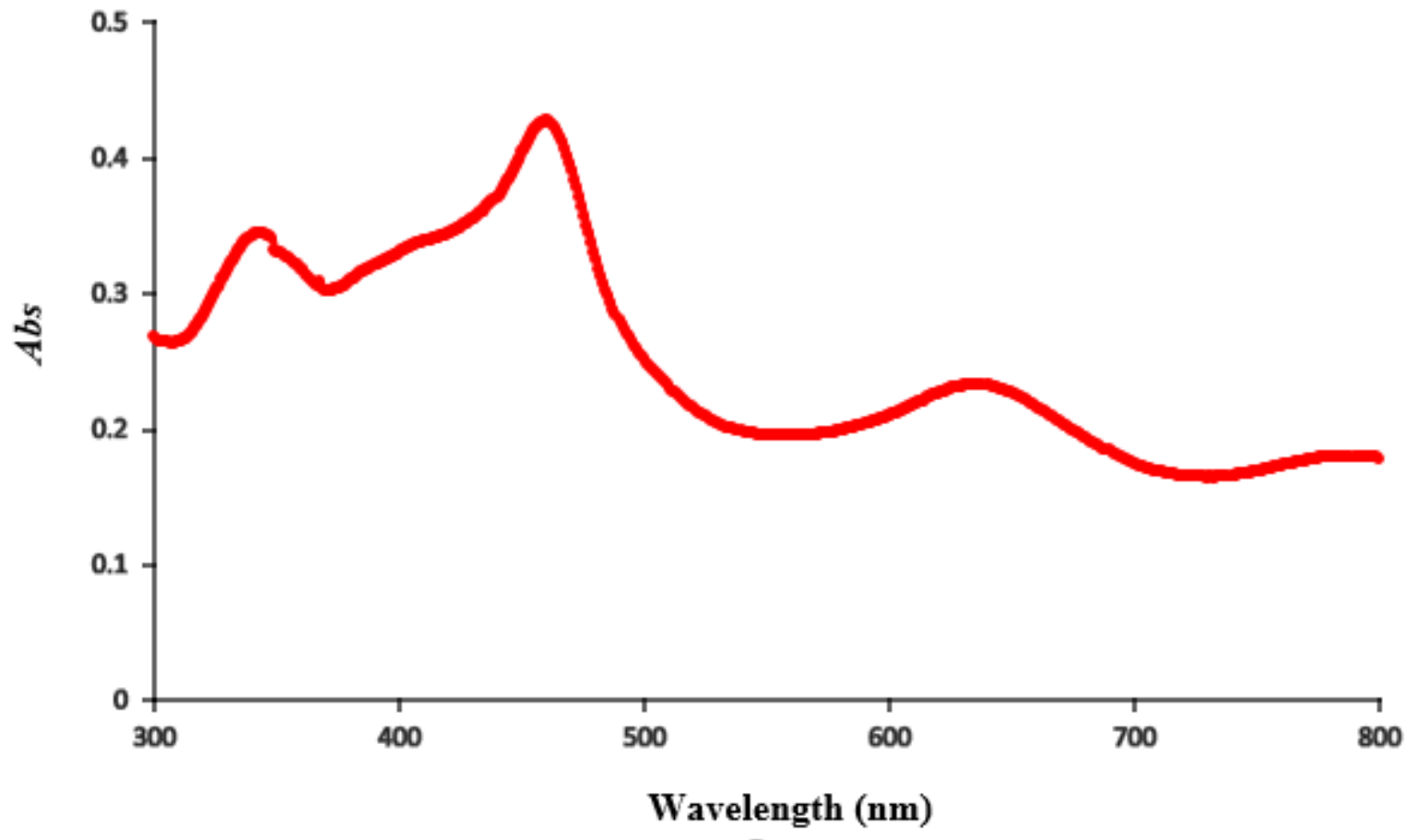

Figure B - 8: UV-Vis Spectrum of $\mathbf{8 8}$ in $5 \%$ TFA- $\mathrm{CH}_{2} \mathrm{Cl}_{2}$ 


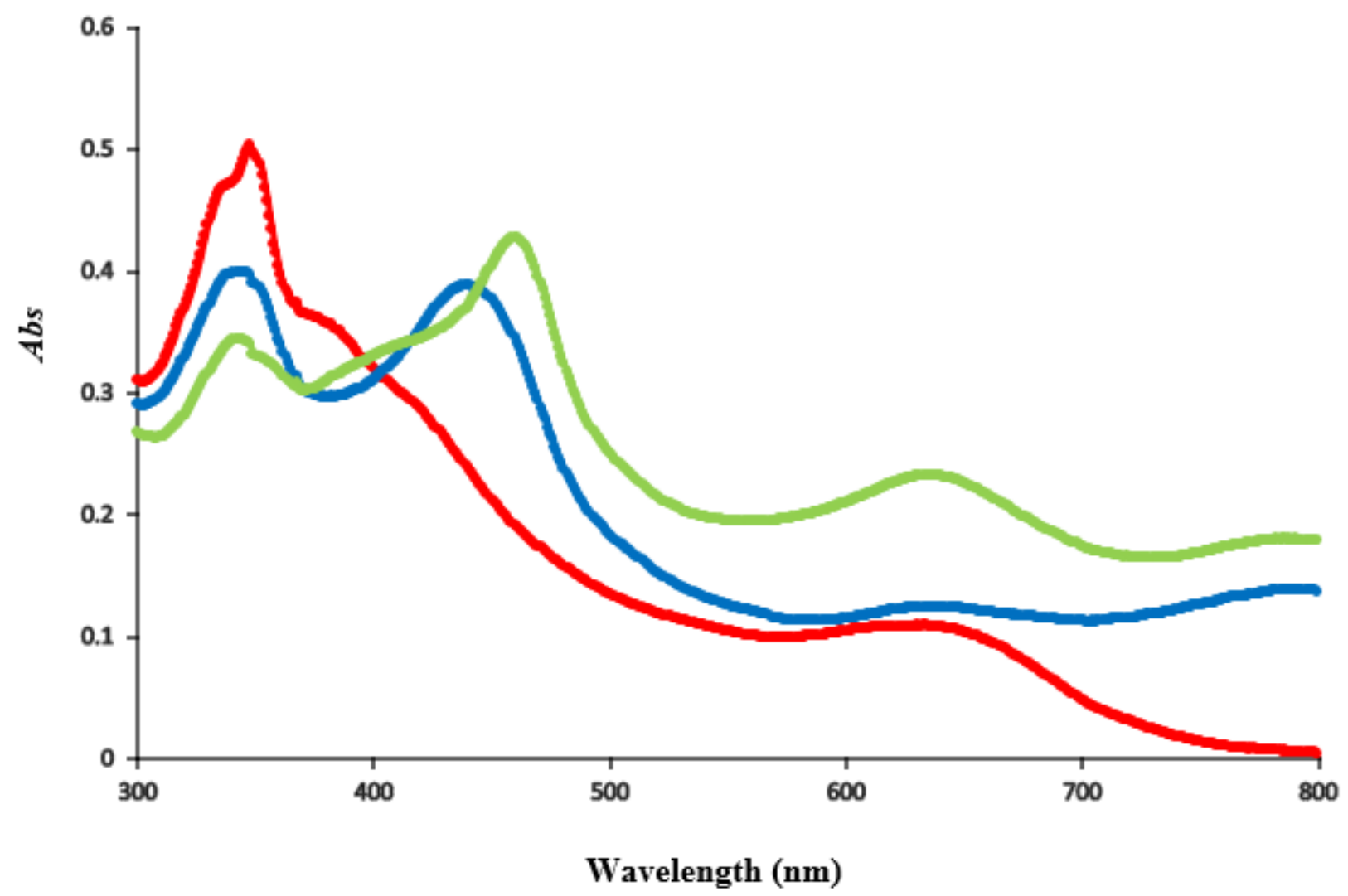

Figure B - 9: UV-Vis Spectra of $\mathbf{8 8}$ in $1 \%$ TEA- $\mathrm{CH}_{2} \mathrm{Cl}_{2}$ (red), 1 equivalent $\mathrm{TFA}-\mathrm{CH}_{2} \mathrm{Cl}_{2}$ (blue), and $5 \%$ TFA- $\mathrm{CH}_{2} \mathrm{Cl}_{2}$ (green) 